Mauricio Alexandre Parente Burdelis

\title{
Ajuste de Taxas de Mutação e de Cruzamento de Algoritmos Genéticos Utilizando-se Inferências Nebulosas
}

Dissertação apresentada à Escola Politécnica da Universidade de São Paulo (EPUSP) como parte dos requisitos para a obtenção do Título de Mestre em Engenharia no Departamento de Engenharia de Computação e Sistemas Digitais (PCS). 
Mauricio Alexandre Parente Burdelis

\section{Ajuste de Taxas de Mutação e de Cruzamento de Algoritmos Genéticos Utilizando-se Inferências Nebulosas}

Dissertação apresentada à Escola Politécnica da Universidade de São Paulo (EPUSP) como parte dos requisitos para a obtenção do Título de Mestre em Engenharia no Departamento de Engenharia de Computação e Sistemas Digitais (PCS).

Área de concentração:

Sistemas Digitais

Orientador: Prof. Livre-Docente

Marco Túlio Carvalho de Andrade 
Este exemplar foi revisado e alterado em relação à versão original, sob responsabilidade única do autor e com a anuência de seu orientador.

São Paulo, 2 de Abril de 2009

Assinatura do autor

Assinatura do orientador

FICHA CATALOGRÁFICA

Burdelis, Mauricio Alexandre Parente

Ajuste de taxas de mutação e de cruzamento de algoritmos genéticos utilizando-se inferências nebulosas/ M.A.P. Burdelis. -ed. rev. -- São Paulo, 2009.

$181 \mathrm{p}$.

Dissertação (Mestrado) - Escola Politécnica da Universidade de São Paulo. Departamento de Engenharia de Computação e Sistemas Digitais.

1. Inteligência Artificial 2. Fuzzy (Inteligência Artificial) 3. Computação Evolutiva 4. Sistemas Híbridos I. Universidade de São Paulo. Escola Politécnica. Departamento de Engenharia de Computação e Sistemas Digitais II. t 


\section{Dedicatória}

A Deus, a meus pais Sergio e Miriam, a toda minha família, e companheiros de trabalho, no laboratório KNOMA e em toda a Universidade de São Paulo. 


\section{Agradecimentos}

Agradeço a Deus, e a todos os meus colegas da Escola Politécnica da Universidade de São

Paulo, em especial a meu orientador: professor Marco Túlio Carvalho de Andrade. Agradeço também ao apoio e carinho de minha família, meus amigos, e todos aqueles que de alguma forma me ajudaram nos momentos de dificuldades. 
"O mais importante para o homem é crer em si mesmo. Sem esta confiança em seus recursos, em sua inteligência, em sua energia, ninguém alcança o triunfo a que aspira."

Thomas Wittlam Atkinson. 


\section{Resumo}

BURDELIS, M. A. P. Ajuste de Taxas de Mutação e de Cruzamento de Algoritmos Genéticos Utilizando-se Inferências Nebulosas. 2009. 181 f. Dissertação (Mestrado) - Escola Politécnica da Universidade de São Paulo, São Paulo, 2009.

Neste trabalho foi realizada uma proposta de utilização de Sistemas de Inferência Nebulosos para controlar, em tempo de execução, parâmetros de Algoritmos Genéticos. Esta utilização busca melhorar o desempenho de Algoritmos Genéticos diminuindo, ao mesmo tempo: a média de iterações necessárias para que um Algoritmo Genético encontre o valor ótimo global procurado; bem como diminuindo o número de execuções do mesmo que não são capazes de encontrar o valor ótimo global procurado, nem mesmo para quantidades elevadas de iterações.

Para isso, foram analisados os resultados de diversos experimentos com Algoritmos Genéticos, resolvendo instâncias dos problemas de Minimização de Funções e do Caixeiro Viajante, sob diferentes configurações de parâmetros. Com base nos resultados obtidos a partir destes experimentos, foi proposto um modelo com a troca de valores de parâmetros de Algoritmos Genéticos, em tempo de execução, pela utilização de Sistemas de Inferência Nebulosos, de forma a melhorar o desempenho do sistema, minimizando ambas as medidas citadas anteriormente.

Palavras-Chave: Algoritmos Genéticos; Sistemas de Inferência Nebulosos; Computação Evolutiva; Computação Nebulosa (ou "Fuzzy"); controle dinâmico de parâmetros; Inteligência Computacional; Inteligência Artificial; Sistemas Inteligentes Híbridos. 


\section{Abstract}

BURDELIS, M. A. P. Adjustments in Genetic Algorithms Mutation and Crossover Rates Using Fuzzy Inferences. 2009. 181 f. Dissertation (Master's Degree) - Escola Politécnica da Universidade de São Paulo, 2009.

This work addressed a proposal of the application of Fuzzy Systems to adjust parameters of Genetic Algorithms, during execution time. This application attempts to improve the performance of Genetic Algorithms by diminishing, at the same time: the average number of necessary generations for a Genetic Algorithm to find the desired global optimum value, as well as diminishing the number of executions of a Genetic Algorithm that are not capable of finding the desired global optimum value even for high numbers of generations.

For that purpose, the results of many experiments with Genetic Algorithms were analyzed; addressing instances of the Function Minimization and the Travelling Salesman problems, under different parameter configurations. With the results obtained from these experiments, a model was proposed, for the exchange of parameter values of Genetic Algorithms, in execution time, by using Fuzzy Systems, in order to improve the performance of the system, minimizing both of the measures previously cited.

Keywords: Genetic Algorithms; Evolutionary Computation; Fuzzy Systems; Dynamic Parameter Control; Computational Intelligence; Artificial Intelligence; Hybrid Intelligent Systems. 


\section{Lista de Figuras}

Figura 1.1: Ilustração conceitual do tipo de transformações entre modelos, almejada pela linha de pesquisa originada em [Andrade - 2002] ................................................ 21

Figura 1.2: Ilustração conceitual do tipo de sistema híbrido almejado neste trabalho. .........24

Figura 4.1: Função utilizada para o problema de minimização, com indivíduos de 16 bits... 49

Figura 4.2: tabela para armazenamento interno das distâncias entre cidades (para o

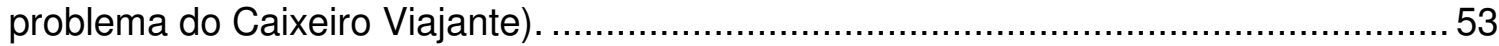

Figura 5.1: partição nebulosa da variável de entrada: "Gerações". .....................................6 60

Figura 5.2: partição nebulosa da variável de entrada: "População" ....................................... 60

Figura 5.3: partição nebulosa da variável de saída: "Taxa de Mutação”.............................. 61

Figura 5.4: partição nebulosa da variável de saída: "Taxa de Cruzamento".........................61

Figura 5.5: partição nebulosa da variável de entrada: "Gerações". ..................................... 66

Figura 5.6: partição nebulosa da variável de entrada: "População"...................................... 66

Figura 5.7: partição nebulosa da variável de saída: "Taxa de Mutação"...............................66

Figura 5.8: partição nebulosa da variável de saída: "Taxa de Cruzamento" ........................67

Figura 5.9: partição nebulosa da variável de entrada: "Gerações". .................................... 67

Figura 5.10: partição nebulosa da variável de entrada: "População" ................................... 68

Figura 7.1: Partição Nebulosa da Variável Ng para o AGN-CV..................................... 101

Figura 7.2: Partição Nebulosa da Variável Pop para o AGN-CV...................................... 102

Figura 7.3: Partição Nebulosa da Variável Pm para o AGN-CV..................................... 103

Figura 7.4: Partição Nebulosa da Variável Pc para o AGN-CV. ...................................... 104

Figura 7.5: Comparação entre os comportamentos das variáveis de saída em função do

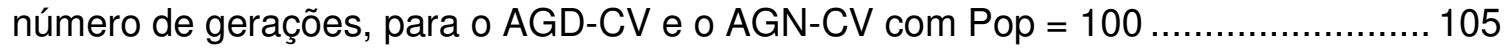

Figura 7.6: Partição Nebulosa da Variável "Ng” para o AGN-MF. ...................................... 106

Figura 7.7: Partição Nebulosa da Variável “Pop” para o AGN-MF.................................... 106

Figura 7.8: Partição Nebulosa da Variável "Pm” para o AGN-MF..................................... 107

Figura 7.9: Partição Nebulosa da Variável "Pc" para o AGN-MF...................................... 108

Figura 7.10: Comparação entre os comportamentos das variáveis de saída em função do número de gerações, para o AGD-MF e o AGN-MF com Pop $=50$ 109

Figura 7.11: Comparação entre os comportamentos das variáveis de saída em função das diferentes configurações (de 1 até 5) do AGN-CV. 


\section{Lista de Tabelas}

Tabela 5.1: resultados do primeiro experimento com o AG-MF. 57

Tabela 5.2: resultados do segundo experimento com o AG-MF.

Tabela 5.3: regras nebulosas para a taxa de cruzamento, retiradas de [Xu, Vukovich 1993].

Tabela 5.4: regras nebulosas para a taxa de mutação, retiradas de [Xu, Vukovich - 1994]. 61

Tabela 5.5: resultados do primeiro experimento com o Sistema Híbrido AGN-MF.... 63

Tabela 5.6: distâncias entre as 10 cidades assumidas para os experimentos com o PCV... 64

Tabela 5.7: resultados do primeiro experimento com o AG-CV. 65

Tabela 5.8: resultados do primeiro experimento com o AGN-CV, utilizando a "base de dados 1" (BD1).

Tabela 5.9: resultados do segundo experimento com o AGN-CV, utilizando a "base de dados 2" (BD2).

Tabela 5.10: exemplo do significado da abreviação "M S V" utilizada para o valor de Pm nas tabelas 5.12 e 5.13 a seguir.

Tabela 5.11: exemplo do significado da abreviação "M L V" utilizada para o valor de Pc nas tabelas 5.12 e 5.13 a seguir.

Tabela 5.12: experimentos com diferentes regras para o controle de $\mathrm{Pm}$, utilizando-se o AGN-BD1.

Tabela 5.13: experimentos com diferentes regras para o controle de Pm, utilizando-se o AGN-BD2.

Tabela 5.14: experimento com o AG-CV, nas mesmas condições dos experimentos dos sistemas híbridos (AGN-BD1 e AGN-BD2), com $\mathrm{Pc}=0,8$ e $\mathrm{Pm}=0,01$.

Tabela 6.1: experimento com o AG que resolve o problema do CV, para tamanho de população $=100$ indivíduos, e Pc = 0,8 (a linha da tabela com menor número de casos que não encontraram o valor mínimo global está circulada com traço contínuo, e a linha da tabela que corresponde à menor média, está circulada em tracejado). 80

Tabela 6.2: experimento com o AG que resolve o problema de Minimização de Funções, para tamanho de população $=70$ indivíduos, e $\mathrm{Pc}=0,8$ (a linha da tabela com menor número de casos que não encontraram o valor mínimo global está circulada com traço 
contínuo, e a linha da tabela que corresponde à menor média, está circulada em tracejado).

Tabela 6.3: percentual de casos que não encontraram o valor ótimo global em até 1000 iterações, nas situações referentes à melhor média de iterações necessárias para encontrá-lo ( $\mathrm{Pm}=0$ e $\mathrm{Pc}=0,5)$, para o AG-CV.

Tabela 6.4: as duas configurações, para cada tamanho de população estudado, que produziram os menores números de casos que não encontraram o valor mínimo global procurado, para o AG-CV.

Tabela 6.5: as quatro configurações, de todos os tamanhos possíveis de população estudados, que produziram os menores números de casos que não encontraram o valor mínimo global procurado, para o AG-CV.

Tabela 6.6: curva "Pm-A".

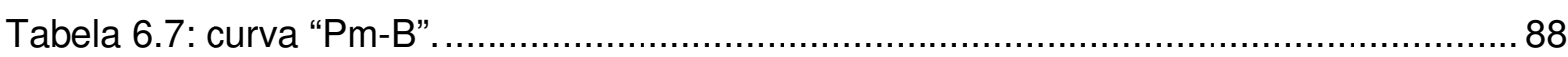

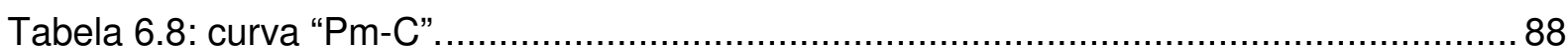

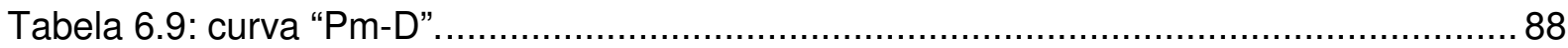

Tabela 6.10: resultados dos experimentos, utilizando as curvas descritas para o ajuste da Pm, para o AG-CV.

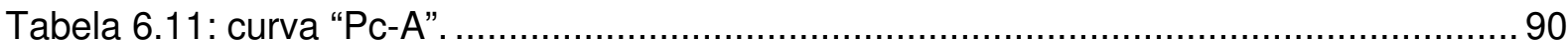

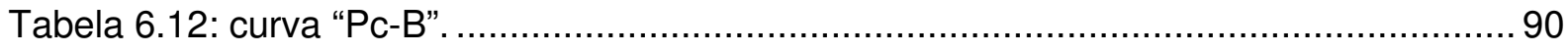

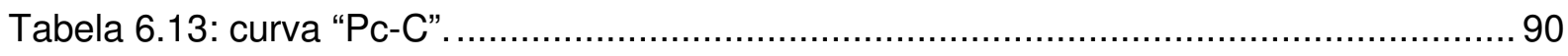

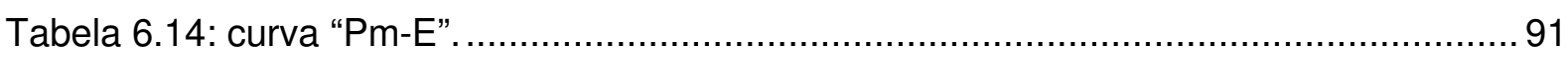

Tabela 6.15: resultados obtidos em experimentos com a utilização das curvas citadas anteriormente, variando Pc e possivelmente Pm, para o AG-CV.

Tabela 7.1: as duas configurações, para cada tamanho de população estudado, que produziram as menores médias de iterações necessárias para encontrar o valor mínimo global, para o AG-CV.

Tabela 7.2: os três melhores resultados obtidos para o AG com ajuste dinâmico de Pm e Pc, para os diferentes tamanhos de população estudados, para o problema do CV.

Tabela 7.3: as duas configurações, para cada tamanho de população estudado, que produziram as menores médias de iterações necessárias para encontrar o valor ótimo global, para o AG-MF.

Tabela 7.4: as duas configurações, para cada tamanho de população estudado, que produziram os menores números de casos que não encontraram o valor ótimo global, para o AG-MF.

Tabela 7.5: os três melhores resultados obtidos para o AG com ajuste dinâmico de Pm e Pc, para os diferentes tamanhos de população estudados, para o problema de minimização de funções. 
Tabela 7.6: resultados obtidos por configurações específicas do AG "clássico" para resolver o problema de minimização de funções, que obtiveram resultados muito próximos aos resultados obtidos pelo AG com ajuste em "degrau"............................................. 100

Tabela 7.7: regras utilizadas no AGN-CV para a variável Pm....................................... 104

Tabela 7.8: regras utilizadas no AGN-CV para a variável Pc. ....................................... 104

Tabela 7.9: resultados obtidos, para diferentes tamanhos de população, para o AGN-CV. 105

Tabela 7.10: regras utilizadas no AGN-MF para a variável "Pm". ................................... 108

Tabela 7.11: regras utilizadas no AGN-MF para a variável "Pc".................................... 108

Tabela 7.12: resultados obtidos, para diferentes tamanhos de população, para o AGN que resolve o problema de minimização de funções......................................................... 109

Tabela 7.13: resultados obtidos, para as diferentes configurações de SIN, variando-se o tipo de transição (do mais abrupto ao mais gradual). 


\section{Lista de Algoritmos}

Algoritmo 1: a implementação utilizada no presente trabalho para Algoritmos Genéticos que resolvem o problema de Minimização de Funções.................................................... 51

Algoritmo 2: a implementação utilizada no presente trabalho para Algoritmos Genéticos que resolvem o problema do Caixeiro Viajante. 


\section{Lista de Abreviaturas}

AG - Algoritmo Genético

AG-CV - Algoritmo Genético desenvolvido para resolver o Problema do "Caixeiro Viajante" AGD - "Algoritmo Genético com Ajuste em Degrau"

AGD-CV - "Algoritmo Genético com Ajuste em Degrau desenvolvido para resolver o Problema do Caixeiro Viajante"

AGD-MF - "Algoritmo Genético com Ajuste em Degrau desenvolvido para resolver o Problema de Minimização de Funções"

AGN - "Algoritmo Genético Nebuloso"

AG-MF - Algoritmo Genético desenvolvido para resolver o Problema de "Minimização de Funções"

AGN-BD1 - "Algoritmo Genético Nebuloso - Base de Dados 1"

AGN-BD2 - "Algoritmo Genético Nebuloso - Base de Dados 2"

AGN-CV - "Algoritmo Genético Nebuloso" desenvolvido para resolver o Problema do "Caixeiro Viajante"

AGN-MF - "Algoritmo Genético Nebuloso" desenvolvido para resolver o Problema de "Minimização de Funções"

ARGAF - "Adaptive Genetic Algorithm Based on Fuzzy Logic Controllers"

BD - Base de Dados

BD1 - "Base de Dados 1"

BD2 - "Base de Dados 2"

BR - Base de Regras

BC - Base de Conhecimento

CE - Computação Evolutiva 
CF - Computação Nebulosa (ou "Computação Fuzzy")

CLN - Controlador Lógico Nebuloso

CN - Computação Neural

DPGA - "Dynamic Parametric Genetic Algorithm"

EER - "Exploitation/Exploration Relationship" (ou Relação entre Aproveitamento e Exploração)

FGA - "Fuzzy Genetic Algorithm"

FEA - "Fuzzy Evolutionary Algorithm"

IA - Inteligência Artificial

IC - Inteligência Computacional

$\mathrm{Ng}$ - número de gerações (ou iterações) realizadas até o momento por um Algoritmo Genético

NP - Não Polinomiais

Pc - Probabilidade de Cruzamento (ou "Taxa” de Cruzamento) de um Algoritmo Genético

PCV - O Problema do "Caixeiro Viajante"

PG - Programação Genética

Pm - Probabilidade de Mutação (ou "Taxa" de Mutação) de um Algoritmo Genético

PMF - O Problema de "Minimização de Funções"

SIN - Sistema de Inferências Nebuloso 


\section{Sumário}

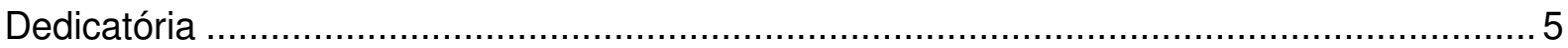

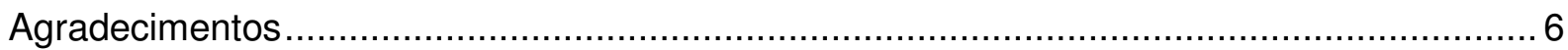

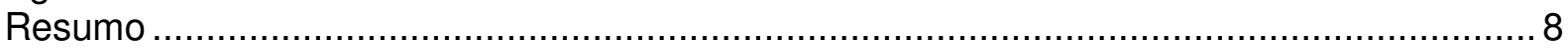

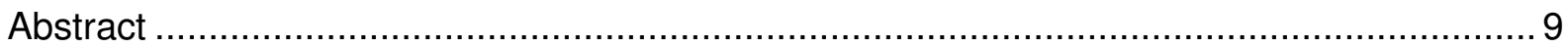

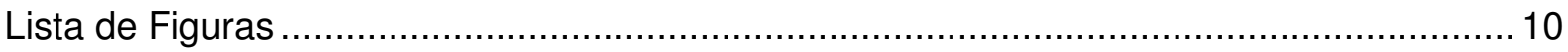

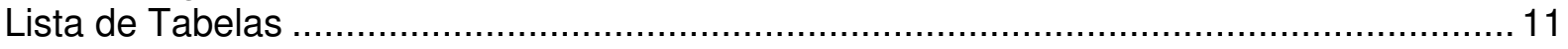

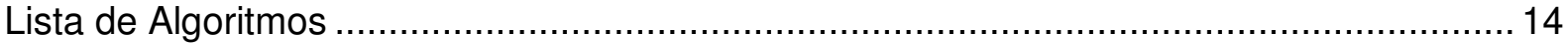

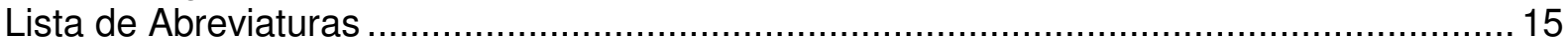

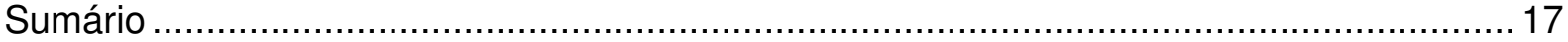

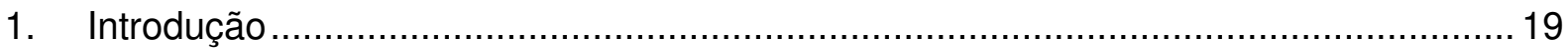

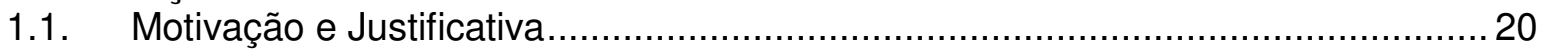

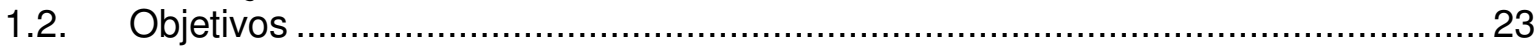

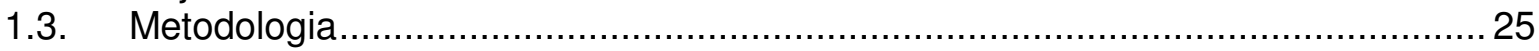

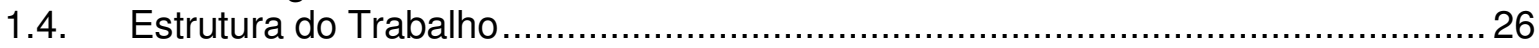

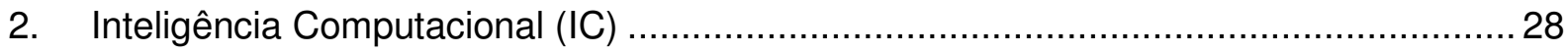

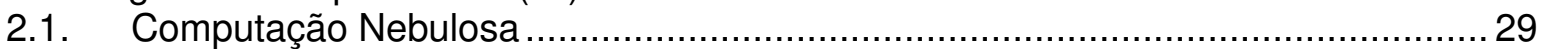

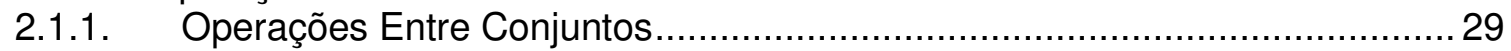

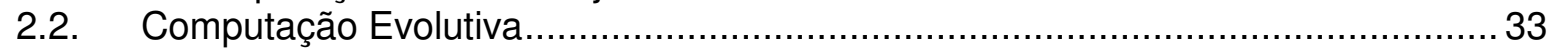

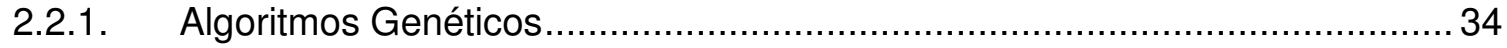

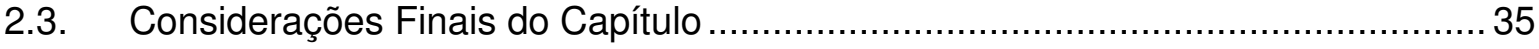

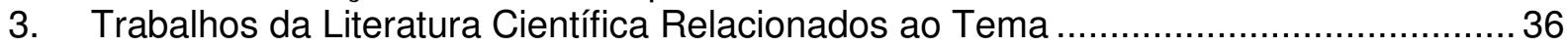

3.1. "Dynamic Parametric GAs" [Lee, Takagi - 1993] .............................................. 36

3.2. "Fuzzy GAs" [Xu, Vukovich - 1993]/"Fuzzy EAs" [Xu, Vukovich - 1994]............... 37

3.3. "Fuzzy Government" [Arnone, Dell'Orto, Tettamanzi - 1994] .............................. 39

3.4. "Adaptive GAs Based on Fuzzy Logic Controllers" [Herrera, Lozano - 1996] ....... 40

3.5. Análise Crítica dos Trabalhos....................................................................... 41

3.5.1. Medidas de Desempenho Utilizadas para Comparar o Sistema Híbrido com o

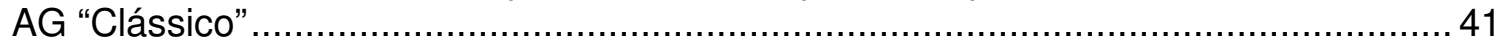

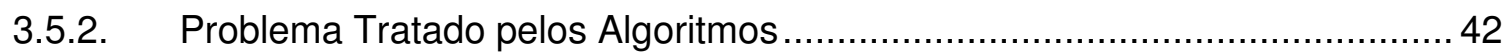

3.5.3. Entradas e Saídas dos Controladores Nebulosos ..................................... 42

3.5.4. O Trabalho Informa os Critérios Utilizados para a Seleção das Entradas e

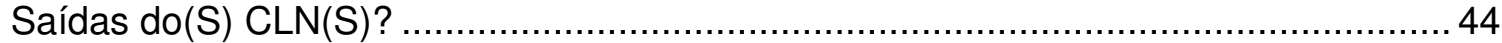

3.5.5. Regras Implementadas pelo(s) SIN(s) ............................................... 44

3.5.6. O Trabalho Informa os Critérios Utilizados para a Elaboração das Regras

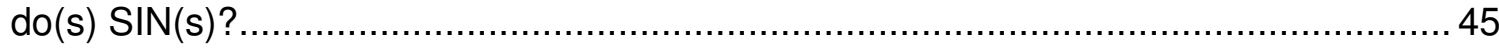

3.5.7. Como os Experimentos Foram Conduzidos? ......................................... 45

3.5.8. Como Foram Ajustados os Parâmetros do AG "Clássico" (Cujo Desempenho

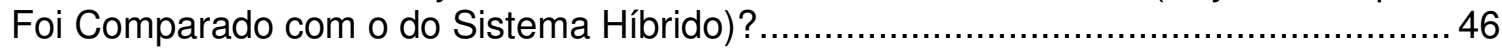

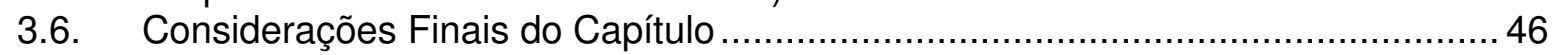

4. Ferramentas Computacionais Desenvolvidas .......................................................... 48

4.1. Minimização de Funções............................................................................. 48

4.1.1. Função Elaborada Para os Experimentos ..................................................... 49

4.1.2. Implementação dos Algoritmos para este Problema .................................50

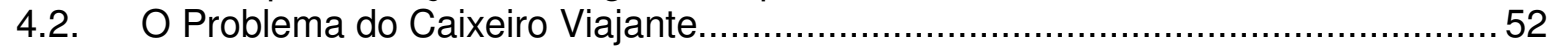

4.2.1. Implementação dos Algoritmos para este Problema ...................................53

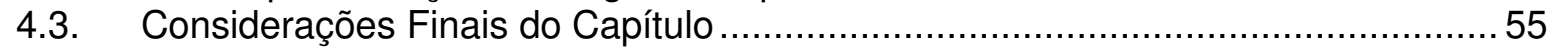

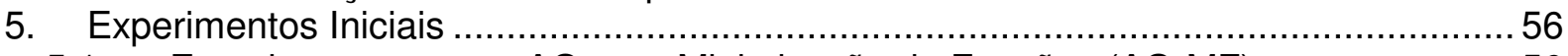

5.1. Experimentos com o AG para Minimização de Funções (AG-MF) ....................... 56 


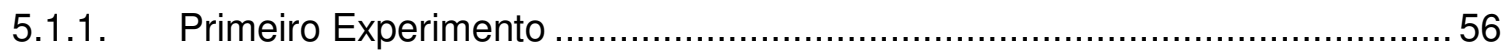

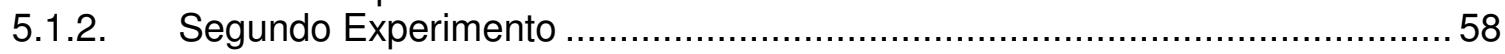

5.2. Experimentos com o Sistema Híbrido para Minimização de Funções (AGN-MF) . 59

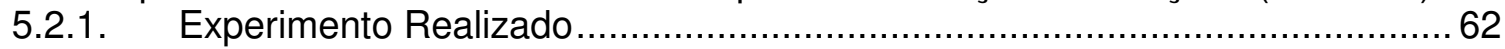

5.3. Experimentos com o AG para o Problema do Caixeiro Viajante (AG-CV).............63

5.3.1. Experimento Realizado .................................................................. 63

5.4. Experimentos com o Sistema Híbrido para o Problema do Caixeiro Viajante (AGN-

CV) 65

5.4.1. Experimento com a "Base de Dados 1"

5.4.2. Experimento com a "Base de Dados 2" ....................................................... 69

5.5. Análise Crítica dos Primeiros Experimentos ..................................................... 70

5.6. Experimentação de Diferentes Regras para Ajustes da Taxa de Mutação pelo SIN, com Taxa de Cruzamento Fixa ............................................................................ 71

5.7. Considerações Finais do Capítulo ................................................................ 75

6. Experimentação de Diversas Configurações para AG's "Clássicos", e Aplicação dos

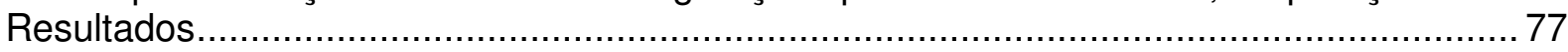

6.1. Experimentação de Diferentes Combinações de Valores de Pm, Pc e Tamanhos

de População, para AG's "Clássicos" ...................................................................... 77

6.1.1. Conclusões a Respeito Destes Experimentos ………………………..... 84

6.2. Considerações Sobre o Controle Dinâmico dos Parâmetros Pm e Pc, Utilizando-se

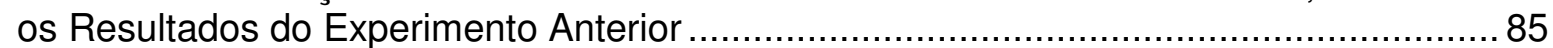

6.2.1. Experimentação de Diferentes Curvas Determinísticas para os Valores de Pm e/ou Pc 86

6.3. Considerações Finais do Capítulo .................................................................91

7. Experimentação de ajustes dos valores de Pm e Pc, por Substituição de Valores.......93

7.1. A Proposta da Substituição de Valores: O Ajuste "Em Degrau"............................93

7.2. Experimentação do Ajuste "em Degrau" para o AG que Resolve o Problema do Caixeiro Viajante (AGD-CV).

7.3. Experimentação do Ajuste "em Degrau" para o AG que Resolve o Problema de Minimização de Funções (AGD-MF) .................................................................... 98

7.4. Experimentação da Técnica de Ajuste "em Degrau" com Inferências Nebulosas,

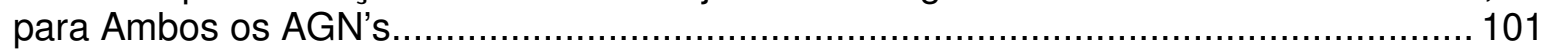

7.4.1. Experimentação da Técnica de Ajuste "em Degrau" com Inferências

Nebulosas, para o PCV (AGN-CV)....................................................................... 101

7.4.2. Experimentação da Técnica de Ajuste "em Degrau" com Inferências

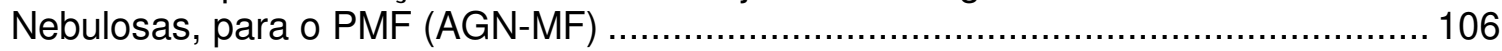

7.5. Discussão Sobre a Resposta do Sistema a Transições Abruptas e Transições

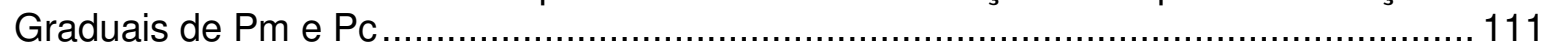

7.6. Considerações Finais do Capítulo ............................................................ 113

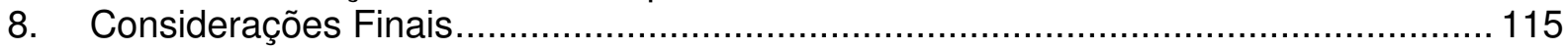

8.1. Cumprimento dos Objetivos Propostos.......................................................... 117

8.2. Contribuições do Trabalho..................................................................... 119

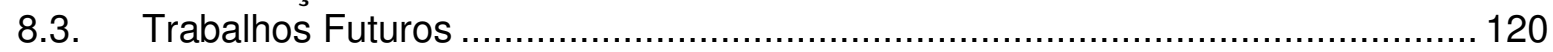

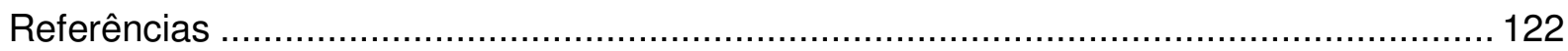




\section{Introdução}

A Inteligência Artificial (ou IA) é um ramo da ciência, que tem demonstrado forte expansão nos últimos anos. Segundo [Rezende - 2003], a IA procura capacitar a realização, por computadores, de funções comumente desempenhadas por seres humanos, utilizando-se conhecimento e raciocínio.

As técnicas pertencentes à IA podem ser empregadas na solução de problemas nãoideais, que normalmente possuem algumas das seguintes características: são tipicamente mal-definidos, difíceis de serem modelados, e/ou possuem grandes espaços de soluções (o que pode tornar muito difícil a solução através de modelagem matemática tradicional). Segundo [Konar - 2000], diversas são as áreas de aplicação de IA, das quais alguns exemplos são: sistemas especialistas; visão computacional e reconhecimento de imagens; planejamento de navegação para robôs; entendimento de linguagem natural e fala; controle inteligente; entre outras.

A Inteligência Computacional (ou IC) pode ser considerada um sucessor da Inteligência Artificial. Este ramo da ciência, segundo [Fogel, Fukuda, Guan - 1999], tem explorado o potencial de criação de máquinas inteligentes, pela modelagem de comportamentos e mecanismos inerentes aos organismos biologicamente inteligentes; em contraste com a IA tradicional, que tem explorado as possibilidades de criar programas que possam competir com seres humanos por meio de heurísticas, conhecimento encapsulado, e lógica simbólica. Em outras palavras: ao invés de focar apenas em resultados obtidos artificialmente (para que sejam semelhantes aos resultados obtidos por seres vivos), a IC também busca imitar a maneira como os seres vivos obtêm estes resultados.

Muitos dos pesquisadores compreendem a Inteligência Computacional como um campo dividido em três sub-campos [van Eck et al. - 2006]:

- Computação Nebulosa - ou "Fuzzy" (doravante referida como "CF");

- Computação Neural (doravante referida como "CN");

- Computação Evolutiva (doravante referida como "CE").

Cada uma destas técnicas possui sua própria área de atuação, e suas vantagens e desvantagens para a modelagem de sistemas em busca de soluções.

A Computação Evolutiva (CE) é inspirada na Teoria da Evolução Natural e da Genética, e é mais conhecida pelas suas subáreas: Algoritmos Genéticos (AG’s); Estratégias de 
Evolução; e Programação Genética [Rezende - 2003]. Segundo [Eberhart, Shi - 2007], o desenvolvimento de Algoritmos Genéticos tem suas origens em trabalhos realizados em 1950 por biólogos, utilizando computadores para simular sistemas genéticos naturais. A proposta original, de Algoritmos Genéticos, da forma como são conhecidos hoje, foi realizada em [Holland - 1975].

Segundo [Eberhart, Shi - 2007], uma perspectiva de Algoritmos Genéticos (AG's) é que eles são algoritmos de busca que refletem, de maneira primitiva, alguns processos da evolução natural. AG's normalmente provêm mecanismos de busca muito efetivos, que podem ser utilizados em aplicações de otimização ou classificação.

A escolha da configuração de diversos parâmetros de AG's, como a taxa de mutação $(\mathrm{Pm})$ e a taxa de cruzamento (Pc) é normalmente deixada para o usuário do AG [Lee, Takagi - 1993]. Porém, muitos obstáculos podem surgir durante a utilização de AG's, como por exemplo: lentidão do processo de busca; e convergência prematura do AG (para um determinado ponto do espaço de busca, cuja aptidão não atenda à aptidão desejada), e as principais causas para estes problemas são, primariamente: a escolha inapropriada dos valores dos parâmetros do AG, e/ou a utilização destes parâmetros de forma fixa (como ocorre num AG "clássico") [Xu, Vukovich - 1993]. Realmente, um usuário de um AG, para um determinado problema, deverá enfrentar uma difícil escolha, para o ajuste dos valores dos parâmetros do $A G$, e o fato de estes parâmetros permanecerem fixos durante a execução de AG's não facilita tentativas de se evitar problemas nesta execução.

Segundo [Lee, Takagi - 1993], como a interação entre a configuração dos parâmetros de um AG com o desempenho deste AG é conhecida por ser complexo, o controle destes parâmetros, em tempo de execução do $A G$, é um alvo primário para a utilização de Sistemas de Inferências Nebulosos (SIN's). Diversos são os trabalhos encontrados na literatura que buscam, ao mesmo tempo, melhorar o desempenho de AG's e/ou minimizar a necessidade de supervisão, da utilização de AG's, por operadores humanos. Como alguns exemplos, podemos citar: [Lee, Takagi - 1993]; [Xu, Vukovich - 1993]; [Xu, Vukovich 1994]; [Arnone, Dell'Orto, Tettamanzi - 1994]; [Herrera, Lozano - 1996]; e [Maturana, Saubion - 2007].

\subsection{Motivação e Justificativa}

Recentemente vislumbrou-se a possibilidade de as três principais técnicas constituintes da IC (CE, CF e CN) possuírem determinadas relações entre si, que permitissem (e regulassem) transformações de modelos (de problemas reais), descritos em uma destas técnicas, em outros modelos (dos mesmos problemas) descritos em outra destas técnicas 
[Andrade - 2002]. Caso estas relações existam e sejam encontradas, duas implicações principais poderiam ocorrer.

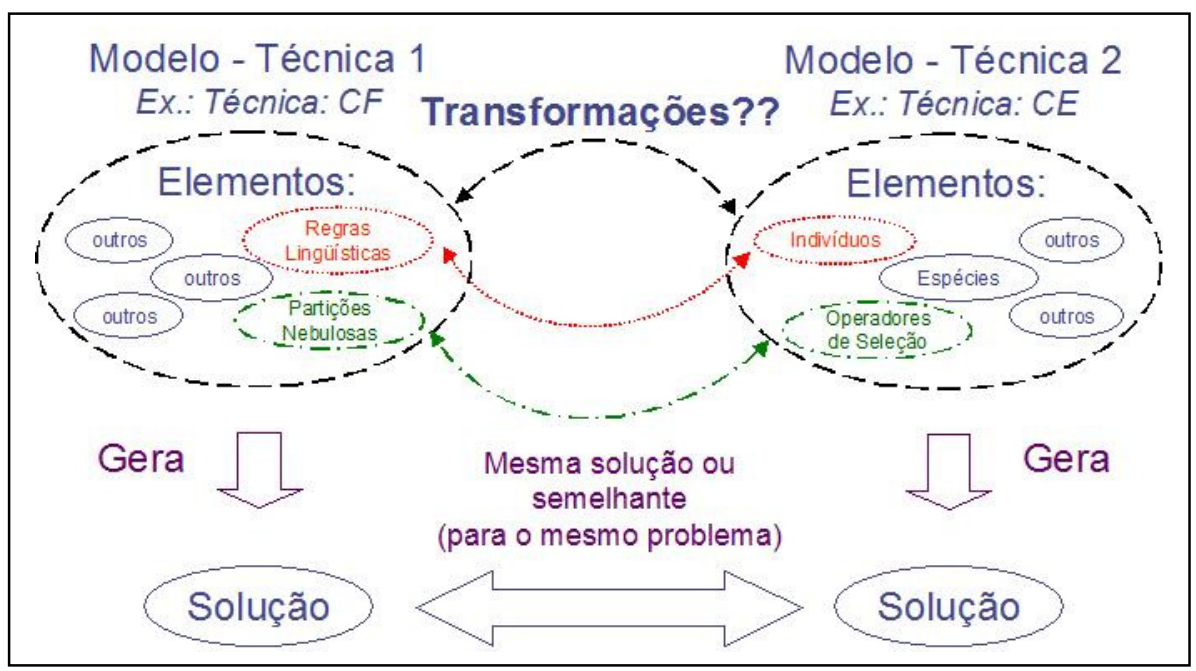

Figura 1.1: Ilustração conceitual do tipo de transformações entre modelos, almejada pela linha de pesquisa originada em [Andrade - 2002].

Em primeiro lugar, a modelagem de problemas pela utilização da Inteligência Computacional passaria a ter maior flexibilidade, e conseqüentemente um maior poder para tratar diferentes problemas. Em outras palavras: uma solução (para um determinado problema) poderá usufruir as vantagens da utilização de modelos descritos nas três diferentes técnicas, caso estas transformações existam e sejam empregadas convenientemente. Por exemplo: um modelo descrito pela técnica de Computação Nebulosa, que não apresentasse resultados satisfatórios para determinados casos particulares de um problema, poderia ser convertido para seu modelo equivalente em Computação Neural, o qual poderia apresentar resultados satisfatórios para estes casos particulares em questão.

Em segundo lugar, segundo [Caversan, Andrade - 2005], esta pesquisa pode abrir caminhos para a descoberta da existência de uma possível técnica fundamental da IC, da qual as técnicas CF, CN e CE poderiam ser casos particulares. Caso este último passo venha a comprovar a existência de tal técnica, essa descoberta poderia mudar a maneira atual de se trabalhar com IC, através de um modelo unificado.

Esta idéia original, surgida em [Andrade - 2002], implica em um vasto trabalho de investigação, para comprovar a existência e o funcionamento destas transformações. Entende-se que este trabalho, por ser muito extenso, deverá ser subdividido em etapas, cada uma destas compreendendo a investigação de transformações entre duas destas três 
técnicas mencionadas, gerando três sub-pesquisas: a busca por relações e transformações entre CF e CN; entre CF e CE; e entre CN e CE.

Em [Caversan - 2006], foram pesquisadas relações e transformações entre modelos descritos utilizando-se Computação Nebulosa, e modelos descritos utilizando-se a Computação Neural. Este trabalho obteve regras diretas de transformação para casos específicos de modelos Neurais.

Em [Fialho - 2007], foram pesquisadas relações e transformações entre modelos descritos utilizando-se Computação Nebulosa, e modelos descritos utilizando-se a Computação Evolutiva. Este trabalho não obteve regras diretas para a transformação de modelos (devido ao fato de que estas técnicas aparentemente possuem naturezas muito diferentes), porém obteve regras para a utilização das duas técnicas em um sistema híbrido, permitindo a evolução (pela Computação Evolutiva) de um modelo descrito pela utilização de Computação Nebulosa. Sendo assim, bases de conhecimento de um Controlador Lógico Nebuloso (ou CLN) foram modeladas como indivíduos de um Algoritmo Genético (ou AG), permitindo a evolução de um CLN para a solução de um problema específico (a navegação de um robô auto-guiado em um circuito).

Outra sub-pesquisa é a busca por relações entre as técnicas CE e CN. Esta terceira pesquisa está em andamento, sob realização de um grupo do Laboratório KNOMA da Escola Politécnica da Universidade de São Paulo.

Sistemas híbridos entre diferentes técnicas de IC também são úteis para esta linha de pesquisa, por propiciar transportes e transformações pontuais de elementos entre as diferentes técnicas envolvidas, e permitir o estudo da iteração entre as mesmas. Segundo [Fialho - 2007], a cada transformação validada entre as técnicas de IC, dá-se mais um passo rumo à constatação da existência de um modelo unificado.

Este trabalho foi motivado pelo estudo de sistemas híbridos, envolvendo CE e CF, referentes à linha de pesquisa originada em [Andrade - 2002]. Segundo [Rezende - 2003], um dos principais objetivos da IA é a integração de diferentes técnicas para formar sistemas mais robustos, os chamados Sistemas Inteligentes Híbridos. Segundo [Fogel, Fukuda, Guan - 1999], cada uma das diferentes técnicas de IC oferece meios úteis e particulares para a solução de problemas, e existe uma importante sinergia potencial que pode ser aproveitada pela combinação de diferentes elementos da IC.

Apesar do fato de o trabalho desta dissertação não lidar com esta busca de maneira direta (pois busca a criação de um sistema híbrido - no qual cada técnica desempenha um papel diferente), espera-se que os resultados obtidos sejam úteis para a compreensão da interação entre CF e CE, bem como para a compreensão da natureza de cada técnica. Espera-se também que as conclusões deste trabalho sejam úteis para futuros trabalhos que almejem estudar relações (e transformações), entre modelos descritos com CF e modelos 
descritos com CE. Ainda segundo [Rezende - 2003], sistemas híbridos podem auxiliar a descoberta de novas funcionalidades das técnicas envolvidas, e o entendimento de como diferentes técnicas podem se relacionar.

Em [Fialho - 2007], estudou-se sistemas híbridos nos quais havia a CF sendo ajustada pela CE. No trabalho desta dissertação, são propostos sistemas híbridos nos quais ocorre a CE sendo controlada pela CF.

\subsection{Objetivos}

Este trabalho tem por objetivo propor sistemas híbridos, nos quais Algoritmos Genéticos terão alguns de seus parâmetros passíveis de alteração (em tempo de execução), por Sistemas de Inferências Nebulosos. Desta forma, pretende-se utilizar as capacidades de classificação e controle de um Sistema de Inferências Nebuloso (SIN) para regular o a operação de um AG.

Alguns parâmetros passíveis de alteração podem ser, por exemplo, a probabilidade (também denominada "taxa") de mutação (doravante referida como "Pm"), a probabilidade (também denominada "taxa") de cruzamento (doravante referida como "Pc"), o tamanho da população de indivíduos (doravante referida como "Pop"), etc. Em [Xu, Vukovich - 1994], são ajustadas a taxa de mutação e a taxa de cruzamento do AG. Em [Lee, Takagi - 1993], o tamanho da população também é ajustado.

Espera-se que o desempenho deste tipo de AG - referido como Algoritmo Genético "Adaptativo" em [Herrera, Lozano - 1996] (devido à possibilidade de adaptação de seus parâmetros em tempo de execução) - seja superior ao desempenho de um Algoritmo Genético "clássico" - ou seja, cujos parâmetros não sofrem alterações desde o início da execução do algoritmo até o seu encerramento.

Com a finalidade de simplificar a notação dos sistemas desenvolvidos e analisados no presente trabalho, este tipo de sistemas híbridos, nos quais AG's utilizam SIN's para ajustar, em tempo de execução, alguns de seus parâmetros, será doravante referido como "Algoritmo Genético Nebuloso", e abreviado como "AGN". Algoritmos Genéticos "clássicos", que mantêm os valores de seus parâmetros durante toda a execução do algoritmo serão referidos apenas como "AG".

É interessante notar que os trabalhos [Xu, Vukovich - 1993] e [Xu, Vukovich - 1994] utilizam, como parâmetros de entrada para o SIN, medidas consideravelmente simples do AG (apenas o tamanho da população, o qual é fixo durante o experimento; e o número de gerações do AG realizadas até o momento da medição). Em [Bäck - 1998 apud Thierens 2002] e [Hinterding, Michalewicz, Eiben - 1997 apud Thierens - 2002], este tipo de controle 
de parâmetros, que não realiza medidas diretas da população de indivíduos do AG, e utiliza comportamentos determinísticos para os parâmetros ajustados em função do número de iterações do AG (também denominado o número de "gerações"), é classificado como "Controle Dinâmico de Parâmetros" ("Dynamic Parameter Control”) em [Bäck - 1998 apud Thierens - 2002] e [Hinterding, Michalewicz, Eiben - 1997 apud Thierens - 2002]. É importante notar que estas medidas (o número de gerações e o tamanho da população) não incluem nenhuma informação a respeito da população de indivíduos do AG (como sua diversidade, sua aptidão média etc). Apesar da simplicidade (e conseqüente facilidade de obtenção) destas medidas, os trabalhos [Xu, Vukovich - 1993] e [Xu, Vukovich - 1994] afirmam que o resultado final obtido pelo sistema híbrido realiza buscas de maneira mais rápida e eficiente que AG's "clássicos". Em outras palavras, obtêm soluções de maior aptidão em relação ao problema selecionado, e em um menor número de iterações.

Estes ótimos resultados, obtidos a partir de medidas relativamente simples, motivaram este trabalho, qual seja o de construir e analisar sistemas híbridos, utilizando Sistemas de Inferência Nebulosos (SIN), para regular em tempo de execução os parâmetros Pm e Pc de AG's, a partir destas mesmas medidas (o número de gerações e o tamanho da população), ou seja, utilizando Controle Dinâmico de Parâmetros.

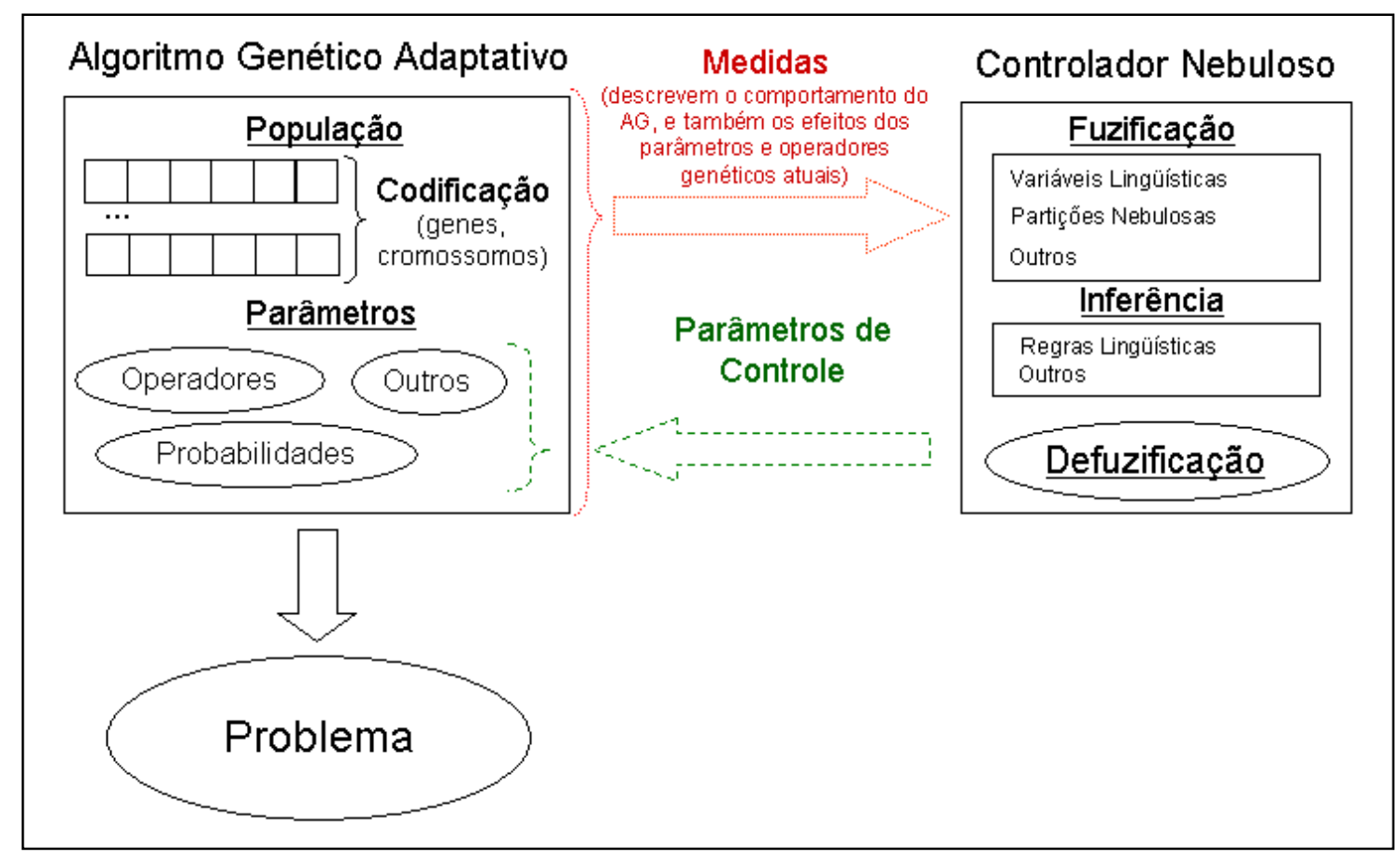

Figura 1.2: Ilustração conceitual do tipo de sistema híbrido almejado neste trabalho. 


\subsection{Metodologia}

Este trabalho foi realizado utilizando-se simulações em ambiente computacional. Uma ferramenta de software foi desenvolvida para a simulação de Algoritmos Genéticos (tanto "clássicos" como também AG's híbridos, com ajuste de parâmetros em tempo de execução, por Sistemas de Inferência Nebulosos), utilizando a linguagem de programação $C$ (escolhida por ser uma linguagem poderosa e simples), em ambiente Windows.

O software também permitirá ao usuário simular um AG nas mesmas condições. Os resultados das simulações em ambos os casos poderão ser comparados, no que diz respeito ao número de iterações que o algoritmo em questão levou para encontrar o valor ótimo global no espaço de busca. Este sistema será simulado para a solução de problemas tipicamente modelados utilizando-se CE, como o "Problema de Minimização de Funções" (doravante referido como "PMF"), e o "Problema do Caixeiro Viajante" (doravante referido como "PCV"). O PCV é um problema conveniente para o estudo de AG's, por ser um problema "Não Polinomial" (doravante referido por "NP"). Além disso, ambos os problemas possuem funções de aptidão que podem ser facilmente calculadas, o que os torna ainda mais adequados para a aplicação de AG's.

Segundo [Crawford - 1992], problemas NP são problemas que não possuem soluções determinísticas que possam ser obtidas computacionalmente em tempo polinomial. Ainda segundo [Crawford - 1992], problemas de classe NP são difíceis (se não impossíveis) de serem resolvidos em "prazos realistas", devido à elevada ordem que possuem (como por exemplo: $O\left(2^{n}\right)$ ou $\left.O(n !)\right)$. Diversos métodos de aproximação têm sido desenvolvidos para lidar com esta classe de problemas, sem a promessa de soluções ótimas. Os AG's são um excelente método de aproximação para lidar com problemas NP.

Desta forma, para se atingir os objetivos apresentados por meio da metodologia proposta, entende-se que os seguintes passos intermediários deverão ser tratados:

- Investigação de trabalhos que utilizem SIN's para ajustar, em tempo de execução, parâmetros de AG's, e como isso pode ser realizado de forma a melhorar critérios pré-definidos de desempenho.

- Investigação de técnicas e regras para se utilizar o Controle Dinâmico de Parâmetros em AG's (conforme definidos em [Bäck - 1998 apud Thierens - 2002] e [Hinterding, Michalewicz, Eiben - 1997 apud Thierens - 2002]), e investigar a viabilidade de sua aplicação para os problemas selecionados.

- Utilização de comportamentos determinísticos para Pm e Pc, em função do tamanho da população e do número de gerações, nos moldes dos comportamentos exemplificados em [Xu, Vukovich - 1993] e [Xu, Vukovich - 1994]. 
- Propor e analisar a utilização destes comportamentos em sistemas híbridos, utilizando SIN's para regular, em tempo de execução, os parâmetros Pm e Pc de AG's.

- Implementar Algoritmos Genéticos em uma ferramenta computacional, e que seja de estrutura modular, que permita sua alteração, para a utilização de diferentes operadores de seleção, de cruzamento, e de mutação, bem como sua utilização para diferentes problemas e representações de indivíduos, e que seja utilizada para a solução de, pelo menos, dois problemas distintos.

- Implementar também AG's com parâmetros ajustáveis, de estrutura suficientemente modular para permitir que este ajuste possa ser feito por SIN's, ou outros tipos de ajustes, como por exemplo por funções, ou substituições determinísticas de valores em condições espec ificas.

- Implementar, também em ferramenta computacional, AG's que utilizem as estruturas do item anterior para a realização de ajustes de parâmetros através de SIN's.

- Fornecer subsídios para futuros trabalhos de investigação de um modelo unificado de IC, pela implementação de um sistema híbrido (utilizando em conjunto AG's e SIN's), por permitir a observação dos limites das áreas de atuação de cada técnica, e como estas interagem entre si.

\subsection{Estrutura do Trabalho}

O próximo capítulo apresenta fundamentos teóricos importantes referentes à Computação Nebulosa ou "Fuzzy" (CF), e à Computação Evolutiva (CE).

O terceiro capítulo do presente trabalho apresenta o estudo de diversos trabalhos da literatura relacionados ao tema, que utilizam Sistemas Nebulosos para ajustar parâmetros de Algoritmos Genéticos, em tempo de execução. Estes trabalhos são analisados sob diversos pontos de vista, como por exemplo: medidas de desempenho utilizadas para comparar os Sistemas Híbridos com AG's "clássicos" (ou seja, AG's que mantêm fixos os valores de seus parâmetros em tempo de execução); o problema tratado pelos algoritmos; as entradas e saídas dos Sistemas Nebulosos utilizados etc.

O quarto capítulo apresenta as ferramentas computacionais desenvolvidas, para a execução dos experimentos do presente trabalho, bem como as instâncias dos problemas utilizados.

O quinto capítulo apresenta os experimentos iniciais realizados, com a ferramenta computacional desenvolvida, para ajustas parâmetros de AG's, em tempo de execução, utilizando "Controle Dinâmico de Parâmetros" ("Dynamic Parameter Control" - [Bäck - 1998 
apud Thierens - 2002] e [Hinterding, Michalewicz, Eiben - 1997 apud Thierens - 2002]) com inferências nebulosas, e cujas conclusões foram utilizadas para nortear futuros experimentos.

O sexto capítulo apresenta diversos experimentos realizados, para se compreender o funcionamento dos AG's "clássicos" implementados para resolver as instâncias já especificadas dos problemas: de "Minimização de Funções" (PMF); e do "Caixeiro Viajante" (PCV). Estes experimentos geraram extensas tabelas, demonstrando o comportamento dos AG's em questão para diferentes valores dos parâmetros "probabilidade (ou taxa) de mutação" (Pm); "probabilidade (ou taxa) de cruzamento" (Pc); e "tamanho da população" de indivíduos do AG (Pop). A análise destes dados foi crucial para o desenvolvimento do trabalho.

O sétimo capítulo apresenta uma proposta do ajuste dos parâmetros Pm e Pc, pela utilização de "Controle Dinâmico de Parâmetros" ("Dynamic Parameter Control" - [Bäck 1998 apud Thierens - 2002] e [Hinterding, Michalewicz, Eiben - 1997 apud Thierens 2002]), em função dos valores de $\mathrm{Ng}$ e Pop. Esta proposta consiste na substituição abrupta de valores de Pm e Pc, e foi denominada, no presente trabalho, como "Ajuste em Degrau". Em seguida, Sistemas de Inferências Nebulosos são utilizados para implementar este tipo de ajuste. Os resultados de cada uma das diferentes abordagens ("Ajuste em Degrau"; e Ajuste com Sistemas de Inferências Nebulosos) são comparados e discutidos.

Finalmente, o oitavo capítulo apresenta as considerações finais do presente trabalho, relacionando as contribuições obtidas a partir do mesmo, e também apresenta possíveis trabalhos futuros (que possam dar continuidade ao trabalho aqui realizado). 


\section{Inteligência Computacional (IC)}

A definição de ramos da ciência como "Inteligência Artificial" (doravante referida como "IA") e "Inteligência Computacional" (doravante referida como "IC") não é trivial, fato que se deve em grande parte à própria dificuldade de se definir o termo "inteligência". Em outras palavras: que características um sistema computacional deve possuir para que possa ser considerado inteligente, e o que o difere de um sistema "não inteligente"? Segundo [Wilson, Keil - 1999], "inteligência" pode ser definida como a habilidade de se adaptar a; modelar; e escolher ambientes, embora no decorrer dos anos muitas definições de inteligência têm sido oferecidas.

Segundo [Jordan, Russell - 1999], existem duas visões complementares de IA: (1) como disciplina de engenharia, cujo objetivo é o de construir "máquinas inteligentes"; e (2) como uma ciência empírica, cujo objetivo é realizar a modelagem computacional da inteligência humana. Ainda segundo [Jordan, Russell - 1999], nos primórdios da IA, estas duas visões eram raramente separadas, mas com o passar dos anos ocorreu uma divisão substancial, com a primeira visão dominando o que se denomina "IA moderna", e a segunda caracterizando em grande parte a "ciência cognitiva moderna".

Segundo [Fogel, Fukuda, Guan - 1999], quando observados sob uma perspectiva menos antropocêntrica, seres humanos; chimpanzés; golfinhos; e até mesmo grupos sociais como formigas e abelhas; cada um constitui exemplos de sistemas inteligentes criados pelo processo natural de evolução, um processo estocástico que tem gerado organismos de intelecto crescente com o tempo. Ao invés de se procurar melhorar soluções por, por exemplo, métodos heurísticos mais rápidos para árvores de seleção, é de interesse examinar os prospectos de geração de máquinas inteligentes, pela modelagem dos processos computacionais da natureza, um paradigma hoje encapsulado como "Inteligência Computacional". Sendo assim, pode-se concluir que a IC possui um menor apoio em métodos estatísticos, que a IA tradicional, e busca não somente imitar o comportamento dos seres vivos ditos "inteligentes", mas também busca fazê-lo imitando os processos internos destes seres, os quais produzem seu comportamento. 


\subsection{Computação Nebulosa}

A Teoria de Conjuntos Nebulosos foi lançada em 1965, com a publicação de [Zadeh 1965], baseada na Teoria de Conjuntos Clássicos, e como uma extensão da mesma. Esta teoria surgiu com o objetivo de viabilizar a modelagem de sistemas vagos e mal-definidos, dos quais não se possui muitas informações precisas. Este tipo de modelagem é obtido tentando-se imitar o raciocínio humano, muitas vezes aproximado e sem precisão numérica, e capaz de lidar facilmente com diversos problemas vagos e mal definidos em seu dia-a-dia. Segundo [Zadeh - 1965], "classes" de definição imprecisa (como por exemplo: "pessoas altas"; ou "números muito maiores que 1") possuem um papel importante no raciocínio humano, particularmente nos domínios de: reconhecimento de padrões; comunicação de informações; e abstrações.

$\mathrm{Na}$ Teoria Clássica de Conjuntos, um Universo possui elementos e conjuntos, e cada elemento do universo possui apenas dois tipos de pertinência a um conjunto qualquer: ou o elemento pertence ao conjunto, ou não pertence ao mesmo. Podemos codificar numericamente estes dois tipos de pertinência, associando, a cada elemento do universo, uma função que representa a pertinência do elemento a cada conjunto (do próprio universo) - denominada função de pertinência. Esta função assume o valor 1 quando o elemento pertence ao conjunto, e 0 quando o elemento não pertence.

Segundo [Zadeh - 1965], a pertinência de um elemento $x$ de um espaço de pontos (ou objetos) $X$ a um conjunto nebuloso $A$ é um valor numérico pertencente a um intervalo de números reais $[0,1]$. Desta forma, a pertinência de um elemento a um conjunto nebuloso também pode assumir valores entre 0 e 1 (além dos próprios valores 0 e 1). Desta forma, surgem situações em que um determinado elemento pertence a um conjunto com, por exemplo, um grau de pertinência de 0,8 , e pertence a outro conjunto com, por exemplo, um grau de pertinência de 0,2.

\subsubsection{Operações Entre Conjuntos}

Neste novo cenário, as operações entre conjuntos, definidas pela Teoria Clássica de Conjuntos, como "união", "intersecção" e "complemento", também precisam ser redefinidas para obterem conformidade com esta extensão. Por exemplo: se um elemento a pertence a um conjunto $A$ com grau 0,7 de pertinência, e a um conjunto $B$ com grau 0,5 de pertinência, então qual será a pertinência de a ao conjunto $A \cup B$ ? Além disso, as extensões dos conceitos originais das operações entre conjuntos (da Teoria Clássica) devem ser reduzidas 
às próprias operações originais, quando os graus de pertinência dos elementos envolvidos forem apenas 0 e 1 .

\subsubsection{Conceito de “Disjunção” (ou “União”)}

Existem diversas operações que atendem às necessidades descritas acima. Para o operador de "união", utilizam-se operadores denominados "Conorma Triangular": funções da forma $f:[0,1][0,1] \rightarrow[0,1]$ (que terão como seus argumentos a pertinência do elemento em questão a cada conjunto, e como saída a pertinência do elemento à união dos conjuntos), que atendem aos seguintes axiomas [Shaw, Simões - 1999]:

- Condições de Contorno:

$$
\begin{aligned}
& \circ f(0,0)=0 \\
& \circ f(0,1)=f(1,0)=f(1,1)=1
\end{aligned}
$$

- Comutatividade:

$$
\text { ○ } f(a, b)=f(b, a)
$$

- Monotonicidade:

- Se "a' $\geq a$ " e "b' $\geq$ b", então "f(a',b') $\geq f(a, b)$ "

- Associatividade.

$$
\circ \quad f(f(a, b), c)=f(a, f(b, c))
$$

- "f" é uma função contínua.

Alguns exemplos de funções que atendem a estes axiomas são [Shaw, Simões - 1999]: união (ou "máximo"), soma algébrica, soma limitada, soma logarítmica, soma drástica e soma disjunta. Exemplos:

- União:

$$
f(a, b)=\max (a, b)
$$

- Soma Algébrica:

$$
f(a, b)=a+b-a \cdot b
$$

\subsubsection{Conceito de "Conjunção" (ou "Intersecção")}

Para o operador de "intersecção", utilizam-se operadores de "Norma triangular": funções da forma $f:[0,1][0,1] \rightarrow[0,1]$ (que obviamente terão como seus argumentos a pertinência do elemento em questão a cada conjunto, e como saída a pertinência do elemento à união dos conjuntos), que atendem aos seguintes axiomas [Shaw, Simões - 1999]:

- Condições de Contorno: 


$$
\begin{aligned}
& \mathrm{f}(1,1)=1 \\
& \circ \quad \mathrm{f}(0,1)=f(1,0)=f(0,0)=0
\end{aligned}
$$

- Comutatividade:

$\circ f(a, b)=f(b, a)$

- Monotonicidade:

- Se "a' $\geq$ a" e "b' $\geq$ b", então "f(a',b') $\geq f(a, b)$ "

- Associatividade:

$$
\circ \quad f(f(a, b), c)=f(a, f(b, c))
$$

- "f" é uma função contínua.

Alguns exemplos de funções que atendem a estes axiomas são [Shaw, Simões - 1999]: intersecção (ou "mínimo"), produto algébrico, produto limitado, produto logarítmico e produto drástico. Exemplos:

- Intersecção:

$$
\begin{aligned}
& f(a, b)=\min (a, b) \\
& \text { - Produto Algébrico: } \quad f(a, b)=a \cdot b
\end{aligned}
$$

\subsubsection{Números Nebulosos e Variáveis Lingüísticas}

Segundo [Rezende - 2003], quando um ser humano está resolvendo um problema complexo, ele primeiro tenta estruturar o conhecimento sobre este problema em conceitos gerais e, depois observa as relações essenciais entre esses conceitos. Essa perspectiva geralmente não permite a definição precisa de uma solução, em termos de números exatos, por exemplo, mas conduz a uma classificação ou agregação qualitativa em categorias gerais ou conjuntos de possíveis soluções. A capacidade de classificar, de modo impreciso, as variáveis de um problema, em termos de conceitos qualitativos em vez de quantitativos, traduz a idéia de uma variável lingüística. O processo nebuloso de representação de conhecimento depende fundamentalmente deste conceito. Para se definir Variáveis Lingüísticas, inicialmente é necessário definir Números Nebulosos:

Segundo [Lee - 1990], um número nebuloso ("fuzzy number") em um universo contínuo "U" (por exemplo: uma linha real), é um conjunto nebuloso "F" em "U", o qual é "normal" e "convexo", ou seja:

- "normal": $\max _{u \in U} \mu_{F}(u)=1$; onde $\mu_{\mathrm{F}}(u)$ representa a função de pertinência do elemento "u" ao conjunto nebuloso "F"; 
- "convexo": $\mu_{F}\left(\lambda u_{1}+(1-\lambda) u_{2}\right) \geq \min \left(\mu_{F}\left(u_{1}\right), \mu_{F}\left(u_{2}\right)\right)$; onde $\mu_{F}(\mathrm{u})$ representa a função de pertinência do elemento " $u$ " ao conjunto nebuloso "F"; $u_{1}, u_{2} \in U ; \lambda \in$ $[0,1]$.

Funções de pertinência não-convexas não possibilitam unicidade na avaliação numérica do valor no eixo horizontal [Shaw, Simões - 1999].

Segundo [Lee - 1990], uma variável lingüística ("linguistic variable") é caracterizada por uma quíntupla (x, T(x), U, G, M), onde:

- $\quad x$ é o nome de uma variável;

- $T(x)$ é o conjunto de nomes de valores lingüísticos de $x$, com cada valor sendo um número nebuloso (ou fuzzy) definido em U;

- U é o universo de discurso;

- G é uma regra sintática para gerar os nomes dos valores de x;

- M é uma regra semântica para associar para cada valor o seu significado.

\subsubsection{Inferência Nebulosa}

A Computação Nebulosa possui grande aplicação no controle de processos, devido ao fato de que o mecanismo de inferência se assemelha muito ao raciocínio de um operador humano. Segundo [Shaw, Simões - 1999], o sucesso mundialmente reconhecido, de sistemas de modelagem e controle baseados em lógica nebulosa, em aplicações industriais, tem comprovado sua utilização como mais uma ferramenta para as disciplinas de engenharia de controle industrial, manufatura, comunicação homem-máquina e em sistemas de tomada de decisão.

É possível que o mecanismo de inferência implemente regras imprecisas e vagas, como por exemplo: "se a temperatura do material no tanque for muito alta vire um pouco a válvula para a direita", a qual não envolve precisão numérica.

Para se realizar um mecanismo de inferência nebulosa, é necessário transformar as variáveis de entrada do domínio categórico (ou "crisp") para o domínio nebuloso (ou "fuzzy"). Em outras palavras, no exemplo acima, quando se tem uma leitura de um valor de temperatura (por exemplo: "40 graus Celsius"), é necessário transportá-lo para o domínio nebuloso, no qual ele assumirá um valor de pertinência a conjuntos nebulosos (por exemplo: "temperatura muito alta"). Com base neste valor, o sistema realizará a inferência, ditando a saída do controlador, ou seja, qual deve ser o movimento da válvula, tipicamente ainda no domínio nebuloso (por exemplo: "a válvula deve ser girada um pouco para a direita, com 0,6 
de confiança"). Este resultado será finalmente convertido novamente para o domínio categórico, que será a saída do controlador (por exemplo: "girar a válvula 35 graus para a direita").

\subsection{Computação Evolutiva}

A computação evolutiva surgiu inspirada na Teoria da Evolução das Espécies, de Charles Darwin. Na natureza, um mecanismo de seleção de indivíduos faz com que sobrevivam apenas os seres vivos melhor adaptados ao meio ambiente (ou em outras palavras: "apenas os mais fortes sobrevivem"). Desta forma, o próprio meio ambiente seleciona apenas os indivíduos considerados "mais aptos", ou "mais adequados para sobreviverem neste meio ambiente", para permanecerem no próprio meio ambiente, enquanto que os indivíduos com menor aptidão são descartados.

Entre os indivíduos sobreviventes, ocorrem cruzamentos e mutações, que podem gerar novos indivíduos ainda mais aptos (ou menos aptos). Sobre a nova população, novas seleções acontecem, e pela repetição deste processo, obtém-se a evolução dos indivíduos. Em outras palavras: a população passa a ter um aumento gradual em sua aptidão ao meioambiente.

A partir da compreensão deste fenômeno natural de evolução, surgiu a idéia de adaptálo para se obter a evolução de soluções de problemas computacionais.

Na computação evolutiva, um problema a ser resolvido corresponde ao meio ambiente, e a população de indivíduos é, na realidade, uma população de soluções (candidatas à solução final do problema em questão). Cada indivíduo (ou "solução-candidata") é avaliado segundo sua aptidão para resolver o problema, e apenas os mais aptos são selecionados. Dentre estes, ocorrem fenômenos de cruzamento (nos quais as soluções "filhas" herdam atributos das soluções "pais"), e de mutação (nos quais as soluções têm algumas de suas características modificadas). Nesta nova população, ocorre uma nova seleção, e este procedimento vai se repetindo para se obter a evolução das soluções (até que se atinja um grau de aptidão desejado para a solução final).

Existem diversas abordagens para sistemas baseados na evolução natural. Entre elas, segundo [Back - 1996 apud Rezende - 2003], podemos destacar:

- Estratégias Evolutivas;

- Algoritmos Genéticos (AG's); e

- Programação Genética (PG)

Segundo [Fialho - 2007], apesar de estas se tratarem de técnicas criadas por autores diferentes, em momentos diferentes e com focos diferentes, todas têm uma estrutura básica 
em comum: realizam fenômenos de reprodução, impõem variações aleatórias, promovem a competição e executam fenômenos de seleção de indivíduos de uma dada população.

As principais diferenças entre uma abordagem e outra são o modo como um indivíduo pode ser codificado juntamente com seus atributos (ou genes), quais operadores atuam entre os indivíduos (em algumas abordagens o cruzamento não é utilizado), e como estes operadores funcionam. Para este trabalho foi escolhida a abordagem dos Algoritmos Genéticos (doravante referida como "AG").

\subsubsection{Algoritmos Genéticos}

Nos AG's estão presentes tanto operações de mutação como de cruzamento. A codificação dos indivíduos em genes tanto pode ser "binária" (cada indivíduo é codificado em um vetor de bits, que assumem apenas valores "0" ou "1"), ou "por valores" (cada indivíduo é codificado como um vetor de números reais).

A codificação binária possui fácil utilização, manipulação e análise, mas pode não ser adequada para se modelar indivíduos que possuam variáveis de valores contínuos. A codificação por valores não possui essa desvantagem, mas infelizmente, na maioria das vezes, torna-se necessário o desenvolvimento de operadores de mutação e cruzamento específicos para o problema [Fialho - 2007].

Como operadores de cruzamento, pode-se utilizar diversos operadores diferentes (dependendo da codificação utilizada). Os mais comuns em AG's são, segundo [Obitko, Slavík - 1999]:

- Ponto de Cruzamento Único;

- Dois Pontos de Cruzamento;

- Uniforme;

- Aritmético.

No operador "Ponto de Cruzamento Único", uma posição dos indivíduos é aleatoriamente selecionada, e o filho é formado copiando os genes do primeiro pai, do início até o ponto de cruzamento; e do outro pai, do ponto de cruzamento até o fim. Ex: $1100.10 \mathrm{X}$ $0101.01=110001$.

Os operadores de mutação também dependem muito da codificação utilizada. Os mais comumente utilizados em AG's são:

- Troca de Valores;

- $\quad$ Aritmética;

- $\quad$ Troca de Posições. 
No operador de mutação por "Troca de Valores", uma ou mais posições do indivíduo são escolhidas aleatoriamente, e os seus valores são trocados por outros valores pertencentes ao universo de discurso do problema. Por exemplo:

Seja o universo "U" dado por: $U=\{x \in \mathrm{N}\}$, e um indivíduo "i" dado pelo seguinte vetor: $\mathrm{i}$ $=\langle 1,(2), 3,4,5,6\rangle$, (onde o número entre parênteses representa a posição selecionada para a mutação), então após a mutação, o novo indivíduo “i'” será dado, por exemplo, por: i' $=<1,(27), 3,4,5,6>$ (exemplo retirado de [Fialho -2007$]$ ).

\subsection{Considerações Finais do Capítulo}

Este capítulo apresentou, brevemente, os principais fundamentos teóricos envolvidos nos sistemas híbridos (que utilizam Sistemas de Inferências Nebulosos para ajustar, em tempo de execução, parâmetros de Algoritmos Genéticos) os quais constituem o principal escopo deste trabalho.

No próximo capítulo, diversos trabalhos que implementaram este tipo de sistemas híbridos são analisados e discutidos. 


\section{Trabalhos da Literatura Científica Relacionados ao Tema}

Diversos estudos já foram realizados na literatura científica visando à construção de sistemas híbridos, envolvendo um sistema de inferências nebuloso para controlar parâmetros de algoritmos genéticos, em tempo de execução. Este capítulo tem por objetivo apresentar e discutir quatro destes trabalhos: "Dynamic Parametric GAs" [Lee, Takagi 1993]; "Fuzzy GAs" [Xu, Vukovich - 1993] / "Fuzzy EAs" [Xu, Vukovich - 1994]; "Fuzzy Government”: [Arnone, Dell'Orto, Tettamanzi - 1994], e "Adaptive GAs Based on Fuzzy Logic Controllers" [Herrera, Lozano - 1996].

\section{1. “Dynamic Parametric GAs” [Lee, Takagi - 1993]}

Neste trabalho, o sistema híbrido criado foi denominado "Dynamic Parametric Genetic Algorithm" (doravante referido como "DPGA"). Segundo este trabalho, as entradas do sistema de controle nebuloso podem ser qualquer combinação de "medidas de desempenho do AG"; e "parâmetros atuais de controle do AG"; e as saídas podem ser novos valores de quaisquer "parâmetros de controle do AG" (que substituirão os valores dos parâmetros atuais de controle).

Um DPGA foi implementado, e utilizado para resolver um problema clássico de controle não-linear, o "problema de controle de um pêndulo invertido".

Para a obtenção da base de regras do sistema de controle nebuloso, os autores utilizaram uma técnica automática, na qual um segundo algoritmo genético evoluía a própria base de regras do sistema de controle nebuloso, o qual ajustava dinamicamente os parâmetros do primeiro AG. Detalhes específicos a respeito desta técnica utilizada para projetar a base de regras do sistema de controle nebuloso fogem do escopo do trabalho desta dissertação. A base de regras obtida através deste experimento possuía em torno de 16 a 18 regras (envolvendo as três variáveis de entrada) para cada uma das três saídas do controlador.

Os resultados obtidos pelo DPGA demonstraram melhor desempenho que os de um AG "clássico" para o mesmo problema. O critério utilizado para comparar os desempenhos dos 
sistemas foi a comparação de duas medidas de desempenho de Algoritmos Genéticos, definidas em [DeJong - 1975 apud Lee, Takagi - 1993]: "online performance" e "offline performance". Segundo [Lee, Takagi - 1993], a primeira tem por finalidade medir o desempenho que o algoritmo apresenta durante sua execução; e a segunda, medir a convergência do algoritmo. Estas medidas são calculadas da seguinte forma:

- Desempenho "Online" ("Online Performance”)

$$
x_{\text {online }}(s)=\frac{1}{T} \sum_{t=1}^{T} f_{e}(t)
$$

- Desempenho "Offline" ("Offline Performance")

$$
x_{\text {offline }}(s)=\frac{1}{T} \sum_{t=1}^{T} f_{e}^{*}(t)
$$

- Legenda:

- $s$ é a estratégia de busca

- e é o ambiente

- $f e(t)$ é o valor da função (a ser otimizada pelo AG) no instante $t$

- $f e^{*}(t)$ é o melhor valor da função obtido até o instante $t$

\section{2. “Fuzzy GAs” [Xu, Vukovich - 1993]/"Fuzzy EAs” [Xu, Vukovich - 1994]}

Estes trabalhos buscam a solução para dois problemas, considerados muito comuns em AG's: a baixa velocidade de busca por soluções; e a convergência prematura do algoritmo. Os sistemas híbridos criados nestes trabalhos receberam os nomes de "Fuzzy Genetic Algorithm" (doravante referido como "FGA") em [Xu, Vukovich - 1993]; e "Fuzzy Evolutionary Algorithm" (doravante referido como "FEA") em [Xu, Vukovich - 1994]. Nesta abordagem, a utilização de um sistema de controle nebuloso visa auxiliar não somente o controle dinâmico dos parâmetros do AG durante sua execução, mas também a seleção dos valores iniciais destes parâmetros.

Em [Xu, Vukovich - 1993], um FGA foi implementado para resolver o problema do caixeiro viajante (em simulações computacionais, utilizando linguagem de programação $\mathrm{C}++$ 
- uma linguagem orientada a objetos - em ambiente Windows). O FGA demonstrou desempenho superior ao de um AG "clássico" para os experimentos conduzidos, em velocidade de convergência do algoritmo, segundo diversas tabelas de resultados demonstradas no trabalho. O trabalho também menciona que o FGA possui maior desempenho quanto à qualidade da solução final obtida.

Em [Xu, Vukovich - 1994], um trabalho semelhante foi realizado, implementando um sistema híbrido para resolver um problema de movimentação de um braço mecânico de um robô. Neste trabalho, o sistema híbrido recebeu o nome de "Fuzzy Evolutionary Algorithm" (doravante referido como "FEA"), mas apesar do nome diferente, o sistema híbrido em questão utilizava também um AG (com parâmetros ajustados por CLN's). O braço mecânico possuía 7 graus de liberdade, e teve apenas 3 juntas sujeitas a variações durante 0 experimento (cujo objetivo era seguir de um ponto a outro em linha reta). Para se modelar o problema utilizando AG's, os genes representavam os estados dos ângulos das juntas, em cada ponto de amostragem do movimento (35 pontos no total, uma amostragem a cada 0,6 s). Assim como em [Xu, Vukovich - 1993], os experimentos foram realizados em simulações computacionais, (utilizando linguagem de programação $\mathrm{C}++$ - linguagem orientada a objetos - em ambiente Windows).

O FEA demonstrou desempenho superior ao de três AG's "convencionais" para os experimentos conduzidos, pois seus resultados apresentaram menor diferença (ou "erro") em relação ao percurso desejado (ou "ideal") do braço mecânico (percurso em linha reta). Além disso, o trabalho também informa que o FEA convergiu mais rapidamente para a solução, que os AG's "simples". Estes três AG's possuíam taxas de cruzamento e taxas de mutação fixas, ligeiramente diferentes entre si, e tomadas dentro de um intervalo de valores considerado "recomendável" para o problema - segundo diretrizes fornecidas em [MicroGA 1992 apud Xu, Vukovich - 1993].

Em ambos os trabalhos, as variáveis de entrada dos CLN's eram:

- o "tamanho da população"; e

- o "número de gerações" realizadas até o momento.

As variáveis de saída dos CLN's eram:

- a "taxa de cruzamento"; e

- a "taxa de mutação" do AG.

Segundo [Xu, Vukovich - 1993], e [Xu, Vukovich - 1994], os experimentos computacionais realizados mostraram que os FGA's (ou FEA's) implementados realizaram buscas por soluções de maneira mais rápida e eficiente que os AG's "convencionais" (ou seja, com parâmetros fixos durante a execução do algoritmo). 


\section{3. “Fuzzy Government” [Arnone, Dell'Orto, Tettamanzi - 1994]}

Este trabalho afirma que o uso de Algoritmos Evolutivos necessita normalmente de supervisão humana, em especial para:

- detectar a emergência de uma solução;

- ajustar os parâmetros de controle do algoritmo; e

- monitorar o andamento da execução do algoritmo.

A proposta deste trabalho é que o uso de um controlador nebuloso possa realizar estas tarefas, buscando reduzir ou até eliminar a necessidade da intervenção humana para a execução do algoritmo. Este trabalho denomina como "Fuzzy Government" o uso de um controlador nebuloso para regular, em tempo de execução, os parâmetros de um Algoritmo Evolutivo. Diferentemente dos outros trabalhos aqui citados, este trabalho não utilizou AG's, mas sim "Programação Evolutiva", na qual os indivíduos são modelados como árvores. Esta abordagem se provou útil para o problema modelado, de "Inferência Simbólica de Fórmulas", pois cada solução-candidata (ou indivíduo) deste problema é uma fórmula algébrica, para qual a representação em árvores pode ser muito conveniente. Embora a utilização de Programação Genética esteja fora do escopo do trabalho desta dissertação, a análise de (Arnone, Dell'Orto, Tettamanzi - 1994) pode ser produtiva para a implementação de um sistema híbrido com AG's.

Diversos CLN's foram implementados neste trabalho, para:

- regular o comprimento máximo permitido para os genótipos;

- regular a probabilidade de mutação;

- ajustar o intervalo de avaliação de fórmulas (para evitar a ocorrência de problemas do tipo "overflow" ou "underflow");

- detectar a emergência de uma solução e parar o algoritmo quando uma solução ótima global for evidenciada.

O experimento foi conduzido em simulações computacionais, em um supercomputador CM-200 [CM - 1992 apud Arnone, Dell'Orto, Tettamanzi - 1994]. Nove instâncias diferentes do problema foram simuladas, sendo que para cada uma foram realizadas duas simulações, uma utilizando o algoritmo com "Fuzzy Government" (sem supervisão humana), e outra utilizando o algoritmo sem "Fuzzy Government", e com supervisão humana. O trabalho afirma que os resultados obtidos pelo sistema híbrido (sem supervisão humana) e os obtidos pelo algoritmo sem "Fuzzy Government" (com supervisão humana) foram quase indistinguíveis. O número médio de gerações necessárias de ambos os algoritmos, para se chegar à solução, foi muito próximo. 


\section{4. "Adaptive GAs Based on Fuzzy Logic Controllers" [Herrera, Lozano - 1996]}

Este trabalho buscou, essencialmente, equilibrar uma medida específica do AG, denominada a "Relação entre Aproveitamento e Exploração" ${ }^{1}$ (doravante referida como "EER"). Esta relação pode ser explicada de maneira informal, segundo [Herrera, Lozano 1996], como o balanço entre "aproveitar-se do que já funciona bem (na população)" (aproveitamento), e "explorar-se novas possibilidades, que possam eventualmente evoluir em algo ainda melhor" (exploração). Segundo os autores e outras referências apontadas neste trabalho - [Li, Lucasius, Kateman - 1992 apud Herrera, Lozano - 1996]; [Mahfoud 1995 apud Herrera, Lozano - 1996]; e [Potts, Giddens, Yadav - 1994 apud Herrera, Lozano - 1996] - o desequilíbrio desta relação pode levar ao problema da "convergência prematura" do AG. O sistema híbrido criado neste trabalho recebeu o nome de "Adaptive Genetic Algorithm Based on Fuzzy Logic Controllers" (doravante referido como "ARGAF").

Segundo [Herrera, Lozano - 1996], as entradas do controlador nebuloso devem ser medidas robustas que descrevam: o comportamento do AG; e os efeitos de seus parâmetros atuais. Além disso, sugere-se que os parâmetros atuais de controle também sejam utilizados como entrada do algoritmo nebuloso. As saídas indicam valores de parâmetros de controle, ou mudanças nestes valores.

A seleção de variáveis de entrada e de saída do controlador nebuloso do sistema híbrido (ARGAF) foi feita, buscando equilibrar o EER. Cada um dos ARGAF's implementados utilizava dois operadores diferentes de cruzamento: um com características de "exploração", e outro com características de "aproveitamento". Nos ARGAF's implementados, o algoritmo nebuloso possuía duas entradas: uma "medida genotípica de diversidade" da população, e uma "medida fenotípica de diversidade" da população. Segundo [Herrera, Lozano - 1996], a primeira corresponde a uma medida da "quantidade" de diversidade da população, enquanto que a segunda corresponde a uma medida da "qualidade" desta diversidade. As saídas do controlador nebuloso foram: a pressão de seleção ("selective pressure") a ser utilizada no mecanismo de seleção do AG; e um parâmetro que ajustava a freqüência de cada um dos dois operadores de cruzamento (podendo assim controlar se o AG possuiria, em próximos passos, um comportamento mais focado em "exploração", ou em "aproveitamento").

Neste trabalho foram implementadas oito variações diferentes de ARGAF's, todas para resolver um problema de minimização de quatro funções específicas (funções estas com características distintas). O que diferiu entre os ARGAF's foram: a estratégia de cruzamento;

\footnotetext{
${ }^{1}$ do original "Exploitation/Exploration Relationship", ou “EER”.
} 
e a família de operadores utilizada. Para cada um dos oito ARGAF's implementados, foram desenvolvidos quatro AG's "convencionais" (a única diferença entre eles foram os valores dos parâmetros fixos). Este experimento foi conduzido por meio de simulações computacionais. Todos os algoritmos foram executados com 5000 gerações, e os resultados de todos os algoritmos foram comparados. Nestas simulações, concluiu-se que os resultados dos ARGAF's eram semelhantes aos resultados das melhores configurações de AG's "clássicos". Desta forma, o trabalho afirma que os ARGAF's podem adaptar automaticamente os valores dos parâmetros de AG's para se atingir os melhores resultados (no caso dos mínimos de funções, atingir menores valores).

\subsection{Análise Crítica dos Trabalhos}

A seguir é apresentada uma análise dos trabalhos citados anteriormente. Convém observar que alguns trabalhos implementaram mais de um CLN no sistema híbrido, sendo que nem todos os CLN's de cada trabalho recebiam as mesmas entradas, e não havia mais de um CLN com a mesma saída. A quantidade de CLN's de cada trabalho, e o estudo detalhado de cada CLN isoladamente está fora do escopo desta análise, a qual busca estudar as funcionalidades do conjunto de CLN's como um todo, em cada trabalho. Podemos analisar os trabalhos sob os seguintes aspectos:

\subsubsection{Medidas de Desempenho Utilizadas para Comparar o Sistema Híbrido com o AG "Clássico"}

- Em [Lee, Takagi - 1993]: foram utilizadas duas medidas, denominadas desempenho "online" e desempenho "offline", definidas em [DeJong - 1975 apud Lee, Takagi 1993].

- Em [Xu, Vukovich - 1993]: foi considerado o número de gerações necessário para cada algoritmo encontrar o valor ótimo (mínimo) global procurado. O trabalho também informa que as soluções obtidas com o sistema híbrido possuíam maior qualidade que as obtidas com o AG "convencional", mas não citados específicos para essa constatação.

- Em [Xu, Vukovich - 1994]: foram consideradas as distâncias, a cada ponto amostrado, entre a posição real do braço mecânico e a posição ideal desejada. $O$ trabalho também informa que o sistema híbrido convergiu para a solução mais rapidamente, mas não fornece dados explicitando este fato. 
- Em (Arnone, Dell'Orto, Tettamanzi - 1994): foram considerados os números médios de gerações necessárias até a convergência para a solução considerada como um valor "ótimo global"; bem como o tempo necessário de processamento computacional (“CPU Time") para convergir à solução.

- Em [Herrera, Lozano - 1996]: como o problema em questão tratava da minimização de funções, foram considerados os valores mínimos de cada algoritmo obtidos em 5000 gerações, bem como uma medida "online" de diversidade da população.

\subsubsection{Problema Tratado pelos Algoritmos}

- Em [Lee, Takagi - 1993]: foi considerado o "problema de controle de um pêndulo invertido" ("inverted pendulum control task").

- Em [Xu, Vukovich - 1993]: foi considerado o problema do caixeiro viajante.

- Em [Xu, Vukovich - 1994]: foi considerado o problema de controle de um braço mecânico de um robô, que tem por objetivo mover-se em linha reta de um ponto até outro.

- Em (Arnone, Dell'Orto, Tettamanzi - 1994): foi considerado o problema de inferência simbólica de fórmulas analíticas.

- Em [Herrera, Lozano - 1996]: foi considerado o problema de minimização de diversas funções com características distintas.

\subsubsection{Entradas e Saídas dos Controladores Nebulosos}

- Em [Lee, Takagi - 1993]:

o três entradas:

- a razão: $\frac{\text { (aptidão média da população) }}{\text { (melhor aptidão da população) }}$

- a razão: $\frac{\text { (pior aptidão da população) }}{\text { (aptidão média da população) }}$;

- mudança na melhor aptidão da população desde a última ação de controle;

- três saídas:

- alteração na taxa de mutação;

- alteração na taxa de cruzamento;

- alteração no tamanho da população. 
- Em [Xu, Vukovich - 1993] e [Xu, Vukovich - 1994]:

- duas entradas:

- o número da geração atual;

- o tamanho da população;

- duas saídas:

- a taxa de mutação;

- a taxa de cruzamento.

- Em (Arnone, Dell'Orto, Tettamanzi - 1994):

- seis tipos de entradas:

- a aptidão média da população;

- os números de exceções do tipo "overflow" e "underflow" ocorridas na última fase de avaliação;

- a taxa de reprodução do algoritmo;

- o comprimento médio de genótipos da população;

- o comprimento do "melhor" genótipo da população; e

- a aptidão de cada indivíduo.

○ seis saídas:

- comprimento máximo permitido para os genótipos;

- taxa de mutação;

- alteração no tamanho do intervalo de avaliação de fórmulas;

- detecção da emergência (surgimento) de uma solução;

- detecção do surgimento de um indivíduo com aptidão muito acima da média da população (denominado "super-indivíduo") - caso seja detectado, medidas são tomadas para assegurar sua permanência na população (elitismo), nas próximas gerações;

- detecção da necessidade de se tomar medidas extras em relação à população, caso possua baixa aptidão e baixa diversidade (por exemplo: o aumento da pressão de seleção).

- Em [Herrera, Lozano - 1996]:

- duas entradas:

- uma "medida genotípica de diversidade" da população; e

- uma "medida fenotípica de diversidade" da população;

- duas saídas:

- um parâmetro que regula a "pressão de seleção" do mecanismo de seleção por "linear ranking";

- um parâmetro que ajustava a freqüência de cada um dos dois operadores de cruzamento - podendo assim influenciar se o AG 
possuiria, em próximos passos, um comportamento mais focado em "exploração" ("exploration”), ou em "aproveitamento" (“exploitation”).

\subsubsection{Trabalho Informa os Critérios Utilizados para a Seleção das Entradas e Saídas do(S) CLN(S)?}

- Em [Lee, Takagi - 1993]: o trabalho não menciona os critérios utilizados para esta seleção, mas menciona que as entradas podem ser quaisquer combinações de medidas de desempenho atuais e parâmetros atuais de controle, e que as saídas podem ser quaisquer parâmetros de controle.

- Em [Xu, Vukovich - 1993], e [Xu, Vukovich - 1994]: o trabalho não menciona.

- Em (Arnone, Dell'Orto, Tettamanzi - 1994): embora o trabalho não forneça detalhes muito específicos a respeito da escolha de todas as entradas e saídas, diversos CLN's foram construídos, cada um com finalidades específicas (e diferentes entradas e saídas). O trabalho detalha a finalidade de cada CLN, e os critérios utilizados para a seleção das entradas e saídas de alguns destes CLN's.

- Em [Herrera, Lozano - 1996]: o trabalho informa os critérios utilizados.

\subsubsection{Regras Implementadas pelo(s) SIN(s)}

- Em [Lee, Takagi - 1993]: foram utilizadas 17 (dezessete) regras para a alteração no tamanho da população; 18 (dezoito) regras para a alteração na taxa de cruzamento; e 16 (dezesseis) regras para a alteração na taxa de mutação, todas citadas no trabalho.

- Em [Xu, Vukovich - 1993], e [Xu, Vukovich - 1994]: foram utilizados 2 (dois) CLN's, um para controlar a taxa de cruzamento, e outro para controlar a taxa de mutação do AG. O trabalho [Xu, Vukovich - 1993] informa as regras nebulosas utilizadas para controlar a taxa de cruzamento, e a partição nebulosa da variável de entrada correspondente ao número de gerações. O trabalho [Xu, Vukovich - 1994] informa as regras nebulosas utilizadas para controlar a taxa de mutação, e a partição nebulosa da variável de entrada correspondente ao número de gerações.

- Em (Arnone, Dell'Orto, Tettamanzi - 1994): diversos CLN's foram construídos, visando tratar quatro problemas: o ajuste do comprimento máximo permitido para os genótipos; ajuste da taxa de mutação; ajuste do tamanho do intervalo de avaliação de fórmulas (para evitar problemas de "overflow" e "underflow"), e detecção da emergência (surgimento) de uma solução (e conseqüente parada do algoritmo ao ser 
evidenciado um "ótimo global"). O trabalho informa as regras nebulosas utilizadas para tratar cada um destes problemas.

- Em [Herrera, Lozano - 1996]: foram utilizados dois CLN's, um para controlar o parâmetro "pe" (o qual influenciava a probabilidade de aplicação de cada um dos dois operadores de cruzamento); e um para controlar o parâmetro "ทmin" (correspondente à "pressão de seleção" do algoritmo). O trabalho informa (por meio de tabelas) as regras implementadas pelos CLN's, bem como as partições nebulosas das variáveis envolvidas (por meio de gráficos).

\subsubsection{Trabalho Informa os Critérios Utilizados para a Elaboração das Regras do(s) SIN(s)?}

- Em [Lee, Takagi - 1993]: o trabalho informa os critérios utilizados para a obtenção das regras.

- Em [Xu, Vukovich - 1993], e [Xu, Vukovich - 1994]: os trabalhos não informam os critérios utilizados para a criação de todas as regras dos SIN's, mas fornecem algumas considerações intuitivas a respeito dos parâmetros regulados pelos SIN's.

- Em (Arnone, Dell'Orto, Tettamanzi - 1994): o trabalho fornece considerações intuitivas para justificar as regras elaboradas.

- Em [Herrera, Lozano - 1996]: o trabalho informa estes critérios, através de diversas considerações intuitivas.

\subsubsection{Como os Experimentos Foram Conduzidos?}

- Em [Lee, Takagi - 1993]: o experimento foi conduzido utilizando-se simulações.

- Em [Xu, Vukovich - 1993], e [Xu, Vukovich - 1994]: os experimentos foram conduzidos em simulações computacionais, utilizando linguagem de programação $\mathrm{C}_{++}$- orientada a objetos - em ambiente Windows.

- Em (Arnone, Dell'Orto, Tettamanzi - 1994): os experimentos foram conduzidos por simulações computacionais em um supercomputador CM-200 [CM - 1992 apud Arnone, Dell'Orto, Tettamanzi - 1994].

- Em [Herrera, Lozano - 1996]: os experimentos foram conduzidos em simulações computacionais. 


\subsubsection{Como Foram Ajustados os Parâmetros do AG "Clássico" (Cujo Desempenho Foi Comparado com o do Sistema Híbrido)?}

- Em [Lee, Takagi - 1993]: o trabalho não menciona quais foram os valores dos parâmetros utilizados no AG "convencional", nem como foram obtidos.

- Em [Xu, Vukovich - 1993], e [Xu, Vukovich - 1994]: foram utilizados os valores recomendados no trabalho [MicroGA - 1992 apud Xu, Vukovich - 1993].

- Em (Arnone, Dell'Orto, Tettamanzi - 1994): foram realizados experimentos, comparando AG's que utilizavam "Fuzzy Government" com AG's "convencionais" supervisionados por operadores humanos. O trabalho não detalha como os operadores humanos ajustaram os parâmetros dos AG's "convencionais".

- Em [Herrera, Lozano - 1996]: foram implementadas oito versões diferentes de ARGAF's (variando-se as estratégias de cruzamento e famílias de operadores utilizadas), e para cada uma destas oito versões, foram implementados quatro AG's "convencionais" (cada um com valores diferentes para seus parâmetros fixos). O trabalho não menciona os critérios utilizados para a seleção dos valores destes parâmetros fixos (dos AG's convencionais), apesar de ter implementado quatro diferentes AG's "clássicos" para cada um dos oito ARGAF's implementados (para fins de comparação).

\subsection{Considerações Finais do Capítulo}

Observando-se os trabalhos citados, sob os diferentes pontos de vista apresentados, percebe-se que a utilização de SIN's para ajustar parâmetros de AG's, em tempo de execução, pode ser realizada de diversas maneiras diferentes. Os diferentes SIN's utilizados, nos sistemas híbridos aqui apresentados, possuíam diferentes variáveis de entrada e de saída, e buscavam aperfeiçoar diferentes medidas de desempenho. Estes sistemas híbridos obtidos também foram aplicados, em diferentes trabalhos, para resolver diversos problemas distintos.

Também é possível se observar que, conforme já mencionado na seção 1.2 do presente trabalho, os trabalhos [Xu, Vukovich - 1993] e [Xu, Vukovich - 1994] utilizam, como parâmetros de entrada para o SIN, medidas consideravelmente simples do AG (apenas o tamanho da população, o qual é fixo durante o experimento; e o número de gerações do AG realizadas até o momento da medição). Estas medidas são muito mais simples que outras medidas utilizadas em diversos outros trabalhos aqui estudados, essencialmente pelo fato 
de os trabalhos [Xu, Vukovich - 1993] e [Xu, Vukovich - 1994] utilizarem a abordagem classificada (em [Bäck - 1998 apud Thierens - 2002] e [Hinterding, Michalewicz, Eiben 1997 apud Thierens - 2002]) como "Controle Dinâmico de Parâmetros" ("Dynamic Parameter Control"), enquanto que os demais trabalhos utilizam a abordagem classificada (em [Bäck - 1998 apud Thierens - 2002] e [Hinterding, Michalewicz, Eiben - 1997 apud Thierens - 2002]) como "Controle Adaptativo de Parâmetros" ("Adaptive Parameter Control"), por realizarem medições na população do AG durante sua execução. Além disso, os trabalhos [Xu, Vukovich - 1993] e [Xu, Vukovich - 1994] também utilizam regras para o SIN que são consideravelmente mais simples e diretas que as utilizadas na maioria dos demais trabalhos. E estes trabalhos ([Xu, Vukovich - 1993] e [Xu, Vukovich - 1994]) afirmam que o desempenho apresentado pelos sistemas híbridos desenvolvidos são superiores aos apresentados por AG's em suas melhores configurações, para as mesmas condições de operação que os próprios sistemas híbridos. Muitos dos demais trabalhos afirmam apenas que os sistemas híbridos desenvolvidos apresentam desempenho apenas similar ao dos AG's em suas melhores configurações.

Por estes motivos, conforme já mencionado na seção 1.2, o presente trabalho tem por objetivo propor e implementar sistemas híbridos semelhantes aos desenvolvidos em [Xu, Vukovich - 1993] e [Xu, Vukovich - 1994], mantendo a abordagem de "Controle Dinâmico de Parâmetros" ("Dynamic Parameter Control"), e utilizando as mesmas variáveis de entrada e de saída para o SIN do sistema híbrido. 


\section{Ferramentas Computacionais Desenvolvidas}

Uma ferramenta computacional foi desenvolvida para a realização de experimentos com Algoritmos Genéticos, bem como com Sistemas Híbridos, envolvendo um Sistema de Inferências Nebuloso para ajustar parâmetros de algoritmos genéticos (em tempo de execução). Esta ferramenta foi aplicada para resolver os seguintes problemas: o "problema de minimização de funções" (PMF), e o "problema do caixeiro viajante" (PCV).

\subsection{Minimização de Funções}

Para testar a ferramenta computacional desenvolvida durante sua construção, bem como para comparar o desempenho de um Algoritmo Genético com o desempenho de um Sistema Híbrido (envolvendo um Sistema de Inferências Nebuloso para ajustar parâmetros de algoritmos genéticos em tempo de execução), esta ferramenta foi utilizada inicialmente para resolver um problema de Minimização de Funções.

Neste caso, cada indivíduo do Algoritmo Genético foi modelado como um vetor de dígitos binários (ou bits - sendo que cada bit pode obviamente valer apenas "0" ou "1"), e corresponde a um valor do domínio da função. Segundo [Obitko, Slavík - 1999], esta é a representação de indivíduos mais usada em Algoritmos Genéticos, e foi selecionada por ser uma representação muito conveniente para a realização de cruzamentos e mutações. Para simulações, foi utilizada uma população de 16 (dezesseis) indivíduos, na qual cada indivíduo possuía 16 (dezesseis) bits. Os vetores de bits foram considerados como valores inteiros e positivos, codificados em notação binária. Desta forma, o espaço de busca do Algoritmo Genético é o intervalo de números inteiros de 0 (valor "zero", correspondente a um vetor com todos os bits em "0") a $2^{16}=$ (valor decimal "65.536", correspondente a um vetor com todos os bits em "1"). 


\subsubsection{Função Elaborada Para os Experimentos}

Uma função foi escolhida para ser minimizada no experimento, a qual deveria ser contínua e assim assumir um valor mínimo no intervalo fechado em questão. Além disso, é desejável que esta função possua vários pontos de valor mínimo local dentro do intervalo, de forma a testar a capacidade do Algoritmo Genético de encontrar o valor mínimo global (e não um valor mínimo local). A função escolhida foi uma soma de senóides e cossenóides, conforme a fórmula abaixo:

$$
f(x)=\underbrace{\left(2+\operatorname{sen}\left(\pi+\frac{\pi \cdot x}{2^{16}}\right)\right)}_{(1)}+\underbrace{0,2 \cdot \cos \left(\frac{2 \cdot \pi \cdot x}{4000}\right)}_{(2)}+\underbrace{0,2 \cdot \cos \left(\frac{2 . \pi \cdot x}{3000}\right)}_{(3)}
$$

A função resultante pode ser observada na figura a seguir:

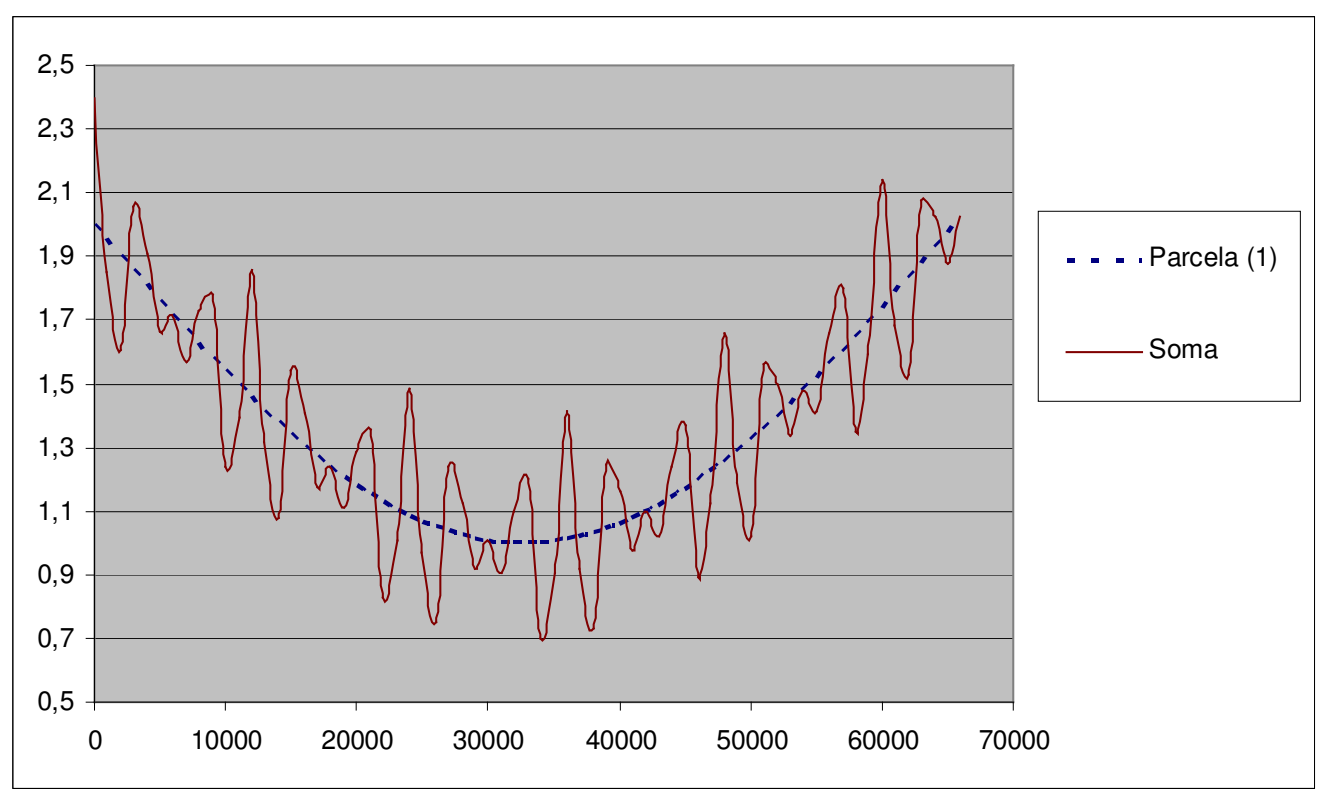

Figura 4.1: Função utilizada para o problema de minimização, com indivíduos de 16 bits.

Esta função foi inspirada em um exemplo encontrado em [Obitko, Slavík - 1999]. A parcela (1) da fórmula da função corresponde a uma curvatura com concavidade voltada para cima, localizada sobre o intervalo correspondente ao espaço de busca do algoritmo. Esta parcela, por si só, assume um único valor mínimo neste intervalo. As parcelas (2) e (3) correspondem a cossenóides de amplitudes relativamente baixas, e freqüências relativamente altas, quando comparadas à senóide da parcela (1). Além disso, as freqüências destas cossenóides não são múltiplas entre si. A soma destas duas parcelas - 
(2) e (3) - gera "ruído" sobre a curvatura da parcela (1), criando diversos "vales", os quais correspondem a pontos de mínimo local na função final

\subsubsection{Implementação dos Algoritmos para este Problema}

Conforme citado na seção anterior, para a construção do Algoritmo Genético para este problema, a codificação dos indivíduos utilizada foi a de vetores binários. Além disso, foram utilizados:

- Mecanismo de Seleção: "Seleção por Classificação" [Rezende - 2003], escolhido por possuir uma distribuição de probabilidades de seleção mais homogênea entre os indivíduos;

- Operador de Cruzamento: operador com "Ponto de Cruzamento Único" [Rezende 2003];

- Operador de Mutação: "Troca de Valores" [Rezende - 2003].

O Algoritmo Genético implementado trabalha com populações de indivíduos de tamanho fixo (ou seja: não varia em tempo de execução). A população inicial é formada com valores aleatórios (sem utilizar nenhum conhecimento prévio a respeito do problema, para sua formação).

É importante salientar que, quando se trabalha com AG's, não existe um único modo de implementação de um algoritmo. Segundo [Rezende - 2003], "Algoritmos Genéticos são uma classe de procedimentos com um conjunto de passos distintos e bem especificados, no qual cada um destes passos possui muitas possíveis variações". Assim sendo, também se fez necessário definir o procedimento a ser utilizado no AG desenvolvido. A ferramenta computacional aqui desenvolvida segue os mesmos passos do exemplo de [Obitko, Slavík 1999] para a minimização de funções de uma dimensão, listados a seguir: 
1 Geração da população inicial;

2 Cálculo da aptidão de cada indivíduo da população;

3 Geração da nova população:

3.1 Elitismo: os "n" indivíduos de maior aptidão são copiados para a nova população (sendo "n" um valor inteiro positivo, fixo durante a execução do algoritmo);

3.2 Geração dos novos indivíduos:

3.2.1 Seleção de 2 (dois) indivíduos da população atual (por operadores de seleção do AG) para cruzamento;

3.2.2 Cruzamento entre estes dois indivíduos, de acordo com a probabilidade (ou taxa) de cruzamento, gerando 2 (dois) indivíduos filhos;

3.2.3 Mutação dos 2 (dois) indivíduos filhos, de acordo com a probabilidade (ou taxa) de mutação;

3.2.4 Os novos 2 (dois) indivíduos são inseridos na nova população;

3.2.5 Repetir os passos "3.2.1" a "3.2.4" até completar a nova população;

4 Substituição da população anterior pela nova população, e incremento do número de iterações realizadas;

Repetir os passos "2" a "4" até atingir o número máximo de iterações desejadas, ou até encontrar o valor mínimo global.

Algoritmo 1: a implementação utilizada no presente trabalho para Algoritmos Genéticos que resolvem o problema de Minimização de Funções.

Para a construção do AGN, o código em linguagem $C$ do programa denominado "Controlador Fuzzy Universal - Versão 5.0" do trabalho [Burdelis, Cepukas, Sofiatti - 2001] foi adaptado para ser utilizado como o código referente ao SIN. Este SIN foi implementado para realizar leituras do tamanho da população ("Pop") (o qual é fixo por toda a duração de cada experimento) e do número de gerações (ou iterações) realizadas até o momento ("Ng"), do AGN. Com base nestes valores, e também na base de conhecimento definida para o problema (que deve ser fornecida em um arquivo de texto com extensão ".fzz", seguindo o padrão definido em [Burdelis, Cepukas, Sofiatti - 2001]), o SIN realiza a inferência nebulosa para determinar quais deverão ser os novos valores de Pm e Pc, e o 
AGN realiza a substituição dos valores anteriores destas grandezas pelos novos (calculados pelo SIN).

Este SIN adaptado do "Controlador Fuzzy Universal - Versão 5.0" do trabalho [Burdelis, Cepukas, Sofiatti - 2001] possui as seguintes características:

- Suporta funções de pertinência triangulares e/ou trapezoidais (dos três tipos seguintes: "Left Fuzzy Number"; "Flat Fuzzy Number" e "Right Fuzzy Number").

- Realiza a fuzificação dos valores de entrada fornecidos pelo AGN, em função da base de dados do SIN.

- Realiza a Inferência Nebulosa utilizando o método "máx-mín" [Shaw, Simões 1999].

- Realiza a defuzificação utilizando o "método do centro da área" [Shaw, Simões 1999].

Nos experimentos iniciais com o $A G N$, este foi programado para realizar uma nova inferência nebulosa (através do SIN) e substituir os valores de Pm e Pc a cada 5 iterações realizadas pelo $A G N$.

\subsection{O Problema do Caixeiro Viajante}

Neste problema, são dados: um conjunto de cidades; e as distâncias entre cada uma delas. Um vendedor (ou "caixeiro") deve, a partir de uma cidade inicial, visitar todas as cidades apenas uma vez, e após isso retornar à cidade inicial. O objetivo é determinar a ordem em que o caixeiro visitará as cidades, de forma que a distância total percorrida por ele seja a mínima possível.

Este problema foi modelado para a aplicação de AG's, para permitir a realização de diversos experimentos, com diferentes tamanhos de população (possibilitando a comparação do desempenho do sistema híbrido com o do AG "clássico" sob diferentes condições). Convém lembrar, aqui, que a população do AG implementado para resolver este problema (AG-CV) é composta por indivíduos, e cada indivíduo corresponde a uma soluçãocandidata para este problema (ou seja, corresponde a um trajeto entre estas cidades). Diferentes valores para o número de cidades "c"; e para o tamanho da população "p" poderão ser utilizados, a fim de evidenciar diferenças entre os desempenhos do AG "clássico" e do sistema híbrido.

As distâncias entre as cidades podem ser armazenadas internamente em uma tabela, tendo as cidades como títulos das colunas e das linhas, conforme a figura a seguir. Nota-se que esta tabela é uma matriz simétrica. Outra característica importante consiste no fato de que os elementos da diagonal principal são nulos. 


\begin{tabular}{|c|r|r|r|r|c|}
\hline \multicolumn{1}{c|}{} & Cidade A & Cidade B & Cidade C & Cidade D & $\ldots$ \\
\hline Cidade A & 0 & 100 & 50 & 120 & $\ldots$ \\
\hline Cidade B & 100 & 0 & 70 & 20 & $\ldots$ \\
\hline Cidade C & 50 & 70 & 0 & 80 & $\ldots$ \\
\hline Cidade D & 120 & 20 & 80 & 0 & $\ldots$ \\
\hline$\ldots$ & $\ldots$ & $\ldots$ & $\ldots$ & $\ldots$ & $\ldots$ \\
\hline
\end{tabular}

Figura 4.2: tabela para armazenamento interno das distâncias entre cidades (para o problema do Caixeiro Viajante).

Para este problema, é interessante utilizar a "Codificação por Permutação" para o AG, pois a única diferença entre as soluções é a ordem em que as cidades serão visitadas. Neste tipo de codificação, cada cromossomo é uma série de números, e cada número representa uma posição em uma seqüência. Este tipo de codificação é útil para problemas de ordenação [Obitko, Slavík - 1999]. Neste caso, cada cromossomo do AG indicará a ordem em que as cidades são visitadas.

\subsubsection{Implementação dos Algoritmos para este Problema}

Para o PCV, a codificação dos indivíduos utilizada para este problema foi a de vetores de números inteiros, no qual cada número representa uma cidade, e o vetor representa o caminho realizado pelo "caixeiro viajante". Esta representação é denominada, em [Potvin 1996], como "Representação por Caminho" ("Path Representation"). Além disso, foram utilizados:

- Mecanismo de Seleção: "Seleção por Classificação" [Rezende - 2003], escolhido, assim como no caso do PMF, por possuir uma distribuição de probabilidades de seleção mais homogênea entre os indivíduos.

- Operador de Cruzamento: operador denominado como "Recombinação de Extremos" (“Edge Recombination") em [Potvin - 1996], que segundo experimentos realizados em [Starkweather et al. - 1991 apud Potvin - 1996], obteve os melhores resultados, em aptidão da solução encontrada, quando comparado com diversos outros operadores para o PCV, para um número fixo de tentativas. 
- Operador de Mutação: foi utilizado o operador de "Permutação" (“Swap”) [Potvin 1996], o qual consiste em permutar dois números aleatórios do vetor (conservando assim os números presentes, porém alterando sua ordem).

A ferramenta computacional aqui desenvolvida, para resolver o PCV, também segue os mesmos passos do exemplo de [Obitko, Slavík - 1999] para a minimização de funções de uma dimensão, com uma única diferença: o operador de cruzamento por "Recombinação de Extremos" ("Edge Recombination”) descrito em [Potvin - 1996] gera apenas um indivíduo filho a partir de dois indivíduos pais. Desta forma, o algoritmo realiza os seguintes passos:

1 Geração da população inicial;

2 Cálculo da aptidão de cada indivíduo da população;

3 Geração da nova população:

3.1 Elitismo: os " $n$ " individuos de maior aptidão são copiados para a nova população (sendo " $n$ " um valor inteiro positivo, fixo durante a execução do algoritmo);

3.2 Geração dos novos indivíduos:

3.2.1 Seleção de 2 (dois) individuos da população atual (por operadores de seleção do AG) para cruzamento;

3.2.2 Cruzamento entre estes dois indivíduos, de acordo com a probabilidade (ou taxa) de cruzamento, gerando apenas 1 individuo filho;

3.2.3 Mutação do indivíduo filho, de acordo com a probabilidade (ou taxa) de mutação;

3.2.4 O novo indivíduo é inserido na nova população;

3.2.5 Repetir os passos "3.2.1" a "3.2.4" até completar a nova população;

4 Substituição da população anterior pela nova população, e incremento do número de iterações realizadas;

Repetir os passos "2" a "4" até atingir o número máximo de iterações desejadas, ou até encontrar o valor mínimo global.

Algoritmo 2: a implementação utilizada no presente trabalho para Algoritmos Genéticos que resolvem o problema do Caixeiro Viajante.

Para simplificar a notação do presente trabalho, as seguintes abreviaturas serão utilizadas deste ponto em diante: "AG-MF" corresponde ao Algoritmo Genético "clássico" elaborado para resolver o problema de minimização de funções. "AGN-MF" corresponde ao AGN elaborado para resolver o problema de minimização de funções. "AG-CV" corresponde ao Algoritmo Genético "clássico" elaborado para resolver o problema do caixeiro viajante. "AGN-CV" corresponde ao AGN elaborado para resolver o problema do caixeiro viajante. 


\subsection{Considerações Finais do Capítulo}

Uma instância específica para cada um dos problemas escolhidos (PCV e PMF) foi especificada; e uma ferramenta computacional foi construída, de forma a permitir a execução de AG's para resolver estas instâncias destes problemas. A modificação dos operadores e da representação dos AG's construídos, para que possam lidar com problemas diferentes, foi viabilizada graças à estrutura modular com a qual a ferramenta computacional foi desenvolvida.

Os AG's implementados foram adaptados também para utilizar SIN's, para o ajuste de parâmetros em tempo de execução, constituindo assim sistemas híbridos, envolvendo duas diferentes técnicas da IC: SIN's e AG's. Com estas ferramentas devidamente implementadas, os primeiros experimentos já podem ser realizados. 


\section{Experimentos Iniciais}

Alguns experimentos iniciais foram realizados com os AG's e AGN's implementados, apresentados no capítulo anterior, abordando-se os dois problemas anteriormente mencionados (PCV e PMF). Estes experimentos foram realizados visando-se utilizar bases de regras (nos SIN's dos AGN's) semelhantes às exemplificadas nos trabalhos [Xu, Vukovich - 1993] e [Xu, Vukovich - 1994], com o objetivo de se obter melhores resultados (ou seja, menores valores para a grandeza "Ng") para os AGN's que para configurações de alto desempenho dos AG's.

\subsection{Experimentos com o AG para Minimização de Funções (AG-MF)}

\subsubsection{Primeiro Experimento}

Inicialmente, o Algoritmo Genético foi executado para minimizar a função citada em 4.1.1, com uma população de 16 (dezesseis) indivíduos, cada um possuindo 16 (dezesseis) bits de tamanho. O ponto que minimiza a função, no intervalo correspondente ao espaço de busca, foi determinado analiticamente como: "34319", e o valor mínimo global da função neste intervalo é $f(34319)=0,6415495$. De posse deste valor, podemos avaliar se o AG implementado encontra o mínimo global da função, ou apenas um ponto de mínimo local. Durante os experimentos, foi utilizado elitismo com o número de indivíduos $\mathrm{n}=2$.

Segundo [Rezende - 2003], geralmente se utiliza valores para as taxas de mutação e de cruzamento do AG na seguinte faixa de valores:

- Taxa (ou "probabilidade") de Mutação $\left(P_{m}\right): 0,001 \leq P_{m} \leq 0,1$;

- Taxa (ou "probabilidade") de Cruzamento $\left(P_{c}\right): 0,6 \leq P_{c} \leq 0,99$.

Segundo [Obitko, Slavík - 1999], recomendam-se valores para as taxas de mutação e de cruzamento do AG dentro das seguintes faixas (com base em estudos empíricos, realizados na maioria dos casos com codificação binária):

- Taxa (ou "probabilidade") de Mutação $\left(P_{m}\right): 0,005 \leq P_{m} \leq 0,01$;

- Taxa (ou "probabilidade") de Cruzamento $\left(P_{c}\right): 0,8 \leq P_{c} \leq 0,95$ (embora em alguns problemas a taxa próxima de 0,6 tenha se mostrado a mais conveniente). 
De acordo com estas recomendações, o primeiro experimento com o AG envolvia uma taxa de mutação $P_{m}=0,01$, e uma taxa de cruzamento $P_{c}=0,8$. Foram realizadas 5 (cinco) execuções do algoritmo, envolvendo diferentes seqüências de números aleatórios, e com um número máximo de 1000 Iterações. Os resultados estão apresentados a seguir:

\begin{tabular}{|r|r|c|}
\hline Execução & $\begin{array}{c}\text { Valor } \\
\text { mínimo } \\
\text { encontrado }\end{array}$ & $\begin{array}{c}\text { Encontrou } \\
\text { o mínimo } \\
\text { global? }\end{array}$ \\
\hline 1 & 34303 & não \\
\hline 2 & 25690 & não \\
\hline 3 & 34320 & não \\
\hline 4 & 34320 & não \\
\hline 5 & 34303 & não \\
\hline
\end{tabular}

Tabela 5.1: resultados do primeiro experimento com o AG-MF.

Como se pode observar na tabela, este AG (com os parâmetros citados anteriormente) não conseguiu encontrar o mínimo global da função, em nenhuma das execuções do algoritmo. Além disso, ao final de cada execução, a maior parte da população era composta por várias cópias do mesmo indivíduo. Por exemplo: na iteração 1000 da primeira execução, 15 indivíduos da população (lembrando-se que havia 16 no total em todo o experimento) já eram cópias do indivíduo "34303". Analisando-se o histórico desta primeira execução, percebe-se que na iteração 16 (no início da execução do algoritmo), a maior parte da população já era composta por instâncias do indivíduo "34303". Casos semelhantes ocorreram na população das outras execuções. Já na execução de número 4 , na iteração 29, a maioria dos indivíduos da população era composta por instâncias do indivíduo "37888" (14 indivíduos), e o indivíduo "34320" (que constituía a maior parte da população na iteração 1000 - eram 10 indivíduos) ainda nem aparecia na população.

Estas informações indicam que este $A G$, com os parâmetros utilizados neste experimento, possui uma grande tendência a "uniformizar" a população com indivíduos iguais. Este comportamento é causado por um fenômeno descrito na literatura como "convergência prematura", em [Herrera, Lozano - 1996]. Segundo [Baker - 1985 apud Herrera, Lozano - 1996], uma rápida convergência ocorre quando um cromossomo ou um pequeno grupo de cromossomos contribuem para um grande número de filhos, por seleção. Como a população é finita, um elevado número de filhos produzidos por um cromossomo significa poucos filhos para o restante da população. Quando muitos cromossomos não produzem nenhum filho, o resultado é uma rápida perda de diversidade, e convergência prematura do algoritmo. Segundo [Whitley - 1994], após diversas gerações, é possível que o mecanismo de seleção leve todos os bits da população de uma determinada posição a 
serem "0" ou "1". Se isso ocorrer sem que o AG esteja convergindo para uma solução satisfatória, então o algoritmo convergiu prematuramente. É importante notar que esta "uniformização" da população, ocasionada pela convergência prematura, não impede completamente o algoritmo de evoluir e encontrar indivíduos mais aptos em iterações futuras (como aconteceu na execução de número 4) devido à ocorrência de mutações na população, mas mesmo assim o desempenho deste algoritmo para 1000 iterações não está satisfatório.

Outra informação importante é que, os valores "34303" e "34320" do espaço de busca possuem grande aptidão, mas não são pontos de mínimo local: são pontos do mesmo "vale" da função onde se encontra o mínimo global "34319". Isto significa que este algoritmo não apresenta a devida capacidade de explorar pontos muito próximos aos indivíduos de sua população, e sugere um aumento da taxa de mutação. Este aumento da taxa de mutação também irá evitar que a população contenha um número muito grande de indivíduos iguais. (Obs: o ponto "25690" pertence a um "vale" da função onde ocorre um mínimo local, mas ainda não é o valor deste mínimo local). Além disso, também é aconselhável se aumentar o tamanho da população, para se evitar a rápida uniformização da população e conseqüente perda de diversidade de conteúdo genético.

Outras 10 (dez) execuções do AG com os mesmos valores para os parâmetros do algoritmo foram realizadas, com um número máximo de iterações de 3000 , e mesmo assim o valor mínimo global não foi encontrado pelo AG, em nenhuma destas execuções.

\subsubsection{Segundo Experimento}

Devido aos resultados do primeiro experimento, a taxa de mutação neste segundo experimento foi aumentada para $P_{m}=0,1$. A taxa de cruzamento permaneceu inalterada $P_{c}$ $=0,8$, assim como todos os demais parâmetros (incluindo o tamanho da população, de 16 indivíduos apenas) e o mecanismo de funcionamento do algoritmo. Este foi executado 10 (dez) vezes, cada uma com uma diferente seqüência de números aleatórios. Os resultados estão apresentados na tabela a seguir: 


\begin{tabular}{|c|c|}
\hline \multicolumn{2}{|c|}{ Algoritmo Genético } \\
Execução & Iteração \\
\hline 1 & 147 \\
\hline 2 & 163 \\
\hline 3 & 5 \\
\hline 4 & 77 \\
\hline 5 & 667 \\
\hline 6 & 525 \\
\hline 7 & 26 \\
\hline 8 & 364 \\
\hline 9 & 89 \\
\hline 10 & 123 \\
\hline
\end{tabular}

Tabela 5.2: resultados do segundo experimento com o AG-MF.

Na tabela, a coluna "Iteração" informa em qual iteração o algoritmo conseguiu encontrar o mínimo global "34319" (e portanto parou sua execução automaticamente). Como se pode observar, este AG (com a nova taxa de mutação) conseguiu encontrar o mínimo global da função em todas as execuções. A média de iterações necessárias, destas 10 execuções, foi: "219" iterações. Existem casos em que o valor mínimo foi encontrado muito rapidamente (na execução 3, foram necessárias apenas 5 iterações), e outros casos em que foi necessário um número de iterações muito acima da média (como na execução 5 , em que foram necessárias 667 iterações). É importante notar que, nesta configuração, o algoritmo não está operando de uma forma ideal [Herrera, Lozano - 1996], porque a elevada taxa de mutação faz com que este se recupere da convergência prematura, ao invés de preveni-la.

\subsection{Experimentos com o Sistema Híbrido para Minimização de Funções (AGN-MF)}

O Sistema Híbrido utiliza o mesmo Algoritmo Genético dos experimentos anteriores, em conjunto com um sistema de inferências nebuloso, o qual ajusta os valores da taxa de mutação e da taxa de cruzamento, em tempo de execução. O sistema de inferências nebuloso, para este sistema híbrido, foi construído a partir de modificações no código do "Controlador Universal Nebuloso" (em linguagem C) encontrado em [Burdelis, Cepukas, Sofiatti - 2001].

Seguindo-se uma abordagem semelhante à utilizada em [Xu, Vukovich - 1993] e [Xu, Vukovich - 1994], o sistema busca regular a taxa de mutação e a taxa de cruzamento do AG com base no número de iterações realizadas até o momento, e no tamanho da população (o 
qual é fixo durante a execução do AGN). Para isso, estas duas variáveis de entrada foram particionadas em conjuntos nebulosos (conforme as figuras a seguir), e o Sistema Híbrido incorporou as regras de [Xu, Vukovich - 1993] para a taxa de cruzamento, e de [Xu, Vukovich - 1994] para a taxa de mutação (conforme a tabela a seguir). Os trabalhos [Xu, Vukovich - 1993], e [Xu, Vukovich - 1994] já apresentavam exemplos de partições nebulosas para as variáveis de entrada e de saída, porém novas partições foram desenvolvidas aqui, por se tratar de outro problema em questão. Estas partições são apresentadas a seguir:

- Variáveis de Entrada do SIN:

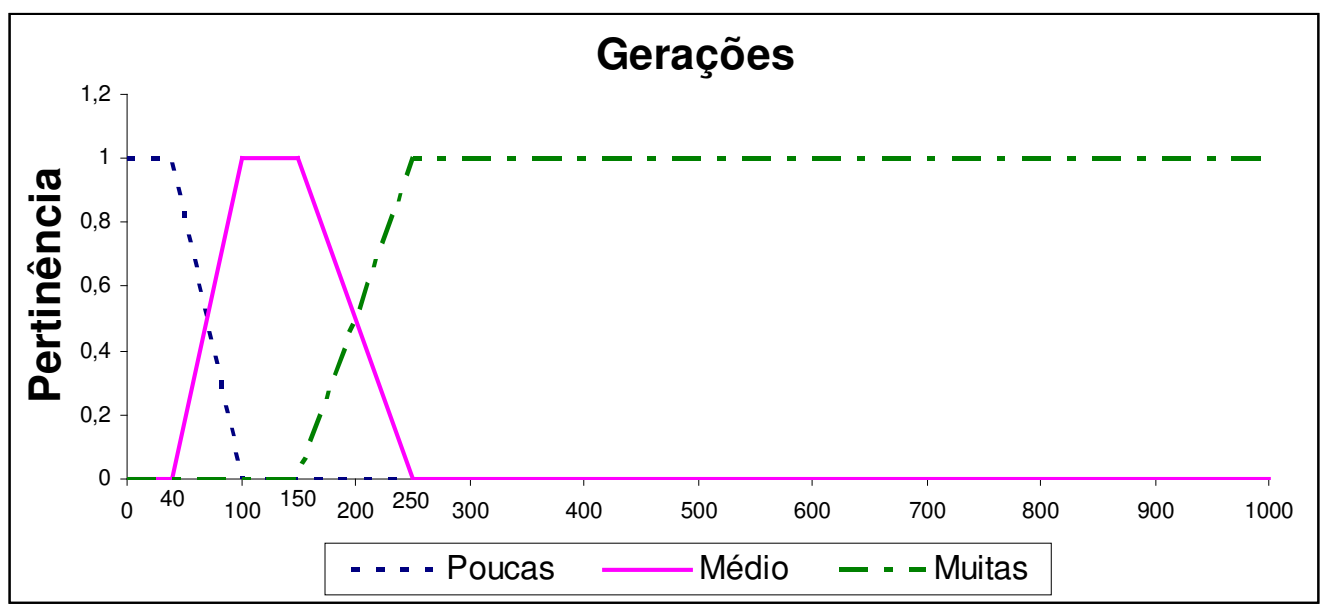

Figura 5.1: partição nebulosa da variável de entrada: "Gerações”.

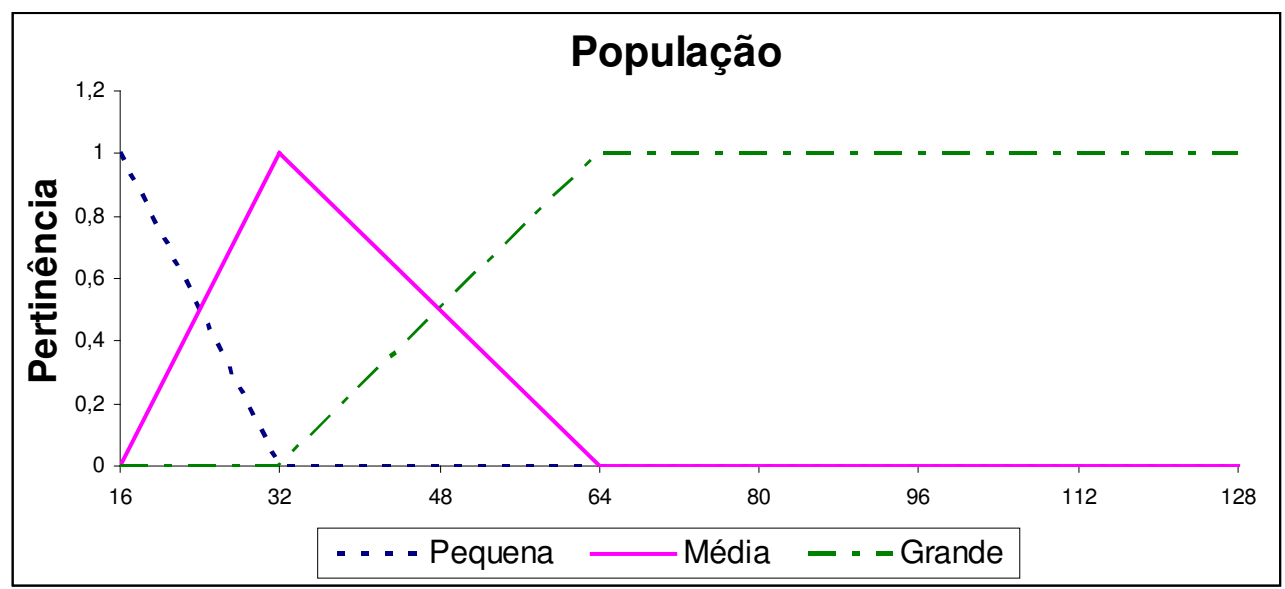

Figura 5.2: partição nebulosa da variável de entrada: "População". 
- Variáveis de Saída do SIN:

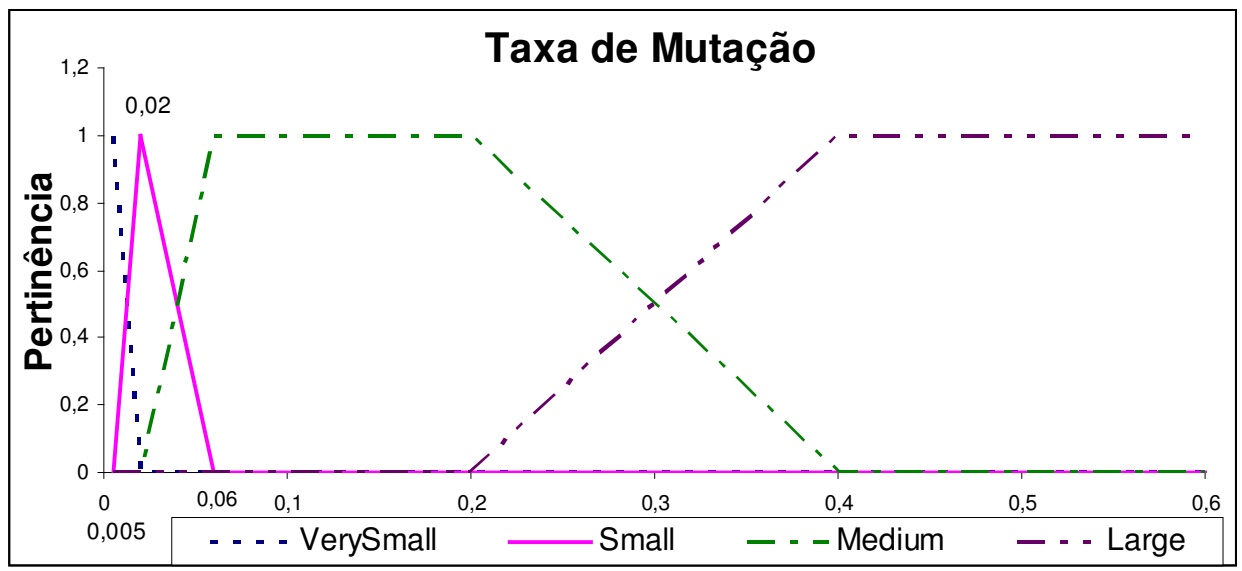

Figura 5.3: partição nebulosa da variável de saída: "Taxa de Mutação".

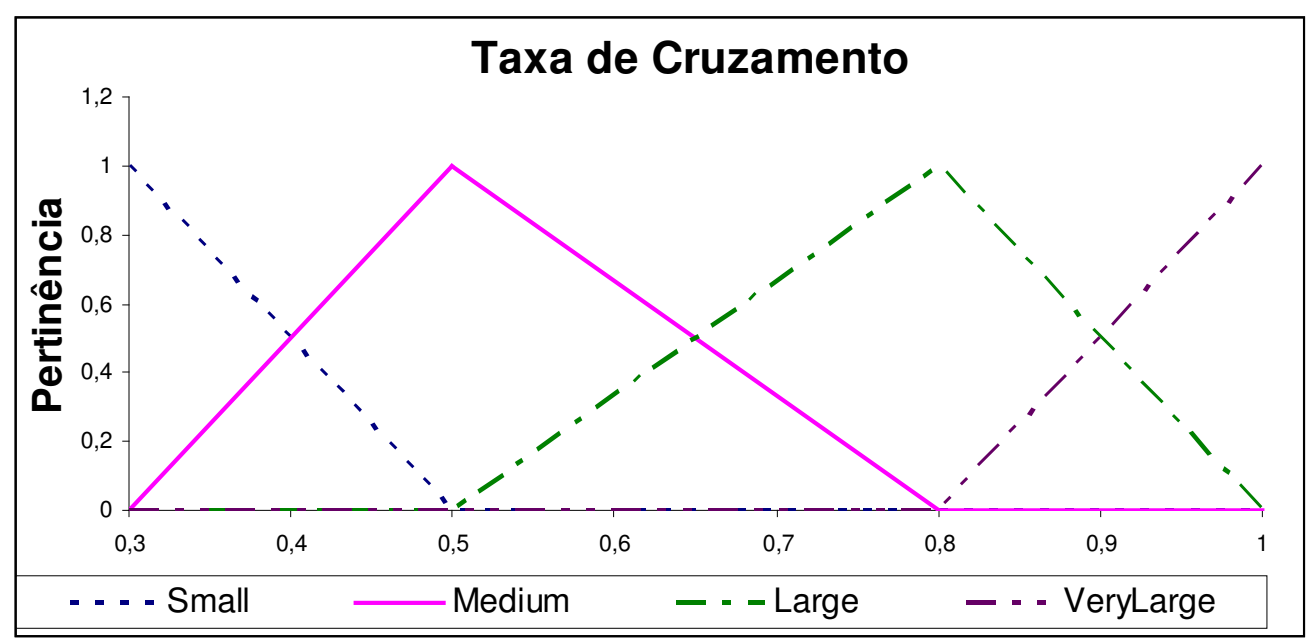

Figura 5.4: partição nebulosa da variável de saída: "Taxa de Cruzamento".

- Regras do SIN:

\begin{tabular}{|c|c|c|c|}
\hline$P c$ & \multicolumn{3}{|c|}{ Tamanho da População } \\
\hline Gerações & Pequena & Média & Grande \\
\hline Poucas & Medium & Small & Small \\
\hline Médio & Large & Large & Medium \\
\hline Muitas & VeryLarge & VeryLarge & Large \\
\hline
\end{tabular}

Tabela 5.3: regras nebulosas para a taxa de cruzamento, retiradas de [Xu, Vukovich 1993].

\begin{tabular}{|c|c|c|c|}
\hline$P m$ & \multicolumn{3}{|c|}{ Tamanho da População } \\
\hline Gerações & Pequena & Média & Grande \\
\hline Poucas & Large & Medium & Small \\
\hline Médio & Medium & Small & VerySmall \\
\hline Muitas & Small & VerySmall & VerySmall \\
\hline
\end{tabular}

Tabela 5.4: regras nebulosas para a taxa de mutação, retiradas de [Xu, Vukovich - 1994]. 
Analisando-se as regras das tabelas 4.3 e 4.4, retiradas de [Xu, Vukovich - 1993] e [Xu, Vukovich - 1994], percebe-se que a taxa de mutação gradualmente diminui, e a taxa de cruzamento gradualmente aumenta, com o decorrer da execução do algoritmo. Além disso, quanto maior for o tamanho da população, menores serão as taxas de cruzamento e de mutação. Segundo [Xu, Vukovich - 1993] e [Xu, Vukovich - 1994], esta abordagem permite que o algoritmo convirja mais rapidamente, e para uma solução de maior aptidão que um Algoritmo Genético simples (ou seja, sem o mecanismo de inferência nebuloso). Este maior desempenho, obtido em função de um comportamento essencialmente "decrescente" para Pm e "crescente" para Pc, pode ser justificado da seguinte maneira: em um intervalo de tempo inicial, é interessante que o AG produza muita diversidade em sua população, e não necessariamente utilize esta diversidade para uma busca mais focada em regiões específicas. Por este motivo, neste intervalo de tempo inicial, utiliza-se $\mathrm{Pm}$ relativamente alta, e Pc relativamente baixa. Conforme a execução do AG vai progredindo, é desejável que o AG gradualmente deixe de produzir diversidade na população, e passe a realizar maior utilização dos indivíduos de sua população, de forma a encontrar as regiões, do espaço e busca, mais aptas a conterem o valor ótimo global procurado. Assim sendo, a Pm vai gradualmente diminuindo, e a Pc, gradualmente aumentando, de forma a se produzir menor exploração de novas regiões do espaço de busca, e maior aproveitamento do conteúdo genético da população, para encontrar o valor ótimo global.

\subsubsection{Experimento Realizado}

Para este primeiro experimento, foram utilizadas as regras e funções de pertinência detalhadas na seção anterior, e o AGN-MF da seção 4.1.2 (com valores iniciais para $P_{m}=$ 0,1 ; e $\left.P_{c}=0,8\right)$. Cada indivíduo possuía 16 bits de tamanho, e a população possuía sempre 16 (dezesseis) indivíduos. A cada 5 (cinco) iterações do AG, o Sistema de Inferência Nebuloso é acionado para determinar os novos valores de $P_{m}$ e $P_{c}$. Foram realizadas 10 (dez) execuções do algoritmo, e os resultados são apresentados na tabela a seguir: 


\begin{tabular}{|c|c|}
\hline \multicolumn{2}{|c|}{ AGN-MF } \\
\hline Execução & Iteração \\
\hline 1 & 151 \\
\hline 2 & 1088 \\
\hline 3 & 5 \\
\hline 4 & 448 \\
\hline 5 & 124 \\
\hline 6 & 126 \\
\hline 7 & 172 \\
\hline 8 & 774 \\
\hline 9 & 650 \\
\hline 10 & 101 \\
\hline \multicolumn{2}{|c}{}
\end{tabular}

Tabela 5.5: resultados do primeiro experimento com o Sistema Híbrido AGN-MF

Os resultados obtidos demonstram que o AGN-MF implementado encontrou o valor mínimo global procurado em todas as suas execuções, porém necessitou de um maior número médio de iterações para isso, em relação ao experimento da seção 5.1.2. O número médio de iterações necessárias, neste caso, é de 364. Apenas em um caso (o segundo) foram necessárias mais de 1000 iterações para que o sistema encontrasse o valor mínimo global procurado. A execução de número 3 obteve o mesmo resultado que a execução de número 3 da seção 5.1.2, pois utilizou a mesma seqüência de números aleatórios, e o Sistema de Inferências Nebuloso entra em ação apenas a cada 5 (cinco) iterações (ou seja: neste caso particular, o algoritmo já havia encontrado o valor ótimo global procurado antes da ação do Sistema Nebuloso).

Porém, é possível que sejam encontrados resultados que encontrem o valor mínimo global mais rapidamente, tanto com a minuciosa exploração de diferentes valores de Pm e Pc no AG, como com a minuciosa exploração de diferentes funções de pertinência e regras nebulosas no AGN-MF.

\subsection{Experimentos com o AG para o Problema do Caixeiro Viajante (AG-CV)}

\subsubsection{Experimento Realizado}

O AG-CV desenvolvido foi utilizado para resolver um PCV com 10 cidades, e com as seguintes distâncias entre elas: 


\begin{tabular}{|c|c|c|c|c|c|c|c|c|c|c|c|}
\hline \multicolumn{12}{|c|}{ Distâncias } \\
\hline & & \multicolumn{10}{|c|}{ Cidades } \\
\hline & & 1 & 2 & 3 & 4 & 5 & 6 & 7 & 8 & 9 & 10 \\
\hline \multirow{10}{*}{$\begin{array}{l}\mathscr{0} \\
\frac{0}{0} \\
\frac{\pi}{0} \\
\frac{0}{0}\end{array}$} & 1 & 0 & 100 & 150 & 190 & 150 & 80 & 200 & 230 & 280 & 250 \\
\hline & 2 & 100 & 0 & 100 & 70 & 110 & 150 & 190 & 100 & 200 & 250 \\
\hline & 3 & 150 & 100 & 0 & 80 & 220 & 100 & 50 & 230 & 250 & 300 \\
\hline & 4 & 190 & 70 & 80 & 0 & 190 & 200 & 180 & 130 & 230 & 250 \\
\hline & 5 & 150 & 110 & 220 & 190 & 0 & 230 & 280 & 150 & 200 & 170 \\
\hline & 6 & 80 & 150 & 100 & 200 & 230 & 0 & 150 & 280 & 300 & 330 \\
\hline & 7 & 200 & 190 & 50 & 180 & 280 & 150 & 0 & 230 & 300 & 350 \\
\hline & 8 & 230 & 100 & 230 & 130 & 150 & 280 & 230 & 0 & 90 & 200 \\
\hline & 9 & 280 & 200 & 250 & 230 & 200 & 300 & 300 & 90 & 0 & 180 \\
\hline & 10 & 250 & 250 & 300 & 250 & 170 & 330 & 350 & 200 & 180 & 0 \\
\hline
\end{tabular}

Tabela 5.6: distâncias entre as 10 cidades assumidas para os experimentos com o PCV.

A menor distância possível para percorrer todas as cidades, nestas condições, já era conhecida como 1120 unidades de distância, e corresponde ao seguinte trajeto: $1 \rightarrow 6 \rightarrow 7 \rightarrow 3 \rightarrow 4 \rightarrow 2 \rightarrow 8 \rightarrow 9 \rightarrow 10 \rightarrow 5 \rightarrow 1$. Obviamente este percurso fechado pode ser percorrido começando em qualquer cidade, assim como também pode ser percorrido na ordem inversa, obtendo-se a mesma distância total percorrida.

Assim como nos experimentos com o PMF, os algoritmos para o PCV também utilizaram elitismo com número de indivíduos $\mathrm{n}=2$.

Os valores utilizados neste experimento inicial foram os mesmos do primeiro experimento com o AG-MF, $\mathrm{Pm}=0,01$ e $\mathrm{Pc}=0,8$. Estes valores estão dentro das faixas de valores geralmente utilizadas para estas grandezas segundo [Rezende - 2003], e também dentro das faixas de valores recomendados segundo [Obitko, Slavík - 1999] para estas grandezas. Para o AG-CV, foram utilizadas 20 execuções para o algoritmo, envolvendo diferentes seqüências de números aleatórios, e com um número máximo de 25 Iterações. A população utilizada possuía tamanho de 100 indivíduos (Pop = 100). Os resultados, em números de iterações necessárias até encontrar o valor mínimo global, por execução, estão apresentados a seguir: 


\begin{tabular}{|c|c|}
\hline \multicolumn{2}{|c|}{$\begin{array}{c}\text { Algoritmo } \\
\text { Genético }\end{array}$} \\
\hline Execução & Iteração \\
\hline 1 & 11 \\
\hline 2 & 8 \\
\hline 3 & 13 \\
\hline 4 & 7 \\
\hline 5 & 11 \\
\hline 6 & 9 \\
\hline 7 & 9 \\
\hline 8 & 4 \\
\hline 9 & 10 \\
\hline 10 & 9 \\
\hline 11 & 12 \\
\hline 12 & 8 \\
\hline 13 & 8 \\
\hline 14 & 8 \\
\hline 15 & 8 \\
\hline 16 & 10 \\
\hline 17 & 8 \\
\hline 18 & 3 \\
\hline 19 & 13 \\
\hline 20 & 5 \\
\hline Média & 8,7 \\
\hline
\end{tabular}

Tabela 5.7: resultados do primeiro experimento com o AG-CV.

Analisando-se a tabela, percebe-se que, nas condições utilizadas, obteve-se um valor médio de 8,7, com máximo em 13 e mínimo em 3 iterações. A única diferença entre as execuções, que pode ter provocado diferenças entre os resultados, foi a seqüência de números aleatórios (ou "sementes") utilizadas. Novos experimentos serão realizados, com o AGN-CV, e os resultados obtidos serão comparados com os desta tabela.

\subsection{Experimentos com o Sistema Híbrido para o Problema do Caixeiro Viajante (AGN-CV)}

Uma vez que no trabalho [Xu, Vukovich - 1993] também é abordado o PCV, neste experimento se resolveu utilizar as mesmas bases de dados e de regras dos exemplos apresentados nos trabalhos [Xu, Vukovich - 1993] e [Xu, Vukovich - 1994]. A mesma base de regras também já foi utilizada no primeiro experimento com o AGN-MF (tabelas 5.3 e 5.4, já apresentadas anteriormente). As bases de dados utilizadas inicialmente envolviam as seguintes partições nebulosas para as variáveis de entrada e de saída do SIN: 
- Variáveis de Entrada do SIN:

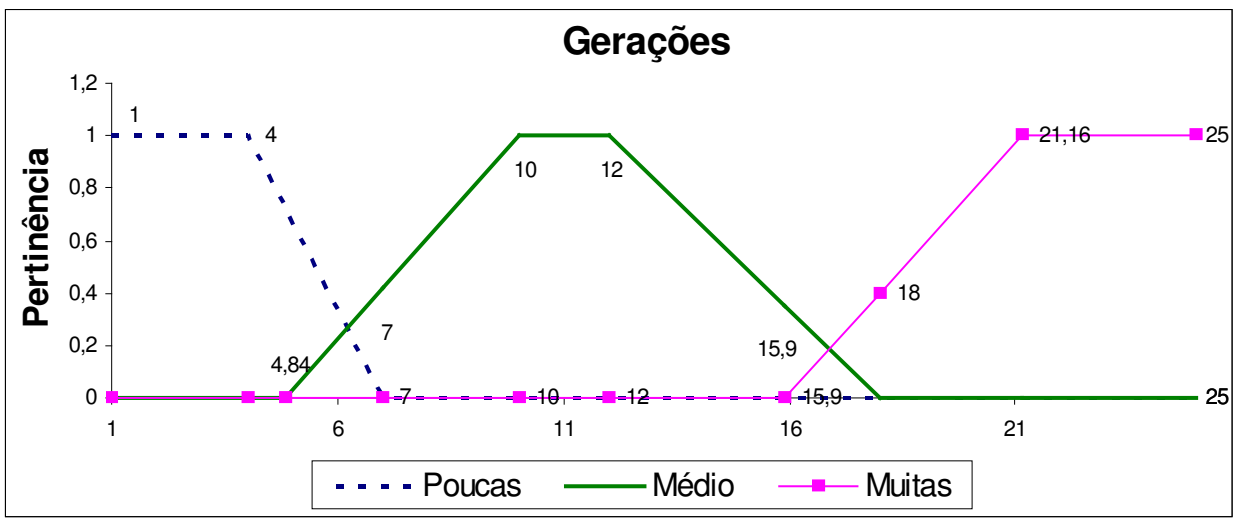

Figura 5.5: partição nebulosa da variável de entrada: "Gerações".

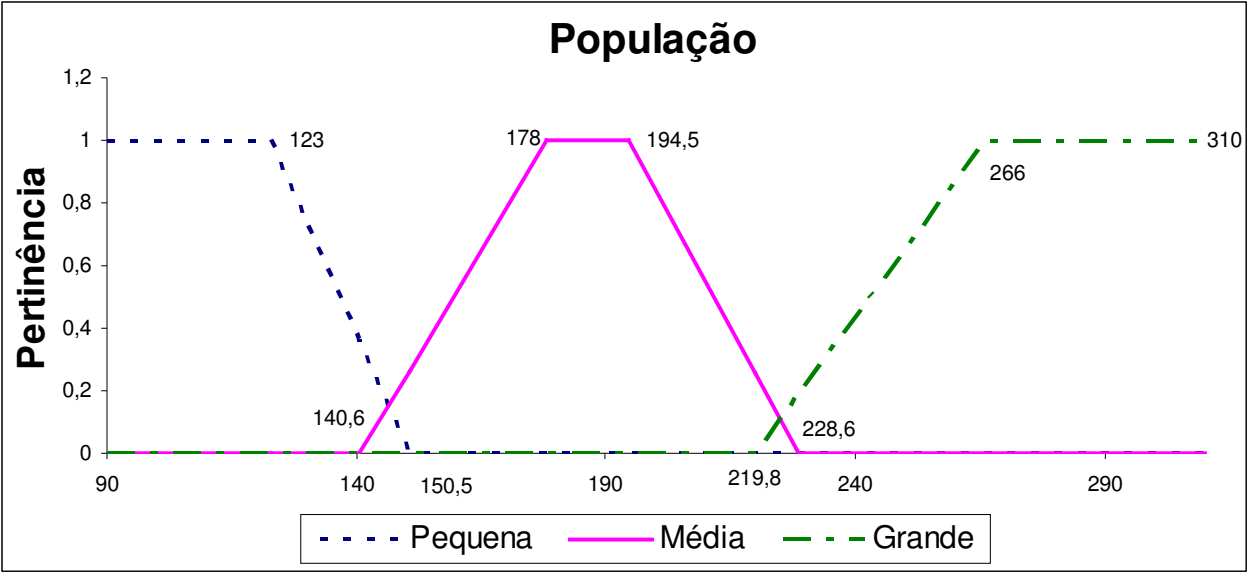

Figura 5.6: partição nebulosa da variável de entrada: "População".

- Variáveis de Saída do SIN:

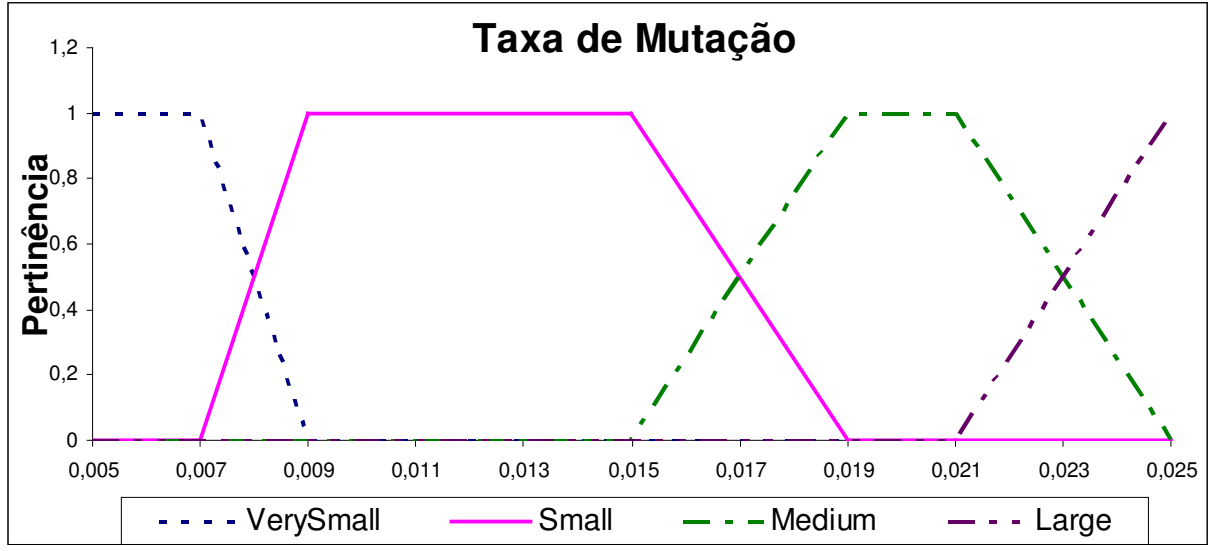

Figura 5.7: partição nebulosa da variável de saída: "Taxa de Mutação". 


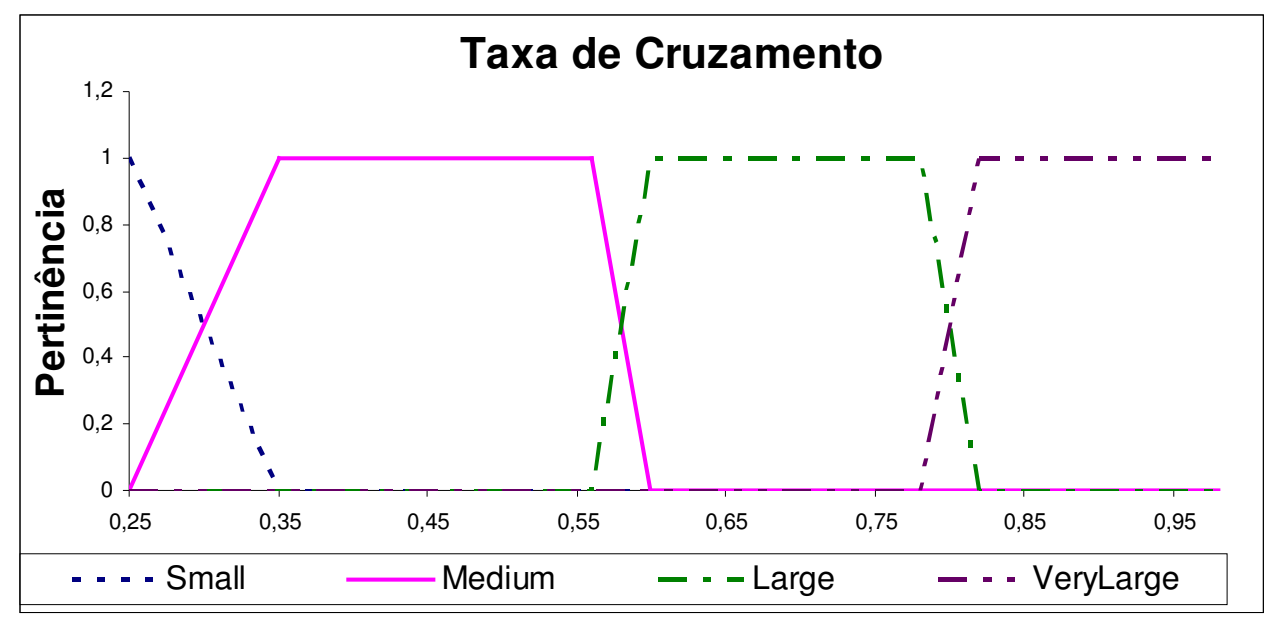

Figura 5.8: partição nebulosa da variável de saída: "Taxa de Cruzamento".

Analisando-se as partições nebulosas das variáveis de entrada, obtidas a partir de [Xu, Vukovich - 1993] e [Xu, Vukovich - 1994], percebe-se que as somas das pertinências em cada ponto do eixo das abscissas não é necessariamente "1", fato que introduz nãolinearidades no modelo. Esta primeira base de dados, com as partições nebulosas apresentadas, será doravante denominada "Base de Dados 1" e abreviada como "BD1". O AGN que utiliza a base de dados BD1 será doravante referido como "Algoritmo Genético Nebuloso - Base de Dados 1", e abreviado como "AGN-BD1".

Uma nova base de dados (com novas partições nebulosas) foi criada, alterando as partições nebulosas para estas duas variáveis ( $\mathrm{Ng}$ e Pop), de forma a se obter a soma das pertinências, em qualquer ponto do eixo das abscissas, com valor "1". As partições nebulosas para as variáveis de saída do SIN (Pm e Pc), nesta nova base de dados, permaneceram inalteradas em relação à BD1. Os resultados são:

- Variáveis de Entrada - BD2:

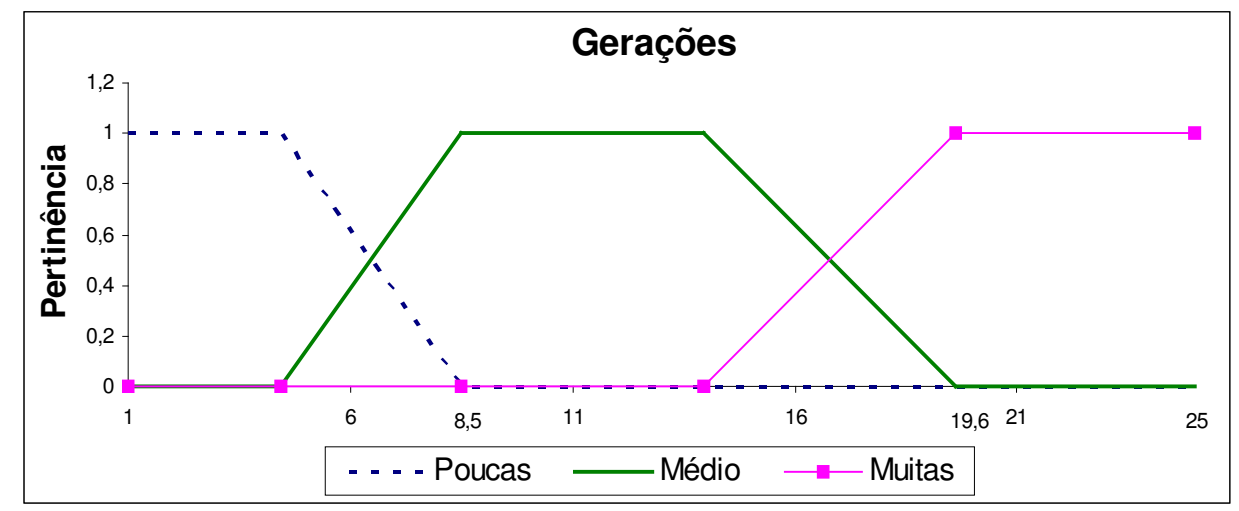

Figura 5.9: partição nebulosa da variável de entrada: "Gerações". 


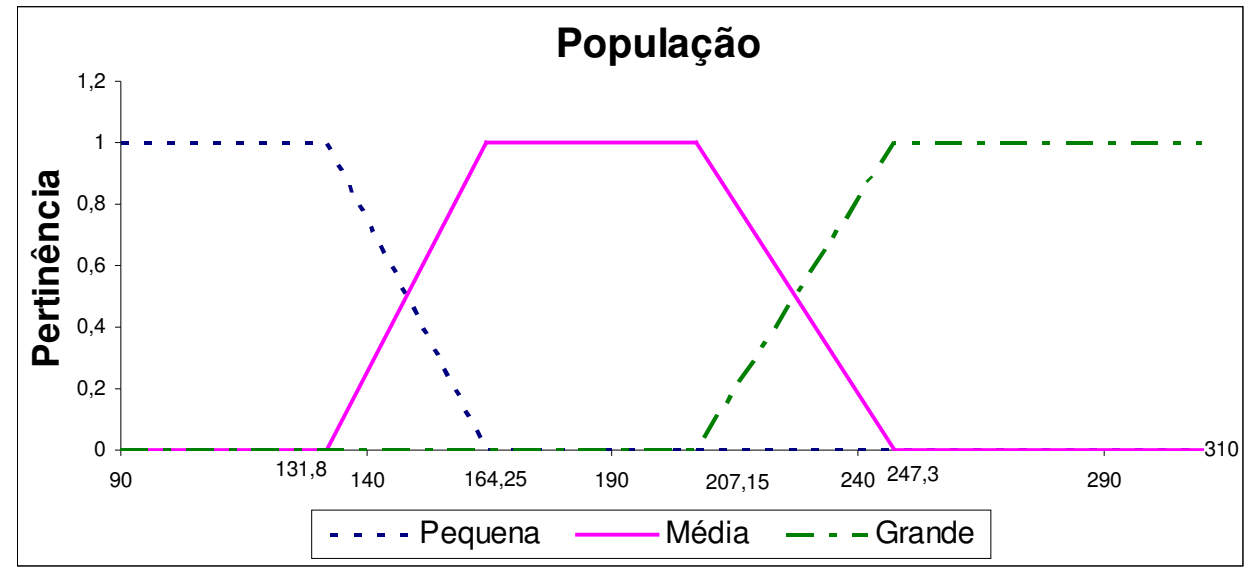

Figura 5.10: partição nebulosa da variável de entrada: "População".

Esta segunda base de dados, com as partições nebulosas apresentadas, será doravante denominada "Base de Dados 2" e abreviada como "BD2". O AGN que utiliza a base de dados BD2 será doravante referido como "Algoritmo Genético Nebuloso - Base de Dados 2", e abreviado como "AGN-BD2".

\subsubsection{Experimento com a "Base de Dados 1"}

Novos experimentos foram realizados com o AGN-CV trabalhando nas mesmas condições do AG-CV do experimento anterior (para fins de comparação), ou seja, com população de 100 indivíduos, número máximo permitido de 25 iterações, e com as mesmas distâncias entre cidades apresentadas na tabela 5.6. Além disso, neste experimento, o AGN-CV utilizou as mesmas bases de dados e de regras dos exemplos apresentados nos trabalhos [Xu, Vukovich - 1993] e [Xu, Vukovich - 1994], ou seja, o modelo com a "Base de Dados 1", apresentado nas figuras 5.5, 5.6, 5.7, e 5.8. O experimento foi executado 20 vezes, cada uma com uma diferente seqüência e números aleatórios. Os resultados obtidos estão descritos na tabela a seguir: 


\begin{tabular}{|c|c|}
\hline \multicolumn{2}{|c|}{ AGN-BD1 } \\
\hline Execução & Iteração \\
\hline 1 & 8 \\
\hline 2 & 13 \\
\hline 3 & 17 \\
\hline 4 & 5 \\
\hline 5 & 11 \\
\hline 6 & 9 \\
\hline 7 & 14 \\
\hline 8 & 10 \\
\hline 9 & 18 \\
\hline 10 & 10 \\
\hline 11 & 6 \\
\hline 12 & 9 \\
\hline 13 & 14 \\
\hline 14 & 12 \\
\hline 15 & 8 \\
\hline 16 & 8 \\
\hline 17 & n/a \\
\hline 18 & 11 \\
\hline 19 & 12 \\
\hline 20 & 13 \\
\hline Média & $\mathbf{1 0 , 9 5}$ \\
\hline
\end{tabular}

Tabela 5.8: resultados do primeiro experimento com o AGN-CV, utilizando a "base de dados 1" (BD1).

Analisando-se esta tabela, percebe-se que a média de iterações necessárias para se encontrar o valor ótimo global aumentou em relação ao experimento com o AG-CV, e, além disso, percebe-se que uma seqüência (a de número 17) não encontrou o valor mínimo global procurado nem mesmo até 25 iterações. Estas observações demonstram uma piora nos resultados em relação ao AG-CV, não justificando assim o uso do AGN-CV.

\subsubsection{Experimento com a "Base de Dados 2"}

Os mesmos experimentos da seção anterior foram realizados, utilizando a "Base de Dados 2". Os resultados podem ser observados a seguir: 


\begin{tabular}{|c|c|}
\hline \multicolumn{2}{|c|}{ AGN-BD2 } \\
\hline Execução & Iteração \\
\hline 1 & 7 \\
\hline 2 & 9 \\
\hline 3 & 9 \\
\hline 4 & 5 \\
\hline 5 & 12 \\
\hline 6 & 14 \\
\hline 7 & 13 \\
\hline 8 & 15 \\
\hline 9 & 20 \\
\hline 10 & 10 \\
\hline 11 & 13 \\
\hline 12 & 10 \\
\hline 13 & 11 \\
\hline 14 & 18 \\
\hline 15 & n/a \\
\hline 16 & 8 \\
\hline 17 & 16 \\
\hline 18 & 19 \\
\hline 19 & 10 \\
\hline 20 & 14 \\
\hline Média & $\mathbf{1 2 , 2 6}$ \\
\hline
\end{tabular}

Tabela 5.9: resultados do segundo experimento com o $A G N-C V$, utilizando a "base de dados 2" (BD2).

Analisando-se esta tabela, pode-se perceber que os resultados são ainda piores. Nestes novos resultados, também existe um caso que não foi capaz de encontrar o valor mínimo global procurado (execução de número 15), e a média dos demais casos aumentou para 12,26 iterações.

\subsection{Análise Crítica dos Primeiros Experimentos}

Estes primeiros experimentos demonstraram, basicamente, que a tentativa de utilização de bases de dados arbitrárias para o AGN-MF, e a tentativa de se utilizar as mesmas bases de dados exemplificadas nos trabalhos [Xu, Vukovich - 1993] e [Xu, Vukovich - 1994] para o AGN-CV não obtiveram resultados nem mesmo melhores que a execução de AG's "clássicos" para os mesmos problemas, com configurações de Pm e Pc arbitrárias. É importante notar que estas configurações podem até mesmo não ser as configurações que maximizam o desempenho destes AG's “clássicos" para estes problemas. Em ambos os casos, foram utilizadas as bases de regras exemplificadas em [Xu, Vukovich - 1993] e [Xu, Vukovich - 1994]. 
Além disso, foi possível observar que os resultados flutuam consideravelmente em função das seqüências de números aleatórios utilizadas em cada execução do algoritmo.

Estes resultados sugeriram a necessidade da realização de investigações mais detalhadas, o que motivou à execução dos experimentos seguintes.

\subsection{Experimentação de Diferentes Regras para Ajustes da Taxa de Mutação pelo SIN, com Taxa de Cruzamento Fixa}

Devido aos resultados obtidos na seção anterior para o AGN não terem apresentado maior desempenho que os resultados para o AG (ou seja, não houve uma menor média de iterações; nem um menor número de casos que não encontraram o valor mínimo global até o número máximo de iterações assumido), decidiu-se realizar uma análise mais profunda do comportamento do AGN. Os valores para as partições nebulosas das variáveis de entrada e de saída do SIN utilizado pelo AGN-MF foram assumidos de maneira heurística, e desta forma acredita-se que seja possível obter melhores resultados, caso partições mais adequadas sejam definidas. Porém, pode-se concluir após os primeiros experimentos que, embora a abordagem de [Xu, Vukovich - 1993] e [Xu, Vukovich - 1994] tenha se mostrado tentadora - por utilizar como variáveis de entrada do SIN medidas de fácil obtenção (apenas o número de iterações realizadas até o momento e o tamanho - fixo - da população), e por obter ótimos resultados (número médio de iterações necessárias inferior, para a obtenção de valores ótimos pelo sistema híbrido) - esta abordagem apresenta dificuldades para sua implementação na prática, sem um método claro para se obter as partições nebulosas das variáveis, o qual permita a obtenção de uma "curva" conveniente para o comportamento das variáveis de saída. Isto se deve justamente ao fato de esta abordagem não realizar medições na população do AG durante sua execução, para determinar a velocidade com que a taxa de mutação deve diminuir, e a velocidade com que a taxa de cruzamento deve aumentar, como ocorre em abordagens definidas em ([Bäck - 1998 apud Thierens - 2002] e [Hinterding, Michalewicz, Eiben - 1997 apud Thierens - 2002]) como "Controle Adaptativo de Parâmetros" ("Adaptive Parameter Control”).

Para nortear futuros experimentos, ainda seguindo-se a abordagem de "Controle Dinâmico de Parâmetros" ([Bäck - 1998 apud Thierens - 2002] e [Hinterding, Michalewicz, Eiben - 1997 apud Thierens - 2002]), novos testes (ou experimentos) foram realizados, buscando-se analisar o comportamento do AGN (referente à média de iterações necessárias para que o algoritmo encontre o valor ótimo global procurado), para diferentes comportamentos da taxa de mutação $(\mathrm{Pm})$ em função do número de gerações - mantendose fixos os parâmetros "tamanho da população" (Pop) e a "taxa de cruzamento" (Pc). O 
objetivo deste experimento foi o de analisar se o comportamento decrescente (ou até mesmo outros comportamentos) para a taxa de mutação (utilizando-se as partições nebulosas de [Xu, Vukovich - 1993] e [Xu, Vukovich - 1994], para os AGN's desenvolvidos neste trabalho) realmente influenciava $(m)$ o desempenho do $A G N$, e como o fazia $(m)$.

Estes experimentos foram realizados alterando-se as regras do SIN do AGN, com o problema do Caixeiro Viajante, com 10 cidades, tamanho de população fixa de 100 indivíduos, taxa de cruzamento fixa em $80 \%$, e número máximo de iterações de 25 , porém ainda se mantendo as partições nebulosas fornecidas em [Xu, Vukovich - 1993] e [Xu, Vukovich - 1994], para as variáveis de entrada e de saída (tanto a BD1 quanto a BD2). Convém aqui notar que, destes dois trabalhos citados, apenas [Xu, Vukovich - 1993] trabalha com o problema do Caixeiro Viajante, do qual foram utilizadas as mesmas partições nebulosas para as variáveis "número de iterações realizadas" $(\mathrm{Ng})$ e "taxa de cruzamento" $(\mathrm{Pc})$. As partições nebulosas utilizadas neste experimento para as variáveis "tamanho da população" (Pop) e "taxa de mutação" (Pm) foram retiradas de [Xu, Vukovich - 1994], o qual lidava com um problema completamente diferente, o problema de controle de um braço mecânico de um robô. Além disso, o trabalho [Xu, Vukovich - 1993] não informa todos os detalhes e operadores utilizados para o AG desenvolvido, o qual pode apresentar diferenças em relação ao AG desenvolvido no presente trabalho, e conseqüentemente as partições nebulosas em questão ainda podem não ser ideais, embora se esteja tratando do problema comum aos dois trabalhos (do Caixeiro Viajante).

Nas tabelas apresentadas a seguir, cada diferente valor lingüístico da variável "taxa de mutação" (Pm) foi abreviado da seguinte forma:

$$
\begin{aligned}
& \text { V - "VerySmall" (ou "MuitoPequeno") } \\
& \text { S - "Small" (ou "Pequeno") } \\
& \text { M - "Medium" (ou "Médio") } \\
& \text { L - "Large" (ou "Grande") }
\end{aligned}
$$

Para cada experimento (ou linha da tabela), a variável "taxa de mutação" assumia três valores lingüísticos diferentes no decorrer do experimento, em função do valor lingüístico da variável "número de gerações". Estes três valores aparecem abreviados em cada linha da tabela. Desta forma, em uma linha em que se leia, por exemplo, os valores: "M S V", para a "taxa de mutação" (ou Pm), entende-se que esta variável possuía as seguintes regras lingüísticas associadas a ela no SIN:

\begin{tabular}{|c|c|c|c|}
\hline SE "Número de gerações" é: & Poucas & Médio & Muitas \\
\hline ENTÃO Pm será: & Medium & Small & VerySmall \\
\hline
\end{tabular}

Tabela 5.10: exemplo do significado da abreviação "M S V" utilizada para o valor de Pm nas tabelas 5.12 e 5.13 a seguir. 
Convém também notar que, para cada uma das tabelas a seguir, em apenas um caso a variável "taxa de cruzamento" teve seu valor também ajustado dinamicamente, de forma crescente - onde se lê na tabela o valor "M L V" para a variável Pc, entenda-se que a taxa de cruzamento também possuía seus valores ajustados pelo SIN, da seguinte maneira:

\begin{tabular}{|c|c|c|c|}
\hline SE "Número de gerações" é: & Poucas & Médio & Muitas \\
\hline ENTÃO Pc será: & Medium & Large & VeryLarge \\
\hline
\end{tabular}

Tabela 5.11: exemplo do significado da abreviação " $M L V$ " utilizada para o valor de Pc nas tabelas 5.12 e 5.13 a seguir.

Obs: também é muito importante notar que a abreviação "V" para a taxa de mutação significa "VerySmall" ou "MuitoPequeno", mas para a taxa de cruzamento significa "VeryLarge" ou "MuitoGrande".

Para cada regra referente à taxa de mutação, foram realizadas no máximo 25 iterações. O algoritmo era encerrado caso o valor ótimo global fosse encontrado (o qual já era conhecido antes da realização do experimento), ou caso o número máximo de iterações fosse atingido. Nas tabelas a seguir, pode-se observar os resultados deste experimento. A média de iterações foi calculada apenas levando em consideração os casos que encontraram o valor ótimo global. A coluna "NC\%" apresenta o percentual de casos (dos 1000 utilizados) que não encontraram o valor ótimo global até a iteração 25 . As tabelas a seguir apresentam os resultados obtidos tanto se utilizando a "Base de Dados1", com partições originais de [Xu, Vukovich - 1993] e [Xu, Vukovich - 1994], bem como se utilizando a "Base de Dados2" obtida através de alterações nestas partições nebulosas originais (ambas as bases de dados foram apresentadas na seção anterior do presente trabalho): 


\begin{tabular}{|c|c|r|r}
\hline \multicolumn{4}{|c}{ AGN-BD1 } \\
\hline Pc & Pm & \multicolumn{1}{|c|}{ Média } & NC\% \\
\hline 0,8 & V V V & 8,815 & $5,6 \%$ \\
\hline 0,8 & V V S & 8,841 & $5,3 \%$ \\
\hline 0,8 & S V V & 8,857 & $4,9 \%$ \\
\hline 0,8 & M V V & 9,129 & $6,3 \%$ \\
\hline 0,8 & V S S & 9,163 & $4,1 \%$ \\
\hline 0,8 & S S S & 9,170 & $5,5 \%$ \\
\hline 0,8 & M S S & 9,181 & $4,1 \%$ \\
\hline 0,8 & M S V & 9,185 & $4,1 \%$ \\
\hline 0,8 & S S V & 9,195 & $5,0 \%$ \\
\hline 0,8 & S S M & 9,208 & $5,3 \%$ \\
\hline 0,8 & S M M & 9,484 & $4,4 \%$ \\
\hline 0,8 & M M S & 9,603 & $5,1 \%$ \\
\hline 0,8 & M M M & 9,648 & $4,7 \%$ \\
\hline 0,8 & M M L & 9,760 & $3,8 \%$ \\
\hline 0,8 & L M S & 10,128 & $4,5 \%$ \\
\hline 0,8 & L M M & 10,158 & $4,1 \%$ \\
\hline 0,8 & M L L & 10,190 & $3,8 \%$ \\
\hline M L V & L M S & 10,697 & $7,9 \%$ \\
\hline 0,8 & L L M & 10,743 & $4,0 \%$ \\
\hline 0,8 & L L L & 10,793 & $4,2 \%$ \\
\hline
\end{tabular}

Tabela 5.12: experimentos com diferentes regras para o controle de $\mathrm{Pm}$, utilizandose o AGN-BD1.

\begin{tabular}{|c|c|r|r|}
\hline \multicolumn{4}{|c|}{ AGN-BD2 } \\
\hline Pc & Pm & \multicolumn{1}{|c|}{ Média } & \multicolumn{1}{c|}{ NC\% } \\
\hline 0,8 & V V S & 8,761 & $5,8 \%$ \\
\hline 0,8 & V V V & 8,792 & $5,5 \%$ \\
\hline 0,8 & S V V & 8,861 & $4,8 \%$ \\
\hline 0,8 & M V V & 8,977 & $4,7 \%$ \\
\hline 0,8 & S S V & 9,090 & $5,7 \%$ \\
\hline 0,8 & S S S & 9,135 & $5,3 \%$ \\
\hline 0,8 & S S M & 9,158 & $5,1 \%$ \\
\hline 0,8 & V S S & 9,179 & $5,5 \%$ \\
\hline 0,8 & M S V & 9,193 & $6,0 \%$ \\
\hline 0,8 & M S S & 9,238 & $5,6 \%$ \\
\hline 0,8 & S M M & 9,602 & $4,2 \%$ \\
\hline 0,8 & M M S & 9,632 & $4,7 \%$ \\
\hline 0,8 & M M M & 9,648 & $4,7 \%$ \\
\hline 0,8 & M M L & 9,672 & $4,3 \%$ \\
\hline 0,8 & L M S & 9,955 & $4,2 \%$ \\
\hline 0,8 & L M M & 10,048 & $2,9 \%$ \\
\hline 0,8 & M L L & 10,253 & $4,3 \%$ \\
\hline 0,8 & L L L & 10,445 & $4,2 \%$ \\
\hline 0,8 & L L M & 10,455 & $3,7 \%$ \\
\hline M L V & L M S & 10,524 & $7,3 \%$ \\
\hline
\end{tabular}

Tabela 5.13: experimentos com diferentes regras para o controle de $\mathrm{Pm}$, utilizandose o $A G N-B D 2$.

Pode-se observar nas tabelas apresentadas, que a maioria dos valores de médias são menores para o caso do AGN-BD1, o que pode indicar que a "Base de Dados 1" pode realmente ser mais adequada ao problema em questão, apesar de introduzir nãolinearidades no modelo. Porém, é importante observar que os casos que possuem as menores médias de iterações necessárias para encontrar o valor ótimo global procurado não são, necessariamente, os casos que possuem variação decrescente para a taxa de mutação, mas sim os casos que envolvem, em suas regras, conseqüentes que implicam nos menores valores para a taxa de mutação ("VerySmall”).

A tabela a seguir mostra os valores obtidos por experimentos realizados sob as mesmas condições, para o mesmo problema (do caixeiro viajante), porém utilizando-se o AG "clássico" (AG-CV), em sua configuração dos experimentos iniciais da seção 5.3.1, ou seja, com $\mathrm{Pm}=0,01$ e $\mathrm{Pc}=0,8$, porém desta vez utilizando-se a média de 1000 execuções diferentes, com seqüências aleatórias diferentes, e também contando os casos em que o AG não encontrou o valor ótimo global em até 25 iterações. 


\begin{tabular}{|c|c|c|c|}
\hline \multicolumn{4}{|c|}{ AG "clássico" } \\
\hline Pc & Pm & Média & NC\% \\
\hline 0,8 & 0,01 & 9,048 & $5,8 \%$ \\
\hline
\end{tabular}

Tabela 5.14: experimento com o AG-CV, nas mesmas condições dos experimentos dos sistemas híbridos ( $A G N-B D 1$ e $A G N-B D 2), \operatorname{com} P C=0,8$ e $P m=0,01$.

Analisando-se estas três tabelas, observa-se que:

(1) Os melhores valores de média de número de iterações ocorreram para regras que possuíam predominantemente os valores lingüísticos "VerySmall" e "Small" em seus conseqüentes, ou seja, regras que imponham valores relativamente baixos para $\mathrm{Pm}$, independentemente do fato de a taxa de $\mathrm{Pm}$ ser crescente ou decrescente no experimento. Desta forma, considerando-se que uma curva decrescente para Pm durante o experimento possa ser benéfica para reduzir a média de iterações necessárias, conforme [Bramlette - 1991 apud Herrera, Lozano - 1996] e [Fogarty - 1989 apud Herrera, Lozano - 1996], então os intervalos de valores considerados nas partições nebulosas necessitam ser aprimorados.

(2) O melhores valores de média de número de iterações, obtidos pelo AGN-BD1 e pelo AGN-BD2 são ainda melhores que o de média obtido para o AG "clássico". Porém, é necessário verificar se outras configurações do AG "clássico" (ou seja: outros valores de $\mathrm{Pc}$ e $\mathrm{Pm}$ ) não seriam capazes de produzir resultados ainda melhores com o AG-CV.

(3) As configurações que possuem as menores porcentagens de casos que não encontraram o valor ótimo global (em até 1000 iterações do algoritmo), não correspondem aos casos que possuem as menores médias, e ocorrem para valores relativamente "médios" da taxa de mutação (também independentemente do fato de as regras gerarem, para Pm, um comportamento crescente ou decrescente).

(4) Embora a "Base de Dados 1" tenha produzido mais casos em que a média de iterações é menor que a gerada pela "Base de Dados 2", estes resultados, para ambas as bases de dados, são muito próximos.

\subsection{Considerações Finais do Capítulo}

Com base nas observações apresentadas no final da seção anterior, percebe-se que no ajuste de parâmetros de AG's por SIN's que não utilizam medidas diretas da população do AG, mas sim que utilizam "Controle Dinâmico de Parâmetros" (segundo [Bäck - 1998 apud 
Thierens - 2002] e [Hinterding, Michalewicz, Eiben - 1997 apud Thierens - 2002]), é muito difícil ajustar o comportamento das taxas de cruzamento e de mutação, de forma a obter o maior desempenho possível do AGN, utilizando-se apenas como entradas do SIN o número de gerações (ou iterações) realizadas até o momento, e o tamanho (fixo) da população. Devido às conclusões obtidas para estes experimentos com o AG-CV, e como os experimentos anteriores com o AG-MF também não produziram os resultados de maior desempenho (esperados para o AGN-MF), desencoraja-se a realização dos mesmos experimentos aqui realizados para o $A G N-C V$, para o $A G N-M F$, sem que seja feita uma maior análise do comportamento de ambos os AG's implementados (AG-CV e AG-MF). Também se conclui que será necessário analisar o comportamento dos AG's (AG-CV e AGMF) para diferentes combinações de valores de Pc e Pm, para que depois se possa inferir:

- Em quais faixas de valores devem ser variadas as taxas de mutação e de cruzamento, para que seja possível observar melhores médias de iterações necessárias para o algoritmo encontrar o valor ótimo global.

- Qual é a melhor configuração de parâmetros para cada um dos AG's "clássicos" (ou seja, o AG-CV e o AG-MF), e qual é o melhor desempenho alcançável para cada um destes AG's (para cada problema em questão PCV ou PMF - e sua atual implementação, conforme os algoritmos 4.1 e 4.2), para que se possa afirmar futuramente se os sistemas híbridos (AGN-CV e AGN-MF) realmente atingiram resultados melhores que os alcançáveis com AG's "clássicos" (AG-CV e AG-MF);

- Quais configurações produzem menores valores médios de iterações necessárias para que o algoritmo encontre o valor ótimo global, quais produzem menores porcentagens de casos que não encontram o valor ótimo global para quantidades muito elevadas de iterações (por exemplo: 1000 iterações), e se existe intersecção entre estes dois conjuntos de configurações. 


\section{Experimentação de Diversas Configurações para AG's "Clássicos", e Aplicação dos Resultados}

A utilização de um comportamento decrescente para a $\mathrm{Pm}$, e um comportamento crescente para a Pc, no AGN desenvolvido para resolver o problema do Caixeiro Viajante, com as partições utilizadas em [Xu, Vukovich - 1993] e [Xu, Vukovich - 1994], não produziu resultados melhores (em termos de média de iterações necessárias para se encontrar o valor mínimo global) que os resultados produzidos pelo AG "clássico".

Além disso, a utilização de partições nebulosas arbitrárias para produzir comportamento crescente para Pc e decrescente para Pm, para o problema de minimização de funções implementado, também não apresentou resultados melhores que os obtidos por um AG. Partindo-se do pressuposto de que se é possível obter maior desempenho para o algoritmo (ou seja: a realização da busca pelo valor ótimo global de maneira mais rápida e eficiente) com comportamentos: decrescente para a Pm e crescente para a Pc - utilizando-se uma base de regras para o SIN com regras semelhantes às regras encontradas em [Xu, Vukovich - 1993] e [Xu, Vukovich - 1994] - é necessário que as bases de dados dos SIN's dos AGN's desenvolvidos (para minimização de funções e para o problema do caixeiro viajante) sejam ajustadas, para que os AGN's apresentem os resultados desejados.

Optou-se então por se analisar o comportamento dos AG's "clássicos" envolvidos (os quais têm seus parâmetros - incluindo $\mathrm{Pm}, \mathrm{Pc}$ e o tamanho da população - fixos durante sua execução), em função dos próprios parâmetros $\mathrm{Pm}$ e Pc, e também para diferentes tamanhos de população. Para isso, foram realizados diversos testes.

\subsection{Experimentação de Diferentes Combinações de Valores de Pm, Pc e Tamanhos de População, para AG's "Clássicos"}

Todos os testes realizados envolveram as seguintes faixas para os valores de Pc e Pm:

- Taxa de Cruzamento: variando de 0,5 a 1, em incrementos de 0,05; 
- Taxa de Mutação: iniciando em 0,1, diminuindo seu valor em 20\% a cada passo, em 25 diferentes passos, sendo que no último assumia valor " 0 ".

Para o AG-CV, foram realizados testes de todas as combinações destes valores de Pc e Pm para diferentes tamanhos de população: de 20 a 100 indivíduos, variando de 20 em 20. Para cada configuração deste experimento, foram realizadas 1000 execuções do algoritmo, cada uma utilizando uma diferente "semente" para a geração de números aleatórios. Cada uma destas diferentes "sementes" produz uma diferente seqüência de números aleatórios. Esta abordagem é interessante para este trabalho, pois permite estudar o comportamento do algoritmo desenvolvido para diferentes seqüências de números aleatórios, além de permitir reproduzir novamente uma mesma seqüência de números, caso algum comportamento interessante tenha sido gerado por aquela seqüência específica. Uma discussão a respeito da suficiência da utilização de 1000 seqüências diferentes de números aleatórios é apresentada no "Apêndice B" do presente trabalho.

Para cada caso, o número máximo de iterações admitido era de 1000. Além disso, em cada caso, as tabelas geradas informam a média de iterações necessárias para o AG encontrar o valor mínimo global (apenas entre os casos que encontraram o valor ótimo global procurado em até 1000 iterações, os demais não entraram na média), e também informam o número de casos que não encontraram este valor ótimo global procurado em até $25,50,100,200,500,700$ e 1000 iterações. As diversas tabelas com os resultados deste experimento se encontram no "Apêndice A" deste documento.

Para o AG-MF, também foram realizados testes de todas as combinações destes valores de Pc e Pm, para os tamanhos de população de 20, 50, 70 e 200 indivíduos, utilizando-se os mesmos critérios e condições para os cálculos dos números médios de iterações necessárias, e números de casos que não encontraram o valor ótimo global procurado até as mesmas quantidades números de iterações $(25,50,100,200,500,700$ e 1000). Como os experimentos com o AG-MF foram realizados após os experimentos com o AG-CV, e para o AG-CV observou-se que a variedade de tamanhos de população utilizada nos experimentos foi um pouco alta (os mesmos resultados poderiam ser observados com menos experimentos, utilizando-se menos variedade de tamanhos para a população), e estes experimentos são computacionalmente pesados (por necessitarem de muito tempo para sua conclusão), optou-se por utilizar para o AG-MF uma variedade menor de tamanhos de população, apenas utilizando-se populações de 20, 50 e 70 indivíduos. O tamanho de população de 200 indivíduos foi utilizado em um experimento posterior, após se verificar que, para populações de 20, 50 e 70 indivíduos o desempenho do AG-MF era consideravelmente inferior ao do AG-CV, e como uma tentativa de se observar o comportamento do AG-MF quando este obtém um desempenho maior. Convém observar que, em ambos os experimentos, as faixas de valores geralmente utilizadas segundo 
[Rezende - 2003], e as faixas de valores recomendados em [Obitko, Slavík - 1999], para $\mathrm{Pm}$ e Pc, estão contidas nas faixas utilizadas nestes experimentos.

Das tabelas produzidas, pode-se observar comportamentos semelhantes em todos os experimentos, sob determinadas condições. Para ambos os AG's implementados (AG-CV e AG-MF), pode-se observar que, para o mesmo valor de Pc, e também o mesmo tamanho da população, sempre existe um valor de Pm que minimiza o número de casos que não encontraram o valor ótimo global procurado até números mais altos de iterações. É importante detalhar de forma clara este critério, pois será usado deste ponto em diante para todo este documento. Para este critério, consideram-se "melhores" as configurações que "zeraram" as quantidades de casos (que não encontraram o valor ótimo global procurado) para faixas de iterações mais altas. Assim sendo, configurações que zeraram a quantidade de casos em uma determinada faixa de iterações (por exemplo: "não até 500") (e portanto, obviamente, também "zeraram" em todas as demais faixas com quantidades maiores de iterações - ainda segundo o mesmo exemplo: "não até 700", e "não até 1000") são considerados "melhores", sob este critério, que todos os demais casos que possuam casos nesta faixa (no mesmo exemplo: "não até 500"), por menores que sejam seus resultados para faixas de quantidades menores de iterações (no mesmo exemplo: "não até 100", "não até 200" etc). Como critério de desempate, caso haja faixas de quantidades de iterações que não possuam "0" casos, para nenhuma das configurações experimentadas, são consideradas como "melhores" as configurações que apresentarem o menor número de casos nesta faixa "não-zerada". Caso as quantidades sejam iguais para mais de uma configuração, é "melhor" a configuração que possuir um menor número de casos na faixa de iterações imediatamente anterior, e assim por diante.

Além disso, sempre existe também um valor de Pm que minimiza a média de iterações necessárias para encontrar o valor ótimo global procurado (lembrando que a média é calculada apenas entre os casos que encontraram o valor ótimo global procurado em até 1000 iterações), mas surpreendentemente estes casos (a minimização da média; e a minimização do número de casos que não encontraram o valor ótimo global procurado até elevadas quantidades de iterações, segundo os critérios apresentados) ocorrem para valores de Pm diferentes. A tabela a seguir ilustra um destes casos, para o AG-CV: 


\begin{tabular}{|c|c|c|c|c|c|c|c|c|c|c|}
\hline $\mathrm{Pc}$ & $\mathrm{Pm}$ & Media & NaoAte25 & NaoAte50 & NaoAte100 & NaoAte200 & NaoAte500 & NaoAte700 & NaoAte1000 & \\
\hline 0.80 & 0.10000 & 42.70 & 538 & 247 & 87 & 21 & 0 & 0 & 0 & 0 \\
\hline 0.80 & 0.08000 & 30.58 & 404 & 147 & 36 & 1 & 0 & 0 & & 0 \\
\hline 0.80 & 0.06400 & 19.92 & 241 & 42 & 4 & 0 & 0 & 0 & & 0 \\
\hline 0.80 & 0.05120 & 1561 & 122 & 74 & $\theta$ & $\theta$ & 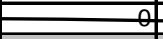 & 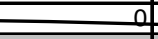 & & 0 \\
\hline 0.80 & 0.04096 & 13.42 & 68 & 6 & 0 & 0 & 0 & 0 & 0 & 0 \\
\hline 0.80 & 0.03277 & 14.49 & 44 & 2 & 45 & -4 & Of & of & 0 & 0 \\
\hline 0.80 & 0.02621 & 19.40 & 41 & 34 & 28 & 20 & 4 & 2 & 0 & 0 \\
\hline 0.80 & 0.02097 & 21.26 & 43 & 42 & 41 & 39 & 24 & 18 & 15 & 5. \\
\hline 0.80 & 0.01678 & 17.30 & 55 & 53 & 51 & 48 & \begin{tabular}{l|l}
42 \\
\end{tabular} & 37 & 35 & 5 \\
\hline 0.80 & 0.01342 & 15.03 & 42 & 41 & 39 & 39 & 35 & 29 & 28 & 8 \\
\hline 0.80 & 0.01074 & 11.59 & 45 & 45 & 45 & 45 & 43 & 43 & 41 & \\
\hline 0.80 & 0.00859 & 9.70 & 54 & 54 & 54 & 54 & 52 & 52 & 52 & \\
\hline 0.80 & 0.00687 & 8.70 & 57 & 56 & 56 & 56 & 56 & 56 & 56 & \\
\hline 0.80 & 0.00550 & 8.75 & 37 & 37 & 37 & 37 & 37 & 37 & 37 & \\
\hline 0.80 & 0.00440 & 8.45 & 49 & 49 & 48 & 48 & 48 & 48 & 48 & \\
\hline 0.80 & 0.00352 & 8.69 & 44 & 44 & 43 & 43 & 43 & 43 & 43 & \\
\hline 0.80 & 0.00281 & 9.60 & 53 & 51 & 51 & 51 & 51 & 51 & 50 & \\
\hline 0.80 & 0.00225 & 8.52 & 56 & 55 & 55 & 54 & 54 & 54 & 54 & \\
\hline 0.80 & $\underline{0} .00180$ & 880 & -----55 & -----57 & -----49 & ----49 & -----49 & ----49 & 49 & \\
\hline 0.80 & 0.00000 & 8.38 & 61 & 61 & 61 & 61 & 61 & 61 & 61 & I] \\
\hline
\end{tabular}

Tabela 6.1: experimento com o AG que resolve o problema do $\mathrm{CV}$, para tamanho de população $=100$ indivíduos, e $P c=0,8$ (a linha da tabela com menor número de casos que não encontraram o valor mínimo global está circulada com traço contínuo, e a linha da tabela que corresponde à menor média, está circulada em tracejado).

É importante notar das tabelas obtidas, que os casos que não encontraram o valor ótimo global procurado em até 1000 iterações já possuíam números aproximadamente constantes de casos que não encontraram o valor ótimo global procurado nas faixas de iterações próximas de 1000, o que significa que estes casos dificilmente o encontrariam para números de iterações superiores a 1000 (sendo que o próprio valor de 1000 iterações já corresponde um número muito elevado). Foi por este motivo que as médias de iterações necessárias para encontrar o valor ótimo global procurado foram calculadas apenas entre os casos que encontraram o valor ótimo global procurado para números de iterações inferiores a 1000; e os demais casos foram considerados como casos incapazes de encontrar o valor ótimo global procurado. Analisando-se a população de alguns destes casos, percebe-se que sofreram convergência prematura, e como conseqüência deste fato, possuem uma população com todos os indivíduos iguais (ou quase todos), "uniformizada" (conforme observado e discutido na seção 5.1.1 do presente trabalho), o que significa que, nestes casos, muito dificilmente $\mathrm{o}$ algoritmo sairá desta condição, mesmo para elevadas quantidades de iterações.

Ainda se analisando os resultados para o AG-CV, observa-se que os valores de Pm que geram o menor número de casos que não encontraram o valor ótimo global procurado (para os diversos valores de Pc e tamanhos de população) ficam entre 0,04096 e 0,08. É interessante notar que sempre é possível se obter casos, para todos os tamanhos de população analisados, em que todas as execuções do algoritmo encontram o valor ótimo (mínimo) global antes de 1000 iterações. Também se pode observar que, quanto menor é o 
tamanho da população, maiores são as quantidades de casos que não encontraram o valor ótimo global procurado, maiores são as médias, e maiores tendem a ser os valores de Pm que obtêm o menor número de casos que não encontraram o valor ótimo global procurado. Estes resultados estão condizentes com o fato de que, quanto maior é a população, melhor é o desempenho do AG (porém também é maior o consumo de recursos computacionais) [Herrera, Lozano - 1996].

Curiosamente, para o AG-CV, a melhor média sempre foi obtida para $\mathrm{Pm}=0$, embora estes casos tenham quase sempre obtido os piores valores para a quantidade de execuções que não encontraram o valor ótimo global procurado - para tamanhos altos de população, esta quantidade não chega a ser muito elevada (para pop $=100$, o pior dos casos teve $17 \%$ das execuções não encontrando o valor ótimo global procurado, e para pop = 80, 29\%); porém para tamanhos menores, este valor passou a ser elevado (para pop $=40$, o pior dos casos teve $62 \%$ das execuções não encontrando o valor ótimo global procurado, e para pop = 20, o preocupante valor de 94\%). Desta forma, pode-se observar que para este AG, a Pm tende a aumentar a média de iterações necessárias para encontrar o valor ótimo global, mas sem sua utilização, o desempenho do algoritmo fica comprometido para muitos dos casos executados. Contudo, a segunda melhor média observada, para cada combinação de Pc e tamanho da população, não ocorre para o menor valor de Pm empregado, mas ainda assim ocorre para valores relativamente baixos de $\mathrm{Pm}$ (abaixo de 1\%).

Analisando-se as tabelas obtidas, para cada combinação de Pm e tamanho da população, observa-se que quanto maior é Pc, menores (e portanto melhores) tendem a ser a média de iterações necessária para encontrar o valor ótimo global procurado, bem como o número de casos não encontraram este valor em até 1000 iterações. Para o mesmo valor de $\mathrm{Pm}$, quando não era o mesmo valor de Pc que gerava ao mesmo tempo a menor média e o menor número de casos que não encontraram o valor ótimo global, estes fatos ocorriam para valores de Pc muito próximos. Para populações maiores, os melhores valores de Pc concentravam-se entre $\mathrm{Pc}=0,9$ e $\mathrm{Pc}=1$. Conforme se diminui o tamanho da população, estes valores tendem a ficar um pouco mais próximos da metade do intervalo de valores utilizado (normalmente entre $\mathrm{Pc}=0,7$ e $\mathrm{Pc}=0,8$ ).

Para o AG-MF, pode-se observar um comportamento semelhante ao observado para o AG-CV, apesar de se tratar de AG's com representações e operadores essencialmente diferentes. A principal diferença é que, para o AG-MF, a melhor média normalmente não ocorre para $\mathrm{Pm}=0$. Uma tabela que ilustra o comportamento deste $A G$ para $P c=0,8$ e população de 70 indivíduos. 


\begin{tabular}{|c|c|c|c|c|c|c|c|c|c|}
\hline $\mathrm{PC}$ & $\mathrm{Pm}$ & Media & NaoAte25 & NaoAte50 & NaoAte100 & NaoAte200 & NaoAte500 & NaoAte700 & NaoAte1000 \\
\hline 0,8 & 0,1 & 41,24 & 494 & 240 & 84 & 16 & 0 & 0 & 0 \\
\hline 0,8 & 0,0 & 31,58 & 413 & 471 & 41 & 2 & $\theta$ & 0 & 0 \\
\hline 0.8 & 0,064 & 29,01 & 367 & 146 & 27 & 0 & 0 & 0 & 0 \\
\hline 0,8 & 0,0512 & 38,21 & उष्ण & 189 & 76 & 22 & $\overline{2}$ & 0 & 0 \\
\hline 0,8 & 0,04096 & 86,29 & 386 & 295 & 213 & 133 & 65 & 44 & 19 \\
\hline 0,8 & 0,03277 & 135,25 & 447 & 413 & 382 & 334 & 255 & 214 & 160 \\
\hline 0,8 & 0,02621 & 82,01 & 450 & 438 & 423 & 406 & 378 & 361 & 333 \\
\hline 0,8 & 0,02097 & 66,2 & 542 & 530 & 524 & 515 & 495 & 484 & 467 \\
\hline 0,8 & 0,01678 & 47,39 & 565 & 562 & 560 & 558 & 545 & 536 & 528 \\
\hline 0,8 & 0,01342 & 35,77 & 595 & 590 & 588 & 584 & 574 & 570 & 566 \\
\hline 0,8 & 0,01074 & 26,94 & 632 & 624 & 623 & 621 & 615 & 612 & 610 \\
\hline 0,8 & 0,00859 & 19,17 & 657 & 653 & 652 & 652 & 651 & 648 & 647 \\
\hline 0,8 & 0,00687 & 16,72 & 682 & 676 & 676 & 676 & 675 & 675 & 673 \\
\hline 0,8 & 0,0055 & 14,64 & 705 & 691 & 691 & 691 & 691 & 691 & 690 \\
\hline 0,8 & 0,0044 & 1459 & $-\ldots-712$ & ----698 & ----698 & -----698 & ----698 & $\ldots \ldots-697$ & 697 \\
\hline 0,8 & 0,00352 & 12,62 & 707 & 694 & 693 & 693 & 693 & 693 & $6 \overline{93}$ \\
\hline 0,8 & $0,0028 T$ & $=73,05 t$ & ----743 & - - - - 694 & $\cdot----692$ & -----692 & -----692 & ----792 & 692 \\
\hline 0,8 & 0,00225 & 13,9 & 728 & 708 & 704 & 704 & 704 & 704 & 704 \\
\hline 0,8 & 0,0018 & 13,8 & 742 & 721 & 715 & 715 & 715 & 715 & 715 \\
\hline 0,8 & 0,00144 & 15,72 & 759 & 735 & 729 & 729 & 728 & 728 & 728 \\
\hline 0,8 & 0,00115 & 15,72 & 754 & 736 & 721 & 721 & 721 & 721 & 721 \\
\hline 0,8 & 0,00092 & 17,86 & 766 & 739 & 719 & 718 & 718 & 718 & 718 \\
\hline 0,8 & 0,00074 & 18,5 & 768 & 736 & 717 & 714 & 714 & 714 & 714 \\
\hline 0,8 & 0,00059 & 20,49 & 759 & 735 & 708 & 702 & 702 & 702 & 702 \\
\hline 0,8 & 0 & 93,6 & 818 & 818 & 815 & 810 & 800 & 792 & 780 \\
\hline
\end{tabular}

Tabela 6.2: experimento com o AG que resolve o problema de Minimização de Funções, para tamanho de população $=70$ indivíduos, e $P c=0,8$ (a linha da tabela com menor número de casos que não encontraram o valor mínimo global está circulada com traço contínuo, e a linha da tabela que corresponde à menor média, está circulada em tracejado).

Para este AG, que resolve o problema de minimização de funções, também se observa que, para os mesmos valores de Pc e tamanho da população, existe uma faixa de valores de Pm que tende a minimizar o número de casos que não encontraram o valor ótimo global procurado. Assim como para o AG-CV, esta faixa tende a ocorrer para valores mais altos de $\mathrm{Pm}$, conforme menor for o tamanho da população. Para tamanhos de população de 70 e 50 indivíduos, esta faixa de valores se encontrava entre $\mathrm{Pm}=0,064$ e $\mathrm{Pm}=0,08$. Já para a população de 20 indivíduos, esta faixa se encontrava entre $\mathrm{Pm}=0,1$ e $\mathrm{Pm}=0,08$. Em todos os casos estes valores de $\mathrm{Pm}$ necessários para que o algoritmo encontre o valor ótimo global procurado são consideravelmente elevados (encontram-se acima das faixas de valores geralmente utilizadas segundo [Rezende - 2003], e das faixas de valores recomendados em [Obitko, Slavík - 1999]). Também se pode observar que, para os tamanhos de população de 50 e 70 indivíduos sempre foi possível encontrar valores de Pc e Pm que encontram o valor ótimo global procurado para todos os casos testados (as 1000 seqüências diferentes de números aleatórios) antes de 1000 iterações. Porém, para a população de 20 indivíduos, não foi possível encontrar tal combinação. A necessidade de valores consideravelmente altos de Pm para que o algoritmo encontre o valor ótimo global procurado, está condizente com os resultados de baixo desempenho obtidos no primeiro experimento com este $A G$, para $P c=0,8$ e $P m=0,01$, e tamanho de população de apenas 
16 indivíduos. Porém, com populações maiores, conseguiu-se reduzir esta necessidade de valores demasiadamente altos para Pm. Segundo [Herrera, Lozano - 1996], se o tamanho da população é pequeno demais, corre-se o risco de o algoritmo convergir depressa demais (e, portanto convergir para um valor não-ótimo, não encontrando o valor ótimo procurado); e se este tamanho for grande demais, o AG pode desperdiçar recursos computacionais. Os resultados aqui obtidos estão condizentes com esta afirmação, uma vez que para tamanhos de população pequenos, não foi possível encontrar o valor ótimo global procurado, antes de 1000 iterações, para todas as 1000 execuções, em nenhuma configuração de parâmetros. Convém também observar que o tamanho ideal de população depende do problema e da implementação do AG em questão, uma vez que a população de apenas 20 indivíduos foi capaz de gerar configurações em que todos os casos encontraram o valor ótimo global procurado antes de 1000 iterações, para o AG-CV. Ainda segundo [Herrera, Lozano - 1996], o tamanho da população é uma das escolhas mais importantes enfrentadas por qualquer usuário de AG's.

Para o AG que resolve o problema de minimização de funções, é importante notar que os casos que obtiveram a menor média de iterações necessárias para encontrar o valor ótimo global procurado, não eram os casos que possuíam $\mathrm{Pm}=0$, mas ainda eram obtidos para valores relativamente baixos de $\mathrm{Pm}$ (entre 0,002 e 0,01), e pertencentes à faixa de valores geralmente utilizadas segundo [Rezende - 2003], e às faixas de valores recomendados em [Obitko, Slavík - 1999].

Também é muito importante notar, dos experimentos com este AG, que os casos de menor média possuem um número muito grande de casos que não encontraram o valor ótimo global procurado (normalmente a maioria dos casos não encontra). Já as configurações de menor (e, portanto, melhor) número de casos que não encontraram o valor ótimo global acabam tendo uma média de iterações muito superior (e, portanto, muito pior). Também se pode observar que existem muitas configurações que possuem, ao mesmo tempo, médias muito elevadas e também números muito elevados de casos que não encontraram o valor ótimo global procurado. Assim como observado para o AG-CV, com o AG que resolve o problema de minimização de funções, para os mesmos valores de Pm e tamanho da população, observa-se que a média e o número de casos que não encontraram o valor ótimo global procurado tendem a diminuir conforme se aumenta a taxa de cruzamento $(\mathrm{Pc})$. Além disso, quando o mínimo da média e do número de casos que não encontraram o valor ótimo global procurado não ocorrem para o mesmo valor de Pc, os valores mínimos de cada uma destas medidas ocorrem para valores de Pc próximos entre si. Uma importante diferença entre o AG-CV e o AG-MF, é que no primeiro, para tamanhos suficientemente grandes de população, o caso que possuía a menor média normalmente também possuía um número relativamente pequeno de casos que não encontraram o valor 
ótimo global procurado até 1000 iterações. Para os tamanhos de população simulados, são apresentados a seguir, nos piores casos (para $\mathrm{Pc}=0,5$ ), a porcentagem de indivíduos que não encontraram o valor ótimo global procurado até 1000 iterações para a simulação correspondente à melhor média (ou seja, com $\mathrm{Pm}=0$ ):

\begin{tabular}{|c|c|c|c|}
\hline $\begin{array}{c}\text { Tamanho da } \\
\text { População }\end{array}$ & Pc & Pm & $\begin{array}{c}\text { Porcentagem de casos } \\
\text { que não encontraram } \\
\text { o valor ótimo global } \\
\text { em até 1000 iterações }\end{array}$ \\
\hline 100 & 0,5 & 0 & $17 \%$ \\
\hline 80 & 0,5 & 0 & $29 \%$ \\
\hline 60 & 0,5 & 0 & $40 \%$ \\
\hline 40 & 0,5 & 0 & $62 \%$ \\
\hline
\end{tabular}

Tabela 6.3: percentual de casos que não encontraram o valor ótimo global em até 1000 iterações, nas situações referentes à melhor média de iterações necessárias para encontrálo $(P m=0$ e $P C=0,5)$, para o $A G-C V$.

Já para o AG utilizado para resolver o problema de minimização de funções, mesmo para a população de 70 indivíduos (maior testada), os casos de melhor média de iterações (para encontrar o valor ótimo global procurado) ainda possuem um número consideravelmente elevado, de casos que não encontraram o valor ótimo global procurado em até 1000 iterações.

\subsubsection{Conclusões a Respeito Destes Experimentos}

Uma importante conclusão da análise apresentada é que, os valores de parâmetros do AG que geram a melhor (ou seja, a menor) média de iterações para casos que encontraram o valor ótimo global procurado, não são os mesmos valores que geram o melhor (ou seja, o menor) número de casos que não encontraram o valor ótimo global procurado. Em outras palavras: um AG pode ser muito sensível à seqüência de números aleatórios envolvida em seu andamento (uma vez que AG's necessitam de gerações de números aleatórios para operarem em diversas de suas etapas internas, como por exemplo: na etapa de geração da população inicial, nas etapas de seleção, cruzamento e mutação).

Desta forma, o mesmo AG pode produzir, em um primeiro caso, dependendo da configuração de seus parâmetros Pc, Pm (e também do tamanho da população), excelentes valores de média de iterações necessárias para seqüências específicas de números aleatórios, mas nem sequer encontrar o valor ótimo global procurado, em tempo hábil, para 
outras seqüências. Já outras configurações podem, em um segundo caso, ser menos sensíveis a estas seqüências, encontrando o valor ótimo global procurado até um número máximo específico de iterações para todas as seqüências (ou pelo menos a maioria destas), mas ainda assim apresentar uma média de iterações necessárias superior (e, portanto, pior) à dos AG's do primeiro caso. Mas mesmo assim, os valores para a média de iterações, no segundo caso, podem ser menores (e, portanto, melhores) que os obtidos para a média com outras configurações, as quais podem produzir elevada média e elevado número de casos que não encontraram o valor ótimo global procurado. De qualquer forma, não foram observadas configurações capazes de produzir, ao mesmo tempo, baixa média de iterações necessárias para encontrar o valor ótimo global, e baixa quantidade de casos que não encontraram este valor, nem mesmo para 1000 iterações. No entanto, resta analisar se é possível se obter resultados que minimizam, ao mesmo tempo, ambas estas medidas de desempenho (média e número de casos), utilizando-se os sistemas híbridos (AGN-CV e AGN-MF).

Assim sendo, conclui-se que, além de se buscar as configurações de parâmetros de AG's que geram baixos valores de médias de iterações necessárias para encontrar o valor ótimo global procurado, é necessário se obter configurações de parâmetros de AG's capazes de encontrar o valor ótimo global procurado de modo robusto (ou seja, para diferentes seqüências de números aleatórios envolvidos em sua execução).

\subsection{Considerações Sobre 0 Controle Dinâmico dos Parâmetros Pm e Pc, Utilizando-se os Resultados do Experimento Anterior}

Ainda mantendo-se a abordagem de buscar a melhoria dos resultados obtidos para médias de iterações necessárias para encontrar o valor ótimo global procurado; e números de casos que não encontram o valor ótimo global procurado - ou seja: de buscar a diminuição destes valores - que foram obtidos utilizando-se de valores de Pm e Pc fixos em tempo de execução, mantém-se a proposta da utilização de ajuste dos parâmetros $\mathrm{Pm}$ e Pc em tempo de execução, em função apenas do "tempo" (ou seja, do número de "gerações" - ou "iterações") e do tamanho da população (o qual é fixo durante o experimento), e ainda buscando atender à premissa de não se utilizar nenhuma medida da população para realizar estes ajustes (como medidas de diversidade da população, grau de convergência etc).

Para isso, entende-se que é necessário encontrar, para cada tamanho de população desejado, as "curvas" dos valores que os parâmetros Pm e Pc deverão assumir em função do "tempo" de execução, que obtêm a melhoria desejada nos resultados. 
As tentativas realizadas anteriormente para se produzir estas curvas, utilizando-se SIN's com regras de inferência retiradas de [Xu, Vukovich - 1993] e [Xu, Vukovich - 1994], partições nebulosas heurísticas (para o AG de minimização de funções), e partições nebulosas retiradas dos trabalhos [Xu, Vukovich - 1993] e [Xu, Vukovich - 1994] (para o AG-CV), não produziram melhorias nos resultados. Estas curvas produziam um comportamento, em tempo de execução, decrescente para Pm, e crescente para Pc; comportamentos estes considerados interessantes para a melhoria dos resultados, segundo diversas referências ([Bramlette - 1991 apud Herrera, Lozano - 1996] e [Fogarty - 1989 apud Herrera, Lozano - 1996]) e considerações intuitivas na seção 5.2 do presente trabalho. Ainda se acredita que estas curvas existam, devido aos bons resultados obtidos em [Xu, Vukovich - 1993] e [Xu, Vukovich - 1994], porém sua obtenção é um processo árduo, uma vez que não se utiliza medidas da população para nortear o comportamento destas curvas.

\subsubsection{Experimentação de Diferentes Curvas Determinísticas para os Valores de Pm e/ou Pc}

Com base nos resultados dos experimentos anteriores, novos experimentos foram realizados, buscando-se obter melhores resultados, utilizando-se curvas com, essencialmente, o mesmo comportamento que o utilizado anteriormente para Pm e Pc, (ou seja: Pm decrescente e Pc crescente no decorrer do "tempo", ou número de iterações) porém utilizando-se valores de Pm e Pc em torno dos valores utilizados nas configurações do $A G$, que produziam os menores números de casos que não encontraram o valor mínimo global procurado (até diferentes faixas de iterações).

A tabela a seguir, retirada dos resultados dos experimentos da seção 6.1, apresenta as duas melhores situações, em quantidades de casos que não encontraram o valor mínimo global procurado, para cada tamanho de população estudado, para o AG-CV:

\begin{tabular}{|c|c|c|c|c|c|c|c|c|c|c}
\hline Pop & Pc & Pm & Media & NaoAte25 & NaoAte50 & NaoAte100 & NaoAte200 & NaoAte500 & NaoAte700 & NaoAte1000 \\
\hline 100 & 0.90 & 0.04096 & 13,49 & 80 & 0 & 0 & 0 & 0 & 0 & 0 \\
\hline 100 & 0.80 & 0.04096 & 13.42 & 68 & 6 & 0 & 0 & 0 & 0 & 0 \\
\hline 80 & 1,00 & 0,04096 & 15,01 & 99 & 14 & 0 & 0 & 0 & 0 & 0 \\
\hline 80 & 0,80 & 0,0512 & 17,72 & 172 & 28 & 0 & 0 & 0 & 0 & 0 \\
\hline 60 & 1 & 0,0512 & 20,45 & 227 & 62 & 2 & 0 & 0 & 0 & 0 \\
\hline 60 & 0,95 & 0,04096 & 18,27 & 174 & 43 & 4 & 0 & 0 & 0 & 0 \\
\hline 40 & 0,70 & 0,05120 & 17,51 & 166 & 27 & 1 & 0 & 0 & 0 & 0 \\
\hline 40 & 0,75 & 0,05120 & 16,88 & 134 & 30 & 1 & 0 & 0 & 0 & 0 \\
\hline 20 & 0,95 & 0,08 & 83,87 & 698 & 415 & 236 & 108 & 15 & 0 & 0 \\
\hline 20 & 1 & 0,0512 & 67,82 & 523 & 308 & 199 & 94 & 7 & 1 & 0 \\
\hline
\end{tabular}

Tabela 6.4: as duas configurações, para cada tamanho de população estudado, que produziram os menores números de casos que não encontraram o valor mínimo global procurado, para o AG-CV. 
Os melhores quatro resultados, em quantidades de casos que não encontraram o valor mínimo global procurado, de todos os tamanhos de população estudados, são apresentados a seguir:

\begin{tabular}{|r|r|c|r|r|r|r|r|r|r|r}
\hline Pop & Pc & Pm & Media & NaoAte25 & NaoAte50 & NaoAte100 & NaoAte200 & NaoAte500 & NaoAte700 & NaoAte100 \\
\hline 100 & 0,9 & 0,04096 & 13,49 & 80 & 0 & 0 & 0 & 0 & 0 & \\
\hline 100 & 0,8 & 0,04096 & 13,42 & 68 & 6 & 0 & 0 & 0 & 0 & \\
\hline 100 & 0,95 & 0,04096 & 13,54 & 70 & 6 & 0 & 0 & 0 & 0 & \\
\hline 100 & 1 & 0,04096 & 13,2 & 61 & 7 & 0 & 0 & 0 & 0 & \\
\hline
\end{tabular}

Tabela 6.5: as quatro configurações, de todos os tamanhos possíveis de população estudados, que produziram os menores números de casos que não encontraram o valor mínimo global procurado, para o AG-CV.

\subsubsection{Experimentos Variando Apenas o Valor de Pm}

Considerando-se a melhor configuração de todas, que corresponde à primeira linha da tabela 6.5, tentou-se inicialmente ajustar, dinamicamente, o valor de Pm, com curvas decrescentes em torno de seu valor nesta linha $(\mathrm{Pm}=0,04096)$, e mantendo-se fixos os demais parâmetros, com tamanho de população de 100 indivíduos, e $P c=0,9$. Nos trabalhos [Xu, Vukovich - 1993] e [Xu, Vukovich - 1994], as "curvas" para Pm e Pc, para um mesmo valor de tamanho de população, possuem três "patamares" distintos, com transição suave entre eles, curvas estas realizadas pelo sistema de inferências nebuloso utilizado. Algumas curvas semelhantes também foram testadas. Todos os experimentos foram realizados considerando 1000 execuções diferentes (cada uma utilizando uma diferente seqüência de números aleatórios - e portanto uma diferente "semente" para a geração de números aleatórios na linguagem de programação utilizada) para cada configuração. As diferentes curvas e seus resultados são apresentados a seguir:

- Curva "Pm-A": não-contínua com 5 patamares de comprimentos iguais, 2 acima de $\mathrm{Pm}=0,04096$ e 2 abaixo deste valor. Os patamares são os valores "vizinhos" utilizados para Pm nos experimentos para o AG "clássico". Além disso, é esperado que, do (valor da média para esta linha) x 120\% em diante, esta curva já tenha percorrido os 5 patamares, e mantenha-se no valor do último patamar. Esta função não é contínua e realiza transições abruptas entre os patamares. 


\begin{tabular}{|c|c|c|c|c|c|}
\hline Gerações & 1 a 3 & 4 a 6 & 7 a 9 & 10 a 12 & 13 a 15 e em diante \\
\hline Valor de Pm & 0,064 & 0,0512 & 0,04096 & 0,032768 & 0,026214 \\
\hline
\end{tabular}

Tabela 6.6: curva "Pm-A".

- $\quad$ Curva "Pm-B": não-contínua com 3 patamares de comprimentos iguais, 1 acima de $\mathrm{Pm}=$ 0,04096 e 1 abaixo deste valor. Os patamares são os valores "vizinhos" utilizados para Pm nos experimentos para o AG "clássico". Além disso, é esperado que, do (valor da média para esta linha) x 120\% em diante, esta curva já tenha percorrido os 3 patamares, e mantenha-se no valor do último patamar. Esta função não é contínua e realiza transições abruptas entre os patamares.

\begin{tabular}{|c|c|c|c|}
\hline Gerações & 1 a 6 & 6 a 10 & 11 a 15 e em diante \\
\hline Valor de Pm & 0,0512 & 0,04096 & 0,032768 \\
\hline
\end{tabular}

Tabela 6.7: curva "Pm-B".

- Curva "Pm-C": não-contínua com 6 patamares de comprimentos iguais, 2 acima de $\mathrm{Pm}=0,04096$ e 3 abaixo deste valor. A diferença entre o valor do patamar mais alto e do patamar mais baixo é maior que das curvas "A" e "B", de forma que as diferenças entre os patamares envolvidos são maiores. Estes 6 patamares são percorridos em um intervalo maior de gerações que os das curvas "A" e "B" (de 1 até 15), de 1 até 25. Esta função não é contínua e realiza transições abruptas entre os patamares.

\begin{tabular}{|c|c|c|c|c|c|c|}
\hline Gerações & 1 a 4 & 5 a 8 & 9 a 13 & 14 a 17 & 18 a 21 & 22 a 25 e em diante \\
\hline Valor de Pm & 0,08 & 0,064 & 0,04096 & 0,026214 & 0,01 & 0,005 \\
\hline
\end{tabular}

Tabela 6.8: curva "Pm-C".

- Curva "Pm-D": o inverso da curva "A", com Pm crescente. Esta curva foi criada para se analisar se o comportamento "decrescente" de Pm realmente produz resultados melhores que os obtidos com uma curva de comportamento "crescente" para Pm.

\begin{tabular}{|c|c|c|c|c|c|}
\hline Gerações & 1 a 3 & 4 a 6 & 7 a 9 & 10 a 12 & 13 em diante \\
\hline Valor de Pm & 0,0262144 & 0,032768 & 0,04096 & 0,0512 & 0,064 \\
\hline
\end{tabular}

Tabela 6.9: curva "Pm-D". 
Resultados:

\begin{tabular}{|r|c|r|r|r|r|r|r|r|r|}
\hline Pc & Pm & Media & NaoAte25 & NaoAte50 & NaoAte100 & NaoAte200 & NaoAte500 & NaoAte700 & NaoAte1000 \\
\hline 0,9 & Curva "Pm-A" & 20,26 & 43 & 25 & 23 & 18 & 6 & 2 & 1 \\
\hline 0,9 & Curva "Pm-B" & 14,21 & 60 & 10 & 6 & 0 & 0 & 0 & 0 \\
\hline 0,9 & Curva "Pm-C" & 14,39 & 47 & 43 & 43 & 43 & 43 & 43 & 42 \\
\hline 0,9 & Curva "Pm-D" & 16,54 & 170 & 32 & 3 & 0 & 0 & 0 & 0 \\
\hline
\end{tabular}

Tabela 6.10: resultados dos experimentos, utilizando as curvas descritas para o ajuste da $P m$, para o AG-CV.

Para os experimentos realizados, não foram observados valores menores para a média de iterações, e nem para o número de casos que não encontraram o valor ótimo global procurado, em relação à melhor configuração do AG "clássico". Todos os casos de controle dinâmico do parâmetro $\mathrm{Pm}$ aqui testados ainda demonstram valores maiores, para ambas estas grandezas. É interessante notar que os resultados da última linha da tabela 6.10 , obtidos para uma curva "crescente" de Pm (a qual apresenta comportamento completamente contrário ao que se busca nestes experimentos), o valor da média de iterações necessárias $(16,54)$ é maior que o obtido com a utilização das curvas "Pm-B" e "Pm-C", porém é, surpreendentemente, melhor (ou seja, menor) que o valor de média obtido com a curva "Pm-A", a qual é decrescente. Além disso, ainda para a curva "Pm-D", embora o número de casos que não encontraram o valor mínimo global procurado até 25 iterações seja o maior de todos; o experimento com esta curva, após 200 iterações, surpreendentemente obteve o menor número de casos não encontraram o valor mínimo, quando comparado com todos os demais (os quais utilizaram comportamento "decrescente" para $\mathrm{Pm}$ ). Estes resultados levam a questionar a efetividade da utilização de curvas "decrescentes" para Pm, nas condições dos experimentos.

\subsubsection{Experimentos Variando Também o Valor de Pc}

Com o objetivo de verificar possíveis melhorias no resultado utilizando-se uma curva de comportamento "crescente" para Pc, tanto com Pm fixo quanto em conjunto com uma curva decrescente de $\mathrm{Pm}$, novos experimentos foram realizados, utilizando as curvas a seguir:

- Curva "Pc-A": não-contínua com 3 patamares de comprimentos iguais, variando de 0,8 a 0,99 - e portanto incluindo o valor de $\mathrm{Pc}=0,9$ utilizado na melhor configuração do AG - com um patamar acima deste valor, e um abaixo deste valor. Para determinar o comprimento de cada patamar, utilizou-se o seguinte 
critério: é esperado que, a partir de $120 \%$ do valor da média obtida na melhor configuração do $A G(13,49 \times 120 \% \cong 16)$, esta curva já tenha percorrido os 3 patamares, e mantenha-se no valor do último patamar.

$\begin{array}{cccc}\text { Gerações } & 1 \text { a } 5 & 6 \text { a } 10 & 11 \text { em diante } \\ \text { Valor de Pc } & 0,8 & 0,9 & 0,99\end{array}$

Tabela 6.11: curva "Pc-A".

- Curva "Pc-B": não-contínua com 5 patamares de comprimentos iguais, variando de 0,6 até 1 - e portanto incluindo o valor de $\mathrm{PC}=0,9$ utilizado na melhor configuração do AG - com 3 patamares abaixo deste valor, e 2 acima deste valor. Para determinar o comprimento de cada patamar, utilizou-se o seguinte critério: é esperado que, quando $\mathrm{Ng}=120 \%$ do valor da média obtida na melhor configuração do $A G(13,49 \times 120 \% \cong 16)$, esta curva esteja próxima de sua metade (ou no terceiro ou no quarto patamar). Depois de percorridos os 5 patamares, é esperado que Pc mantenha-se no valor do último patamar até a última (milésima) iteração.

$\begin{array}{ccccccc}\text { Gerações } & 1 \text { a } 4 & 5 \text { a } 8 & 9 \text { a } 13 & 14 \text { a } 17 & 18 \text { a } 21 & 22 \text { em diante } \\ \text { Valor de Pc } & 0,6 & 0,7 & 0,8 & 0,9 & 0,95 & 1\end{array}$

Tabela 6.12: curva "PC-B".

- Curva "Pc-C": o inverso da curva "Pc-B", com Pc decrescente. Esta curva foi criada para se analisar se o comportamento "crescente" de Pc realmente produz resultados melhores que os obtidos com uma curva de comportamento "decrescente" para Pc.

$\begin{array}{ccccccc}\text { Gerações } & 1 \text { a } 4 & 5 \text { a } 8 & 9 \text { a } 13 & 14 \text { a } 17 & 18 \text { a } 21 & 22 \text { em diante } \\ \text { Valor de Pc } & 1 & 0,95 & 0,9 & 0,8 & 0,7 & 0,6\end{array}$

Tabela 6.13: curva "PC-C".

- Curva "Pm-E": nova curva para Pm, que corresponde ao inverso da curva "PmC", com Pm crescente. Esta curva foi criada com o comportamento oposto do procurado para Pm, para ser utilizada em conjunto com a curva "Pc-C", para 
verificar se os comportamentos: decrescente de Pm e crescente de Pc realmente produzem melhores resultados que seus inversos.

$\begin{array}{ccccccc}\text { Gerações } & 1 \text { a } 4 & 5 \text { a } 8 & 9 \text { a } 13 & 14 \text { a } 17 & 18 \text { a } 21 & 22 \text { em diante } \\ \text { Valor de Pm } & 0,01 & 0,01 & 0,026 & 0,041 & 0,064 & 0,08\end{array}$

Tabela 6.14: curva "Pm-E".

Com base nestas curvas, e também nas curvas criadas para Pm na seção anterior, alguns experimentos foram elaborados, com a variação simultânea de Pm e Pc, e um experimento foi realizado variando-se apenas $\mathrm{Pc}$. Todos os experimentos foram realizados considerando 1000 execuções diferentes (cada uma utilizando uma diferente seqüência de números aleatórios - e portanto uma diferente "semente" para a geração de números aleatórios na linguagem de programação utilizada) para cada configuração. Os resultados são apresentados na tabela a seguir:

\begin{tabular}{|c|c|c|c|c|c|c|c|c|c|}
\hline $\mathrm{Pc}$ & $\mathrm{Pm}$ & \begin{tabular}{|l|} 
Media \\
\end{tabular} & NaoAte25 & NaoAte50 & NaoAte100 & \begin{tabular}{|l|} 
NaoAte200 \\
\end{tabular} & NaoAte500 & \begin{tabular}{|l|} 
NaoAte700 \\
\end{tabular} & NaoAte 1000 \\
\hline Curva "Pc-A" & Curva "Pm-B" & 13.09 & 51 & 8 & 1 & 0 & 0 & 0 & \\
\hline Curva "Pc-B" & Curva "Pm-C" & 13.63 & 49 & 45 & 44 & 43 & 43 & 43 & 43 \\
\hline Curva "Pc-A" & 0.04096 & 13.53 & 77 & 4 & 0 & 0 & 0 & 0 & 0 \\
\hline Curva "Pc-C" & Curva "Pm-E" & 11.65 & 55 & 25 & 5 & 0 & 0 & 0 & \\
\hline
\end{tabular}

Tabela 6.15: resultados obtidos em experimentos com a utilização das curvas citadas anteriormente, variando Pc e possivelmente Pm, para o AG-CV.

Analisando-se estes resultados obtidos, não se identifica valor melhor que os obtidos com as melhores configurações do AG "clássico". Além disso, utilizando-se os comportamentos completamente contrários aos que se busca nestes experimentos, como ocorreu na última linha da tabela 6.15, percebe-se que a média de iterações necessárias foi menor (e portanto melhor) que a das demais linhas.

\subsection{Considerações Finais do Capítulo}

A partir das tabelas (disponíveis no "Apêndice A" deste trabalho) obtidas a partir dos experimentos com AG's "clássicos" (ou seja, AG's que mantêm fixos os valores de seus parâmetros em tempo de execução), foi possível observar que: nem sempre as configurações que obtêm a menor média de iterações necessárias (para encontrar o valor ótimo global), são as mesmas configurações que obtêm o menor número de casos que não encontram o valor ótimo global procurado (em até 1000 iterações). Na realidade, observouse que a minimização de cada um destes critérios citados ocorre para configurações diferentes. 
De posse destas tabelas geradas, é possível analisar o comportamento dos AG's clássicos, e a partir disto, propor comportamentos determinísticos (em função do tamanho da população - Pop - e do número de iterações realizadas até o momento - Ng) para os parâmetros Pc e Pm, a fim de otimizar o desempenho dos AG's.

Embora existam trabalhos que sustentem a existência de curvas decrescentes para Pm que diminuem a média de iterações necessárias para encontrar o valor ótimo global procurado ([Bramlette - 1991 apud Herrera, Lozano - 1996] e [Fogarty - 1989 apud Herrera, Lozano - 1996]), e possam existir curvas para Pc que também melhorem o desempenho de um AG, estas curvas ainda não foram encontradas nos experimentos do presente trabalho, mesmo após diversas tentativas, para o AGN-CV. Estes resultados também desencorajam a busca exaustiva por curvas específicas para o AGN-MF.

Assim sendo, estas observações sugerem a necessidade de se buscar novos critérios para a utilização do "Controle Dinâmico de Parâmetros" ("Dynamic Parameter Control" [Bäck - 1998 apud Thierens - 2002] e [Hinterding, Michalewicz, Eiben - 1997 apud Thierens - 2002]) dos parâmetros Pm e Pc, em função do tamanho da população (Pop) e do número de iterações realizadas até o momento $(\mathrm{Ng})$, bem como a realização de novos experimentos. 


\section{Experimentação de ajustes dos valores de Pm e Pc, por Substituição de Valores}

Uma das principais dificuldades de se tentar encontrar curvas de Pc e Pm em função do número de $\mathrm{Ng}$ é que não se tem medidas da população durante a execução do AG (as quais seriam medidas caso se utilizasse uma abordagem de "Controle Adaptativo de Parâmetros", segundo [Bäck - 1998 apud Thierens - 2002] e [Hinterding, Michalewicz, Eiben - 1997 apud Thierens - 2002]), que possam servir de base para alterações nos valores destes parâmetros. Embora os experimentos com diferentes curvas para $\mathrm{Pm}$ e $\mathrm{Pc}$ realizados no capítulo anterior tenham sido realizados apenas para o problema do Caixeiro Viajante, e com populações de 100 indivíduos, os resultados obtidos são desencorajadores para a realização de novos experimentos com outras configurações. Para se evitar uma abordagem de busca por "tentativa e erro" por curvas ideais de Pm e Pc, o que seria um processo extremamente penoso e de difícil justificativa, decidiu-se propor, ainda seguindo-se a abordagem de Controle Dinâmico de Parâmetros ([Bäck - 1998 apud Thierens - 2002] e [Hinterding, Michalewicz, Eiben - 1997 apud Thierens - 2002]), uma nova abordagem para o comportamento de $\mathrm{Pm}$ e $\mathrm{Pc}$, em função do número de iterações (e tamanho da população), com base nos resultados obtidos nos experimentos com o AG "clássico".

\subsection{A Proposta da Substituição de Valores: O Ajuste "Em Degrau"}

Basicamente, a nova proposta consiste em utilizar, inicialmente, a configuração de parâmetros que obteve a melhor média (nos experimentos com o $A G$ ), até um número de gerações próximo desta média. Com isso, garante-se a maior velocidade para se encontrar o valor ótimo global (para os casos que o encontram, neste primeiro momento), porém, ainda existe uma quantidade razoável de casos que não encontram o valor ótimo (mínimo) global procurado, sendo que destes, muitos não o encontrarão nem mesmo para 1000 iterações (conforme apresentado nos resultados do AG "clássico"). A partir deste número de gerações, troca-se os valores de Pm e Pc para a configuração que obteve o menor número possível de casos que não encontraram o valor ótimo global procurado (nos experimentos com o AG). Espera-se que esta configuração force a o algoritmo a encontrar o ótimo global 
nos demais casos, desde que, para estes demais casos, a população não tenha atingido uma situação "irreparável" pelo emprego da configuração inicial (ou seja, que não tenha sido prejudicada por uma possível convergência prematura do algoritmo, a tal ponto que não encontrará o valor ótimo procurado, nem mesmo após a troca de valores).

\subsection{Experimentação do Ajuste "em Degrau" para o AG que Resolve o Problema do Caixeiro Viajante (AGD-CV)}

Para o AG-CV, para cada tamanho de população testado (20 a 100, em incrementos de 20), temos os seguintes resultados que minimizam a média de iterações necessárias para encontrar o valor ótimo (mínimo) global (dos casos que o fazem até 1000 iterações):

\begin{tabular}{|r|r|r|r|r|r|r|r|r|r|r|}
\hline Pop & Pc & Pm & Media & NaoAte25 & NaoAte50 & NaoAte100 & NaoAte200 & NaoAte500 & NaoAte700 & NaoAte1000 \\
\hline 100 & 1,00 & 0 & 8,04 & 22 & 22 & 22 & 22 & 22 & 22 & 22 \\
\hline 100 & 0,95 & 0 & 8,05 & 36 & 36 & 36 & 36 & 36 & 36 & 36 \\
\hline 80 & 1,00 & 0 & 8,4 & 58 & 58 & 58 & 58 & 58 & 58 & 58 \\
\hline 80 & 0,90 & 0 & 8,47 & 82 & 82 & 82 & 82 & 82 & 82 & 82 \\
\hline 60 & 1,00 & 0 & 8,92 & 138 & 138 & 138 & 138 & 138 & 138 & 138 \\
\hline 60 & 0,85 & 0 & 8,97 & 179 & 179 & 179 & 179 & 179 & 179 & 179 \\
\hline 40 & 0,80 & 0 & 8,48 & 85 & 85 & 85 & 85 & 85 & 85 & 85 \\
\hline 40 & 0,75 & 0 & 8,58 & 72 & 72 & 72 & 72 & 72 & 72 & 72 \\
\hline 20 & 0,75 & 0 & 9,75 & 824 & 824 & 824 & 824 & 824 & 824 & 824 \\
\hline 20 & 0,95 & 0 & 9,79 & 742 & 742 & 742 & 742 & 742 & 742 & 742 \\
\hline
\end{tabular}

Tabela 7.1: as duas configurações, para cada tamanho de população estudado, que produziram as menores médias de iterações necessárias para encontrar o valor mínimo global, para o AG-CV.

Assim sendo, seguindo-se essa nova abordagem proposta, para configurações com tamanho de população de 100 indivíduos, o AG iniciaria sua execução com $\mathrm{Pc}=1$; e Pm = 0 (configuração que produz a melhor média de iterações necessárias para localizar o valor mínimo global), e em alguma iteração próxima do valor desta melhor média (a qual é 8,04 então um valor próximo inteiro poderia ser, por exemplo, 9), trocar-se-ia estes valores de Pc e Pm para o valor que produz o menor número possível de casos que não encontraram o valor ótimo global procurado em até 1000 iterações, que conforme a tabela 6.4 , seria $\mathrm{Pc}=$ 0,9 e $\mathrm{Pm}=0,04096$.

Os experimentos foram realizados utilizando-se diversos "pontos de troca" (ou seja: número da iteração em que ocorre a troca dos valores de Pc e Pm), para cada um dos tamanhos de população estudados (lembrando que, existe apenas 1 ponto de troca para cada configuração do sistema, e que cada uma destas configurações foi executada 1000 vezes, cada uma destas vezes com uma diferente semente para a geração da seqüência de números aleatórios). Convém salientar que não é recomendável se utilizar "pontos de troca" muito elevados, uma vez que, caso a troca tenha sucesso e ocasione a que os casos que ainda não encontraram o valor ótimo global o façam, se isto ocorrer para um valor de 
iteração suficientemente alto, estes casos causarão um aumento considerável na média de iterações necessárias, o que não é desejável.

Estes novos sistemas, com controle dinâmico de parâmetros para os AG's implementados, que realizam apenas a troca, entre os valores iniciais e finais de Pm e Pc, foram denominados: "Algoritmo Genético com Ajuste em Degrau desenvolvido para resolver o Problema do Caixeiro Viajante" (doravante abreviado como AGD-CV), e "Algoritmo Genético com Ajuste em Degrau desenvolvido para resolver o Problema de Minimização de Funções" (doravante abreviado como AGD-MF). Todos os resultados dos experimentos com diferentes iterações de troca para o AGD-CV e para o AGD-MF podem ser vistos no Apêndice C deste documento. Ao se analisar as tabelas completas do "Apêndice C", percebe-se que, dependendo do ponto de troca escolhido, os resultados podem variar consideravelmente quanto ao desempenho do algoritmo.

Os melhores resultados obtidos com esta abordagem são apresentados a seguir:

\begin{tabular}{|r|r|r|r|r|r|r|r|r|r}
\hline Pop & $\begin{array}{c}\text { Iteração de } \\
\text { Troca }\end{array}$ & Media & NaoAte25 & NaoAte50 & NaoAte100 & NaoAte200 & NaoAte500 & NaoAte700 & NaoAte10C \\
\hline 100 & 13 & 9,01 & 26 & 4 & 1 & 0 & 0 & 0 & \\
\hline 100 & 14 & 8,73 & 19 & 3 & 0 & 0 & 0 & 0 & \\
\hline 100 & 15 & 9,02 & 22 & 10 & 1 & 0 & 0 & 0 & \\
\hline 80 & 11 & 10,17 & 45 & 7 & 0 & 0 & 0 & 0 & \\
\hline 80 & 12 & 9,94 & 41 & 3 & 0 & 0 & 0 & 0 & \\
\hline 80 & 13 & 9,92 & 33 & 10 & 0 & 0 & 0 & 0 & \\
\hline 60 & 12 & 12,87 & 95 & 23 & 1 & 0 & 0 & 0 & \\
\hline 60 & 13 & 12,56 & 94 & 23 & 2 & 0 & 0 & 0 & \\
\hline 60 & 21 & 12,97 & 103 & 29 & 0 & 0 & 0 & 0 & \\
\hline 40 & 13 & 31,64 & 249 & 153 & 78 & 23 & 1 & 0 & \\
\hline 40 & 14 & 31,04 & 279 & 168 & 75 & 15 & 0 & 0 & \\
\hline 40 & 15 & 33,55 & 274 & 168 & 88 & 30 & 0 & 0 & \\
\hline 20 & 9 & 82,91 & 651 & 400 & 253 & 123 & 10 & 0 & \\
\hline 20 & 10 & 78,17 & 636 & 388 & 221 & 116 & 8 & & 2 \\
\hline 20 & 11 & 75,74 & 641 & 391 & 211 & 95 & 11 & & 4 \\
\hline
\end{tabular}

Tabela 7.2: os três melhores resultados obtidos para o AG com ajuste dinâmico de Pm e Pc, para os diferentes tamanhos de população estudados, para o problema do CV.

Analisando-se os resultados obtidos para a população de 100 indivíduos, observa-se que a melhor média obtida $(8,73)$ não é melhor que a melhor média obtida com 0 AG "clássico" $(8,04$, na tabela 7.1$)$, porém, esta média $(8,73)$ é consideravelmente menor que a média obtida com o AG "clássico" para a configuração que possui o melhor número de casos que não encontraram o valor ótimo global procurado (conforme a tabela 6.4, média de 13,49), e foi obtida com um número bem menor de casos que não encontraram o valor ótimo global que a configuração de melhor média do AG "clássico" (segundo a tabela 7.1, 22 casos que não encontraram o valor ótimo global nem mesmo até a iteração 1000). De fato, o número de casos que não encontraram o valor ótimo global procurado obtidos para o caso 
de melhor média do AG com controle dinâmico de parâmetros é de 19 casos que não encontraram o valor ótimo global procurado até 25 iterações, 3 casos que não encontraram o valor ótimo global procurado até 50 iterações, e nenhum caso que não encontrou o valor ótimo global após a iteração 75. A configuração do AG "clássico" que produziu o menor número de casos que não encontraram o valor ótimo global produziu apenas 80 casos que não o fizeram até a iteração 25, e nenhum caso que não o fez após 50 iterações. Embora o controle dinâmico não tenha apresentado nenhum resultado absolutamente melhor em nenhum dos dois critérios considerados (média e número de casos que não encontraram o valor ótimo global procurado), percebe-se que este conseguiu combinar bons resultados para os dois critérios.

Resultados semelhantes podem ser observados para populações de 80 e de 60 indivíduos, com valores de quantidade de casos que não encontraram o valor ótimo global procurado próximos às melhores configurações de AG "clássico" para este fim, porém com significativa redução na média de iterações necessárias (para encontrar o valor ótimo global) em relação a estes casos (porém com a média ainda não menor à melhor configuração possível do AG "clássico" para este fim). Para a população de 40 indivíduos, observa-se que - AG com controle dinâmico de parâmetros não produziu resultados melhores que as melhores configurações do AG "clássico". A própria configuração do AG "clássico" que produz o menor número de casos que não encontraram o valor ótimo global procurado, produziu tanto um valor para a média quanto um valor para a quantidade de casos que não encontraram o valor ótimo global procurado, melhores que a melhor configuração do AG com controle dinâmico para este tamanho de população.

Para a população de 20 indivíduos, os valores de média obtidos com este AG com controle dinâmico de parâmetros também permaneceram consideravelmente altos, e não houve melhora significativa no número de casos que não encontraram o valor ótimo global procurado. Em particular, a segunda melhor configuração do AG "clássico" para o número de casos que não encontraram o valor ótimo global procurado (última linha da tabela 6.4), apresentou melhores resultados sob os dois critérios estudados (média e quantidade de casos que não encontraram o valor ótimo global) que a melhor configuração do AG com controle dinâmico para este tamanho de população.

Analisando-se os resultados, percebe-se que o emprego deste AG, com este ajuste específico de parâmetros em tempo de execução, tem seu uso justificável para tamanhos de população suficientemente grandes (nos experimentos em questão, para o AG-CV, populações de 60, 80 e 100 indivíduos). Isso pode ser compreendido intuitivamente, pela idéia de que, quanto maior é a população, mais dificilmente esta atingirá, ainda nas primeiras iterações, um estado irreparável (ou muito difícil de reparar), uma vez que, por haver uma maior quantidade de indivíduos, maiores serão as chances de se possuir maior 
quantidade de indivíduos diferentes, e também menor será a probabilidade de seleção de cada indivíduo, pela utilização do mecanismo de seleção por classificação.

Porém, é importante notar que os casos que possuem populações relativamente pequenas, são os casos que mais necessitam de melhoria, por obviamente possuírem os resultados mais pobres. Para o caso de população de 60 indivíduos, por exemplo, percebese que o emprego do controle dinâmico de parâmetros é mais justificável que seu emprego para a população de 100 indivíduos, uma vez que para a população de 60 indivíduos a configuração de melhor média possuía porcentagem em torno de $14 \%$ de casos que não encontraram o valor ótimo global procurado até 1000 iterações conforme a tabela 7.1, enquanto que com o controle dinâmico quase todos encontravam o valor ótimo global até 100 iterações, conforme a tabela 7.2. Já para o caso de população de 100 indivíduos, a configuração de melhor média possuía porcentagem em torno de apenas $2 \%$ de casos que não encontraram o valor ótimo global procurado até 1000 iterações conforme a tabela 7.1, o que pode não necessariamente justificar a utilização desta técnica de controle dinâmico, com estes critérios, para este caso.

Também é importante notar que resultados semelhantes a estes melhores resultados obtidos com o AG com ajuste em "degrau" (para populações suficientemente grandes, como de 100, 80 ou 60 indivíduos) não foram obtidos em nenhuma das diferentes configurações estudadas de AG's "clássicos". 


\subsection{Experimentação do Ajuste "em Degrau" para o AG que Resolve o Problema de Minimização de Funções (AGD-MF)}

Para o AG que resolve o problema de minimização de funções, para cada tamanho de população testado $(20,50,70$ e 200$)$, temos os seguintes resultados que minimizam a média de iterações necessárias para encontrar o valor ótimo global (dos casos que o encontram em até 1000 iterações):

\begin{tabular}{|c|c|c|c|c|c|c|c|c|c|c}
\hline Pop & Pc & Pm & Media & NaoAte25 & NaoAte50 & NaoAte100 & NaoAte200 & NaoAte500 & NaoAte700 & NaoAte1000 \\
\hline 200 & 1,00 & 0,0000 & 8,81 & 234 & 234 & 234 & 234 & 234 & 234 & 234 \\
\hline 200 & 0,95 & 0,0000 & 8,88 & 248 & 248 & 248 & 248 & 248 & 248 & 248 \\
\hline 70 & 0,85 & 0,0055 & 11,42 & 657 & 653 & 652 & 652 & 652 & 652 & 652 \\
\hline 70 & 0,90 & 0,0044 & 11,48 & 653 & 646 & 646 & 646 & 646 & 646 & 646 \\
\hline 50 & 0,95 & 0,0044 & 13,91 & 787 & 761 & 761 & 761 & 761 & 761 & 761 \\
\hline 50 & 0,95 & 0,0069 & 13,92 & 755 & 732 & 732 & 732 & 732 & 732 & 732 \\
\hline 20 & 0,50 & 0,0000 & 6 & 995 & 995 & 995 & 995 & 995 & 995 & 995 \\
\hline 20 & 1,00 & 0,0055 & 43,97 & 957 & 920 & 904 & 900 & 897 & 897 & 897 \\
\hline
\end{tabular}

Tabela 7.3: as duas configurações, para cada tamanho de população estudado, que produziram as menores médias de iterações necessárias para encontrar o valor ótimo global, para o AG-MF.

Também para o AG que resolve o problema de minimização de funções, para cada tamanho de população testado $(20,50,70$ e 200$)$, temos os seguintes resultados que minimizam o número de casos não encontram o valor ótimo global em até diferentes faixas de iterações:

\begin{tabular}{|c|c|c|c|c|c|c|c|c|c|c}
\hline Pop & Pc & Pm & Media & NaoAte25 & NaoAte50 & NaoAte100 & NaoAte200 & NaoAte500 & NaoAte700 & NaoAte100 \\
\hline 200 & 0,70 & 0,0512 & 13,11 & 50 & 0 & 0 & 0 & 0 & 0 & 0 \\
\hline 200 & 0,65 & 0,0512 & 13,43 & 60 & 0 & 0 & 0 & 0 & 0 & 0 \\
\hline 70 & 0,95 & 0,0640 & 27,53 & 342 & 134 & 20 & 0 & 0 & 0 & 0 \\
\hline 70 & 1,00 & 0,0640 & 27,9 & 366 & 131 & 24 & 0 & 0 & 0 & 0 \\
\hline 50 & 1,00 & 0,0800 & 41,33 & 514 & 257 & 81 & 9 & 0 & 0 & 0 \\
\hline 50 & 0,95 & 0,0640 & 40,85 & 460 & 259 & 85 & 10 & 0 & 0 & 0 \\
\hline 20 & 0,90 & 0,0800 & 187,1 & 817 & 677 & 546 & 371 & 94 & 36 & 8 \\
\hline 20 & 1,00 & 0,1000 & 152 & 821 & 609 & 429 & 271 & 69 & 24 & 9 \\
\hline
\end{tabular}

Tabela 7.4: as duas configurações, para cada tamanho de população estudado, que produziram os menores números de casos que não encontraram o valor ótimo global, para o AG-MF.

Assim como ocorreu para o AGD-CV, os experimentos para o AGD-MF foram realizados utilizando-se diversos possíveis "pontos de troca" (ou seja: número da iteração em que ocorre a troca dos valores de $\mathrm{Pc}$ e $\mathrm{Pm}$ ), para cada um dos tamanhos de população estudados. Também conforme realizado para o AGD-CV, não foram testados "pontos de troca" muito elevados, uma vez que, caso a troca tenha sucesso e ocasione que o algoritmo encontre o valor ótimo global nos casos que ainda não o fizeram até a iteração da própria 
troca, se isto ocorrer para um valor de iteração suficientemente alto, estes casos causarão um aumento considerável na média de iterações necessárias, o que não é desejável.

Os melhores resultados obtidos com esta abordagem são apresentados a seguir:

\begin{tabular}{|c|c|c|c|c|c|c|c|c|c|}
\hline Pop & $\begin{array}{c}\text { Iteração } \\
\text { de Troca }\end{array}$ & Media & NaoAte25 & NaoAte50 & NaoAte100 & NaoAte200 & NaoAte500 & NaoAte700 & NaoAte1000 \\
\hline 200 & 5 & 12,55 & 40 & 0 & 0 & 0 & 0 & 0 & 0 \\
\hline 200 & 6 & 12,64 & 50 & 1 & 0 & 0 & 0 & 0 & 0 \\
\hline 200 & 7 & 12,32 & 58 & 3 & 1 & 0 & 0 & 0 & 0 \\
\hline 70 & 3 & 28,73 & 369 & 136 & 26 & 1 & 0 & 0 & 0 \\
\hline 70 & 4 & 27,94 & 361 & 136 & 15 & 0 & 0 & 0 & 0 \\
\hline 70 & 5 & 28,82 & 374 & 137 & 25 & 1 & 0 & 0 & 0 \\
\hline 50 & 3 & 41,44 & 497 & 254 & 88 & 12 & 0 & 0 & 0 \\
\hline 50 & 4 & 43,17 & 535 & 265 & 102 & 9 & 0 & 0 & 0 \\
\hline 50 & 5 & 43,12 & 546 & 282 & 90 & 12 & 0 & 0 & 0 \\
\hline 20 & 2 & 189,77 & 831 & 666 & 542 & 351 & 117 & 54 & 15 \\
\hline 20 & 3 & 186,13 & 829 & 678 & 542 & 350 & 108 & 41 & 12 \\
\hline 20 & 5 & 186,81 & 836 & 690 & 547 & 346 & 104 & 50 & 16 \\
\hline
\end{tabular}

Tabela 7.5: os três melhores resultados obtidos para o AG com ajuste dinâmico de Pm e PC, para os diferentes tamanhos de população estudados, para o problema de minimização de funções.

Ao se analisar a tabela apresentada, percebe-se que, para o problema de minimização de funções, as iterações de troca que produziram os melhores resultados são valores consideravelmente mais baixos que aqueles obtidos para o PCV. Além disso, ao se analisar as tabelas completas do "Apêndice C", percebe-se que, para este problema de minimização de funções, os resultados tendem a piorar consideravelmente conforme se aumenta o valor da iteração em que ocorre a troca de valores (dos iniciais para os finais) de Pm e Pc.

Analisando-se os resultados obtidos para a população de 200 indivíduos, observa-se um fenômeno semelhante aos casos das populações de 100, 80 e 60 indivíduos para o PCV: a melhor média obtida $(12,32)$ não é melhor que a melhor média obtida com o AG "clássico" $(8,81$, na tabela 7.3$)$, porém, esta média $(12,32)$ é consideravelmente menor que a média obtida com o AG "clássico" para a configuração que possui o melhor número de casos que não encontraram o valor ótimo global procurado (conforme a tabela 7.4, média de 13,11), e foi obtida com um número bem menor de casos que não encontraram o valor ótimo global, que a configuração de melhor média do AG "clássico" (segundo a tabela 7.3, 234 casos que não encontraram o valor ótimo global nem mesmo até a iteração 1000). Porém, os números de casos que não encontraram o valor ótimo global procurado, para as melhores configurações do AGD-MF, são também um pouco superiores aos números obtidos para as configurações que os minimizam, com o AG "clássico", para este problema. Porém, assim como nos casos de populações suficientemente grandes para o AGD-CV, esta configuração para o AGD-MF também foi capaz de obter certo equilíbrio entre a média e o número de casos que não encontraram o valor ótimo global procurado, combinando assim bons resultados para estas duas grandezas. Porém, para o AG-MF "clássico", existem 
configurações que apresentam resultados próximos aos obtidos pelas melhores configurações do AGD-MF, apresentados na tabela a seguir:

\begin{tabular}{|c|c|c|c|c|c|c|c|c|c|c|}
\hline Pop & Pc & Pm & Media & NaoAte25 & NaoAte50 & NaoAte100 & NaoAte200 & NaoAte500 & NaoAte700 & NaoAte1000 \\
\hline 200 & 0,90 & 0,04096 & 12,56 & 44 & 4 & 1 & 0 & 0 & 0 & 0 \\
\hline 200 & 0,85 & 0,04096 & 12,62 & 30 & 8 & 2 & 0 & 0 & 0 & 0 \\
\hline 200 & 1,00 & 0,04096 & 12,67 & 32 & 5 & 4 & 1 & 0 & 0 & 0 \\
\hline 200 & 0,95 & 0,0512 & 12,82 & 40 & 1 & 0 & 0 & 0 & 0 & 0 \\
\hline 200 & 1 & 0,0512 & 12,97 & 51 & 3 & 0 & 0 & 0 & 0 & 0 \\
\hline
\end{tabular}

Tabela 7.6: resultados obtidos por configurações específicas do AG "clássico" para resolver o problema de minimização de funções, que obtiveram resultados muito próximos aos resultados obtidos pelo AG com ajuste em "degrau".

Ao se comparar a tabela 7.6 com os resultados da tabela 7.5 para populações de 200 indivíduos, percebe-se que nenhuma configuração do AG "clássico" é melhor, ao mesmo tempo em média e em número de casos que não encontraram o valor ótimo global procurado, que nenhum dos casos da tabela 7.6, mas os resultados são muito próximos. Isto significa que, para este caso, o AGD-MF encontrou resultados correspondentes às configurações mais "equilibradas" do AG-MF "clássico" (uma vez que foram muito pouco melhores que estes resultados específicos).

Além disso, ao se comparar os resultados para populações de tamanhos 70, 50 e 20, percebe-se que os resultados obtidos não possuem desempenho atrativo, assim como ocorreu para populações suficientemente pequenas para o PCV. Nestes casos (para o problema de minimização de funções, com AGD-MF, para populações de 70, 50 e 20 indivíduos), observa-se que as melhores configurações obtiveram resultados semelhantes (apenas um pouco maiores), em números de casos que não encontraram o valor ótimo global procurado, aos resultados obtidos para as configurações que minimizam esta grandeza com o AG "clássico", porém as médias obtidas foram ainda piores que as médias destas configurações do AG "clássico".

Sendo assim, também para o problema de minimização de funções, percebe-se que o uso do AGD pode gerar bons resultados (embora, nos experimentos para este problema, os melhores resultados obtidos eram muito próximos a resultados passíveis de obtenção pelo AG-MF), ainda para populações suficientemente grandes, porém necessitando de populações maiores que as necessárias para a implementação do AGD-CV para este trabalho (pois para o AGD-CV, bons resultados foram obtidos até mesmo para populações de 60 indivíduos, enquanto que o AGD-MF não apresentou resultados atrativos para populações de 70 indivíduos).

Uma vez estudado o impacto deste tipo de ajuste de taxas de mutação e de cruzamento, com a troca abrupta dos valores de $\mathrm{Pm}$ e $\mathrm{Pc}$, resta estudar as conseqüências da utilização de Sistemas de Inferência Nebulosos (SIN) para realizarem esta tarefa (o que proporcionará transições mais suaves entre os valores iniciais e finais de $\mathrm{Pm}$ e $\mathrm{Pc}$ ). 


\subsection{Experimentação da Técnica de Ajuste "em Degrau” com Inferências Nebulosas, para Ambos os AGN's}

Regras e funções de pertinência para a utilização de um SIN para realizar o ajuste de valores de $\mathrm{Pm}$ e Pc, foram elaboradas com base nos resultados do experimento anterior. Pela utilização dos SIN's elaborados, os AGN's produzidos (para o problema do caixeiro viajante, e para o problema de minimização de funções) passam a ter comportamento semelhante aos AG's com ajuste em "degrau" produzidos anteriormente (ou seja, o AGD-MF e o AGD-CV). Além disso, como os SIN's destes AGN's utilizam também como valores de entrada o tamanho da população, não é necessário construir um AG para cada tamanho de população, como era o caso para os AG's com ajuste em "degrau". Desta forma, é necessário construir apenas um AGN para cada problema, e o próprio SIN implementado cuidará de realizar o ajuste adequado para cada tamanho de população estudado.

\subsubsection{Experimentação da Técnica de Ajuste “em Degrau” com Inferências Nebulosas, para o PCV (AGN-CV)}

Para o AGN-CV, foram utilizadas as seguintes partições nebulosas (para as variáveis de entrada e de saída do SIN) e regras:

- Número de Gerações $(\mathrm{Ng})$ :

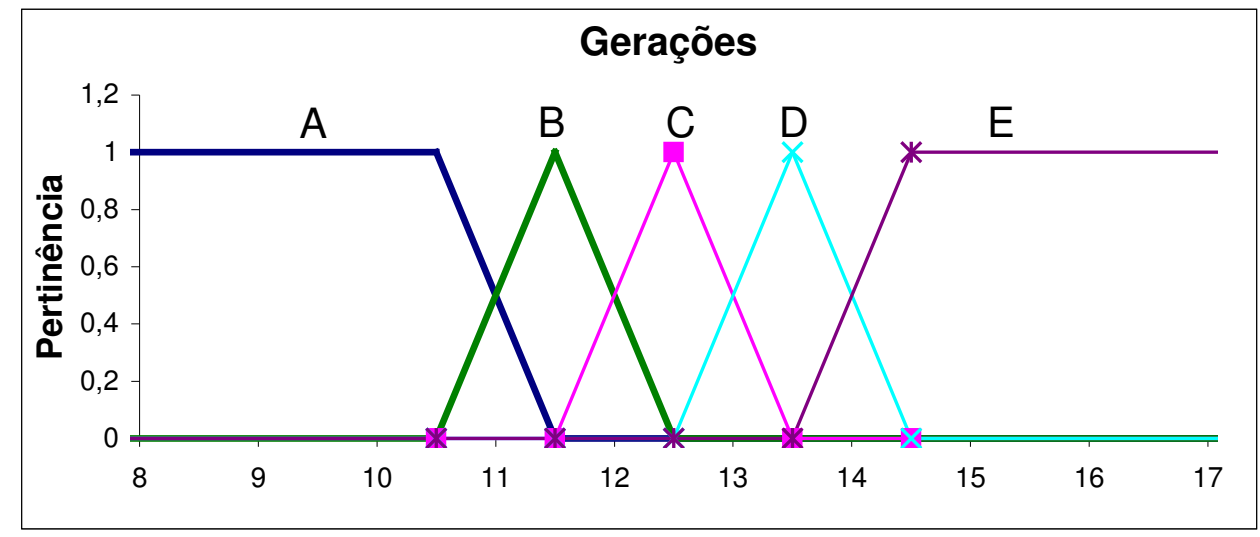

Figura 7.1: Partição Nebulosa da Variável Ng para o AGN-CV.

Deste gráfico é interessante notar que as iterações de troca estão situadas exatamente no centro da transição entre o conjunto nebuloso anterior e o posterior, de forma que estas 
correspondam ao centro da transição entre os valores assumidos pelas variáveis de saída. Por exemplo: para a população de 100 indivíduos, o AGN-CV utiliza como iteração de troca a de número 14. Observando-se o gráfico, percebe-se que a iteração 14 está exatamente no centro da transição entre os conjuntos nebulosos "D" e "E". Outra observação importante é que, embora o gráfico apresente, no eixo das abscissas, apenas valores de 8 a 17, o universo de discurso da variável $\mathrm{Ng}$ é de 1 até 1000 , sendo que os pontos de 1 até 8 possuem pertinência 1 ao conjunto "A" e 0 aos demais; e os pontos de 17 a 1000 possuem pertinência 1 ao conjunto "E" e 0 aos demais conjuntos nebulosos.

- Tamanho da População:

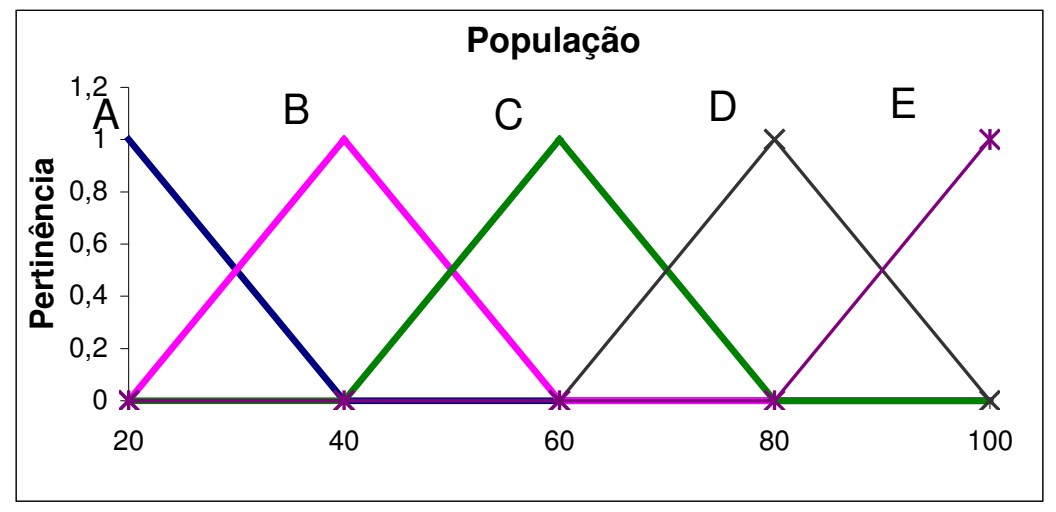

Figura 7.2: Partição Nebulosa da Variável Pop para o AGN-CV. 
- Taxa de Mutação:

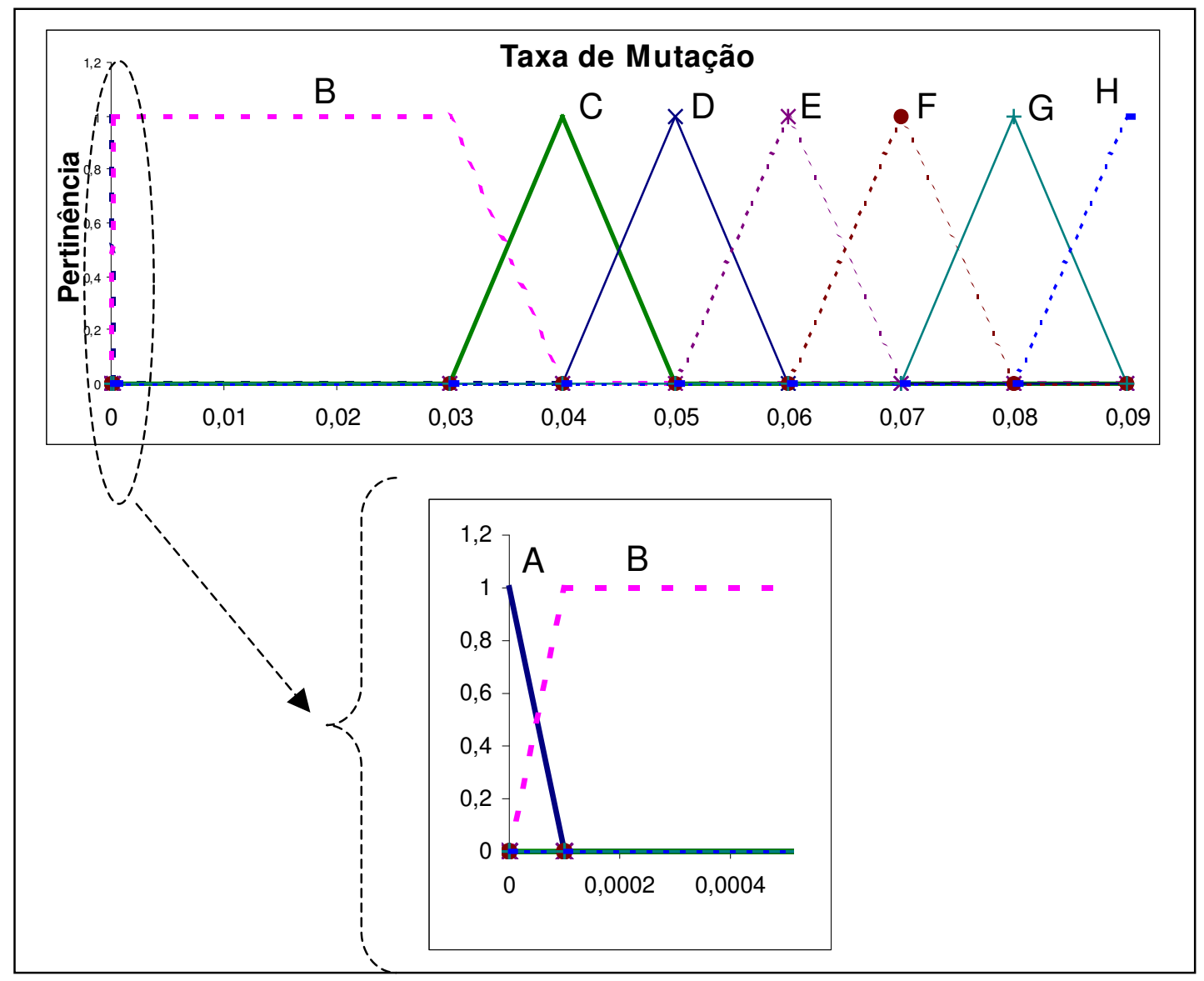

Figura 7.3: Partição Nebulosa da Variável Pm para o AGN-CV.

É importante notar que os conjuntos nebulosos B, E, F, e H aparecem em pontilhado no gráfico, mas foram adicionados apenas para fins de completeza do modelo, pois não são utilizados pelas regras construídas para este sistema (uma vez que valores nestas faixas não apresentaram resultados interessantes para os sistemas desenvolvidos). 
- Taxa de Cruzamento:

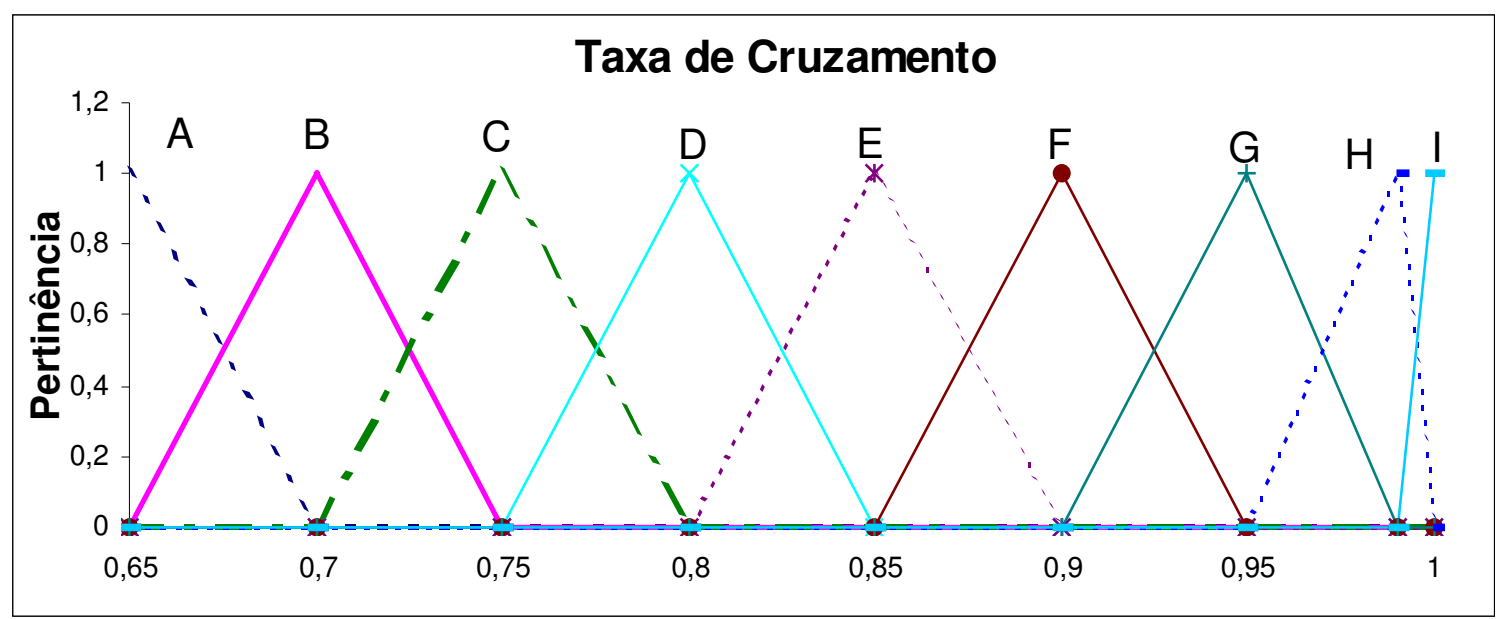

Figura 7.4: Partição Nebulosa da Variável Pc para o AGN-CV.

É importante notar que os conjuntos nebulosos $\mathrm{A}, \mathrm{C}, \mathrm{E}$, e H aparecem em pontilhado no gráfico, mas foram adicionados apenas para fins de completeza do modelo, pois não são utilizados pelas regras construídas para este sistema (uma vez que valores nestas faixas não apresentaram resultados interessantes para os sistemas desenvolvidos).

- Regras:

\begin{tabular}{|c|c|c|c|c|c|}
\hline \multicolumn{7}{|c|}{ Regras para Pm } \\
\hline & \multicolumn{5}{|c|}{ Pop } \\
\hline Ng & A & B & C & D & E \\
\hline A & $A$ & $A$ & $A$ & $A$ & $A$ \\
\hline B & $G$ & $A$ & $A$ & $A$ & $A$ \\
\hline C & $G$ & $A$ & $A$ & $A$ & $A$ \\
\hline D & $G$ & $A$ & $D$ & $C$ & $A$ \\
\hline E & $G$ & $D$ & $D$ & $C$ & $C$ \\
\hline
\end{tabular}

Tabela 7.7: regras utilizadas no AGN-CV para a variável Pm.

\begin{tabular}{|c|c|c|c|c|c|}
\hline \multicolumn{6}{|c|}{ Regras para Pc } \\
\hline & & & Pop & & \\
\hline $\mathrm{Ng}$ & A & B & C & D & $E$ \\
\hline A & $D$ & $D$ & 1 & 1 & 1 \\
\hline B & $G$ & $D$ & I & I & $I$ \\
\hline C & $G$ & $D$ & I & I & I \\
\hline D & $G$ & $D$ & $I$ & $I$ & 1 \\
\hline$E$ & $G$ & $B$ & I & I & $F$ \\
\hline
\end{tabular}

Tabela 7.8: regras utilizadas no AGN-CV para a variável PC. 
Os gráficos a seguir ilustram a diferença do comportamento das variáveis Pm e Pc, em função de $\mathrm{Ng}$, entre o uso do AGN-CV e o uso do AGD-CV, para um tamanho de população de 100 indivíduos:

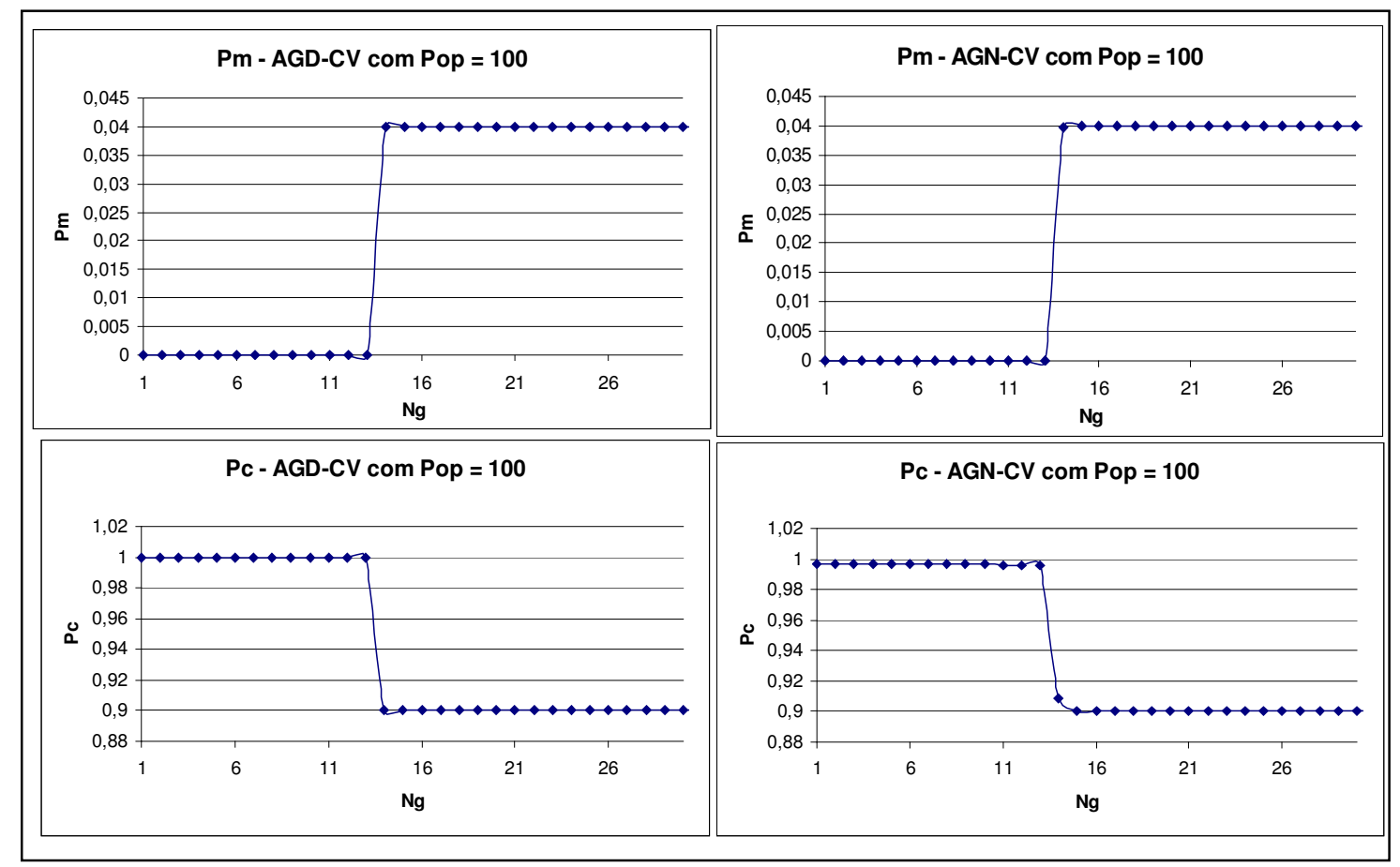

Figura 7.5: Comparação entre os comportamentos das variáveis de saída em função do número de gerações, para o AGD-CV e o AGN-CV com Pop $=100$

Embora na figura todos os gráficos apresentem no eixo das abscissas os números de gerações de 1 até 30 , as variáveis de saída Pm e Pc mantêm seu valor constante até a geração de número 1000. Conforme se pode observar na figura, as transições realizadas pelo AGN-CV são um pouco mais suaves que as transições do AGD-CV, e os patamares assumidos por estas variáveis para o AGN-CV não coincidem exatamente com os patamares assumidos para o AGD-CV, mas possuem valores muito próximos. Embora a figura ilustre apenas o comportamento das variáveis Pm e Pc em função de $\mathrm{Ng}$ para Pop = 100, comportamentos semelhantes são observados também para os outros tamanhos de população abordados.

Os resultados produzidos, para o PCV, são apresentados a seguir:

\begin{tabular}{|c|c|c|c|c|c|c|c|c}
\hline Pop & Media & NaoAte25 & NaoAte50 & NaoAte100 & NaoAte200 & NaoAte500 & NaoAte700 & NaoAte1001 \\
\hline 100 & 9,05 & 23 & 5 & 2 & 0 & 0 & 0 & 0 \\
\hline 80 & 9,99 & 34 & 9 & 1 & 0 & 0 & 0 & 0 \\
\hline 60 & 13,04 & 94 & 32 & 4 & 0 & 0 & 0 & 0 \\
\hline 40 & 30,81 & 265 & 154 & 83 & 13 & 0 & 0 & 0 \\
\hline 20 & 76,64 & 616 & 387 & 209 & 113 & 14 & 0 & 0 \\
\hline
\end{tabular}

Tabela 7.9: resultados obtidos, para diferentes tamanhos de população, para o AGN-CV. 


\subsubsection{Experimentação da Técnica de Ajuste "em Degrau" com Inferências Nebulosas, para o PMF (AGN-MF)}

Para o AGN-MF, foram utilizadas as seguintes partições nebulosas (para as variáveis de entrada e de saída do SIN) e regras:

- Número de Gerações $(\mathrm{Ng})$ :

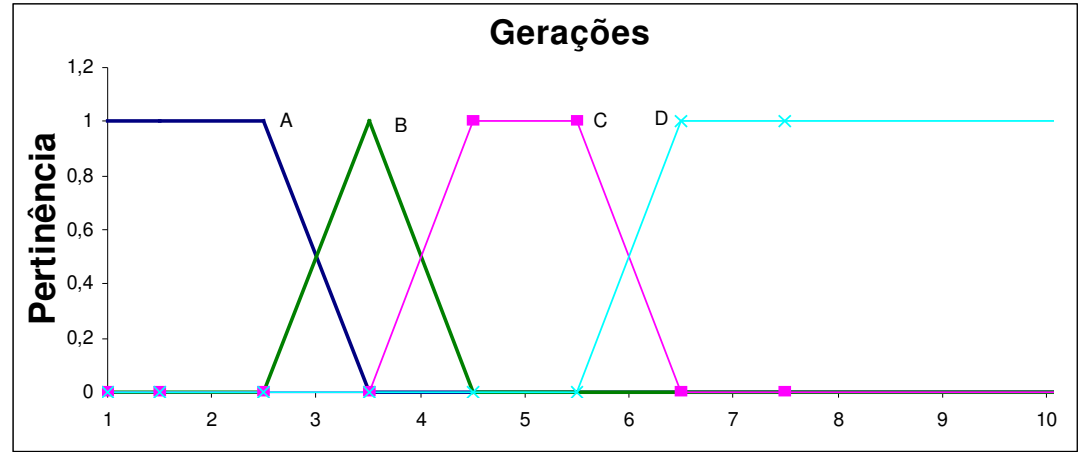

Figura 7.6: Partição Nebulosa da Variável "Ng" para o AGN-MF.

É importante observar que o universo de discurso desta variável vai de 1 até 1000 , e embora o gráfico não tenha representado todos os pontos, estes de 10 a 1000 possuem pertinência 1 ao conjunto nebuloso "D", e pertinência 0 a todos os demais.

- Tamanho da População:

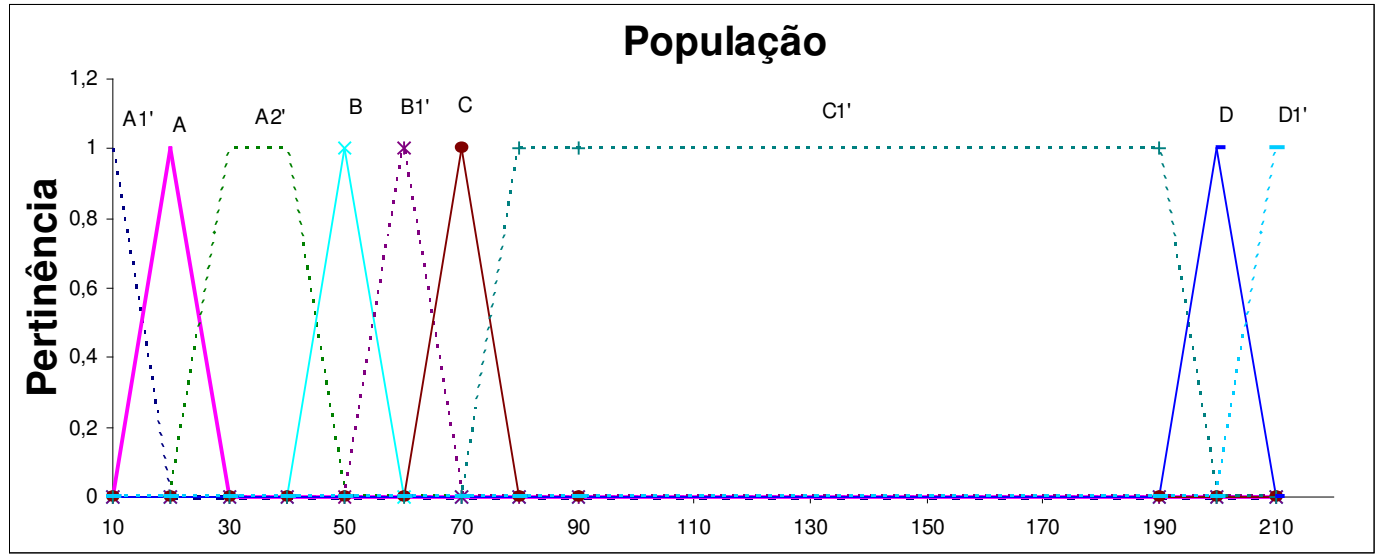

Figura 7.7: Partição Nebulosa da Variável "Pop" para o AGN-MF.

É importante notar que os conjuntos nebulosos A1', A2', B1', C1' e D1' aparecem em pontilhado no gráfico, e não são utilizados pelas regras construídas para este sistema (uma vez que foram utilizadas, experimentalmente, apenas populações de tamanhos de 20, 50, 70 e 200 indivíduos). 
- Taxa de Mutação:

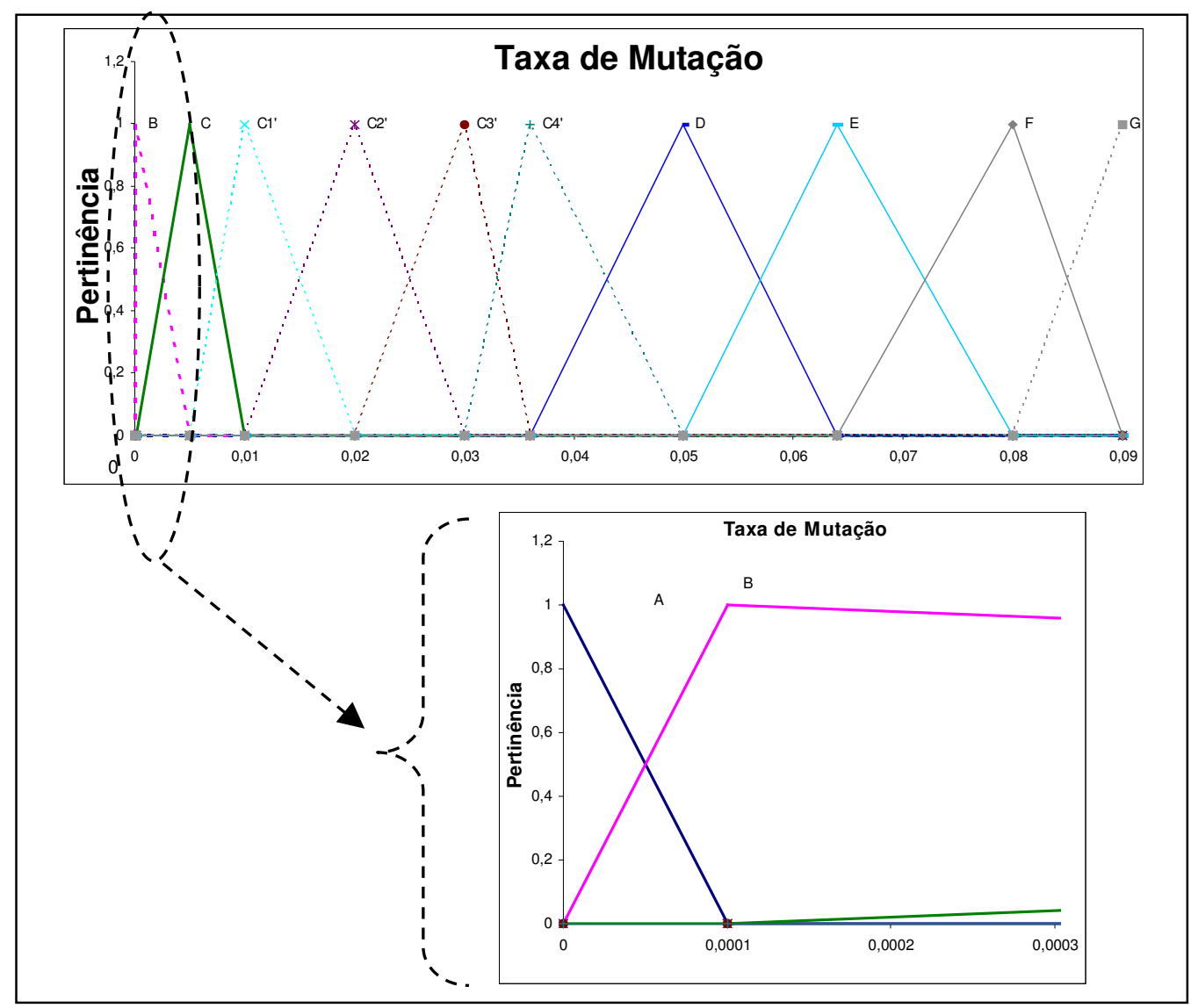

Figura 7.8: Partição Nebulosa da Variável "Pm" para o AGN-MF.

É importante notar que os conjuntos nebulosos B, C1', C2', C3', C4' e G aparecem em pontilhado no gráfico, e não são utilizados pelas regras construídas para este sistema (uma vez que valores nestas faixas não apresentaram resultados interessantes para os sistemas desenvolvidos). 
- Taxa de Cruzamento:

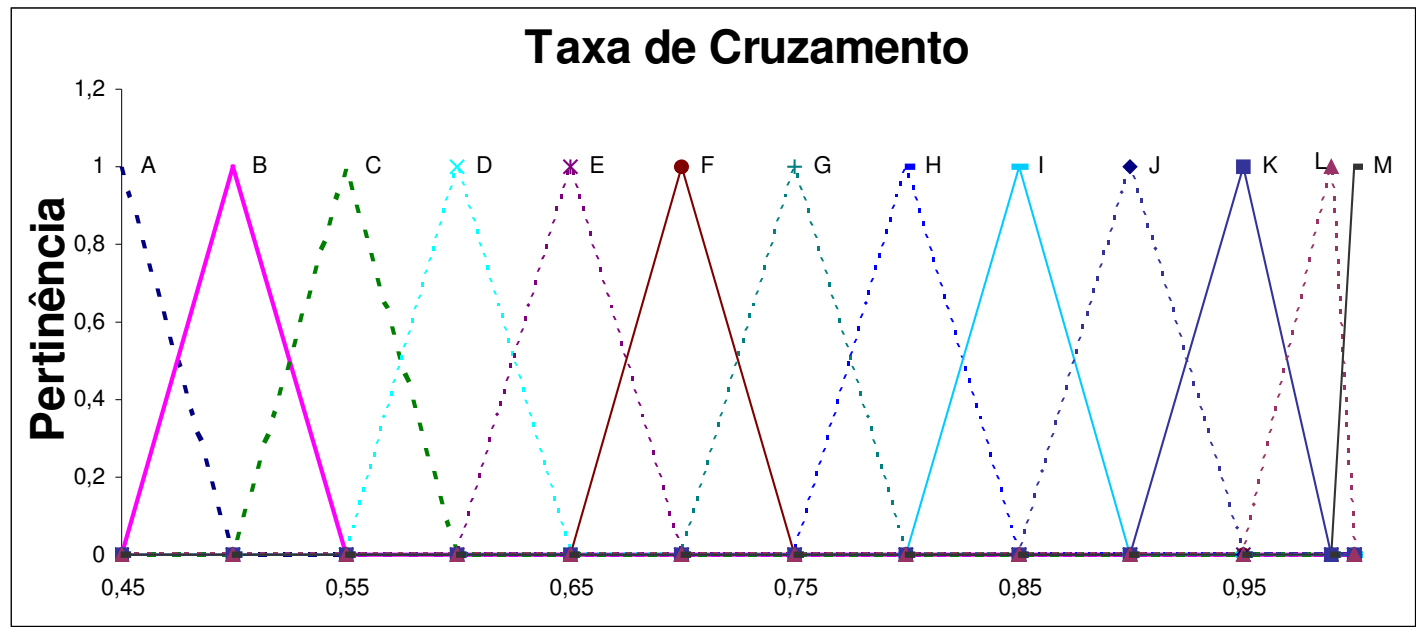

Figura 7.9: Partição Nebulosa da Variável "PC" para o AGN-MF.

É importante notar que os conjuntos nebulosos A, C, D, E, G, H, J, e L aparecem em pontilhado no gráfico, e não são utilizados pelas regras construídas para este sistema (uma vez que valores nestas faixas não apresentaram resultados interessantes para os sistemas desenvolvidos).

- Regras:

\begin{tabular}{|c|c|c|c|c|}
\hline \multicolumn{6}{|c|}{ Regras para Pm } \\
\hline & \multicolumn{5}{|c|}{ Pop } \\
\hline $\mathbf{N g}$ & A & B & C & D \\
\hline A & $A$ & $C$ & $C$ & $A$ \\
\hline B & $F$ & $F$ & $C$ & $A$ \\
\hline C & $F$ & $F$ & $E$ & $A$ \\
\hline D & $F$ & $F$ & $E$ & $D$ \\
\hline
\end{tabular}

Tabela 7.10: regras utilizadas no AGN-MF para a variável "Pm".

\begin{tabular}{|c|c|c|c|c|}
\hline \multicolumn{5}{|c|}{ Regras para Pc } \\
\hline & \multicolumn{5}{|c|}{ Pop } \\
\hline $\mathbf{N g}$ & A & B & C & D \\
\hline A & $B$ & $K$ & $I$ & $M$ \\
\hline B & $I$ & $M$ & $I$ & $M$ \\
\hline C & $I$ & $M$ & $K$ & $M$ \\
\hline D & $I$ & $M$ & $K$ & $F$ \\
\hline
\end{tabular}

Tabela 7.11: regras utilizadas no AGN-MF para a variável "PC". 
Os gráficos a seguir ilustram a diferença do comportamento das variáveis Pm e Pc, em função de $\mathrm{Ng}$, entre o uso do AGN-MF e o uso do AGD-MF, para um tamanho de população de 50 indivíduos:
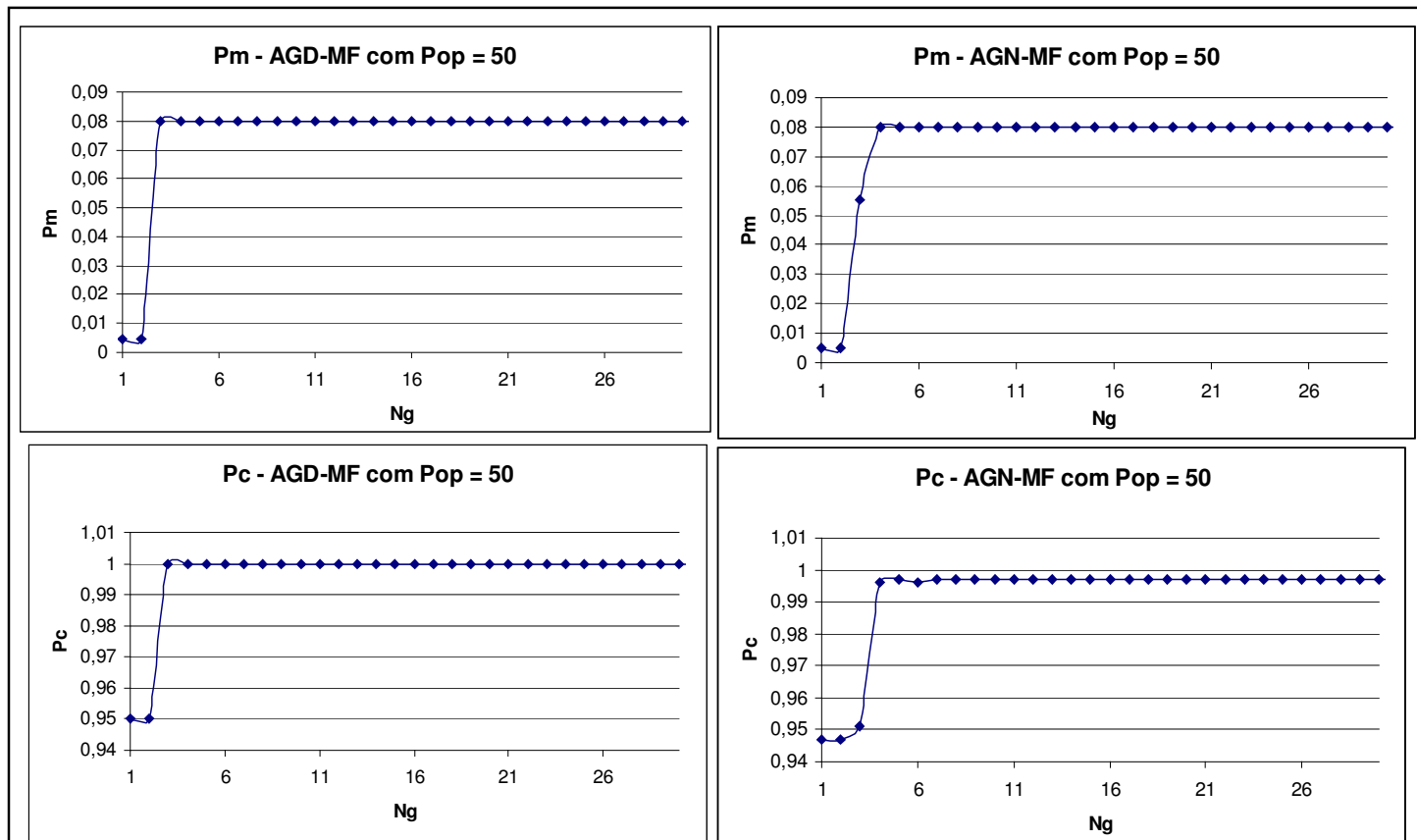

Pc - AGN-MF com Pop $=50$

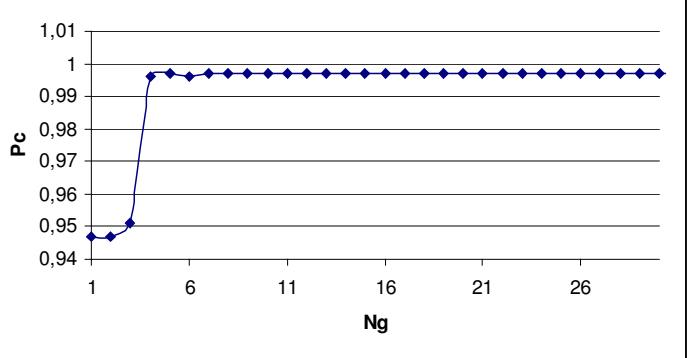

Figura 7.10: Comparação entre os comportamentos das variáveis de saída em função do número de gerações, para o AGD-MF e o AGN-MF com Pop $=50$.

Embora na figura todos os gráficos apresentem no eixo das abscissas os números de gerações de 1 até 30 , as variáveis de saída $\mathrm{Pm}$ e Pc mantêm seu valor constante até a geração de número 1000. Conforme se pode observar na figura, assim como ocorria para os algoritmos implementados para o PCV, as transições realizadas pelo AGN-MF são um pouco mais suaves que as transições do AGD-MF, e os patamares assumidos por estas variáveis para o AGN-MF não coincidem exatamente com os patamares assumidos para o AGD-MF, mas possuem valores muito próximos. Embora a figura ilustre apenas 0 comportamento das variáveis $\mathrm{Pm}$ e $\mathrm{Pc}$ em função de $\mathrm{Ng}$ para Pop $=50$, comportamentos semelhantes são observados também para os outros tamanhos de população abordados.

Os resultados obtidos para o AGN-MF são apresentados a seguir:

\begin{tabular}{|c|c|c|c|c|c|c|c|c}
\hline Pop & Media & NaoAte25 & NaoAte50 & NaoAte100 & NaoAte200 & NaoAte500 & NaoAte700 & NaoAte1000 \\
\hline 200 & 12,74 & 51 & 4 & 1 & 0 & 0 & 0 & 0 \\
\hline 70 & 30,13 & 383 & 162 & 31 & 1 & 0 & 0 & 0 \\
\hline 50 & 41,62 & 524 & 261 & 82 & 8 & 0 & 0 & 0 \\
\hline 20 & 179,72 & 828 & 703 & 531 & 350 & 98 & 53 & 24 \\
\hline
\end{tabular}

Tabela 7.12: resultados obtidos, para diferentes tamanhos de população, para o AGN que resolve o problema de minimização de funções. 
Observando-se estes resultados, percebe-se que os resultados obtidos com o AGN foram muito próximos aos obtidos para o AG com ajuste em "degrau", porém um pouco inferiores (as médias de iterações necessárias para se obter o valor ótimo global procurado, e as quantidades de casos que não encontraram este valor ótimo global, são um pouco maiores para os melhores resultados do AGN, que para os melhores resultados obtidos pelo AG com ajuste em "degrau"). Porém, comparando-se estes resultados do AGN com os resultados obtidos com AG's "clássicos", percebe-se que seu uso, assim como o uso do AG com ajuste em "degrau", também é atrativo por apresentar resultados que equilibram, ao mesmo tempo, a média de iterações necessárias, e o número de casos que não encontraram o valor ótimo global procurado. A comparação dos resultados deste AGN, com os das melhores configurações de AG's "clássicos" levam a observações semelhantes às obtidas pela comparação dos resultados do AG com ajuste em "degrau" com os das melhores configurações de AG's "clássicos", no que diz respeito às médias de iterações necessárias para se obter o valor ótimo global procurado e ao número de casos que não encontraram este valor ótimo global até 1000 iterações (conforme apresentado nas seções 7.2 e 7.3). Assim sendo, uso do AGN é também justificável para populações de tamanho suficientemente grande, como, para o AGN-CV: para populações de 100, 80 e 60 indivíduos; e para o AGN que resolve o problema de minimização de funções: para populações de 200 indivíduos. Da mesma forma, para populações menores, os resultados obtidos são piores que os de outras possíveis configurações do próprio AG "clássico". Isto leva a crer que, assim como para o AG com ajuste em "degrau", seu uso é justificável para populações suficientemente grandes.

Também é importante notar que, para o PCV, resultados semelhantes a estes obtidos pelo AGN (para populações suficientemente grandes, como de 100, 80 ou 60 indivíduos) não foram obtidos em nenhuma das diferentes configurações estudadas de AG's "clássicos", assim como ocorreu para o AG com ajuste em "degrau". Já para o AGN que resolve o problema de minimização de funções, os resultados obtidos para populações de 200 indivíduos, são muito semelhantes a outros resultados passíveis de obtenção para determinadas configurações do AG "clássico", já apresentados na tabela 7.6. Neste caso, entende-se que o AGN-MF não encontrou valores melhores que os passíveis de obtenção por configurações de um AG "clássico", mas foi capaz de encontrar resultados muito próximos à configuração do AG "clássico" que produz os melhores resultados (ou seja, os mais "equilibrados" para: as médias de iterações necessárias para se obter o valor ótimo global procurado, e as quantidades de casos que não encontraram este valor ótimo global). 


\subsection{Discussão Sobre a Resposta do Sistema a Transições Abruptas e Transições Graduais de Pm e Pc}

Os resultados obtidos sugerem que, para alterações mais abruptas de Pm e Pc (como no uso de AG's com ajuste em "degrau"), os resultados tendem a ser melhores (ou seja, com menores valores para as médias de iterações necessárias para se obter o valor ótimo global procurado, e menores as quantidades de casos que não encontraram este valor ótimo global) que os de AG's com alterações mais graduais de Pm e Pc no decorrer de sua execução (como no uso de AGN's). Um novo experimento foi realizado, com 5 diferentes AGN's, para resolver o mesmo problema do caixeiro viajante dos experimentos anteriores, com população de 100 indivíduos. A única diferença entre estes AGN's estava na base de dados do SIN de cada um, que ocasionava transições mais graduais ou mais abruptas entre os valores iniciais e finais de Pc e Pm. Estas configurações foram numeradas de 1 (transição mais abrupta) até 5 (transição mais gradual), e produziram o comportamento em função do número de gerações conforme os gráficos a seguir: 


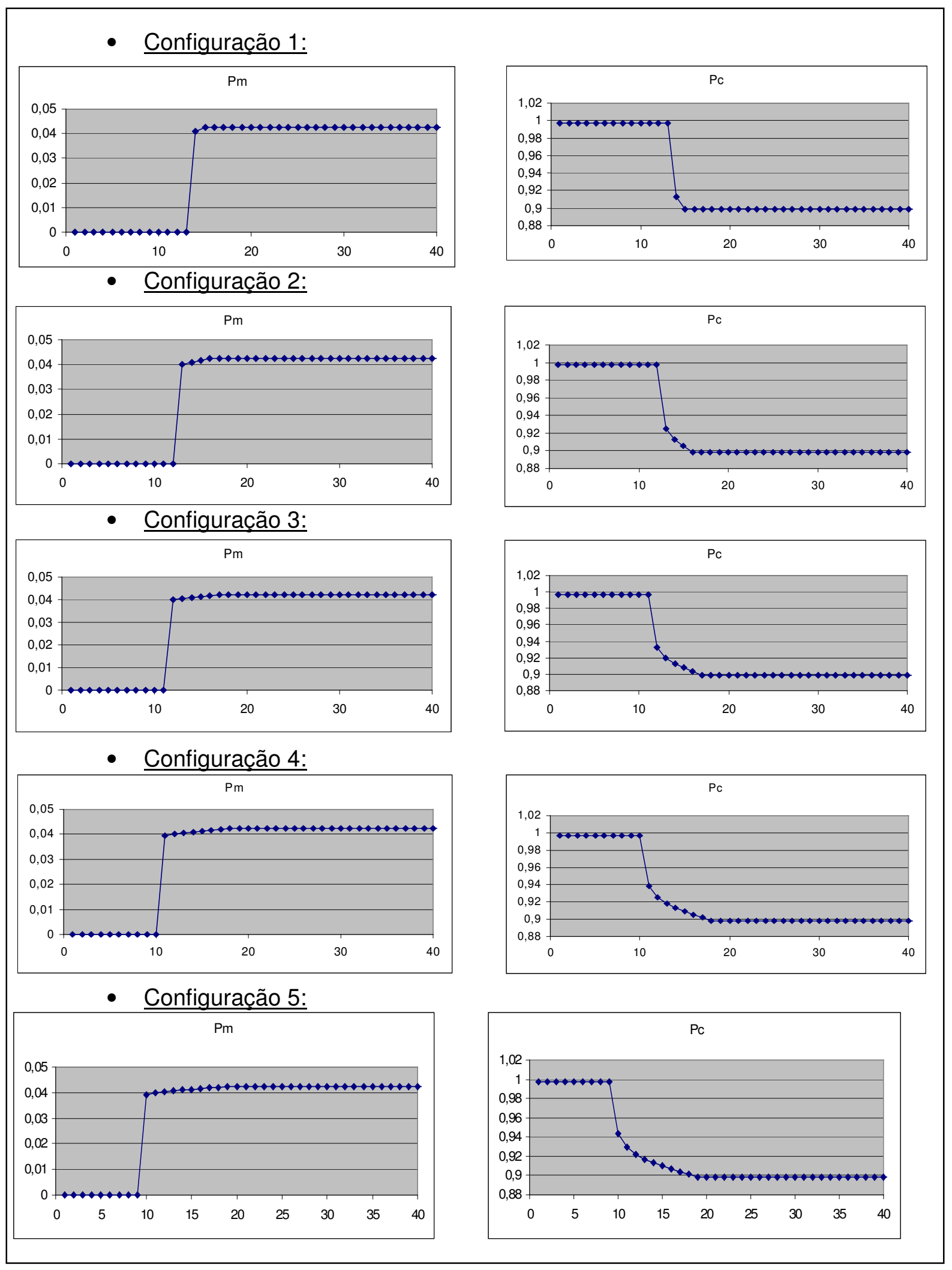

Figura 7.11: Comparação entre os comportamentos das variáveis de saída em função das diferentes configurações (de 1 até 5) do AGN-CV. 
Com estas diferentes configurações, obtiveram-se os seguintes resultados (para 1000 seqüências diferentes de números aleatórios):

\begin{tabular}{|c|c|c|c|c|c|c|c|c|c|}
\hline Pop & $\begin{array}{c}\text { Configura } \\
\text { ção }\end{array}$ & Media & NaoAte25 & NaoAte50 & NaoAte100 & NaoAte200 & NaoAte500 & NaoAte700 & NaoAte1000 \\
\hline 100 & 1 & 8,73 & 14 & 2 & 0 & 0 & 0 & 0 & 0 \\
\hline 100 & 2 & 8,78 & 16 & 2 & 0 & 0 & 0 & 0 & 0 \\
\hline 100 & 3 & 8,86 & 24 & 2 & 0 & 0 & 0 & 0 & 0 \\
\hline 100 & 4 & 9,12 & 27 & 0 & 0 & 0 & 0 & 0 & 0 \\
\hline 100 & 5 & 9,27 & 31 & 1 & 0 & 0 & 0 & 0 & 0 \\
\hline
\end{tabular}

Tabela 7.13: resultados obtidos, para as diferentes configurações de SIN, variando-se o tipo de transição (do mais abrupto ao mais gradual).

Analisando-se esta tabela, observa-se que, quanto mais gradual é a transição, maior é a média de iterações necessárias para encontrar o valor ótimo global, e também maiores são os números de casos que não encontram o valor ótimo global procurado em até 25 iterações. $O$ número de casos que não o encontram em até 50 iterações não segue o mesmo comportamento, porém, em todos os casos este número é muito pequeno $(0,1$ ou 2 em 1000), o que dificulta sua consideração nesta análise. Desta forma, estas observações sugerem que, quanto mais abruptas forem as transições entre os valores iniciais e finais de $\mathrm{Pm}$ e $\mathrm{Pc}$, mais rapidamente o $\mathrm{AG}$ responderá a esta transição, e melhores serão os resultados.

\subsection{Considerações Finais do Capítulo}

A partir da utilização da "substituição de valores" de Pc e Pm, começando com a configuração que produz a menor média de iterações necessárias (para que o algoritmo encontre o valor ótimo global); e trocando-se estes valores pelos da configuração que produziu o menor número de casos que não encontraram o valor ótimo global (para cada faixa de iterações), foi possível, para tamanhos de população suficientemente grandes, obter certo equilíbrio entre as duas medidas, produzindo algoritmos com "Controle Dinâmico de Parâmetros" ("Dynamic Parameter Control”) em [Bäck - 1998 apud Thierens - 2002] e [Hinterding, Michalewicz, Eiben - 1997 apud Thierens - 2002], que obtiveram, ao mesmo tempo, uma baixa média de iterações necessárias para encontrar o valor ótimo global, e baixas quantidades de casos que não foram capazes de encontrar este valor procurado, até diferentes faixas de iterações.

Este ajuste por substituição de valores pode ser realizado também por Sistemas de Inferência Nebulosos, os quais propiciam trocas mais suaves de valores. Embora os 
resultados obtidos para os sistemas híbridos com inferências nebulosas tenham apresentado bom desempenho, o sistema provou produzir melhores resultados para trocas abruptas de valores. 


\section{Considerações Finais}

Neste trabalho foram analisadas (e posteriormente propostas) técnicas para se ajustar os parâmetros Pc e Pm de AG's, em tempo de execução, através de Sistemas de Inferência Nebulosos. Estes SIN's utilizavam como entradas, para a inferência, apenas o número de iterações realizadas pelo algoritmo até o momento; e o tamanho da população (o qual é fixo durante toda a execução do $A G$ ); e sem realizar nenhuma leitura das condições da população do AG. Este tipo de AG utiliza o ajuste de valores não-fixos de parâmetros durante sua execução, classificada em diversos trabalhos ([Bäck - 1998 apud Thierens 2002] e [Hinterding, Michalewicz, Eiben - 1997 apud Thierens - 2002]), como "Controle Dinâmico de Parâmetros" ("Dynamic Parameter Control"). Em trabalhos como [Xu, Vukovich - 1993], e [Xu, Vukovich - 1994] esta abordagem apresenta resultados muito atrativos, utilizando medidas do $A G$ e regras de inferência muito mais simples que as utilizadas em outros trabalhos, com AG's que utilizam o denominado "Controle Adaptativo de Parâmetros" ("Adaptive Parameter Control”) ([Bäck - 1998 apud Thierens - 2002] e [Hinterding, Michalewicz, Eiben - 1997 apud Thierens - 2002]). Esta abordagem envolve a realização de medidas da população de indivíduos, e regras de inferência baseadas nestas medidas.

Embora diversos trabalhos, como por exemplo, [Bramlette - 1991 apud Herrera, Lozano - 1996] e [Fogarty - 1989 apud Herrera, Lozano - 1996], apresentem justificativas (e fórmulas obtidas empiricamente) para a realização do ajuste da taxa de mutação (Pm) com um comportamento decrescente (em função do número de iterações), percebe-se que, na prática, a obtenção destas curvas se faz muito árdua. Algumas causas para isto envolvem: 0 fato de estas curvas serem muito específicas; e o fato de dependerem muito do problema e da implementação específica do AG. Assim sendo, sem se realizar medidas diretas da população, como seu grau de diversidade e estado de convergência, a obtenção destas curvas pode se tornar um processo realizado "às cegas". O mesmo se verifica para comportamentos crescentes de $\mathrm{Pc}$ em função do número de iterações realizadas pelo $\mathrm{AG}$. Embora diversas tentativas tenham sido realizadas, os AGN's implementados não demonstraram melhorias nos resultados para diferentes curvas, o que implica que, caso existam, sejam realmente muito específicas.

No presente trabalho, ainda se buscou obter melhorias dos resultados de um AG "clássico" com a utilização de um AG com "Controle Dinâmico de Parâmetros" (definido em [Bäck - 1998 apud Thierens - 2002] e [Hinterding, Michalewicz, Eiben - 1997 apud Thierens 
- 2002]), sem se utilizar abordagens do tipo "tentativa e erro" para se encontrar curvas específicas para os comportamentos de $\mathrm{Pm}$ e Pc em função do número de iterações. Para isso, realizou-se uma análise do comportamento dos dois AG's "clássicos" implementados, para diversas configurações dos parâmetros $\mathrm{Pm}$ e Pc, e também do tamanho da população de indivíduos.

Observando-se os resultados destes diversos experimentos (encontrados no "Apêndice A" deste documento), nota-se que: algumas configurações produzem melhores médias de iterações (necessárias para se encontrar o valor ótimo global procurado) que outras; e também que algumas configurações são muito mais sensíveis às seqüências utilizadas de números aleatórios (necessárias para o funcionamento de AG's) que outras. Em outras palavras: algumas configurações podem produzir resultados muito bons ou muito ruins, dependendo da seqüência utilizada em sua operação; enquanto outras configurações mantêm seu comportamento mais estável, menos dependente de seqüências específicas de números aleatórios, possuindo assim maior "robustez" em seu funcionamento.

Também se observou que os casos de melhor (ou seja, menor) média produziram um elevado número de casos que não encontraram o valor ótimo global em até 1000 iterações (um número muito elevado de iterações para os problemas e configurações utilizados). Isto indica que estes casos muito provavelmente não encontrariam mais o valor procurado, até mesmo para maiores números de iterações.

Além disso, observou-se que as configurações com melhores (ou seja, menores) números de casos que não encontraram o valor ótimo global (em até diversas faixas de iterações), possuíam uma média de iterações necessárias para encontrá-lo relativamente elevada. Também se observou que é muito difícil encontrar configurações destes parâmetros para AG's clássicos, que gerem casos com valores próximos, ao mesmo tempo, da melhor média e do melhor número de casos que não encontraram o valor ótimo global, para diferentes faixas de iterações.

Com base nestas medidas e observações, propôs-se uma abordagem, com ajuste dos parâmetros de Pc e Pm em tempo de execução do AG, de forma a proporcionar equilíbrio entre estas duas medidas de desempenho utilizadas. Esta abordagem foi realizada para os dois problemas utilizados no presente trabalho (minimização de funções, e caixeiro viajante), e com duas abordagens distintas: uma primeira realizando trocas abruptas entre os valores iniciais e finais de Pm e Pc; e outra realizando esta transição de maneira inevitavelmente mais gradual, através da utilização de sistemas de inferência nebulosos.

Observou-se que os resultados obtidos apresentaram, para tamanhos de população suficientemente grandes: médias (de iterações necessárias para se encontrar o valor ótimo global) próximas, porém um pouco piores, que as obtidas pela melhor configuração de AG's "clássicos" para este fim. Ao mesmo tempo, para tamanhos de população suficientemente 
grandes, os resultados também apresentaram números (de casos que não encontraram o valor ótimo global) muito próximos, porém um pouco piores que os obtidos pela melhor configuração de AG's clássicos para este fim. Porém, é interessante notar que ambos os valores foram obtidos para a mesma configuração, ao mesmo tempo, proporcionando equilíbrio entre estas duas grandezas.

Observou-se também que estes resultados foram melhores para os AG's que resolviam o problema do CV, do que para os AG's que resolviam o problema de minimização de funções. Neste segundo caso, mesmo para um tamanho de população consideravelmente grande (200 indivíduos), constata-se que o AGN-MF e o AGD-MF foram capazes de encontrar valores apenas um pouco melhores para a média (de iterações necessárias) e o número de casos (que não encontraram o valor ótimo global), a valores que já eram obtidos para configurações específicas do AG "clássicos". Porém isto indica que a abordagem utilizada é capaz de encontrar valores iguais ou melhores aos encontráveis com diferentes configurações de AG's clássicos. Esta observação também indica,que este tipo de abordagem pode ser melhor, para problemas e implementações específicas de AG's, mas condições mais específicas, que levam ao sucesso desta abordagem, necessitam de maior investigação em trabalhos futuros.

Também convém observar que, para o tipo específico de ajuste de Pm e Pc estudado no presente trabalho, observou-se que a utilização de mudanças bruscas dos valores de Pc e Pm produziram melhores resultados (ou seja, menor média de iterações necessárias e menor número de casos que não encontraram o valor ótimo global) que a utilização de mudanças graduais. Desta forma, os AG's com ajuste em "degrau" produziram melhores resultados que os AGN's, nos estudos realizados, assim como AGN's com mudanças mais bruscas entre os valores iniciais e finais de Pm e Pc produziram melhores resultados que AGN's com mudanças mais graduais.

\subsection{Cumprimento dos Objetivos Propostos}

Foram analisados diversos trabalhos da literatura, que utilizaram SIN's para ajustar, em tempo de execução, parâmetros de AG's, bem como os métodos utilizados em cada trabalho para melhorar critérios pré-definidos de desempenho.

Algoritmos Genéticos foram implementados em uma ferramenta computacional, de estrutura suficientemente modular para permitir sua alteração, para a utilização de diferentes operadores de seleção, de cruzamento, e de mutação, bem como sua utilização para diferentes problemas e representações de indivíduos. Conforme especificado nos objetivos do trabalho e metodologia, esta ferramenta foi utilizada extensivamente na solução de dois 
problemas tipicamente abordados com AG's: a minimização de funções e o problema do caixeiro viajante.

Esta mesma ferramenta foi modificada, de forma a permitir o ajuste de seus parâmetros em tempo de execução, tanto por comportamentos determinísticos em função do número de gerações, quanto pela utilização de sistemas de inferência nebulosos (para este fim, foi adaptada grande parte do código do "Controlador Universal Nebuloso" desenvolvido em [Burdelis, Cepukas, Sofiatti - 2001]).

Em diversos experimentos, foram utilizados comportamentos determinísticos para Pm e Pc, em função do tamanho da população e do número de gerações, nos moldes dos comportamentos exemplificados em [Xu, Vukovich - 1993] e [Xu, Vukovich - 1994]. No presente trabalho não foram encontradas curvas determinísticas para Pm e Pc nos moldes dos exemplos dos trabalhos [Xu, Vukovich - 1993] e [Xu, Vukovich - 1994] que gerassem resultados melhores que os obtidos nas melhores configurações de AG's "clássicos". Porém, as diversas tentativas empregadas levam a crer que estes comportamentos determinísticos buscados são muito específicos, e de difícil obtenção sem a realização de medidas diretamente da população de indivíduos do AG.

Assim sendo, uma extensa análise foi realizada, para diferentes tamanhos de população, e também para os diferentes problemas abordados (Caixeiro Viajante e Minimização de Funções), sobre o comportamento de AG's "clássicos" sob diversas configurações diferentes de Pm e Pc. Estas medidas levaram à observação de diferentes desempenhos de AG's segundo duas grandezas: a média de iterações realizadas até a obtenção do valor ótimo global buscado, e a variação da qualidade dos resultados perante diferentes seqüências de números aleatórios utilizadas na operação dos AG's (levando a diversos casos que não encontravam o valor ótimo global procurado em até quantidades muito grandes de iterações).

Uma nova proposta foi realizada, ainda mantendo a abordagem de Controle Dinâmico de Parâmetros ("Dynamic Parameter Control"), para melhorar o desempenho dos AG's segundo os dois critérios observados. Esta proposta foi realizada utilizando-se duas possíveis abordagens: uma primeira determinística, alterando os valores de Pm e Pc em função do número de iterações, a qual foi denominada "ajuste em degrau"; e uma segunda, com base nos resultados da primeira, envolvendo sistemas híbridos, que empregam SIN's para regular os parâmetros Pm e Pc de AG's em tempo de execução.

As duas abordagens apresentaram resultados relevantes para populações suficientemente grandes, sendo que o tamanho necessário da população para a obtenção estes resultados variou em função do problema e da implementação do AG.

É esperado que este trabalho, por utilizar sistemas híbridos que envolvem CF e CE, possa servir de subsídio para futuros trabalhos de investigação de um modelo unificado para 
a IC, permitindo: a observação de como as diferentes técnicas interagem entre si, e a observação dos limites da área de atuação de cada técnica.

Além disso, como um estudo analítico paralelo (mas necessário para a obtenção de resultados) foram colocadas em contraste diferentes configurações dos parâmetros $\mathrm{Pm} e$ Pc, para os 2 AG's implementados, para resolver as instâncias, utilizadas no presente trabalho, dos problemas: do "Caixeiro Viajante" e de "Minimização de Funções".

\subsection{Contribuições do Trabalho}

O presente trabalho realizou uma análise detalhada da aplicação prática de Controle Dinâmico de Parâmetros em AG's, utilizando-se SIN's. Embora as medidas utilizadas, para a aplicação deste tipo de controle de parâmetros em AG's, sejam simples e de fácil obtenção, observa-se que a aplicação desta técnica para diferentes problemas não é trivial, uma vez que: não se tem medidas diretas do estado da população (para basear novas ações de controle); e as curvas de interesse (do comportamento dos parâmetros ajustados) dependem do problema abordado e da implementação utilizada.

Avaliou-se o comportamento sob o ponto de vista de duas medidas de desempenho (média de iterações necessárias para a obtenção do valor ótimo global; e número de casos que não encontraram este valor em até diferentes faixas de iterações), para diferentes configurações de AG's "clássicos". Estes foram implementados especificamente para resolver dois problemas: a minimização de funções; e Caixeiro Viajante. A partir destes dados, observa-se que diferentes configurações de $\mathrm{Pm}, \mathrm{Pc}$ e tamanho de população para AG's podem produzir resultados com características completamente diferentes, sob o ponto de vista destas duas medidas de desempenho mencionadas.

O presente trabalho também propôs uma técnica de "Controle Dinâmico de Parâmetros" para AG's, baseada nestas medidas realizadas, alterando-se convenientemente os valores de Pm e Pc para se obter bons resultados, para ambas as medidas de desempenho já mencionadas, ao mesmo tempo. Este tipo de ajuste de parâmetros foi implementado por meio de alterações determinísticas de Pm e Pc (denominada neste trabalho "Ajuste em Degrau"), e também utilizando-se de um sistema híbrido, empregando SIN's para regular os parâmetros dos AG's em tempo de execução.

É importante notar que uma grande vantagem do método aqui empregado é o fato de o mesmo ser suficientemente claro e bem determinado, para ser reutilizado em trabalhos futuros. Para isso, basta: realizar a análise do comportamento do AG "clássico" envolvido, perante diferentes valores de $\mathrm{Pm}$ e $\mathrm{Pc}$; identificar quais as configurações que minimizam cada uma das grandezas mencionadas; e realizar a alteração, em tempo de execução, da 
configuração que gera a menor média para a configuração que gera o menor número de casos (incapazes de encontrar o valor ótimo global) - embora a iteração em que esta mudança deve ocorrer necessita ser determinada empiricamente.

A abordagem aqui proposta, de "Controle Dinâmico de Parâmetros", não elimina nem reduz a necessidade da existência de um operador humano para supervisionar e propor alterações na configuração do sistema. Isto ocorre porque, embora o sistema final realize alterações convenientes nos valores de Pm e Pc (de modo automático), ainda se faz necessária a existência do operador humano para investigar e encontrar o comportamento devido do mecanismo que realiza o ajuste automático de parâmetros (no caso específico deste trabalho, encontrar os valores a serem utilizados para o SIN e/ou para o sistema de ajuste em "degrau").

\subsection{Trabalhos Futuros}

Em seguida apresentam-se algumas sugestões de possíveis trabalhos futuros:

- Investigação formal do tamanho mínimo de população, necessário e suficiente para a utilização do Controle Dinâmico de Parâmetros aqui desenvolvido, em função do problema abordado pelo AG, sua implementação e suas condições de operação.

- Investigação de condições formais para nortear a aplicação de curvas decrescentes para a Pm e curvas crescentes para a Pc, em tempo de execução e em função do número de gerações, para diferentes problemas e implementações.

- Para a pesquisa de um modelo unificado para a IC, buscar intersecções entre as áreas de atuação da CE e da CF. Uma sugestão é a utilização do planejamento de trajetórias por AG's, conforme realizado em [Xu, Vukovich - 1994], e a utilização de SIN's para controlar trajetórias nas mesmas condições. Uma possível desvantagem deste tipo de aplicação é que, para trajetórias suficientemente grandes, os indivíduos do AG utilizado podem se tornar muito grandes, o que tornara seu processamento computacional muito pesado.

- Investigação de regras, para o "Controle Adaptativo de Parâmetros" de AG's (ou seja, utilizando medidas do estado da população para a inferência de alterações nos parâmetros do $A G$ ), em tempo de execução, que levem em conta: não apenas a média de iterações (necessárias para se encontrar soluções de elevada aptidão), mas também a resposta do sistema a diferentes seqüências de números aleatórios em sua operação, contabilizando também o número de casos (incapazes de 
encontrar soluções com a aptidão desejada para quantidades elevadas de iterações).

- Neste trabalho, foram utilizadas apenas funções de pertinência (para conjuntos nebulosos) de 2 dimensões (ou seja, de $\mathfrak{R} \rightarrow \mathfrak{R}$ ). Utilizando-se pares de valores para Pm e Pc, pode-se propor funções de pertinência de 3 dimensões (ou seja, de $\mathfrak{R}^{2} \rightarrow \mathfrak{R}$ ), e investigar se esta abordagem poderia obter sistemas híbridos com desempenhos ainda maiores.

- Neste trabalho foram abordadas apenas instâncias dos problemas: PCV e PMF. Futuros trabalhos podem tentar realizar a implementação das técnicas aqui propostas para outros problemas. 


\section{Referências}

[Andrade - 2002] ANDRADE, M. T. C. de. Uma contribuição à pesquisa em inteligência computacional. Tese (Livre Docência) - Escola Politécnica da Universidade de São Paulo, São Paulo, 2002.

[Arnone, Dell'Orto, Tettamanzi - 1994] ARNONE, S.; DELL'ORTO, M.; TETTAMANZI, A. Toward a fuzzy government of genetic populations. IEEE Conference on Tools with Artificial Intelligence, v. 6, p.585-591, 1994.

[Bäck - 1996 apud Rezende - 2003] BÄCK, T. Evolutionary Algorithms in Theory and Practice. Oxford University Press, 1996.

[Bäck - 1998 apud Thierens - 2002] BÄCK, T. An overview of parameter control methods by self-adaptation in evolutionary algorithms. Fundamenta informaticae 34, 1-15, 1998.

[Baker - 1985 apud Herrera, Lozano - 1996] BAKER J. E. Adaptive selection methods for genetic algorithms, em: Proc. First Int. Conf. on Genetic Algorithms (L. Erlbaum Associates, Hillsdale, MA, 1985) 101-111.

[Bramlette - 1991 apud Herrera, Lozano - 1996] BRAMLETTE, M. F. Initialization, mutation and selection methods in genetic algorithms for function optimization, em: BELEW, R.; BOOKER, L.B., Eds., Proc. of the Fourth Int. Conf. on Genetic Algorithms (Morgan Kaufmmann, San Mateo, 1991) 100-107.

[Burdelis, Cepukas, Sofiatti - 2001] BURDELIS, M. A. P.; CEPUKAS, A. L.; SOFIATTI, R. A. Ambiente de Desenvolvimento de Controladores Nebulosos. Trabalho de conclusão de curso (Graduação) - Escola Politécnica da Universidade de São Paulo, São Paulo, 2001.

[Caversan - 2006] CAVERSAN, F. L. Exploração de relações entre técnicas simbólicas e conexionistas da inteligência computacional. Dissertação (Mestrado) - Escola Politécnica da Universidade de São Paulo, São Paulo, 2006. 
[Caversan, Andrade - 2005] CAVERSAN, F. L.; ANDRADE, M. T. C. Exploração de relações isomórficas entre técnicas simbólicas e conexionistas da inteligência computacional. INFOCOMP Journal of Computer Science, v. 4, n. 1, p. 19-25, 2005.

[CM - 1992 apud Arnone, Dell'Orto, Tettamanzi - 1994] Thinking Machines Corporation, Cambridge, Massachussets. CM User's Guide, edição da versão 6.1, outubro, 1991. Reimpresso com correções em dezembro de 1992.

[Crawford - 1992] CRAWFORD, K. D. Solving the n-queens problem using genetic algorithms. Proceedings of the ACM/SIGAPP Symposium on Applied Computing, ACM Press, New York, NY, USA, p. 1039-1047, 1992.

[DeJong - 1975 apud Lee, Takagi - 1993] DEJONG, K. A. An analysis of the behavior of a class of genetic adaptive systems. Dissertação de Doutorado, University of Michigan, University Microfilms 76- 9381, 1975.

[Eberhart, Shi - 2007] EBERHART, R. C.; SHI, Y. Computational Intelligence: Concepts to Implementations. Elsevier Inc, 2007.

[Fialho - 2007] FIALHO, A. R. S. Exploração de Relações Entre as Técnicas Nebulosas e Evolutivas da Inteligência Computacional. Dissertação (Mestrado) - Escola Politécnica da Universidade de São Paulo, São Paulo, 2007.

[Fogel - 1995 apud Eberhart, Shi - 2007] FOGEL, D. B. Evolutionary Computation: Toward a New Philosophy of Machine Intelligence. IEEE Press, Piscataway, NJ, 1995

[Fogel, Fukuda, Guan - 1999] FOGEL, D. B.; FUKUDA, T.; GUAN, L. Scanning the special issue/technology on computational intelligence. Proceedings of the IEEE, v. 87, n. 9, p. 1415-1422, 1999.

[Fogel, Owens, Walsh - 1966] FOGEL, L. J.; OWENS, A. J.; WALSH, M. J. Artificial Intelligence Through Simulated Evolution. New York: John Wiley \& Sons, Inc., 1966.

[Fogarty - 1989 apud Herrera, Lozano - 1996] FOGARTY, T. C. Varying the probability of mutation in the genetic algorithm, em: SCHAFFER, J. D., Ed., Proc. of the Third Int. Conf. on Genetic Algorithms (Morgan Kaufmann Publishers, San Mateo, 1989) 104-109. 
[Gajski, Kuhn - 1983] GAJSKI, D.; KUHN, R. H. New VLSI tools. IEEE Computer, v.16, p. 11-14, 1983.

[Herrera, Lozano - 1996] HERRERA, F.; LOZANO, M. Adaptation of genetic algorithms parameters based on fuzzy logic controllers. In F. Herrera and J.L. Verdegay, editors, Genetic Algorithms and Soft Computing, pages 95 - 125. Physica Verlag, 1996.

[Hinterding, Michalewicz, Eiben - 1997 apud Thierens - 2002] HINTERDING, R.; MICHALEWICZ, Z.; EIBEN, G. Adaptation in Evolutionary Computation: A Survey, Proc. of the 1997 IEEE Conference on Evolutionary Computation, pp. 65-69, IEEE Press, 1997.

[Holland - 1975] HOLLAND, J. Adaptation In Natural And Artificial Systems. Ann Arbor: The University of Michigan Press, 1975.

[Jordan, Russell - 1999] JORDAN M.I.; RUSSELL S. Computational Intelligence, prefácio de The Mit Encyclopedia Of The Cognitive Sciences. The MIT Press, Massachussets, 1999.

[Konar - 2000] KONAR, A. Artificial Intelligence and Soft Computing: Behavioral and Cognitive Modeling of the Human Brain. CRC Press, Inc, Boca Raton, FL, USA

[Koza - 1992] KOZA, J. R. Genetic Programming: On The Programming Of Computers By Means Of Natural Selection. Cambridge, MA: The MIT Press, 1992.

[Lee - 1990] LEE, C. C. Fuzzy Logic in Control Systems: Fuzzy Logic Controller - Part I, IEEE Transactions on Systems, Man and Cybernetics, Vol. 20, no 2, pp. 404-418, March/April 1990.

[Lee, Takagi - 1993] LEE, C. C.; TAKAGI, H. Dynamic control of genetic algorithms using fuzzy logic techniques. S. Forrest, Ed., Proc. of the Fifth Int. Conf. on Genetic Algorithms (Morgan Kaufmmann, San Mateo, 1993) 76-83.

[Li, Lucasius, Kateman - 1992 apud Herrera, Lozano - 1996] LI, T-H.; LUCASIUS, C. B.; KATEMAN, G. Optimization of calibration data with the dynamic genetic algorithm. Analytica Chimica Acta 2768 (1992) 123-134. 
[Mahfoud - 1995 apud Herrera, Lozano - 1996] MAHFOUD, S. W. Niching methods for genetic algorithms. IlliGAL Report No. 95001, Urbana: University of Illinois, Illinois Genetic Algorithms Laboratory (1995).

[Maturana, Saubion - 2007] MATURANA, J.; SAUBION, F Towards a generic control strategy for Evolutionary Algorithms: an adaptive fuzzy-learning approach .Evolutionary Computation, 2007. CEC 2007. IEEE Congress on Volume, Issue , 25-28 Sept. 2007 Page(s):4546 - 4553

[MicroGA - 1992 apud Xu, Vukovich - 1993] MicroGA, Emergent Behavior Ltd., Palo Alto, CA, USA, 1992.

[Obitko, Slavík - 1999] OBITKO, M.; SLAVÍK, P. Visualization of Genetic Algorithms in a Learning Environment. Spring Conference on Computer Graphics, SCCG'99. Bratislava: Comenius University, 1999, p. 101-106. ISBN 80-223-1357-2.

[Potts, Giddens, Yadav - 1994 apud Herrera, Lozano - 1996] POTTS, J. C.; GIDDENS, T. D.; YADAV, S. D. The development and evaluation of an improved genetic algorithm based on migration and artificial selection. IEEE Trans. On Systems, Man, and Cybernetics 24 (1994) 73-86.

[Potvin - 1996] POTVIN, J.-Y. Genetic algorithms for the traveling salesman problem. Annals of Operations Research, v. 63, n. 3, p. 337-370, jun 1996.

[Rechenberg - 1965] RECHENBERG, I. Cybernetic solution path of an experimental problem. UK: Royal Aircraft Establishment, 1965.

[Rezende - 2003] REZENDE, S. O. Sistemas inteligentes: fundamentos e aplicações. Barueri, SP. Editora Manole, 2003.

[Shaw, Simões - 1999] SIMÕES, M. G.; SHAW, I. S. Controle e Modelagem Fuzzy. São Paulo, SP. Editora Edgard Blücher, 1999.

[Starkweather et al. - 1991 apud Potvin - 1996] STARKWEATHER, T.; McDANIEL, S.; MATHIAS, K.; WHITLEY, D.; WHITLEY, C. A Comparison of Genetic Sequencing Operators, in Proceedings of the Fourth Int. Conf. on Genetic Algorithms (ICGA'91), University of California at San Diego, San Diego, CA, pp. 69-76. 
[Thierens - 2002] THIERENS, D. Adaptive mutation rate control schemes in genetic algorithms, Department of Information and Computing Sciences, Utrecht University, Technical Report, 2002.

[van Eck et al. - 2006] van ECK, N.J.; WALTMAN, L.; van den BERG, J.; KAYMAK, U. Visualizing the computational intelligence field. [Application Notes] Computational Intelligence Magazine, IEEE (1): 6-10, 2006.

[Whitley - 1994] Whitley, D. A Genetic Algorithm Tutorial. Statistics and Computing (4):6585, 1994.

[Wilson, Keil - 1999] WILSON, R. A.; KEIL, F. C. The Mit Encyclopedia Of The Cognitive Sciences. The MIT Press, Massachussets, 1999.

[Xu, Vukovich - 1993] - XU, H. Y.; VUKOVICH, G. A fuzzy genetic algorithm with effective search and optimization. Proc. of 1993 International Joint Conference on Neural Networks (1993) 2967-2970.

[Xu, Vukovich - 1994] - XU, H. Y.; VUKOVICH, G. Fuzzy evolutionary algorithms and automatic robot trajectory generation. Proc. of The First IEEE Conference on Evolutionary Computation (1994) 595-600.

[Zadeh - 1965] ZADEH, L. A. Fuzzy sets. Information Control, v. 8, p. 338-353, 1965. 


\section{Apêndice A - Tabelas de Experimentos com AG}

Experimentos com o AG desenvolvido para solucionar o problema do "Caixeiro Viajante":

- Para tamanho da população $=100$

\begin{tabular}{|c|c|c|c|c|c|c|c|c|c|}
\hline $\mathrm{Pc}$ & $\mathrm{Pm}$ & Media & \begin{tabular}{|l|} 
NaoAte25 \\
\end{tabular} & \begin{tabular}{|l|} 
NaoAte50 \\
\end{tabular} & \begin{tabular}{|l|} 
NaoAte100 \\
\end{tabular} & NaoA te200 & \begin{tabular}{|l|} 
NaoAte500 \\
\end{tabular} & \begin{tabular}{|l|} 
NaoAte700 \\
\end{tabular} & NaoAte 1000 \\
\hline 0.50 & 0.10000 & 47.17 & 566 & 293 & 114 & 20 & 0 & 0 & 0 \\
\hline 0.50 & 0.08000 & 30.44 & 395 & 146 & 37 & 1 & 0 & 0 & 0 \\
\hline 0.50 & 0.06400 & 21.53 & 252 & 70 & 8 & 1 & 0 & 0 & 0 \\
\hline 0.50 & 0.05120 & 18.31 & 157 & 46 & 4 & 0 & 0 & 0 & 0 \\
\hline 0.50 & 0.04096 & 22.95 & 136 & 84 & 46 & 14 & 0 & 0 & 0 \\
\hline 0.50 & 0.03277 & 35.86 & 117 & 95 & 71 & 50 & 14 & 5 & 2 \\
\hline 0.50 & 0.02621 & 46.58 & 122 & 117 & 107 & 96 & 57 & 43 & 29 \\
\hline 0.50 & 0.02097 & 38.61 & 128 & 122 & 118 & 111 & 88 & 81 & 67 \\
\hline 0.50 & 0.01678 & 20.72 & 113 & 109 & 107 & 104 & 99 & 93 & 89 \\
\hline 0.50 & 0.01342 & 18.45 & 124 & 121 & 120 & 118 & 112 & 111 & 106 \\
\hline 0.50 & 0.01074 & 12.22 & 132 & 132 & 132 & 129 & 127 & 127 & 126 \\
\hline 0.50 & 0.00859 & 11.08 & 129 & 123 & 123 & 123 & 121 & 120 & 120 \\
\hline 0.50 & 0.00687 & 10.98 & 142 & 132 & 131 & 131 & 130 & 130 & 129 \\
\hline 0.50 & 0.00550 & 9.83 & 136 & 130 & 130 & 129 & 129 & 129 & 129 \\
\hline 0.50 & 0.00440 & 10.67 & 141 & 130 & 129 & 128 & 128 & 127 & 127 \\
\hline 0.50 & 0.00352 & 9.81 & 160 & 149 & 146 & 146 & 146 & 146 & 146 \\
\hline 0.50 & 0.00281 & 10.12 & 142 & 131 & 129 & 129 & 129 & 128 & 128 \\
\hline 0.50 & 0.00225 & 11.65 & 170 & 155 & 149 & 149 & 148 & 148 & 147 \\
\hline 0.50 & 0.00180 & 9.98 & 134 & 124 & 118 & 117 & 117 & 117 & 117 \\
\hline 0.50 & 0.00000 & 9.13 & 171 & 171 & 171 & 171 & 171 & 171 & 171 \\
\hline 0.55 & 0.10000 & 45.06 & 542 & 268 & 103 & 18 & 0 & 0 & 0 \\
\hline 0.55 & 0.08000 & 28.10 & 378 & 137 & 22 & 0 & 0 & 0 & 0 \\
\hline 0.55 & 0.06400 & 21.61 & 262 & 67 & 8 & 0 & 0 & 0 & 0 \\
\hline 0.55 & 0.05120 & 16.68 & 126 & 31 & 0 & 0 & 0 & 0 & 0 \\
\hline 0.55 & 0.04096 & 18.27 & 98 & 50 & 24 & 6 & 0 & 0 & 0 \\
\hline 0.55 & 0.03277 & 27.54 & 97 & 79 & 52 & 34 & 5 & 0 & 0 \\
\hline 0.55 & 0.02621 & 35.50 & 90 & 81 & 70 & 62 & 37 & 24 & 15 \\
\hline 0.55 & 0.02097 & 37.14 & 118 & 116 & 112 & 104 & 88 & 79 & 65 \\
\hline 0.55 & 0.01678 & 22.18 & 117 & 114 & 111 & 108 & 104 & 99 & 92 \\
\hline 0.55 & 0.01342 & \begin{tabular}{|l|}
14.91 \\
\end{tabular} & 106 & 103 & 102 & 100 & 100 & 99 & 95 \\
\hline 0.55 & 0.01074 & 14.33 & 114 & 111 & 111 & 111 & 105 & 105 & 103 \\
\hline 0.55 & 0.00859 & \begin{tabular}{|l|}
12.27 \\
\end{tabular} & 114 & 110 & 110 & 108 & 106 & 105 & 104 \\
\hline 0.55 & 0.00687 & 10.31 & 114 & 112 & 112 & 112 & 112 & 111 & 111 \\
\hline 0.55 & 0.00550 & 10.15 & 135 & 128 & 127 & 127 & 126 & 126 & 126 \\
\hline 0.55 & 0.00440 & \begin{tabular}{|l|} 
\\
\end{tabular} & 137 & 130 & 129 & 128 & 128 & 128 & 127 \\
\hline 0.55 & 0.00352 & 9.51 & 118 & 113 & 112 & 111 & 111 & 111 & 111 \\
\hline 0.55 & 0.00281 & 9.53 & 115 & 111 & 109 & 108 & 108 & 108 & 108 \\
\hline 0.55 & 0.00225 & 9.67 & 119 & 113 & 106 & 106 & 106 & 106 & 106 \\
\hline 0.55 & 0.00180 & 9.52 & 128 & 120 & 117 & 117 & 117 & 117 & 117 \\
\hline 0.55 & 0.00000 & 8.94 & 125 & 125 & 125 & 125 & 125 & 125 & 125 \\
\hline 0.60 & 0.10000 & 42.19 & 545 & 245 & 95 & 15 & 0 & 0 & 0 \\
\hline 0.60 & 0.08000 & 28.11 & 386 & 128 & 23 & 1 & 0 & 0 & 0 \\
\hline 0.60 & 0.06400 & 21.12 & 256 & 56 & 4 & 0 & 0 & 0 & 0 \\
\hline 0.60 & 0.05120 & 16.79 & 129 & 26 & 4 & 0 & 0 & 0 & 0 \\
\hline 0.60 & 0.04096 & 17.69 & 104 & 50 & 19 & 3 & 0 & 0 & 0 \\
\hline 0.60 & 0.03277 & 26.63 & 91 & 67 & 55 & 32 & 4 & 1 & 0 \\
\hline 0.60 & 0.02621 & 40.60 & 91 & 86 & 79 & 64 & 33 & 22 & 9 \\
\hline 0.60 & 0.02097 & 22.59 & 72 & 69 & 60 & 58 & 49 & 42 & 38 \\
\hline 0.60 & 0.01678 & 19.20 & 94 & 94 & 91 & 87 & 81 & 79 & 73 \\
\hline 0.60 & 0.01342 & 18.90 & 98 & 96 & 95 & 94 & 88 & 85 & 80 \\
\hline 0.60 & 0.01074 & 11.63 & 90 & 88 & 88 & 88 & 86 & 85 & 84 \\
\hline 0.60 & 0.00859 & 12.70 & 98 & 96 & 96 & 96 & 94 & 93 & 91 \\
\hline 0.60 & 0.00687 & 9.29 & 95 & 93 & 93 & 92 & 92 & 92 & 92 \\
\hline 0.60 & 0.00550 & 9.48 & 99 & 93 & 93 & 93 & 92 & 92 & 92 \\
\hline 0.60 & 0.00440 & 9.56 & 112 & 106 & 105 & 103 & 103 & 103 & 103 \\
\hline 0.60 & 0.00352 & 9.17 & 117 & 108 & 107 & 107 & 107 & 107 & 107 \\
\hline 0.60 & 0.00281 & 10.20 & 102 & 93 & 93 & 92 & 90 & 90 & 90 \\
\hline 0.60 & 0.00225 & 9.07 & 108 & 105 & 104 & 104 & 104 & 104 & 104 \\
\hline 0.60 & 0.00180 & 9.14 & 102 & 99 & 98 & 98 & 98 & 98 & 98 \\
\hline 0.60 & 0.00000 & 8.70 & 123 & 123 & 123 & 123 & 123 & 123 & 123 \\
\hline
\end{tabular}


- Para tamanho da população = 100 (cont.)

\begin{tabular}{|c|c|c|c|c|c|c|c|c|c|}
\hline $\mathrm{Pc}$ & $\mathrm{Pm}$ & Media & NaoAte25 & NaoAte50 & NaoAte100 & NaoAte200 & NaoAte500 & NaoAte700 & NaoAte 1000 \\
\hline 0.65 & 0.10000 & 45.18 & 545 & 291 & 114 & 14 & 0 & 0 & 0 \\
\hline 0.65 & 0.08000 & 28.69 & 378 & 129 & 34 & 0 & 0 & 0 & 0 \\
\hline 0.65 & 0.06400 & 20.76 & 256 & 58 & 3 & 0 & 0 & 0 & 0 \\
\hline 0.65 & 0.05120 & 16.33 & 145 & 21 & 0 & 0 & 0 & 0 & 0 \\
\hline \begin{tabular}{|l|}
0.65 \\
\end{tabular} & 0.04096 & 15.18 & 70 & 22 & 11 & 2 & 0 & 0 & 0 \\
\hline \begin{tabular}{|l|}
0.65 \\
\end{tabular} & 0.03277 & 22.78 & 72 & 61 & 43 & 22 & 3 & 1 & 0 \\
\hline 0.65 & 0.02621 & 33.46 & 79 & 71 & 63 & 46 & 25 & 14 & 7 \\
\hline 0.65 & 0.02097 & 29.35 & 80 & 79 & 74 & 66 & 53 & 44 & 35 \\
\hline 0.65 & 0.01678 & 24.67 & 89 & 87 & 86 & 82 & 75 & 70 & 60 \\
\hline \begin{tabular}{|l|}
0.65 \\
\end{tabular} & 0.01342 & 14.46 & 85 & 84 & 82 & 80 & 76 & 75 & 72 \\
\hline 0.65 & 0.01074 & 10.97 & 78 & 76 & 76 & 76 & 75 & 74 & 73 \\
\hline 0.65 & 0.00859 & 10.71 & 79 & 79 & 78 & 78 & 76 & 76 & 75 \\
\hline 0.65 & 0.00687 & 9.74 & 93 & 88 & 88 & 88 & 88 & 87 & 87 \\
\hline 0.65 & 0.00550 & 9.06 & 81 & 78 & 78 & 78 & 78 & 78 & 78 \\
\hline \begin{tabular}{|l|}
0.65 \\
\end{tabular} & 0.00440 & 8.98 & 94 & 91 & 91 & 91 & 91 & 91 & 91 \\
\hline 0.65 & 0.00352 & 9.17 & 88 & 81 & 81 & 81 & 81 & 81 & 81 \\
\hline \begin{tabular}{|l|}
0.65 \\
\end{tabular} & 0.00281 & 8.88 & 98 & 90 & 90 & 90 & 90 & 90 & 90 \\
\hline 0.65 & 0.00225 & 9.10 & 74 & 69 & 69 & 69 & 68 & 68 & 68 \\
\hline 0.65 & 0.00180 & 9.07 & 94 & 85 & 83 & 83 & 83 & 83 & 83 \\
\hline 0.65 & 0.00000 & 8.78 & 92 & 92 & 92 & 92 & 92 & 92 & 92 \\
\hline 0.70 & 0.10000 & 45.76 & 576 & 279 & 108 & 17 & 0 & 0 & 0 \\
\hline 0.70 & 0.08000 & 28.16 & 387 & 136 & 25 & 2 & 0 & 0 & 0 \\
\hline 0.70 & 0.06400 & 20.63 & 236 & 56 & 4 & 0 & 0 & 0 & 0 \\
\hline \begin{tabular}{|l|}
0.70 \\
\end{tabular} & 0.05120 & \begin{tabular}{|l|}
16.78 \\
\end{tabular} & 143 & 20 & 1 & 0 & 0 & 0 & 0 \\
\hline \begin{tabular}{|l|}
0.70 \\
\end{tabular} & 0.04096 & \begin{tabular}{|l|l}
14.78 \\
\end{tabular} & 80 & 26 & 6 & 0 & 0 & 0 & 0 \\
\hline 0.70 & 0.03277 & 18.54 & 67 & 37 & 20 & 12 & 2 & 1 & 0 \\
\hline 0.70 & 0.02621 & 23.39 & 47 & 42 & 36 & 27 & 14 & 8 & 4 \\
\hline 0.70 & 0.02097 & 32.51 & 75 & 74 & 70 & 65 & 48 & 38 & 27 \\
\hline \begin{tabular}{|l|}
0.70 \\
\end{tabular} & 0.01678 & 17.55 & 72 & 72 & 72 & 70 & 63 & 60 & 57 \\
\hline 0.70 & 0.01342 & 16.12 & 51 & 50 & 50 & 46 & 44 & 42 & 37 \\
\hline \begin{tabular}{|l|}
0.70 \\
\end{tabular} & 0.01074 & 14.38 & 60 & 59 & 59 & 58 & 56 & 53 & 50 \\
\hline \begin{tabular}{|l|}
0.70 \\
\end{tabular} & 0.00859 & 10.65 & 62 & 61 & 61 & 61 & 59 & 59 & 58 \\
\hline 0.70 & 0.00687 & 9.78 & 64 & 63 & 63 & 62 & 62 & 62 & 61 \\
\hline \begin{tabular}{|l|}
0.70 \\
\end{tabular} & 0.00550 & 8.98 & 73 & 72 & 72 & 72 & 72 & 72 & 72 \\
\hline \begin{tabular}{|l|}
0.70 \\
\end{tabular} & 0.00440 & 9.72 & 66 & 63 & 63 & 63 & 63 & 63 & 62 \\
\hline \begin{tabular}{|l|}
0.70 \\
\end{tabular} & 0.00352 & 8.69 & 63 & 60 & 60 & 60 & 60 & 60 & 60 \\
\hline 0.70 & 0.00281 & 8.82 & 72 & 68 & 68 & 68 & 68 & 68 & 68 \\
\hline 0.70 & 0.00225 & 8.97 & 71 & 67 & 66 & 66 & 66 & 66 & 66 \\
\hline 0.70 & 0.00180 & 8.68 & 71 & 69 & 67 & 67 & 67 & 67 & 67 \\
\hline 0.70 & 0.00000 & 8.37 & 87 & 87 & 87 & 87 & 87 & 87 & 87 \\
\hline 0.75 & 0.10000 & 44.47 & 561 & 263 & 109 & 20 & 0 & 0 & 0 \\
\hline 0.75 & 0.08000 & 28.80 & 368 & 154 & 29 & 0 & 0 & 0 & 0 \\
\hline 0.75 & 0.06400 & 20.91 & 265 & 65 & 3 & 0 & 0 & 0 & 0 \\
\hline \begin{tabular}{|l|}
0.75 \\
\end{tabular} & 0.05120 & 15.99 & 133 & 22 & 0 & 0 & 0 & 0 & 0 \\
\hline 0.75 & 0.04096 & 13.70 & 78 & 10 & 0 & 0 & 0 & 0 & 0 \\
\hline 0.75 & 0.03277 & 15.20 & 66 & 30 & 15 & 2 & 0 & 0 & 0 \\
\hline 0.75 & 0.02621 & 25.78 & 45 & 44 & 36 & 29 & 16 & 6 & 1 \\
\hline 0.75 & 0.02097 & 24.03 & 51 & 49 & 45 & 42 & 31 & 24 & 17 \\
\hline 0.75 & 0.01678 & 17.06 & 49 & 49 & 47 & 45 & 43 & 38 & 34 \\
\hline 0.75 & 0.01342 & 11.36 & 65 & 64 & 64 & 64 & 64 & 61 & 61 \\
\hline \begin{tabular}{|l|}
0.75 \\
\end{tabular} & 0.01074 & 14.81 & 77 & 77 & 77 & 76 & 70 & 67 & 65 \\
\hline 0.75 & 0.00859 & 10.96 & 62 & 61 & 61 & 61 & 60 & 59 & 58 \\
\hline 0.75 & 0.00687 & 10.65 & 63 & 62 & 61 & 61 & 59 & 59 & 58 \\
\hline \begin{tabular}{|l|}
0.75 \\
\end{tabular} & 0.00550 & 8.76 & 61 & 58 & 57 & 57 & 57 & 57 & 57 \\
\hline 0.75 & 0.00440 & 8.75 & 68 & 64 & 64 & 64 & 64 & 64 & 64 \\
\hline 0.75 & 0.00352 & 8.82 & 52 & 49 & 48 & 48 & 48 & 48 & 48 \\
\hline 0.75 & 0.00281 & 9.09 & 80 & 74 & 70 & 70 & 70 & 70 & 70 \\
\hline 0.75 & 0.00225 & 8.85 & 67 & 63 & 63 & 63 & 63 & 63 & 63 \\
\hline 0.75 & 0.00180 & 8.74 & 81 & 78 & 78 & 77 & 77 & 77 & 77 \\
\hline 0.75 & 0.00000 & 8.36 & 84 & 84 & 84 & 84 & 84 & 84 & 84 \\
\hline
\end{tabular}


- Para tamanho da população $=100$ (cont.)

\begin{tabular}{|c|c|c|c|c|c|c|c|c|c|}
\hline Pc & Pm & Media & NaoAte25 & NaoAte50 & NaoAte100 & NaoAte200 & NaoAte500 & NaoAte700 & NaoAte1000 \\
\hline
\end{tabular}

\begin{tabular}{|c|c|c|c|c|c|c|c|c|c|}
\hline & & & & & & & & & \\
\hline 0.80 & 0.10000 & 42.70 & 538 & 247 & 87 & 21 & 0 & 0 & 0 \\
\hline 0.80 & 0.08000 & 30.58 & 404 & 147 & 36 & 1 & 0 & 0 & 0 \\
\hline 0.80 & 0.06400 & 19.92 & 241 & \begin{tabular}{l|l}
42 \\
\end{tabular} & 4 & 0 & 0 & 0 & 7 \\
\hline 0.80 & 0.05120 & 15.61 & 122 & 14 & 0 & 0 & 0 & 0 & 0 \\
\hline 0.80 & 0.04096 & 13.42 & 68 & 6 & 0 & 0 & 0 & 0 & 0 \\
\hline 0.80 & 0.03277 & 14.49 & 44 & 22 & 15 & 4 & 0 & 0 & 0 \\
\hline 0.80 & 0.02621 & 19.40 & 41 & 34 & 28 & 20 & 4 & 2 & 0 \\
\hline 0.80 & 0.02097 & 21.26 & 43 & 42 & 41 & 39 & 24 & 18 & 15 \\
\hline 0.80 & 0.01678 & 17.30 & 55 & 53 & 51 & 48 & 42 & 37 & 35 \\
\hline 0.80 & 0.01342 & 15.03 & 42 & 41 & 39 & 39 & 35 & 29 & 28 \\
\hline 0.80 & 0.01074 & 11.59 & 45 & 45 & 45 & 45 & 43 & 43 & 41 \\
\hline 0.80 & 0.00859 & 9.70 & 54 & 54 & 54 & 54 & 52 & 52 & 52 \\
\hline 0.80 & 0.00687 & 8.70 & 57 & 56 & 56 & 56 & 56 & 56 & 56 \\
\hline 0.80 & 0.00550 & 8.75 & 37 & 37 & 37 & 37 & 37 & 37 & 37 \\
\hline 0.80 & 0.00440 & 8.45 & 49 & 49 & 48 & 48 & 48 & 48 & 48 \\
\hline 0.80 & 0.00352 & 8.69 & 44 & 44 & 43 & 43 & 43 & 43 & 43 \\
\hline 0.80 & 0.00281 & 9.60 & 53 & 51 & 51 & 51 & 51 & 51 & 50 \\
\hline 0.80 & 0.00225 & 8.52 & 56 & 55 & 55 & 54 & 54 & 54 & 54 \\
\hline 0.80 & 0.00180 & 8.80 & 55 & 51 & 49 & 49 & 49 & 49 & 49 \\
\hline 0.80 & 0.00000 & 8.38 & 61 & 61 & 61 & 61 & 61 & 61 & 61 \\
\hline 0.85 & 0.10000 & 47.84 & 575 & 306 & 117 & 28 & 0 & 0 & 0 \\
\hline 0.85 & 0.08000 & 28.56 & 383 & 138 & 26 & 2 & 0 & 0 & 0 \\
\hline 0.85 & 0.06400 & 21.33 & 259 & 55 & 7 & 0 & 0 & 0 & 0 \\
\hline 0.85 & 0.05120 & 15.90 & 134 & 12 & 0 & 0 & 0 & 0 & 0 \\
\hline 0.85 & 0.04096 & 14.05 & 88 & 11 & 0 & 0 & 0 & 0 & 0 \\
\hline 0.85 & 0.03277 & 13.12 & 36 & 11 & 6 & 2 & 0 & 0 & 0 \\
\hline 0.85 & 0.02621 & 17.99 & 38 & 29 & 24 & 16 & 7 & 2 & 1 \\
\hline 0.85 & 0.02097 & 22.71 & 37 & 36 & 36 & 32 & 22 & 18 & 10 \\
\hline 0.85 & 0.01678 & 16.41 & 37 & 35 & 34 & 34 & 29 & 27 & 23 \\
\hline 0.85 & 0.01342 & 14.86 & 47 & 46 & 45 & 45 & 42 & 39 & 36 \\
\hline 0.85 & 0.01074 & 111.96 & 42 & 42 & 41 & 41 & 37 & 37 & 35 \\
\hline 0.85 & 0.00859 & 8.79 & 51 & 51 & 51 & 51 & 51 & 51 & 51 \\
\hline 0.85 & 0.00687 & 10.35 & 46 & 45 & 45 & 45 & 45 & 42 & 42 \\
\hline 0.85 & 0.00550 & 8.43 & 36 & 36 & 36 & 36 & 36 & 36 & 36 \\
\hline 0.85 & 0.00440 & 8.46 & 47 & 47 & 47 & 47 & 47 & 47 & 47 \\
\hline 0.85 & 0.00352 & 8.34 & 49 & 49 & 49 & 49 & 49 & 49 & 49 \\
\hline 0.85 & 0.00281 & 8.34 & 40 & 40 & 40 & 40 & 40 & 40 & 40 \\
\hline 0.85 & 0.00225 & 8.28 & 56 & 56 & 56 & 56 & 56 & 56 & 56 \\
\hline 0.85 & 0.00180 & 8.36 & 46 & 46 & 45 & 45 & 45 & 45 & 45 \\
\hline 0.85 & 0.00000 & 8.07 & 47 & 47 & 47 & 47 & 47 & 47 & 47 \\
\hline 0.90 & 0.10000 & 44.21 & 577 & 284 & 94 & 15 & 0 & 0 & 0 \\
\hline 0.90 & 0.08000 & 28.09 & 380 & 141 & 20 & 1 & 0 & 0 & 0 \\
\hline 0.90 & 0.06400 & 21.43 & 265 & 68 & 6 & 0 & 0 & 0 & 0 \\
\hline 0.90 & 0.05120 & 16.33 & 137 & 14 & 1 & 0 & 0 & 0 & 0 \\
\hline 0.90 & 0.04096 & 13.49 & 80 & 0 & 0 & 0 & 0 & 0 & 0 \\
\hline 0.90 & 0.03277 & 13.37 & 47 & 13 & 4 & 3 & 0 & 0 & 0 \\
\hline 0.90 & 0.02621 & 17.63 & 37 & 27 & 22 & 15 & 3 & 1 & 0 \\
\hline 0.90 & 0.02097 & 21.22 & 35 & 33 & 33 & 28 & 16 & 11 & 7 \\
\hline 0.90 & 0.01678 & 19.21 & 39 & 39 & 37 & 36 & 31 & 29 & 22 \\
\hline 0.90 & 0.01342 & 14.48 & 51 & 51 & 51 & 50 & 43 & 42 & 40 \\
\hline 0.90 & 0.01074 & 10.66 & 34 & 34 & 34 & 33 & 33 & 32 & 31 \\
\hline 0.90 & 0.00859 & 10.91 & 43 & 43 & 43 & 43 & 41 & 41 & 39 \\
\hline 0.90 & 0.00687 & 9.50 & 35 & 34 & 34 & 34 & 34 & 34 & 33 \\
\hline 0.90 & 0.00550 & 8.51 & 49 & 49 & 49 & 49 & 49 & 49 & 49 \\
\hline 0.90 & 0.00440 & 8.53 & 43 & 43 & 43 & 43 & 43 & 43 & 43 \\
\hline 0.90 & 0.00352 & 9.21 & 48 & 48 & 48 & 48 & 48 & 48 & 47 \\
\hline 0.90 & 0.00281 & 8.42 & 33 & 32 & 32 & 32 & 32 & 32 & 32 \\
\hline 0.90 & 0.00225 & 8.27 & 37 & 36 & 36 & 36 & 36 & 36 & 36 \\
\hline 0.90 & 0.00180 & 8.22 & 35 & 34 & 34 & 34 & 34 & 34 & 34 \\
\hline 0.90 & 0.00000 & 8.13 & 35 & 35 & 35 & 35 & 35 & 35 & 35 \\
\hline
\end{tabular}


- Para tamanho da população = 100 (cont.)

\begin{tabular}{|c|c|c|c|c|c|c|c|c|c|}
\hline Pc & $\mathrm{Pm}$ & Media & NaoAte25 & NaoAte50 & NaoAte100 & NaoAte200 & NaoAte500 & NaoAte700 & NaoAte 1000 \\
\hline 0.95 & 0.10000 & 42.08 & 551 & 261 & 83 & 16 & 0 & 0 & 0 \\
\hline 0.95 & 0.08000 & 28.94 & 380 & 146 & 26 & 2 & 0 & 0 & 0 \\
\hline 0.95 & 0.06400 & 21.16 & 259 & 56 & 7 & 0 & 0 & 0 & 0 \\
\hline 0.95 & 0.05120 & 16.61 & 166 & 14 & 0 & 0 & 0 & 0 & 0 \\
\hline 0.95 & 0.04096 & 13.54 & 70 & 6 & 0 & 0 & 0 & 0 & 0 \\
\hline 0.95 & 0.03277 & 12.83 & 43 & 7 & 4 & 1 & 0 & 0 & 0 \\
\hline 0.95 & 0.02621 & 14.04 & 30 & 18 & 16 & 6 & 1 & 0 & 0 \\
\hline 0.95 & 0.02097 & 24.96 & 32 & 30 & 29 & 26 & 19 & 15 & 4 \\
\hline 0.95 & 0.01678 & 17.39 & 31 & 28 & 28 & 26 & 17 & 14 & 11 \\
\hline 0.95 & 0.01342 & 12.72 & 22 & 22 & 21 & 21 & 19 & 19 & 16 \\
\hline 0.95 & 0.01074 & 9.86 & 36 & 35 & 35 & 35 & 34 & 33 & 33 \\
\hline 0.95 & 0.00859 & 10.01 & 34 & 34 & 34 & 33 & 32 & 32 & 31 \\
\hline 0.95 & 0.00687 & 8.60 & 33 & 32 & 32 & 32 & 32 & 32 & 32 \\
\hline 0.95 & 0.00550 & 8.55 & 26 & 26 & 26 & 26 & 26 & 26 & 26 \\
\hline 0.95 & 0.00440 & 8.39 & 29 & 29 & 29 & 29 & 29 & 29 & 29 \\
\hline 0.95 & 0.00352 & 8.24 & 38 & 38 & 38 & 38 & 38 & 38 & 38 \\
\hline 0.95 & 0.00281 & 8.43 & 35 & 34 & 34 & 34 & 34 & 34 & 34 \\
\hline 0.95 & 0.00225 & 8.26 & 30 & 30 & 30 & 30 & 30 & 30 & 30 \\
\hline 0.95 & 0.00180 & 8.33 & 31 & 30 & 30 & 30 & 30 & 30 & 30 \\
\hline 0.95 & 0.00000 & 8.05 & 36 & 36 & 36 & 36 & 36 & 36 & 36 \\
\hline 1.00 & 0.10000 & 46.75 & 589 & 326 & 99 & 14 & 0 & 0 & 0 \\
\hline 1.00 & 0.08000 & 29.58 & 384 & 148 & 41 & 3 & 0 & 0 & 0 \\
\hline 1.00 & 0.06400 & 20.28 & 242 & 49 & 3 & 0 & 0 & 0 & 0 \\
\hline 1.00 & 0.05120 & 16.35 & 151 & 20 & 1 & 0 & 0 & 0 & 0 \\
\hline 1.00 & 0.04096 & 13.20 & 61 & 7 & 0 & 0 & 0 & 0 & 0 \\
\hline 1.00 & 0.03277 & 11.76 & 32 & 2 & 1 & 0 & 0 & 0 & 0 \\
\hline 1.00 & 0.02621 & 13.27 & 33 & 11 & 10 & 8 & 0 & 0 & 0 \\
\hline 1.00 & 0.02097 & 16.03 & 22 & 20 & 19 & 16 & 8 & 7 & 4 \\
\hline 1.00 & 0.01678 & 13.23 & 19 & 18 & 17 & 17 & 13 & 11 & 9 \\
\hline 1.00 & 0.01342 & 9.98 & 18 & 18 & 18 & 18 & 16 & 16 & 16 \\
\hline 1.00 & 0.01074 & 10.93 & 28 & 28 & 28 & 28 & 27 & 27 & 25 \\
\hline 1.00 & 0.00859 & 8.73 & 25 & 25 & 25 & 25 & 25 & 25 & 25 \\
\hline 1.00 & 0.00687 & 9.16 & 25 & 25 & 25 & 25 & 23 & 23 & 23 \\
\hline 1.00 & 0.00550 & 10.23 & 19 & 19 & 19 & 19 & 19 & 19 & 17 \\
\hline 1.00 & 0.00440 & 8.39 & 21 & 20 & 20 & 20 & 20 & 20 & 20 \\
\hline 1.00 & 0.00352 & 8.18 & 21 & 21 & 21 & 21 & 21 & 21 & 21 \\
\hline 1.00 & 0.00281 & 8.29 & 26 & 26 & 26 & 26 & 26 & 26 & 26 \\
\hline 1.00 & 0.00225 & 8.28 & 21 & 20 & 19 & 19 & 19 & 19 & 19 \\
\hline 1.00 & 0.00180 & 8.19 & 25 & 25 & 25 & 25 & 25 & 25 & 25 \\
\hline 1.00 & 0.00000 & 8.04 & 22 & 22 & 22 & 22 & 22 & 22 & 22 \\
\hline
\end{tabular}


- Para tamanho da população $=80$

\begin{tabular}{|c|c|c|c|c|c|c|c|c|c|}
\hline $\mathrm{Pc}$ & $\mathrm{Pm}$ & Media & NaoAte25 & NaoAte50 & NaoAte100 & NaoAte200 & NaoAte500 & NaoAte700 & NaoAte1000 \\
\hline 0.50 & 0.10000 & 56.28 & 561 & 313 & 157 & 43 & 2 & 0 & 0 \\
\hline 0.50 & 0.08000 & 33.10 & 414 & 165 & 47 & 11 & 0 & 0 & 0 \\
\hline 0.50 & 0.06400 & 25.78 & 310 & 115 & 21 & 0 & 0 & 0 & 0 \\
\hline 0.50 & 0.05120 & 22.37 & 212 & 85 & 22 & 1 & 0 & 0 & 0 \\
\hline 0.50 & 0.04096 & 27.52 & 172 & 116 & 62 & 15 & 0 & 0 & 0 \\
\hline 0.50 & 0.03277 & 50.42 & 158 & 139 & 119 & 84 & 27 & 16 & 7 \\
\hline 0.50 & 0.02621 & 54.73 & 158 & 152 & 141 & 120 & 83 & 64 & 48 \\
\hline 0.50 & 0.02097 & 39.39 & 148 & 144 & 140 & 134 & 115 & 102 & 88 \\
\hline 0.50 & 0.01678 & 28.82 & 186 & 175 & 174 & 171 & 160 & 156 & 145 \\
\hline 0.50 & 0.01342 & 18.70 & 186 & 177 & 176 & 174 & 169 & 167 & 163 \\
\hline 0.50 & 0.01074 & 16.42 & 189 & 173 & 172 & 169 & 168 & 164 & 162 \\
\hline 0.50 & 0.00859 & 12.90 & 206 & 197 & 195 & 193 & 188 & 188 & 188 \\
\hline 0.50 & 0.00687 & 12.51 & 203 & 189 & 187 & 185 & 184 & 184 & 183 \\
\hline 0.50 & 0.00550 & 12.78 & 220 & 201 & 198 & 198 & 196 & 196 & 195 \\
\hline 0.50 & 0.00440 & 12.25 & 222 & 200 & 193 & 193 & 193 & 193 & 192 \\
\hline 0.50 & 0.00352 & 12.34 & 209 & 183 & 174 & 174 & 174 & 174 & 173 \\
\hline 0.50 & 0.00281 & 13.17 & 227 & 206 & 201 & 200 & 199 & 199 & 197 \\
\hline 0.50 & 0.00225 & 14.50 & 218 & 198 & 188 & 184 & 182 & 182 & 180 \\
\hline 0.50 & 0.00180 & 13.24 & 239 & 220 & 202 & 199 & 199 & 198 & 198 \\
\hline 0.50 & 0.00144 & 13.91 & 250 & 228 & 204 & 195 & 195 & 195 & 195 \\
\hline 0.50 & 0.00115 & 14.43 & 238 & 229 & 208 & 197 & 193 & 193 & 193 \\
\hline 0.50 & 0.00092 & 15.21 & 245 & 233 & 212 & 202 & 195 & 195 & 195 \\
\hline 0.50 & 0.00074 & 16.53 & 271 & 252 & 231 & 212 & 207 & 207 & 207 \\
\hline 0.50 & 0.00059 & 20.74 & 289 & 273 & 252 & 229 & 215 & 215 & 215 \\
\hline 0.50 & 0.00000 & 9.51 & 291 & 291 & 291 & 291 & 291 & 291 & 291 \\
\hline 0.55 & 0.10000 & 53.26 & 594 & 310 & 147 & 36 & 2 & 0 & 0 \\
\hline 0.55 & 0.08000 & 32.43 & 410 & 170 & 44 & 7 & 0 & 0 & 0 \\
\hline 0.55 & 0.06400 & 24.55 & 296 & 97 & 13 & 0 & 0 & 0 & 0 \\
\hline 0.55 & 0.05120 & 20.48 & 181 & 78 & 11 & 1 & 0 & 0 & 0 \\
\hline 0.55 & 0.04096 & 26.05 & 161 & 99 & 48 & 19 & 1 & 0 & 0 \\
\hline 0.55 & 0.03277 & 45.50 & 156 & 139 & 110 & 70 & 19 & 8 & 2 \\
\hline 0.55 & 0.02621 & 58.22 & 154 & 141 & 127 & 105 & 61 & 48 & 25 \\
\hline 0.55 & 0.02097 & 33.98 & 133 & 128 & 125 & 117 & 92 & 81 & 74 \\
\hline 0.55 & 0.01678 & 23.57 & 141 & 138 & 134 & 131 & 122 & 118 & 111 \\
\hline 0.55 & 0.01342 & 17.93 & 152 & 147 & 145 & 142 & 136 & 135 & 131 \\
\hline 0.55 & 0.01074 & 14.57 & 156 & 150 & 148 & 146 & 143 & 142 & 140 \\
\hline 0.55 & 0.00859 & 15.50 & 168 & 157 & 157 & 157 & 153 & 153 & 149 \\
\hline 0.55 & 0.00687 & 11.61 & 163 & 154 & 152 & 151 & 150 & 149 & 149 \\
\hline 0.55 & 0.00550 & 11.57 & 181 & 168 & 163 & 162 & 161 & 160 & 160 \\
\hline 0.55 & 0.00440 & 11.19 & 186 & 168 & 164 & 164 & 162 & 162 & 162 \\
\hline 0.55 & 0.00352 & 11.03 & 194 & 175 & 170 & 169 & 168 & 168 & 168 \\
\hline 0.55 & 0.00281 & 11.89 & 225 & 202 & 187 & 185 & 184 & 184 & 184 \\
\hline 0.55 & 0.00225 & 14.66 & 185 & 171 & 163 & 160 & 159 & 158 & 156 \\
\hline 0.55 & 0.00180 & 10.98 & 185 & 168 & 160 & 157 & 157 & 157 & 157 \\
\hline 0.55 & 0.00144 & 12.55 & 218 & 198 & 192 & 183 & 181 & 181 & 181 \\
\hline 0.55 & 0.00115 & 16.10 & 219 & 203 & 185 & 179 & 174 & 172 & 171 \\
\hline 0.55 & 0.00092 & 13.64 & 227 & 213 & 197 & 188 & 185 & 185 & 185 \\
\hline 0.55 & 0.00074 & 13.49 & 226 & 207 & 198 & 191 & 186 & 186 & 186 \\
\hline 0.55 & 0.00059 & 17.43 & 224 & 209 & 197 & 187 & 179 & 177 & 176 \\
\hline 0.55 & 0.00000 & 9.33 & 227 & 227 & 227 & 227 & 227 & 227 & 227 \\
\hline
\end{tabular}


- Para tamanho da população $=80$ (cont.)

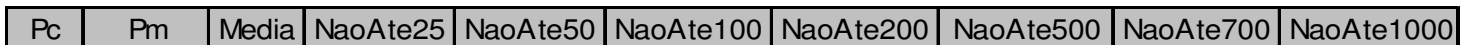

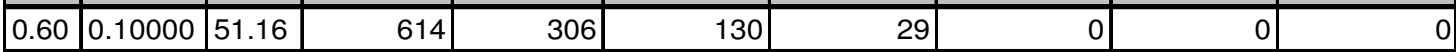
\begin{tabular}{|l|l|l|r|r|r|r|r|r|r|}
\hline 0.60 & 0.08000 & 35.21 & 454 & 200 & 68 & 5 & 0 & 0 & 0 \\
\hline
\end{tabular}

\begin{tabular}{|l|l|l|l|l|l|l|l|l|r|}
\hline 0.60 & 0.06400 & 24.44 & 295 & 99 & 14 & 1 & 0 & 0 & 0 \\
\hline 0.60 & 0.05120 & 19.66 & 176 & 57 & 17 & 0 & 0 & 0 \\
\hline
\end{tabular}

\begin{tabular}{r|r|r|r|r|r|}
\hline 0.60 & 0.05120 & 19.66 & 176 & 57 & 17 \\
\hline 0.60 & 0.04096 & 22.97 & 148 & 80 & 43 \\
\hline
\end{tabular}

\begin{tabular}{|l|l|l|r|r|r|}
\hline 0.60 & 0.04096 & 22.97 & 148 & 80 & 43 \\
\hline 0.60 & 0.0327 & 33.37 & 120 & 96 & 79 \\
\hline
\end{tabular}

\begin{tabular}{l|l|l|r|}
\hline 0.60 & 0.03277 & 33.37 & 120 \\
\hline 0.60 & 0.0262 & 5.43 & 133 \\
\hline
\end{tabular}

\begin{tabular}{|l|l|l|l|l|l}
\hline 0.60 & 0.02621 & 50.43 \\
\hline 0.60 & 0.02097 & 35.32 & \\
\hline
\end{tabular}

\begin{tabular}{l|l|l|l|l}
0.60 & 0.02097 & 35.32 \\
\hline
\end{tabular}

\begin{tabular}{|l|l|l|l|}
\hline 0.60 & 0.01678 & 27.65 \\
\hline
\end{tabular}

\begin{tabular}{|l|l|l|l|l|l}
\hline 0.60 & 0.01342 & 21.48 \\
\hline 0.00 & 0.0174 & 11.52 &
\end{tabular}

\begin{tabular}{l|l|l|l|l|l}
0.60 & 0.01074 & 11.52 \\
\hline 0.00 & 0.0059 & 11.92 & \\
\hline
\end{tabular}

$120 \quad 96$

\begin{tabular}{|l|l|l|l|}
\hline 0.60 & 0.00859 & 11.92 \\
\hline 0.60 & 0.00687 & 11.57
\end{tabular}

\begin{tabular}{|l|l|l|}
\hline 0.60 & 0.00687 & 11.57 \\
\hline
\end{tabular}

\begin{tabular}{l|l|l|l|}
\hline 0.60 & 0.00550 & 10.89 \\
\hline
\end{tabular}

\begin{tabular}{|l|l|l|}
\hline 0.60 & 0.00440 & 10.77 \\
\hline 0.60 & 0.00352 & 10.01 \\
\hline
\end{tabular}

\begin{tabular}{|l|l|l|}
\hline 0.60 & 0.00352 & 10.01 \\
\hline 0.60 & 0.00281 & 10.89 \\
\hline
\end{tabular}

\begin{tabular}{|l|l|l|}
\hline 0.60 & 0.00281 & 10.89 \\
\hline
\end{tabular}

\begin{tabular}{|l|l|l|}
\hline 0.60 & 0.00225 & 10.00 \\
\hline
\end{tabular}

\begin{tabular}{|l|l|l|}
\hline 0.60 & 0.00180 & 10.29 \\
\hline
\end{tabular}

\begin{tabular}{|l|l|l|}
\hline 0.60 & 0.00144 & 11.17 \\
\hline 0.60 & 0.00115 & 12.83
\end{tabular}

133

120

96 79

\begin{tabular}{|l|l|l|}
\hline 0.60 & 0.00115 & 12.83 \\
\hline
\end{tabular}

\begin{tabular}{l|l|l|}
\hline 0.60 & 0.00092 & 12.69 \\
\hline
\end{tabular}

\begin{tabular}{|l|l|l|}
\hline 0.60 & 0.00074 & 13.03 \\
\hline
\end{tabular}

\begin{tabular}{|l|l|l|}
\hline 0.60 & 0.00059 & 13.04 \\
\hline
\end{tabular}

\begin{tabular}{|l|l|l|}
\hline 0.60 & 0.00000 & 9.24 \\
\hline
\end{tabular}

\begin{tabular}{|l|l|l|}
\hline 0.65 & 0.10000 & 46.76 \\
\hline
\end{tabular}

\begin{tabular}{|l|l|l|}
\hline 0.65 & 0.08000 & 32.86 \\
\hline
\end{tabular}

\begin{tabular}{|l|l|l|}
0.65 & 0.06400 & 23.18 \\
\hline
\end{tabular}

\begin{tabular}{|l|l|l|}
\hline 0.65 & 0.05120 & 19.57 \\
\hline
\end{tabular}

\begin{tabular}{|l|l|l|}
\hline 0.65 & 0.04096 & 20.33 \\
\hline
\end{tabular}

\begin{tabular}{|l|l|l|}
\hline 0.65 & 0.03277 & 34.08 \\
\hline
\end{tabular}

\begin{tabular}{|l|l|l|}
\hline 0.65 & 0.02621 & 49.62 \\
\hline
\end{tabular}

\begin{tabular}{l|l|l|}
\hline 0.65 & 0.02097 & 42.71 \\
\hline
\end{tabular}

\begin{tabular}{|l|l|l|}
\hline 0.65 & 0.01678 & 21.43 \\
\hline
\end{tabular}

\begin{tabular}{|l|l|l|}
\hline 0.65 & 0.01342 & 22.79 \\
\hline
\end{tabular}

\begin{tabular}{|l|l|l|}
\hline 0.65 & 0.01074 & 13.53 \\
\hline
\end{tabular}

136

$118 \quad 113$

133

133

\begin{tabular}{ll}
113 & 107 \\
\hline 133
\end{tabular}

133

\begin{tabular}{l|l}
133 & 127 \\
\hline 131 & 130 \\
\hline
\end{tabular}

150

139

$147 \quad 147$

150

\begin{tabular}{|l|l|l|l|}
\hline 0.65 & 0.00859 & 13.15 & 134 \\
\hline
\end{tabular}

\begin{tabular}{|l|l|l|l|}
\hline 0.65 & 0.00687 & 9.68 & 130 \\
\hline
\end{tabular}

\begin{tabular}{l|l|l|}
\hline 0.65 & 0.00550 & 9.78 \\
\hline
\end{tabular}

\begin{tabular}{|l|l|l|}
\hline 0.65 & 0.00440 & 10.37 \\
\hline
\end{tabular}

\begin{tabular}{|l|l|l|}
\hline 0.65 & 0.00352 & 10.13 \\
\hline
\end{tabular}

\begin{tabular}{|l|l|l|}
\hline 0.65 & 0.00281 & 10.75 \\
\hline
\end{tabular}

\begin{tabular}{|l|l|l|}
\hline 0.65 & 0.00225 & 10.04 \\
\hline
\end{tabular}

\begin{tabular}{|l|l|l|}
\hline 0.65 & 0.00180 & 10.65 \\
\hline
\end{tabular}

\begin{tabular}{|l|l|l|}
\hline 0.65 & 0.00144 & 10.40 \\
\hline
\end{tabular}

\begin{tabular}{|l|l|l|}
0.65 & 0.00115 & 14.01 \\
\hline
\end{tabular}

\begin{tabular}{|l|l|l|}
\hline 0.65 & 0.00092 & 12.31 \\
\hline
\end{tabular}

\begin{tabular}{|l|l|l|}
\hline 0.65 & 0.00074 & 13.19 \\
\hline
\end{tabular}

\begin{tabular}{|l|l|l|}
\hline 0.65 & 0.00059 & 14.18 \\
\hline
\end{tabular}

$150 \quad 143$

\begin{tabular}{l|l|}
135 & 135 \\
\hline 143 & 140
\end{tabular}

$144 \quad 140$

15

181

148

137

168

153

143 140

\begin{tabular}{l|l|l|}
140 & 140 & 139 \\
\hline 148
\end{tabular}

\begin{tabular}{r|r|r|r|}
140 & 140 & 139 & 139 \\
\hline 148 & 147 & 147 & 147 \\
\hline 131 & 124 & 124 & 124 \\
\hline 168 & 162 & 160
\end{tabular}

\begin{tabular}{|l|l|l|l|}
168 & 124 & 124 & 124 \\
\hline 150 & 162 & 160 & 159 \\
\hline
\end{tabular}

\begin{tabular}{l|l|l|l|}
168 & 162 & 160 & 159 \\
150 & 145 & 145 & 145 \\
\hline
\end{tabular}

177

\begin{tabular}{l|l|r|r|r|}
175 & 164 & 155 & 149 & 149 \\
\hline 177 & 161 & 150 & 145 & 143 \\
\hline 170 & 157 & 145 & 142 & 138 \\
\hline
\end{tabular}

\begin{tabular}{l|r|r|}
137 & 130 & 129 \\
\hline 164 & 155 & 149 \\
\hline
\end{tabular}

$170 \quad 157$

172

\begin{tabular}{l|l|}
172 & 166 \\
\hline 162 & 155 \\
\hline
\end{tabular}

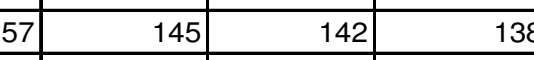

192

537

\begin{tabular}{l|l}
166 & 154 \\
\hline
\end{tabular}

192

\begin{tabular}{l|r|r|}
537 & 278 & 114 \\
\hline 408 & 171 & 52 \\
\hline
\end{tabular}

\begin{tabular}{r|r}
408 & 171 \\
\hline 180 & 73 \\
\hline
\end{tabular}

$180 \quad 53$

145

128

\begin{tabular}{r|r|r|}
180 & 53 & 6 \\
145 & 71 & 27 \\
\hline 128 & 98 & 76 \\
\hline 129 & 114 & 102 \\
\hline
\end{tabular}

\begin{tabular}{l|l|l|}
121 & 114 & 113 \\
\hline 118 & 114 & 112 \\
\hline
\end{tabular}

\begin{tabular}{l|l}
118 & 114 \\
\hline 128 & 124 \\
\hline
\end{tabular}

134

\begin{tabular}{r|r|r|}
\hline 114 & 112 & 11 \\
\hline 124 & 124 & 120 \\
\hline 129 & 128 & 128 \\
\hline 114 & 114 & 114 \\
\hline
\end{tabular}

\begin{tabular}{l|l|}
120 & 114 \\
\hline
\end{tabular}

\begin{tabular}{|c|c|c|c|c|c|}
\hline 129 & 128 & 128 & 127 & 127 & 124 \\
\hline 114 & 114 & 114 & 111 & 109 & 108 \\
\hline 129 & 129 & 128 & 128 & 128 & 128 \\
\hline 130 & 128 & 128 & 128 & 128 & 128 \\
\hline 142 & 139 & 139 & 138 & 138 & 138 \\
\hline 124 & 120 & 120 & 120 & 120 & 120 \\
\hline 125 & 119 & 118 & 117 & 117 & 117 \\
\hline 145 & 139 & 138 & 138 & 138 & 138 \\
\hline 135 & 131 & 130 & 130 & 130 & 129 \\
\hline 145 & 132 & 132 & 132 & 132 & 132 \\
\hline 158 & 133 & 126 & 124 & 122 & 122 \\
\hline 164 & 146 & 142 & 141 & 140 & 140 \\
\hline 157 & 148 & 135 & 133 & 133 & 132 \\
\hline 153 & 144 & 135 & 129 & 128 & 128 \\
\hline 181 & 181 & 181 & 181 & 181 & 181 \\
\hline
\end{tabular}

\begin{tabular}{|l|l|l|}
\hline 0.65 & 0.00000 & 8.96 \\
\hline
\end{tabular}

\begin{tabular}{l|l}
136 & 130 \\
\hline 151 & 142 \\
\hline
\end{tabular}

\begin{tabular}{l|l}
151 & 142 \\
\hline 144 & 124 \\
\hline
\end{tabular}

\begin{tabular}{l|l}
144 & 125 \\
\hline 153 & 145
\end{tabular}

144

\begin{tabular}{l|l|}
153 & 145 \\
\hline 145 & 135 \\
\hline
\end{tabular}

\begin{tabular}{l|l}
145 & 135 \\
\hline 160 & 145 \\
\hline 169 & 158 \\
\hline
\end{tabular}

169

172

160

181

\begin{tabular}{r|r|r|}
\hline 154 & 144 & 141 \\
\hline 144 & 139 & 133 \\
\hline 192 & 192 & 192 \\
\hline
\end{tabular}

\begin{tabular}{|c|c|c|c|c|}
\hline 114 & 26 & 0 & 0 & 0 \\
\hline 52 & 6 & 0 & 0 & 0 \\
\hline 9 & 0 & 0 & 0 & 0 \\
\hline
\end{tabular}

\begin{tabular}{r|r|r|r|r|}
\hline 9 & 0 & 0 & 0 & 0 \\
\hline 6 & 0 & 0 & 0 & 0 \\
\hline 7 & 5 & 0 & 0 & 0 \\
\hline
\end{tabular}

\begin{tabular}{|r|r|r|r|r|}
\hline 6 & 0 & 0 & 0 & 0 \\
\hline 27 & 5 & 0 & 0 & 0 \\
\hline 76 & 45 & 6 & 4 & 0 \\
\hline 02 & 87 & 53 & 37 & 19 \\
\hline 13 & 96 & 78 & 72 & 51 \\
\hline
\end{tabular}


- Para tamanho da população = 80 (cont.)

\begin{tabular}{|c|c|c|c|c|c|c|c|c|c|}
\hline $\mathrm{Pc}$ & $\mathrm{Pm}$ & Media & NaoAte25 & NaoAte50 & NaoAte100 & NaoAte200 & NaoAte500 & NaoAte700 & NaoAte1000 \\
\hline 0.70 & 0.10000 & 51.42 & 586 & 318 & 143 & 29 & 0 & 0 & 0 \\
\hline 0.70 & 0.08000 & 34.11 & 457 & 207 & 46 & 4 & 0 & 0 & 0 \\
\hline 0.70 & 0.06400 & 23.82 & 285 & 105 & 6 & 0 & 0 & 0 & 0 \\
\hline 0.70 & 0.05120 & 18.76 & 191 & 35 & 4 & 0 & 0 & 0 & 0 \\
\hline 0.70 & 0.04096 & 19.21 & 134 & 61 & 21 & 6 & 0 & 0 & 0 \\
\hline 0.70 & 0.03277 & 27.67 & 107 & 80 & 60 & 27 & 3 & 1 & 0 \\
\hline 0.70 & 0.02621 & 42.01 & 102 & 95 & 88 & 75 & 39 & 22 & 13 \\
\hline 0.70 & 0.02097 & 35.63 & 96 & 92 & 90 & 77 & 61 & 48 & 38 \\
\hline 0.70 & 0.01678 & 27.75 & 125 & 122 & 121 & 117 & 103 & 98 & 89 \\
\hline 0.70 & 0.01342 & 19.15 & 118 & 115 & 114 & 112 & 108 & 106 & 100 \\
\hline 0.70 & 0.01074 & 13.12 & 116 & 113 & 112 & 111 & 107 & 106 & 105 \\
\hline 0.70 & 0.00859 & 10.38 & 115 & 111 & 111 & 111 & 109 & 109 & 109 \\
\hline 0.70 & 0.00687 & 10.75 & 117 & 112 & 111 & 111 & 109 & 108 & 108 \\
\hline 0.70 & 0.00550 & 12.16 & 140 & 133 & 132 & 132 & 132 & 131 & 129 \\
\hline 0.70 & 0.00440 & 11.09 & 135 & 129 & 128 & 127 & 126 & 124 & 124 \\
\hline 0.70 & 0.00352 & 9.69 & 112 & 106 & 103 & 103 & 102 & 102 & 102 \\
\hline 0.70 & 0.00281 & 10.70 & 127 & 116 & 114 & 114 & 113 & 112 & 112 \\
\hline 0.70 & 0.00225 & 10.49 & 143 & 138 & 132 & 131 & 131 & 130 & 130 \\
\hline 0.70 & 0.00180 & 10.10 & 140 & 135 & 130 & 126 & 126 & 126 & 126 \\
\hline 0.70 & 0.00144 & 9.84 & 146 & 142 & 135 & 133 & 133 & 133 & 133 \\
\hline 0.70 & 0.00115 & 10.53 & 127 & 124 & 121 & 117 & 115 & 115 & 115 \\
\hline 0.70 & 0.00092 & 9.92 & 123 & 116 & 113 & 109 & 109 & 109 & 109 \\
\hline 0.70 & 0.00074 & 10.27 & 130 & 126 & 117 & 113 & 113 & 113 & 113 \\
\hline 0.70 & 0.00059 & 11.62 & 124 & 120 & 115 & 109 & 105 & 105 & 105 \\
\hline 0.70 & 0.00000 & 8.71 & 145 & 145 & 145 & 145 & 145 & 145 & 145 \\
\hline 0.75 & 0.10000 & 47.04 & 585 & 285 & 110 & 21 & 0 & 0 & 0 \\
\hline 0.75 & 0.08000 & 32.24 & 419 & 171 & 45 & 1 & 0 & 0 & 0 \\
\hline 0.75 & 0.06400 & 23.61 & 296 & 89 & 10 & 1 & 0 & 0 & 0 \\
\hline 0.75 & 0.05120 & 17.73 & 165 & 40 & 2 & 0 & 0 & 0 & 0 \\
\hline 0.75 & 0.04096 & 18.34 & 129 & 57 & 20 & 0 & 0 & 0 & 0 \\
\hline 0.75 & 0.03277 & 23.13 & 95 & 65 & 40 & 18 & 2 & 2 & 0 \\
\hline 0.75 & 0.02621 & 34.79 & 91 & 79 & 69 & 54 & 30 & 21 & 10 \\
\hline 0.75 & 0.02097 & 33.50 & 95 & 89 & 86 & 79 & 61 & 46 & 38 \\
\hline 0.75 & 0.01678 & 26.64 & 116 & 112 & 112 & 106 & 89 & 86 & 78 \\
\hline 0.75 & 0.01342 & 17.75 & 103 & 101 & 98 & 94 & 87 & 83 & 81 \\
\hline 0.75 & 0.01074 & 15.30 & 113 & 108 & 108 & 107 & 105 & 102 & 99 \\
\hline 0.75 & 0.00859 & 11.53 & 94 & 89 & 89 & 86 & 84 & 82 & 82 \\
\hline 0.75 & 0.00687 & 9.42 & 97 & 92 & 92 & 92 & 92 & 92 & 92 \\
\hline 0.75 & 0.00550 & 10.93 & 101 & 100 & 99 & 98 & 98 & 96 & 96 \\
\hline 0.75 & 0.00440 & 9.96 & 109 & 103 & 102 & 102 & 101 & 101 & 101 \\
\hline 0.75 & 0.00352 & 9.39 & 102 & 93 & 92 & 92 & 92 & 92 & 92 \\
\hline 0.75 & 0.00281 & 9.13 & 101 & 96 & 96 & 96 & 96 & 96 & 96 \\
\hline 0.75 & 0.00225 & 9.42 & 106 & 103 & 101 & 100 & 100 & 100 & 100 \\
\hline 0.75 & 0.00180 & 9.64 & 118 & 114 & 110 & 107 & 107 & 107 & 107 \\
\hline 0.75 & 0.00144 & 9.40 & 121 & 110 & 108 & 107 & 107 & 107 & 107 \\
\hline 0.75 & 0.00115 & 9.71 & 114 & 109 & 107 & 105 & 103 & 103 & 103 \\
\hline 0.75 & 0.00092 & 10.68 & 123 & 117 & 108 & 104 & 102 & 102 & 102 \\
\hline 0.75 & 0.00074 & 10.20 & 110 & 108 & 103 & 101 & 99 & 99 & 99 \\
\hline 0.75 & 0.00059 & 10.44 & 119 & 113 & 107 & 101 & 100 & 100 & 100 \\
\hline 0.75 & 0.00000 & 8.59 & 125 & 125 & 125 & 125 & 125 & 125 & 125 \\
\hline
\end{tabular}


- $\quad$ Para tamanho da população $=80$ (cont.)

\begin{tabular}{|c|c|c|c|c|c|c|c|c|c|}
\hline $\mathrm{Pc}$ & $\mathrm{Pm}$ & Media & NaoAte25 & NaoAte50 & NaoAte100 & NaoAte200 & NaoAte500 & \begin{tabular}{l|l} 
NaoAte700 \\
\end{tabular} & NaoAte 1000 \\
\hline 0.80 & 0.10000 & 50.62 & 604 & 329 & 116 & 28 & 0 & 0 & 0 \\
\hline 0.80 & 0.08000 & 32.59 & 443 & 170 & 45 & 4 & 0 & 0 & 0 \\
\hline 0.80 & 0.06400 & 22.44 & 293 & 64 & 10 & 0 & 0 & 0 & 0 \\
\hline 0.80 & 0.05120 & 17.72 & 172 & 28 & 0 & 0 & 0 & 0 & 0 \\
\hline 0.80 & 0.04096 & 16.57 & 120 & 33 & 6 & 0 & 0 & 0 & 0 \\
\hline 0.80 & 0.03277 & 20.32 & 80 & 49 & 33 & 17 & 0 & 0 & 0 \\
\hline 0.80 & 0.02621 & 32.67 & 81 & 71 & 65 & 48 & 24 & 12 & 6 \\
\hline 0.80 & 0.02097 & 32.18 & 84 & 80 & 77 & 66 & 50 & 42 & 31 \\
\hline 0.80 & 0.01678 & 23.81 & 92 & 88 & 87 & 82 & 75 & 72 & 63 \\
\hline 0.80 & 0.01342 & 22.87 & 107 & 102 & 102 & 97 & 90 & 86 & 78 \\
\hline 0.80 & 0.01074 & 12.89 & 78 & 77 & 77 & 76 & 75 & 72 & 71 \\
\hline 0.80 & 0.00859 & 10.80 & 91 & 90 & 89 & 89 & 87 & 87 & 86 \\
\hline 0.80 & 0.00687 & 11.43 & 89 & 85 & 85 & 84 & 84 & 81 & 81 \\
\hline 0.80 & 0.00550 & 8.97 & 100 & 97 & 97 & 97 & 97 & 97 & 97 \\
\hline 0.80 & 0.00440 & 9.82 & 89 & 83 & 83 & 83 & 83 & 82 & 82 \\
\hline 0.80 & 0.00352 & 9.20 & 92 & 86 & 84 & 84 & 84 & 84 & 84 \\
\hline 0.80 & 0.00281 & 9.39 & 100 & 94 & 94 & 93 & 93 & 93 & 93 \\
\hline 0.80 & 0.00225 & 9.21 & 105 & 101 & 98 & 98 & 98 & 98 & 98 \\
\hline 0.80 & 0.00180 & 9.44 & 105 & 101 & 97 & 95 & 95 & 95 & 95 \\
\hline 0.80 & 0.00144 & 9.08 & 87 & 82 & 81 & 81 & 81 & 81 & 81 \\
\hline 0.80 & 0.00115 & 9.45 & 89 & 85 & 83 & 80 & 80 & 80 & 80 \\
\hline 0.80 & 0.00092 & 9.18 & 85 & 79 & 78 & 77 & 77 & 77 & 77 \\
\hline 0.80 & 0.00074 & 11.37 & 100 & 98 & 96 & 92 & 86 & 86 & 86 \\
\hline 0.80 & 0.00059 & 10.63 & 92 & 90 & 89 & 87 & 85 & 84 & 84 \\
\hline 0.80 & 0.00000 & 8.68 & 113 & 113 & 113 & 113 & 113 & 113 & 113 \\
\hline 0.85 & 0.10000 & 49.69 & 602 & 307 & 117 & 26 & 1 & 0 & 0 \\
\hline 0.85 & 0.08000 & 32.54 & 421 & 170 & 46 & 4 & 0 & 0 & 0 \\
\hline 0.85 & 0.06400 & 21.92 & 264 & 74 & 5 & 0 & 0 & 0 & 0 \\
\hline 0.85 & 0.05120 & 18.14 & 181 & 35 & 1 & 0 & 0 & 0 & 0 \\
\hline 0.85 & 0.04096 & 15.47 & 107 & 18 & 3 & 0 & 0 & 0 & 0 \\
\hline 0.85 & 0.03277 & 19.37 & 94 & 47 & 34 & 10 & 0 & 0 & 0 \\
\hline 0.85 & 0.02621 & 27.59 & 66 & 56 & 45 & 32 & 9 & 5 & 0 \\
\hline 0.85 & 0.02097 & 29.55 & 76 & 74 & 72 & 66 & 50 & 37 & 31 \\
\hline 0.85 & 0.01678 & 21.97 & 75 & 74 & 72 & 70 & 58 & 51 & 47 \\
\hline 0.85 & 0.01342 & 19.06 & 90 & 90 & 89 & 85 & 79 & 75 & 71 \\
\hline 0.85 & 0.01074 & 13.07 & 70 & 69 & 69 & 69 & 65 & 63 & 62 \\
\hline 0.85 & 0.00859 & 10.50 & 70 & 67 & 67 & 67 & 66 & 66 & 65 \\
\hline 0.85 & 0.00687 & 9.38 & 75 & 72 & 71 & 71 & 71 & 71 & 71 \\
\hline 0.85 & 0.00550 & 9.53 & 86 & 85 & 85 & 85 & 84 & 84 & 84 \\
\hline 0.85 & 0.00440 & 9.68 & 75 & 72 & 72 & 72 & 72 & 72 & 71 \\
\hline 0.85 & 0.00352 & 9.16 & 85 & 84 & 82 & 82 & 82 & 82 & 82 \\
\hline 0.85 & 0.00281 & 8.69 & 80 & 80 & 80 & 80 & 80 & 80 & 80 \\
\hline 0.85 & 0.00225 & 8.83 & 84 & 78 & 78 & 78 & 78 & 78 & 78 \\
\hline 0.85 & 0.00180 & 8.85 & 80 & 78 & 78 & 77 & 77 & 77 & 77 \\
\hline 0.85 & 0.00144 & 9.44 & 91 & 91 & 90 & 89 & 88 & 88 & 88 \\
\hline 0.85 & 0.00115 & 9.34 & 102 & 99 & 97 & 96 & 95 & 95 & 95 \\
\hline 0.85 & 0.00092 & 9.77 & 89 & 89 & 85 & 82 & 81 & 81 & 81 \\
\hline 0.85 & 0.00074 & 10.21 & 104 & 101 & 99 & 97 & 93 & 93 & 93 \\
\hline 0.85 & 0.00059 & 9.49 & 96 & 95 & 92 & 92 & 90 & 90 & 90 \\
\hline 0.85 & 0.00000 & 8.61 & 99 & 99 & 99 & 99 & 99 & 99 & 99 \\
\hline
\end{tabular}


- Para tamanho da população $=80$ (cont.)

\begin{tabular}{|c|c|c|c|c|c|c|c|c|c|}
\hline $\mathrm{Pc}$ & $\mathrm{Pm}$ & Media & NaoAte25 & NaoAte50 & NaoAte100 & NaoAte200 & NaoAte500 & NaoA te700 & NaoAte 1000 \\
\hline 0.90 & 0.10000 & 51.28 & 620 & 327 & 130 & 30 & 0 & 0 & 0 \\
\hline 0.90 & 0.08000 & 32.66 & 443 & 166 & 36 & 6 & 0 & 0 & 0 \\
\hline 0.90 & 0.06400 & 23.81 & 317 & 92 & 7 & 0 & 0 & 0 & 0 \\
\hline 0.90 & 0.05120 & 17.53 & 178 & 31 & 0 & 0 & 0 & 0 & 0 \\
\hline 0.90 & 0.04096 & 15.42 & 111 & 22 & 2 & 0 & 0 & 0 & $\overline{0}$ \\
\hline 0.90 & 0.03277 & 17.43 & 76 & 38 & 23 & 9 & 0 & 0 & 0 \\
\hline 0.90 & 0.02621 & 26.34 & 71 & 57 & 41 & 34 & 11 & 4 & 2 \\
\hline 0.90 & 0.02097 & 26.14 & 60 & 53 & 50 & 45 & 34 & 25 & 18 \\
\hline 0.90 & 0.01678 & 23.91 & 56 & 56 & 56 & 55 & 46 & 42 & 33 \\
\hline 0.90 & 0.01342 & 15.19 & 75 & 74 & 74 & 72 & 67 & 64 & 62 \\
\hline 0.90 & 0.01074 & 10.27 & 65 & 63 & 63 & 63 & 63 & 63 & 62 \\
\hline 0.90 & 0.00859 & 10.25 & 72 & 69 & 69 & 69 & 69 & 69 & 68 \\
\hline 0.90 & 0.00687 & 9.46 & 78 & 78 & 78 & 78 & 77 & 77 & 77 \\
\hline 0.90 & 0.00550 & 8.85 & 72 & 71 & 70 & 70 & 70 & 70 & 70 \\
\hline 0.90 & 0.00440 & 9.04 & 75 & 73 & 73 & 73 & 73 & 73 & 73 \\
\hline 0.90 & 0.00352 & 8.95 & 80 & 78 & 78 & 78 & 78 & 78 & 78 \\
\hline 0.90 & 0.00281 & 8.62 & 67 & 66 & 66 & 66 & 66 & 66 & 66 \\
\hline 0.90 & 0.00225 & 8.68 & 78 & 78 & 77 & 77 & 77 & 77 & 77 \\
\hline 0.90 & 0.00180 & 8.72 & 78 & 76 & 76 & 76 & 76 & 76 & 76 \\
\hline 0.90 & 0.00144 & 9.03 & 71 & 66 & 63 & 63 & 63 & 63 & 63 \\
\hline 0.90 & 0.00115 & 8.98 & 71 & 69 & 66 & 65 & 65 & 65 & 65 \\
\hline 0.90 & 0.00092 & 10.15 & 89 & 88 & 85 & 78 & 77 & 77 & 77 \\
\hline 0.90 & 0.00074 & 9.39 & 70 & 69 & 68 & 64 & 63 & 63 & 63 \\
\hline 0.90 & 0.00059 & 9.58 & 65 & 63 & 62 & 57 & 56 & 56 & 56 \\
\hline 0.90 & 0.00000 & 8.47 & 82 & 82 & 82 & 82 & 82 & 82 & 82 \\
\hline 0.95 & 0.10000 & 49.40 & 567 & 301 & 114 & 26 & 0 & 0 & 0 \\
\hline 0.95 & 0.08000 & 31.97 & 444 & 172 & 43 & 2 & 0 & 0 & 0 \\
\hline 0.95 & 0.06400 & 24.39 & 317 & 91 & 13 & 1 & 0 & 0 & 0 \\
\hline 0.95 & 0.05120 & 17.91 & 181 & 34 & 0 & 0 & 0 & 0 & 0 \\
\hline 0.95 & 0.04096 & 14.90 & 105 & 11 & 1 & 0 & 0 & 0 & 0 \\
\hline 0.95 & 0.03277 & 15.26 & 65 & 25 & 16 & 2 & 0 & 0 & 0 \\
\hline 0.95 & 0.02621 & 24.90 & 53 & 43 & 36 & 29 & 11 & 7 & 1 \\
\hline 0.95 & 0.02097 & 27.87 & 66 & 62 & 56 & 48 & 27 & 19 & 14 \\
\hline 0.95 & 0.01678 & 17.89 & 54 & 51 & 49 & 45 & 37 & 34 & 31 \\
\hline 0.95 & 0.01342 & 16.82 & 65 & 63 & 63 & 59 & 55 & 48 & 47 \\
\hline 0.95 & 0.01074 & 13.76 & 64 & 63 & 63 & 63 & 56 & 56 & 54 \\
\hline 0.95 & 0.00859 & 11.88 & 60 & 58 & 58 & 57 & 56 & 54 & 53 \\
\hline 0.95 & 0.00687 & 11.48 & 68 & 66 & 66 & 66 & 66 & 66 & 63 \\
\hline 0.95 & 0.00550 & 9.01 & 74 & 72 & 72 & 72 & 72 & 72 & 72 \\
\hline 0.95 & 0.00440 & \begin{tabular}{|l|}
8.78 \\
\end{tabular} & 50 & 49 & 49 & 49 & 49 & 49 & 49 \\
\hline 0.95 & 0.00352 & 8.89 & 55 & 53 & 53 & 53 & 53 & 53 & 53 \\
\hline 0.95 & 0.00281 & 8.73 & 57 & 57 & 57 & 57 & 57 & 57 & 57 \\
\hline 0.95 & 0.00225 & 8.77 & 70 & 70 & 68 & 68 & 68 & 68 & 68 \\
\hline 0.95 & 0.00180 & 8.78 & 63 & 63 & 62 & 61 & 61 & 61 & 61 \\
\hline 0.95 & 0.00144 & 9.15 & 73 & 70 & 68 & 68 & 67 & 67 & 67 \\
\hline 0.95 & 0.00115 & 8.91 & 72 & 72 & 71 & 70 & 70 & 70 & 70 \\
\hline 0.95 & 0.00092 & 9.47 & 56 & 52 & 50 & 47 & 47 & 47 & 47 \\
\hline \begin{tabular}{|l|}
0.95 \\
\end{tabular} & 0.00074 & 9.50 & 65 & 63 & 62 & 62 & 60 & 60 & 60 \\
\hline 0.95 & 0.00059 & 8.88 & 76 & 74 & 73 & 72 & 72 & 72 & 72 \\
\hline 0.95 & 0.00000 & 8.50 & 65 & 65 & 65 & 65 & 65 & 65 & 65 \\
\hline 1.00 & 0.10000 & 45.15 & 575 & 280 & 104 & 13 & 0 & 0 & 0 \\
\hline 1.00 & 0.08000 & 34.52 & 450 & 196 & 53 & 2 & 0 & 0 & 0 \\
\hline 1.00 & 0.06400 & 23.59 & 298 & 82 & 11 & 0 & 0 & 0 & 0 \\
\hline 1.00 & 0.05120 & 18.45 & 184 & 40 & 3 & 0 & 0 & 0 & 0 \\
\hline 1.00 & 0.04096 & 15.01 & 99 & 14 & 0 & 0 & 0 & 0 & 0 \\
\hline 1.00 & 0.03277 & 14.46 & 81 & 14 & 8 & 2 & 0 & 0 & 0 \\
\hline 1.00 & 0.02621 & 17.77 & 50 & 31 & 25 & 15 & 1 & 0 & 0 \\
\hline 1.00 & 0.02097 & 28.65 & 54 & 47 & 44 & 38 & 24 & 16 & 6 \\
\hline 1.00 & 0.01678 & 19.99 & 59 & 56 & 55 & 49 & 39 & 34 & 31 \\
\hline 1.00 & 0.01342 & 15.74 & 64 & 63 & 62 & 59 & 56 & 51 & 50 \\
\hline 1.00 & 0.01074 & 15.06 & 61 & 59 & 59 & 59 & 56 & 54 & 50 \\
\hline 1.00 & 0.00859 & 12.75 & 52 & 51 & 51 & 50 & 49 & 47 & 45 \\
\hline 1.00 & 0.00687 & 9.88 & 57 & 56 & 56 & 56 & 56 & 56 & 55 \\
\hline 1.00 & 0.00550 & 8.99 & 49 & 49 & 49 & 49 & 49 & 49 & 49 \\
\hline 1.00 & 0.00440 & 8.77 & 51 & 48 & 48 & 48 & 48 & 48 & 48 \\
\hline 1.00 & 0.00352 & 8.68 & 38 & 38 & 38 & 38 & 38 & 38 & 38 \\
\hline 1.00 & 0.00281 & 8.70 & 67 & 66 & 66 & 66 & 66 & 66 & 66 \\
\hline 1.00 & 0.00225 & 8.87 & 61 & 60 & 59 & 58 & 58 & 58 & 58 \\
\hline 1.00 & 0.00180 & 8.79 & 62 & 61 & 60 & 60 & 60 & 60 & 60 \\
\hline 1.00 & 0.00144 & 8.55 & 41 & 40 & 39 & 39 & 39 & 39 & 39 \\
\hline 1.00 & 0.00115 & 8.57 & 52 & 50 & 50 & 49 & 49 & 49 & 49 \\
\hline 1.00 & 0.00092 & \begin{tabular}{|l|}
8.97 \\
\end{tabular} & 53 & 52 & 50 & 49 & 48 & 48 & 48 \\
\hline 1.00 & 0.00074 & 9.30 & 61 & 60 & 58 & 56 & 55 & 55 & 55 \\
\hline 1.00 & 0.00059 & 8.91 & 51 & 51 & 49 & 47 & 47 & 47 & 47 \\
\hline 1.00 & 0.00000 & 8.40 & 58 & 58 & 58 & 58 & 58 & 58 & 58 \\
\hline
\end{tabular}


- Para tamanho da população $=60$

\begin{tabular}{|c|c|c|c|c|c|c|c|c|c|}
\hline $\mathrm{Pc}$ & $\mathrm{Pm}$ & Media & NaoAte25 & NaoAte50 & NaoAte100 & NaoAte200 & NaoAte500 & NaoAte700 & \begin{tabular}{|l|} 
NaoAte 1000 \\
\end{tabular} \\
\hline 0.50 & 0.10000 & 64.13 & 622 & 361 & 179 & 70 & 3 & 0 & 0 \\
\hline 0.50 & 0.08000 & 44.22 & 490 & 246 & 107 & 22 & 0 & 0 & 0 \\
\hline 0.50 & 0.06400 & 32.84 & 365 & 169 & 62 & 4 & 0 & 0 & 0 \\
\hline 0.50 & 0.05120 & 31.33 & 307 & 161 & 63 & 9 & 0 & 0 & 0 \\
\hline 0.50 & 0.04096 & 50.50 & 285 & 220 & 149 & 68 & 6 & 0 & 0 \\
\hline 0.50 & 0.03277 & 75.36 & 226 & 188 & 159 & 124 & 59 & 34 & 11 \\
\hline 0.50 & 0.02621 & 80.32 & 245 & 226 & 213 & 195 & 146 & 122 & 89 \\
\hline 0.50 & 0.02097 & 53.66 & 249 & 227 & 222 & 214 & 186 & 173 & 153 \\
\hline 0.50 & 0.01678 & 37.96 & 261 & 238 & 236 & 231 & 209 & 203 & 192 \\
\hline 0.50 & 0.01342 & 21.54 & 258 & 235 & 231 & 226 & 218 & 217 & 213 \\
\hline 0.50 & 0.01074 & 18.07 & 278 & 252 & 250 & 249 & 242 & 241 & 239 \\
\hline 0.50 & 0.00859 & 17.99 & 285 & 249 & 246 & 244 & 236 & 236 & 234 \\
\hline 0.50 & 0.00687 & 18.62 & 296 & 260 & 252 & 247 & 242 & 239 & 238 \\
\hline 0.50 & 0.00550 & 17.51 & 302 & 250 & 243 & 242 & 237 & 236 & 235 \\
\hline 0.50 & 0.00440 & 17.47 & 324 & 280 & 259 & 257 & 254 & 254 & 252 \\
\hline 0.50 & 0.00352 & 20.92 & 321 & 267 & 247 & 240 & 236 & 235 & 231 \\
\hline 0.50 & 0.00281 & 22.85 & 348 & 304 & 276 & 265 & 260 & 259 & 255 \\
\hline 0.50 & 0.00225 & 20.83 & 361 & 321 & 289 & 277 & 275 & 272 & 271 \\
\hline 0.50 & 0.00180 & 18.95 & 367 & 319 & 293 & 278 & 276 & 276 & 275 \\
\hline 0.50 & 0.00144 & 24.31 & 378 & 347 & 308 & 279 & 270 & 270 & 269 \\
\hline 0.50 & 0.00115 & 28.43 & 387 & 358 & 313 & 288 & 278 & 274 & 272 \\
\hline 0.50 & 0.00092 & 28.29 & 363 & 344 & 311 & 280 & 264 & 262 & 261 \\
\hline 0.50 & 0.00074 & 30.03 & 376 & 346 & 315 & 283 & 265 & 261 & 260 \\
\hline 0.50 & 0.00059 & 40.50 & 381 & 365 & 339 & 301 & 253 & 250 & 250 \\
\hline 0.50 & 0.00000 & 9.82 & 406 & 406 & 406 & 406 & 406 & 406 & 406 \\
\hline 0.55 & 0.10000 & 65.05 & 646 & 366 & 177 & 64 & 4 & 0 & 0 \\
\hline 0.55 & 0.08000 & 43.07 & 532 & 238 & 97 & 15 & 0 & 0 & 0 \\
\hline 0.55 & 0.06400 & 31.18 & 355 & 162 & 47 & 4 & 0 & 0 & 0 \\
\hline 0.55 & 0.05120 & 29.22 & 267 & 135 & 53 & 9 & 0 & 0 & 0 \\
\hline 0.55 & 0.04096 & 37.85 & 215 & 148 & 97 & 43 & 2 & 1 & 0 \\
\hline 0.55 & 0.03277 & 68.00 & 218 & 192 & 163 & 119 & 52 & 35 & 15 \\
\hline 0.55 & 0.02621 & 73.95 & 220 & 205 & 192 & 170 & 126 & 107 & 74 \\
\hline 0.55 & 0.02097 & 46.30 & 246 & 225 & 217 & 204 & 185 & 172 & 157 \\
\hline 0.55 & 0.01678 & 36.36 & 237 & 213 & 212 & 205 & 193 & 188 & 174 \\
\hline 0.55 & 0.01342 & 21.74 & 228 & 210 & 205 & 200 & 194 & 189 & 186 \\
\hline 0.55 & 0.01074 & 15.46 & 266 & 247 & 242 & 242 & 239 & 237 & 236 \\
\hline 0.55 & 0.00859 & 16.89 & 240 & 219 & 213 & 210 & 208 & 207 & 204 \\
\hline 0.55 & 0.00687 & 14.77 & 277 & 242 & 236 & 233 & 230 & 230 & 229 \\
\hline 0.55 & 0.00550 & 15.14 & 271 & 236 & 231 & 224 & 219 & 219 & 219 \\
\hline 0.55 & 0.00440 & 17.28 & 302 & 264 & 252 & 250 & 247 & 246 & 244 \\
\hline 0.55 & 0.00352 & 18.17 & 320 & 271 & 251 & 247 & 241 & 240 & 239 \\
\hline 0.55 & 0.00281 & 18.80 & 345 & 299 & 275 & 272 & 270 & 270 & 267 \\
\hline 0.55 & 0.00225 & 21.23 & 338 & 297 & 265 & 257 & 254 & 252 & 249 \\
\hline 0.55 & 0.00180 & 18.76 & 334 & 306 & 273 & 260 & 255 & 254 & 254 \\
\hline 0.55 & 0.00144 & 18.66 & 341 & 307 & 265 & 256 & 250 & 250 & 249 \\
\hline 0.55 & 0.00115 & 25.75 & 350 & 324 & 294 & 262 & 250 & 248 & 247 \\
\hline 0.55 & 0.00092 & 22.45 & 336 & 317 & 285 & 263 & 249 & 249 & 248 \\
\hline 0.55 & 0.00074 & 25.03 & 333 & 315 & 274 & 248 & 234 & 232 & 232 \\
\hline 0.55 & 0.00059 & 28.46 & 331 & 309 & 279 & 255 & 232 & 231 & 229 \\
\hline 0.55 & 0.00000 & 9.88 & 356 & 356 & 356 & 356 & 356 & 356 & 356 \\
\hline
\end{tabular}


- Para tamanho da população $=60$ (cont.)

\begin{tabular}{|c|c|c|c|c|c|c|c|c|c|}
\hline $\mathrm{Pc}$ & $\mathrm{Pm}$ & Media & NaoAte25 & NaoAte50 & NaoAte100 & NaoAte200 & NaoAte500 & NaoAte700 & NaoAte1000 \\
\hline 0.60 & 0.10000 & 59.62 & 601 & 343 & 162 & 57 & 3 & 0 & 0 \\
\hline 0.60 & 0.08000 & 40.65 & 478 & 233 & 86 & 12 & 2 & 0 & 0 \\
\hline 0.60 & 0.06400 & 28.01 & 330 & 129 & 32 & 2 & 0 & 0 & 0 \\
\hline 0.60 & 0.05120 & 26.00 & 263 & 110 & 39 & 3 & 0 & 0 & 0 \\
\hline 0.60 & 0.04096 & 36.66 & 240 & 155 & 86 & 42 & 2 & 0 & 0 \\
\hline 0.60 & 0.03277 & 57.14 & 199 & 162 & 133 & 97 & 28 & 12 & 2 \\
\hline 0.60 & 0.02621 & 72.28 & 213 & 193 & 182 & 158 & 96 & 77 & 51 \\
\hline 0.60 & 0.02097 & 54.24 & 209 & 196 & 192 & 184 & 161 & 146 & 123 \\
\hline 0.60 & 0.01678 & 34.81 & 230 & 215 & 211 & 206 & 192 & 186 & 174 \\
\hline 0.60 & 0.01342 & 20.68 & 204 & 186 & 182 & 180 & 178 & 177 & 170 \\
\hline 0.60 & 0.01074 & 19.45 & 245 & 225 & 223 & 220 & 216 & 214 & 210 \\
\hline 0.60 & 0.00859 & 13.97 & 240 & 216 & 213 & 212 & 212 & 212 & 210 \\
\hline 0.60 & 0.00687 & 15.58 & 249 & 218 & 214 & 211 & 209 & 208 & 206 \\
\hline 0.60 & 0.00550 & 16.44 & 257 & 225 & 221 & 220 & 214 & 213 & 212 \\
\hline 0.60 & 0.00440 & 14.84 & 269 & 230 & 212 & 209 & 207 & 207 & 206 \\
\hline 0.60 & 0.00352 & 16.03 & 267 & 232 & 218 & 214 & 211 & 209 & 209 \\
\hline 0.60 & 0.00281 & 16.96 & 259 & 213 & 193 & 185 & 182 & 182 & 181 \\
\hline 0.60 & 0.00225 & 15.04 & 277 & 251 & 228 & 223 & 222 & 222 & 221 \\
\hline 0.60 & 0.00180 & 18.28 & 278 & 251 & 229 & 222 & 220 & 219 & 216 \\
\hline 0.60 & 0.00144 & 18.09 & 280 & 256 & 232 & 209 & 205 & 205 & 205 \\
\hline 0.60 & 0.00115 & 18.81 & 296 & 272 & 238 & 215 & 211 & 211 & 211 \\
\hline 0.60 & 0.00092 & 21.68 & 298 & 285 & 255 & 234 & 219 & 218 & 218 \\
\hline 0.60 & 0.00074 & 24.11 & 301 & 285 & 261 & 231 & 214 & 213 & 213 \\
\hline 0.60 & 0.00059 & 24.11 & 309 & 296 & 271 & 240 & 226 & 226 & 225 \\
\hline 0.60 & 0.00000 & 9.63 & 320 & 320 & 320 & 320 & 320 & 320 & 320 \\
\hline 0.65 & 0.10000 & 60.13 & 631 & 352 & 181 & 52 & 1 & 0 & 0 \\
\hline 0.65 & 0.08000 & 39.78 & 493 & 231 & 76 & 14 & 0 & 0 & 0 \\
\hline 0.65 & 0.06400 & 29.77 & 374 & 146 & 35 & 3 & 0 & 0 & 0 \\
\hline 0.65 & 0.05120 & 25.60 & 282 & 106 & 25 & 2 & 0 & 0 & 0 \\
\hline 0.65 & 0.04096 & 27.35 & 190 & 110 & 56 & 16 & 0 & 0 & 0 \\
\hline 0.65 & 0.03277 & 55.94 & 208 & 160 & 132 & 94 & 23 & 13 & 2 \\
\hline 0.65 & 0.02621 & 66.03 & 200 & 180 & 166 & 142 & 95 & 71 & 48 \\
\hline 0.65 & 0.02097 & 58.21 & 205 & 189 & 182 & 172 & 141 & 125 & 101 \\
\hline 0.65 & 0.01678 & 29.86 & 195 & 182 & 181 & 174 & 162 & 157 & 148 \\
\hline 0.65 & 0.01342 & 23.08 & 192 & 178 & 176 & 172 & 165 & 161 & 155 \\
\hline 0.65 & 0.01074 & 19.42 & 209 & 200 & 197 & 193 & 190 & 188 & 183 \\
\hline 0.65 & 0.00859 & \begin{tabular}{|l|}
14.87 \\
\end{tabular} & 227 & 209 & 206 & 205 & 201 & 201 & 199 \\
\hline 0.65 & 0.00687 & 12.64 & 201 & 185 & 180 & 180 & 180 & 179 & 178 \\
\hline 0.65 & 0.00550 & 11.80 & 225 & 200 & 193 & 193 & 192 & 192 & 192 \\
\hline 0.65 & 0.00440 & 14.48 & 247 & 214 & 200 & 198 & 195 & 195 & 194 \\
\hline 0.65 & 0.00352 & 13.14 & 239 & 205 & 190 & 188 & 186 & 186 & 186 \\
\hline 0.65 & 0.00281 & 13.97 & 256 & 225 & 196 & 195 & 193 & 193 & 193 \\
\hline 0.65 & 0.00225 & 14.96 & 267 & 242 & 213 & 211 & 209 & 209 & 208 \\
\hline 0.65 & 0.00180 & 14.71 & 237 & 217 & 195 & 188 & 188 & 186 & 186 \\
\hline 0.65 & 0.00144 & 14.37 & 255 & 239 & 221 & 209 & 206 & 206 & 206 \\
\hline 0.65 & 0.00115 & \begin{tabular}{|l|}
15.49 \\
\end{tabular} & 255 & 240 & 210 & 198 & 198 & 197 & 197 \\
\hline 0.65 & 0.00092 & 23.04 & 261 & 246 & 226 & 202 & 192 & 191 & 188 \\
\hline 0.65 & 0.00074 & 20.61 & 281 & 261 & 241 & 226 & 213 & 212 & 211 \\
\hline 0.65 & 0.00059 & 23.72 & 298 & 287 & 271 & 248 & 232 & 228 & 228 \\
\hline 0.65 & 0.00000 & 9.45 & 283 & 283 & 283 & 283 & 283 & 283 & 283 \\
\hline
\end{tabular}


- Para tamanho da população $=60$ (cont.)

\begin{tabular}{|c|c|c|c|c|c|c|c|c|c|}
\hline $\mathrm{Pc}$ & $\mathrm{Pm}$ & Media & NaoAte25 & NaoAte50 & NaoAte100 & NaoAte200 & NaoAte500 & NaoAte700 & NaoAte1000 \\
\hline 0.70 & 0.10000 & 58.67 & 631 & 352 & 171 & 53 & 2 & 0 & 0 \\
\hline 0.70 & 0.08000 & 39.66 & 495 & 247 & 78 & 11 & 0 & 0 & 0 \\
\hline 0.70 & 0.06400 & 27.33 & 336 & 134 & 29 & 0 & 0 & 0 & 0 \\
\hline 0.70 & 0.05120 & 24.34 & 257 & 99 & 25 & 1 & 0 & 0 & 0 \\
\hline 0.70 & 0.04096 & 23.97 & 200 & 86 & 37 & 8 & 0 & 0 & 0 \\
\hline 0.70 & 0.03277 & 50.88 & 203 & 168 & 138 & 82 & 11 & 4 & 0 \\
\hline 0.70 & 0.02621 & 59.53 & 172 & 152 & 145 & 117 & 68 & 52 & 32 \\
\hline 0.70 & 0.02097 & 45.25 & 171 & 160 & 154 & 138 & 118 & 111 & 90 \\
\hline 0.70 & 0.01678 & 30.09 & 171 & 165 & 162 & 159 & 148 & 137 & 130 \\
\hline 0.70 & 0.01342 & 22.77 & 191 & 185 & 184 & 181 & 177 & 174 & 166 \\
\hline 0.70 & 0.01074 & 17.35 & 217 & 210 & 207 & 204 & 201 & 200 & 196 \\
\hline 0.70 & 0.00859 & 12.40 & 181 & 162 & 162 & 161 & 158 & 157 & 157 \\
\hline 0.70 & 0.00687 & 13.66 & 195 & 179 & 173 & 171 & 169 & 168 & 167 \\
\hline 0.70 & 0.00550 & 12.32 & 234 & 218 & 213 & 213 & 213 & 211 & 211 \\
\hline 0.70 & 0.00440 & 12.38 & 231 & 200 & 196 & 195 & 193 & 193 & 193 \\
\hline 0.70 & 0.00352 & 13.18 & 224 & 196 & 186 & 185 & 183 & 182 & 182 \\
\hline 0.70 & 0.00281 & 13.06 & 249 & 229 & 215 & 211 & 209 & 209 & 209 \\
\hline 0.70 & 0.00225 & 13.93 & 241 & 212 & 196 & 194 & 194 & 193 & 192 \\
\hline 0.70 & 0.00180 & 13.09 & 229 & 204 & 183 & 180 & 178 & 178 & 178 \\
\hline 0.70 & 0.00144 & 16.08 & 248 & 235 & 209 & 198 & 192 & 192 & 192 \\
\hline 0.70 & 0.00115 & 14.88 & 219 & 205 & 182 & 163 & 162 & 162 & 162 \\
\hline 0.70 & 0.00092 & 17.06 & 247 & 231 & 208 & 191 & 184 & 184 & 184 \\
\hline 0.70 & 0.00074 & 17.98 & 264 & 251 & 233 & 214 & 204 & 204 & 204 \\
\hline 0.70 & 0.00059 & 24.34 & 268 & 259 & 240 & 210 & 196 & 195 & 193 \\
\hline 0.70 & 0.00000 & 9.29 & 248 & 248 & 248 & 248 & 248 & 248 & 248 \\
\hline 0.75 & 0.10000 & 52.70 & 610 & 325 & 133 & 35 & 0 & 0 & 0 \\
\hline 0.75 & 0.08000 & 39.58 & 485 & 219 & 78 & 15 & 0 & 0 & 0 \\
\hline 0.75 & 0.06400 & 28.53 & 360 & 135 & 33 & 2 & 0 & 0 & 0 \\
\hline 0.75 & 0.05120 & 21.91 & 230 & 78 & 15 & 0 & 0 & 0 & 0 \\
\hline 0.75 & 0.04096 & 23.16 & 189 & 95 & 32 & 4 & 0 & 0 & 0 \\
\hline 0.75 & 0.03277 & 40.70 & 176 & 133 & 95 & 55 & 12 & 1 & 0 \\
\hline 0.75 & 0.02621 & 63.67 & 161 & 149 & 140 & 115 & 72 & 58 & 29 \\
\hline 0.75 & 0.02097 & 57.77 & 186 & 171 & 164 & 156 & 127 & 109 & 84 \\
\hline 0.75 & 0.01678 & 44.81 & 159 & 156 & 155 & 146 & 132 & 116 & 98 \\
\hline 0.75 & 0.01342 & 26.18 & 165 & 157 & 154 & 149 & 144 & 137 & 129 \\
\hline 0.75 & 0.01074 & 16.54 & 177 & 160 & 157 & 154 & 149 & 147 & 145 \\
\hline 0.75 & 0.00859 & 13.21 & 184 & 173 & 172 & 171 & 171 & 169 & 168 \\
\hline 0.75 & 0.00687 & 11.84 & 191 & 177 & 173 & 172 & 171 & 170 & 170 \\
\hline 0.75 & 0.00550 & 13.08 & 192 & 176 & 173 & 172 & 171 & 170 & 169 \\
\hline 0.75 & 0.00440 & 11.20 & 198 & 177 & 174 & 174 & 172 & 172 & 172 \\
\hline 0.75 & 0.00352 & 13.19 & 183 & 163 & 156 & 155 & 155 & 153 & 152 \\
\hline 0.75 & 0.00281 & 13.70 & 210 & 181 & 171 & 166 & 166 & 165 & 164 \\
\hline 0.75 & 0.00225 & 11.86 & 196 & 180 & 169 & 167 & 166 & 166 & 166 \\
\hline 0.75 & 0.00180 & 13.21 & 192 & 180 & 169 & 161 & 161 & 161 & 160 \\
\hline 0.75 & 0.00144 & 12.88 & 194 & 178 & 166 & 157 & 154 & 154 & 154 \\
\hline 0.75 & 0.00115 & 13.38 & 202 & 187 & 173 & 164 & 161 & 161 & 161 \\
\hline 0.75 & 0.00092 & 16.65 & 219 & 208 & 199 & 185 & 175 & 175 & 174 \\
\hline 0.75 & 0.00074 & 15.14 & 211 & 204 & 192 & 180 & 171 & 171 & 171 \\
\hline 0.75 & 0.00059 & 18.09 & 214 & 203 & 197 & 172 & 165 & 163 & 163 \\
\hline 0.75 & 0.00000 & 9.21 & 244 & 244 & 244 & 244 & 244 & 244 & 244 \\
\hline
\end{tabular}


- Para tamanho da população $=60$ (cont.)

\begin{tabular}{|c|c|c|c|c|c|c|c|c|c|}
\hline $\mathrm{Pc}$ & $\mathrm{Pm}$ & Media & NaoAte25 & NaoAte50 & NaoAte100 & NaoAte200 & NaoAte500 & NaoAte700 & NaoAte1000 \\
\hline 0.80 & 0.10000 & 55.56 & 621 & 333 & 145 & 40 & 2 & 0 & 0 \\
\hline 0.80 & 0.08000 & 38.75 & 502 & 218 & 75 & 5 & 0 & 0 & 0 \\
\hline 0.80 & 0.06400 & 27.33 & 340 & 122 & 24 & 2 & 0 & 0 & 0 \\
\hline 0.80 & 0.05120 & 21.97 & 229 & 79 & 10 & 0 & 0 & 0 & 0 \\
\hline 0.80 & 0.04096 & 22.61 & 179 & 86 & 25 & 5 & 0 & 0 & 0 \\
\hline 0.80 & 0.03277 & 33.47 & 155 & 121 & 88 & 34 & 5 & 1 & 0 \\
\hline 0.80 & 0.02621 & 43.72 & 122 & 111 & 102 & 81 & 41 & 28 & 20 \\
\hline 0.80 & 0.02097 & 48.84 & 149 & 141 & 131 & 124 & 97 & 80 & 62 \\
\hline 0.80 & 0.01678 & 40.73 & 180 & 172 & 169 & 164 & 149 & 142 & 124 \\
\hline 0.80 & 0.01342 & 22.08 & 161 & 156 & 152 & 148 & 141 & 137 & 132 \\
\hline 0.80 & 0.01074 & 13.67 & 164 & 154 & 153 & 152 & 150 & 148 & 147 \\
\hline 0.80 & 0.00859 & 13.08 & 168 & 159 & 157 & 157 & 153 & 152 & 151 \\
\hline 0.80 & 0.00687 & 12.47 & 159 & 146 & 142 & 141 & 139 & 137 & 137 \\
\hline 0.80 & 0.00550 & 12.25 & 163 & 148 & 145 & 144 & 144 & 143 & 142 \\
\hline 0.80 & 0.00440 & 10.74 & 158 & 142 & 138 & 138 & 137 & 137 & 137 \\
\hline 0.80 & 0.00352 & 10.67 & 160 & 148 & 143 & 143 & 143 & 142 & 142 \\
\hline 0.80 & 0.00281 & 13.09 & 192 & 175 & 165 & 163 & 162 & 160 & 160 \\
\hline 0.80 & 0.00225 & 11.26 & 186 & 169 & 162 & 157 & 157 & 157 & 157 \\
\hline 0.80 & 0.00180 & 12.56 & 198 & 184 & 169 & 163 & 161 & 161 & 161 \\
\hline 0.80 & 0.00144 & 12.65 & 189 & 180 & 168 & 158 & 156 & 156 & 156 \\
\hline 0.80 & 0.00115 & 15.03 & 212 & 202 & 180 & 170 & 164 & 164 & 164 \\
\hline 0.80 & 0.00092 & 14.61 & 213 & 204 & 194 & 179 & 176 & 176 & 175 \\
\hline 0.80 & 0.00074 & 15.81 & 198 & 187 & 175 & 163 & 156 & 156 & 155 \\
\hline 0.80 & 0.00059 & 14.43 & 201 & 189 & 173 & 168 & 160 & 160 & 160 \\
\hline 0.80 & 0.00000 & 9.02 & 207 & 207 & 207 & 207 & 207 & 207 & 207 \\
\hline 0.85 & 0.10000 & 56.35 & 630 & 352 & 158 & 43 & 1 & 0 & 0 \\
\hline 0.85 & 0.08000 & 36.80 & 493 & 203 & 64 & 8 & 0 & 0 & 0 \\
\hline 0.85 & 0.06400 & 28.06 & 352 & 134 & 29 & 0 & 0 & 0 & 0 \\
\hline 0.85 & 0.05120 & 21.88 & 253 & 79 & 9 & 0 & 0 & 0 & 0 \\
\hline 0.85 & 0.04096 & 19.43 & 162 & 58 & 14 & 1 & 0 & 0 & 0 \\
\hline 0.85 & 0.03277 & 27.22 & 131 & 84 & 53 & 27 & 3 & 0 & 0 \\
\hline 0.85 & 0.02621 & 53.64 & 132 & 116 & 103 & 90 & 47 & 28 & 10 \\
\hline 0.85 & 0.02097 & 43.73 & 137 & 123 & 116 & 109 & 88 & 71 & 56 \\
\hline 0.85 & 0.01678 & 26.14 & 119 & 115 & 109 & 103 & 94 & 88 & 80 \\
\hline 0.85 & 0.01342 & 22.99 & 156 & 154 & 153 & 149 & 141 & 138 & 130 \\
\hline 0.85 & 0.01074 & 17.55 & 152 & 144 & 140 & 139 & 133 & 132 & 128 \\
\hline 0.85 & 0.00859 & 14.49 & 144 & 141 & 140 & 139 & 137 & 136 & 133 \\
\hline 0.85 & 0.00687 & 11.35 & 149 & 137 & 135 & 135 & 134 & 134 & 133 \\
\hline 0.85 & 0.00550 & 9.94 & 171 & 162 & 160 & 160 & 160 & 160 & 160 \\
\hline 0.85 & 0.00440 & 10.32 & 163 & 153 & 148 & 148 & 148 & 148 & 148 \\
\hline 0.85 & 0.00352 & 10.27 & 156 & 141 & 137 & 136 & 136 & 136 & 136 \\
\hline 0.85 & 0.00281 & 10.90 & 172 & 155 & 149 & 147 & 146 & 146 & 146 \\
\hline 0.85 & 0.00225 & 10.27 & 177 & 163 & 157 & 156 & 156 & 156 & 156 \\
\hline 0.85 & 0.00180 & 10.82 & 167 & 154 & 148 & 144 & 143 & 143 & 143 \\
\hline 0.85 & 0.00144 & 11.11 & 178 & 170 & 159 & 155 & 154 & 154 & 154 \\
\hline 0.85 & 0.00115 & 11.09 & 148 & 139 & 134 & 128 & 127 & 127 & 127 \\
\hline 0.85 & 0.00092 & 12.00 & 147 & 146 & 143 & 137 & 134 & 133 & 133 \\
\hline 0.85 & 0.00074 & 14.27 & 166 & 160 & 147 & 142 & 139 & 139 & 137 \\
\hline 0.85 & 0.00059 & 16.16 & 174 & 167 & 157 & 152 & 142 & 141 & 140 \\
\hline 0.85 & 0.00000 & 8.97 & 179 & 179 & 179 & 179 & 179 & 179 & 179 \\
\hline
\end{tabular}


- Para tamanho da população $=60$ (cont.)

\begin{tabular}{|c|c|c|c|c|c|c|c|c|c|}
\hline $\mathrm{Pc}$ & $\mathrm{Pm}$ & Media & NaoAte25 & \begin{tabular}{|l|} 
NaoAte50 \\
\end{tabular} & NaoAte100 & NaoAte200 & NaoAte500 & \begin{tabular}{|l|} 
NaoAte700 \\
\end{tabular} & NaoAte 1000 \\
\hline 0.90 & 0.10000 & 54.63 & 635 & 341 & 147 & 33 & 0 & 0 & 0 \\
\hline 0.90 & 0.08000 & 38.41 & 509 & 215 & 76 & 6 & 0 & 0 & 0 \\
\hline 0.90 & 0.06400 & 28.07 & 357 & 136 & 26 & 0 & 0 & 0 & 0 \\
\hline 0.90 & 0.05120 & 20.06 & 228 & 44 & 6 & 0 & 0 & 0 & 0 \\
\hline 0.90 & 0.04096 & 18.58 & 160 & 48 & 12 & 0 & 0 & 0 & 0 \\
\hline 0.90 & 0.03277 & 23.22 & 121 & 76 & 48 & 16 & 0 & 0 & 0 \\
\hline 0.90 & 0.02621 & 44.92 & 133 & 112 & 93 & 78 & 31 & 20 & 9 \\
\hline 0.90 & 0.02097 & 48.44 & 125 & 119 & 111 & 104 & 81 & 61 & 44 \\
\hline 0.90 & 0.01678 & 30.00 & 105 & 99 & 97 & 93 & 82 & 72 & 62 \\
\hline 0.90 & 0.01342 & 22.21 & 125 & 121 & 120 & 118 & 110 & 107 & 100 \\
\hline 0.90 & 0.01074 & 14.07 & 147 & 142 & 140 & 140 & 137 & 136 & 134 \\
\hline 0.90 & 0.00859 & 12.59 & 144 & 134 & 134 & 134 & 134 & 131 & 130 \\
\hline 0.90 & 0.00687 & 13.14 & 135 & 125 & 124 & 123 & 121 & 121 & 119 \\
\hline 0.90 & 0.00550 & 10.71 & 135 & 128 & 124 & 124 & 124 & 123 & 123 \\
\hline 0.90 & 0.00440 & 10.40 & 144 & 132 & 127 & 127 & 126 & 126 & 126 \\
\hline 0.90 & 0.00352 & 9.85 & 129 & 121 & 118 & 118 & 118 & 118 & 118 \\
\hline 0.90 & 0.00281 & 10.51 & 160 & 156 & 145 & 144 & 144 & 144 & 144 \\
\hline 0.90 & 0.00225 & \begin{tabular}{|l|}
10.01 \\
\end{tabular} & 142 & 135 & 130 & 129 & 129 & 129 & 129 \\
\hline 0.90 & 0.00180 & 10.31 & 140 & 135 & 127 & 125 & 125 & 125 & 125 \\
\hline 0.90 & 0.00144 & 10.40 & 162 & 158 & 147 & 144 & 144 & 144 & 144 \\
\hline 0.90 & 0.00115 & 10.99 & 163 & 156 & 144 & 140 & 140 & 140 & 140 \\
\hline 0.90 & 0.00092 & 11.68 & 165 & 165 & 153 & 148 & 146 & 146 & 146 \\
\hline 0.90 & 0.00074 & 11.28 & 157 & 151 & 146 & 139 & 138 & 138 & 138 \\
\hline 0.90 & 0.00059 & 11.65 & 156 & 154 & 148 & 139 & 137 & 137 & 137 \\
\hline 0.90 & 0.00000 & 8.97 & 155 & 155 & 155 & 155 & 155 & 155 & 155 \\
\hline 0.95 & 0.10000 & 53.52 & 618 & 329 & 132 & 38 & 2 & 0 & 0 \\
\hline 0.95 & 0.08000 & 36.00 & 481 & 209 & 70 & 5 & 0 & 0 & 0 \\
\hline 0.95 & 0.06400 & 27.26 & 343 & 129 & 24 & 0 & 0 & 0 & 0 \\
\hline 0.95 & 0.05120 & 20.05 & 226 & 52 & 6 & 0 & 0 & 0 & 0 \\
\hline 0.95 & 0.04096 & 18.27 & 174 & 43 & 4 & 0 & 0 & 0 & 0 \\
\hline 0.95 & 0.03277 & 22.40 & 124 & 70 & 37 & 19 & 0 & 0 & 0 \\
\hline 0.95 & 0.02621 & 39.25 & 118 & 97 & 85 & 60 & 19 & 10 & 3 \\
\hline 0.95 & 0.02097 & 40.24 & 118 & 102 & 94 & 80 & 61 & 46 & 34 \\
\hline 0.95 & 0.01678 & 26.20 & 102 & 98 & 97 & 93 & 86 & 81 & 70 \\
\hline 0.95 & 0.01342 & 20.32 & 132 & 131 & 130 & 128 & 120 & 119 & 113 \\
\hline 0.95 & 0.01074 & 13.20 & 132 & 127 & 126 & 124 & 122 & 119 & 119 \\
\hline 0.95 & 0.00859 & 13.07 & 114 & 111 & 110 & 110 & 108 & 107 & 105 \\
\hline 0.95 & 0.00687 & 14.49 & 141 & 132 & 130 & 129 & 128 & 127 & 124 \\
\hline 0.95 & 0.00550 & 11.32 & 132 & 123 & 123 & 123 & 123 & 122 & 121 \\
\hline 0.95 & 0.00440 & 11.45 & 139 & 132 & 130 & 130 & 128 & 128 & 127 \\
\hline 0.95 & 0.00352 & 9.52 & 119 & 115 & 114 & 114 & 114 & 114 & 114 \\
\hline 0.95 & 0.00281 & 10.42 & 131 & 127 & 125 & 123 & 123 & 122 & 122 \\
\hline 0.95 & 0.00225 & 10.12 & 129 & 122 & 119 & 116 & 116 & 116 & 116 \\
\hline 0.95 & 0.00180 & 11.00 & 134 & 126 & 118 & 116 & 116 & 115 & 115 \\
\hline 0.95 & 0.00144 & 10.91 & 129 & 124 & 117 & 111 & 110 & 110 & 110 \\
\hline 0.95 & 0.00115 & 11.16 & 136 & 127 & 121 & 115 & 114 & 114 & 114 \\
\hline 0.95 & 0.00092 & 10.33 & 131 & 124 & 119 & 119 & 116 & 116 & 116 \\
\hline 0.95 & 0.00074 & 10.81 & 139 & 135 & 132 & 127 & 124 & 124 & 124 \\
\hline 0.95 & 0.00059 & 11.15 & 132 & 131 & 127 & 119 & 117 & 117 & 117 \\
\hline 0.95 & 0.00000 & 9.14 & 148 & 148 & 148 & 148 & 148 & 148 & 148 \\
\hline 1.00 & 0.10000 & 58.83 & 620 & 344 & 169 & 46 & 1 & 0 & 0 \\
\hline 1.00 & 0.08000 & 35.45 & 446 & 198 & 56 & 7 & 0 & 0 & 0 \\
\hline 1.00 & 0.06400 & 26.22 & 339 & 114 & 22 & 2 & 0 & 0 & 0 \\
\hline 1.00 & 0.05120 & 20.45 & 227 & 62 & 2 & 0 & 0 & 0 & 0 \\
\hline 1.00 & 0.04096 & 18.08 & 160 & 44 & 6 & 0 & 0 & 0 & 0 \\
\hline 1.00 & 0.03277 & 20.73 & 113 & 52 & 39 & 11 & 0 & 0 & 0 \\
\hline 1.00 & 0.02621 & 30.36 & 92 & 74 & 64 & 43 & 11 & 5 & 3 \\
\hline 1.00 & 0.02097 & 38.05 & 85 & 78 & 71 & 64 & 44 & 31 & 19 \\
\hline 1.00 & 0.01678 & 27.77 & 109 & 100 & 100 & 94 & 83 & 73 & 67 \\
\hline 1.00 & 0.01342 & 17.46 & 92 & 86 & 85 & 84 & 78 & 75 & 72 \\
\hline 1.00 & 0.01074 & 17.37 & 132 & 126 & 126 & 126 & 118 & 117 & 113 \\
\hline 1.00 & 0.00859 & 12.68 & 105 & 105 & 105 & 105 & 104 & 103 & 101 \\
\hline 1.00 & 0.00687 & 13.35 & 115 & 108 & 106 & 106 & 104 & 103 & 101 \\
\hline 1.00 & 0.00550 & 10.29 & 113 & 111 & 111 & 111 & 111 & 111 & 110 \\
\hline 1.00 & 0.00440 & 9.72 & 114 & 107 & 107 & 107 & 107 & 107 & 107 \\
\hline 1.00 & 0.00352 & 9.71 & 111 & 102 & 100 & 100 & 100 & 100 & 100 \\
\hline 1.00 & 0.00281 & 10.16 & 133 & 126 & 122 & 122 & 121 & 121 & 121 \\
\hline 1.00 & 0.00225 & 9.61 & 112 & 112 & 109 & 107 & 107 & 107 & 107 \\
\hline 1.00 & 0.00180 & 9.81 & 118 & 115 & 109 & 106 & 106 & 106 & 106 \\
\hline 1.00 & 0.00144 & 10.71 & 130 & 122 & 113 & 110 & 109 & 109 & 109 \\
\hline 1.00 & 0.00115 & 10.09 & 123 & 118 & 116 & 110 & 110 & 110 & 110 \\
\hline 1.00 & 0.00092 & 10.72 & 118 & 114 & 112 & 106 & 105 & 104 & 104 \\
\hline 1.00 & 0.00074 & 11.29 & 113 & 111 & 107 & 99 & 98 & 97 & 97 \\
\hline 1.00 & 0.00059 & 10.85 & 110 & 108 & 103 & 99 & 95 & 95 & 95 \\
\hline
\end{tabular}


- Para tamanho da população $=40$

\begin{tabular}{|c|c|c|c|c|c|c|c|c|c|}
\hline Pc & $\mathrm{Pm}$ & Media & NaoAte25 & NaoAte50 & NaoAte100 & NaoAte200 & NaoAte500 & NaoAte700 & NaoAte1000 \\
\hline 0.50 & 0.10000 & 81.60 & 700 & 425 & 234 & 117 & 10 & 1 & 0 \\
\hline 0.50 & 0.08000 & 63.50 & 593 & 333 & 183 & 72 & 1 & 0 & 0 \\
\hline 0.50 & 0.06400 & 52.42 & 503 & 277 & 159 & 37 & 1 & 1 & 0 \\
\hline 0.50 & 0.05120 & 58.35 & 410 & 253 & 177 & 74 & 8 & 3 & 0 \\
\hline 0.50 & 0.04096 & 91.75 & 383 & 278 & 236 & 162 & 39 & 20 & 3 \\
\hline 0.50 & 0.03277 & 111.06 & 381 & 308 & 275 & 227 & 129 & 96 & 56 \\
\hline 0.50 & 0.02621 & 95.09 & 427 & 349 & 327 & 310 & 252 & 229 & 194 \\
\hline 0.50 & 0.02097 & 59.24 & 383 & 314 & 302 & 288 & 270 & 254 & 233 \\
\hline 0.50 & 0.01678 & 49.42 & 425 & 349 & 329 & 314 & 300 & 291 & 277 \\
\hline 0.50 & 0.01342 & 30.77 & 445 & 359 & 340 & 330 & 319 & 315 & 312 \\
\hline 0.50 & 0.01074 & 26.79 & 467 & 388 & 371 & 367 & 356 & 354 & 352 \\
\hline 0.50 & 0.00859 & 28.40 & 470 & 390 & 359 & 346 & 338 & 333 & 333 \\
\hline 0.50 & 0.00687 & 31.21 & 469 & 388 & 349 & 331 & 324 & 320 & 317 \\
\hline 0.50 & 0.00550 & 47.85 & 539 & 450 & 405 & 381 & 362 & 357 & 349 \\
\hline 0.50 & 0.00440 & 41.81 & 547 & 455 & 406 & 387 & 373 & 369 & 363 \\
\hline 0.50 & 0.00352 & 41.84 & 560 & 490 & 426 & 404 & 393 & 387 & 382 \\
\hline 0.50 & 0.00281 & 52.52 & 543 & 473 & 414 & 382 & 361 & 359 & 349 \\
\hline 0.50 & 0.00225 & 51.93 & 566 & 502 & 429 & 388 & 367 & 363 & 355 \\
\hline 0.50 & 0.00180 & 46.42 & 578 & 518 & 448 & 393 & 372 & 368 & 366 \\
\hline 0.50 & 0.00144 & 49.29 & 585 & 538 & 458 & 410 & 378 & 374 & 373 \\
\hline 0.50 & 0.00115 & 63.41 & 580 & 535 & 483 & 414 & 363 & 360 & 357 \\
\hline 0.50 & 0.00092 & 79.72 & 602 & 567 & 519 & 453 & 391 & 377 & 371 \\
\hline 0.50 & 0.00074 & 85.25 & 623 & 593 & 540 & 480 & 405 & 397 & 390 \\
\hline 0.50 & 0.00059 & 115.87 & 652 & 632 & 588 & 522 & 431 & 409 & 397 \\
\hline 0.50 & 0.00000 & 10.26 & 618 & 617 & 617 & 617 & 617 & 617 & 617 \\
\hline 0.55 & 0.10000 & 88.70 & 682 & 426 & 244 & 125 & 16 & 5 & 0 \\
\hline 0.55 & 0.08000 & 57.27 & 586 & 296 & 168 & 48 & 0 & 0 & 0 \\
\hline 0.55 & 0.06400 & 50.55 & 498 & 269 & 131 & 44 & 3 & 0 & 0 \\
\hline 0.55 & 0.05120 & 51.08 & 407 & 246 & 147 & 50 & 4 & 1 & 0 \\
\hline 0.55 & 0.04096 & 74.56 & 367 & 254 & 195 & 128 & 26 & 8 & 2 \\
\hline 0.55 & 0.03277 & 105.24 & 351 & 271 & 237 & 204 & 109 & 75 & 39 \\
\hline 0.55 & 0.02621 & 86.74 & 344 & 271 & 251 & 234 & 191 & 161 & 126 \\
\hline 0.55 & 0.02097 & 55.90 & 380 & 325 & 310 & 295 & 274 & 258 & 243 \\
\hline 0.55 & 0.01678 & 38.98 & 379 & 324 & 313 & 308 & 296 & 291 & 279 \\
\hline 0.55 & 0.01342 & 27.82 & 399 & 345 & 327 & 321 & 316 & 314 & 308 \\
\hline 0.55 & 0.01074 & 28.72 & 429 & 357 & 338 & 326 & 319 & 317 & 313 \\
\hline 0.55 & 0.00859 & 29.71 & 455 & 390 & 358 & 344 & 336 & 332 & 330 \\
\hline 0.55 & 0.00687 & 30.73 & 471 & 386 & 363 & 352 & 343 & 337 & 335 \\
\hline 0.55 & 0.00550 & 32.53 & 470 & 393 & 354 & 339 & 325 & 322 & 319 \\
\hline 0.55 & 0.00440 & 34.94 & 485 & 388 & 347 & 334 & 323 & 319 & 314 \\
\hline 0.55 & 0.00352 & 40.76 & 518 & 441 & 380 & 355 & 343 & 338 & 333 \\
\hline 0.55 & 0.00281 & 39.59 & 530 & 464 & 393 & 362 & 347 & 344 & 341 \\
\hline 0.55 & 0.00225 & 46.00 & 527 & 468 & 402 & 356 & 342 & 337 & 331 \\
\hline 0.55 & 0.00180 & 47.65 & 525 & 469 & 409 & 373 & 359 & 357 & 346 \\
\hline 0.55 & 0.00144 & 50.88 & 548 & 514 & 459 & 404 & 377 & 372 & 369 \\
\hline 0.55 & 0.00115 & 58.74 & 571 & 543 & 491 & 430 & 395 & 390 & 384 \\
\hline 0.55 & 0.00092 & 60.00 & 566 & 531 & 484 & 422 & 376 & 371 & 367 \\
\hline 0.55 & 0.00074 & 66.81 & 561 & 527 & 492 & 442 & 382 & 377 & 370 \\
\hline 0.55 & 0.00059 & 77.35 & 586 & 561 & 526 & 472 & 407 & 390 & 389 \\
\hline 0.55 & 0.00000 & 10.14 & 597 & 597 & 597 & 597 & 597 & 597 & 597 \\
\hline
\end{tabular}


- Para tamanho da população $=40$ (cont.)

\begin{tabular}{|c|c|c|c|c|c|c|c|c|c|}
\hline Pc & $\mathrm{Pm}$ & Media & NaoAte25 & NaoAte50 & NaoAte100 & NaoAte200 & NaoAte500 & NaoAte700 & NaoAte 1000 \\
\hline 0.60 & 0.10000 & 80.37 & 704 & 434 & 244 & 97 & 6 & 1 & 0 \\
\hline 0.60 & 0.08000 & 57.41 & 583 & 329 & 173 & 45 & 1 & 1 & 0 \\
\hline 0.60 & 0.06400 & 44.64 & 459 & 247 & 123 & 27 & 0 & 0 & 0 \\
\hline 0.60 & 0.05120 & 45.05 & 385 & 214 & 115 & 42 & 2 & 0 & 0 \\
\hline 0.60 & 0.04096 & 63.28 & 333 & 226 & 166 & 90 & 18 & 6 & 0 \\
\hline 0.60 & 0.03277 & 92.32 & 320 & 248 & 218 & 175 & 83 & 49 & 28 \\
\hline 0.60 & 0.02621 & 89.43 & 328 & 272 & 257 & 237 & 185 & 149 & 120 \\
\hline 0.60 & 0.02097 & 71.02 & 373 & 313 & 296 & 286 & 261 & 244 & 215 \\
\hline 0.60 & 0.01678 & 36.38 & 368 & 318 & 304 & 298 & 282 & 277 & 270 \\
\hline 0.60 & 0.01342 & 28.48 & 379 & 318 & 306 & 294 & 284 & 280 & 277 \\
\hline 0.60 & 0.01074 & 34.33 & 394 & 328 & 307 & 296 & 287 & 283 & 275 \\
\hline 0.60 & 0.00859 & 20.81 & 412 & 339 & 322 & 308 & 305 & 305 & 304 \\
\hline 0.60 & 0.00687 & 26.00 & 421 & 346 & 312 & 301 & 293 & 291 & 290 \\
\hline 0.60 & 0.00550 & 35.79 & 483 & 411 & 372 & 356 & 342 & 340 & 335 \\
\hline 0.60 & 0.00440 & 26.96 & 467 & 413 & 366 & 349 & 343 & 342 & 340 \\
\hline 0.60 & 0.00352 & 35.44 & 490 & 425 & 372 & 346 & 328 & 325 & 324 \\
\hline 0.60 & 0.00281 & 37.45 & 471 & 416 & 359 & 328 & 311 & 308 & 304 \\
\hline 0.60 & 0.00225 & 37.31 & 486 & 442 & 391 & 342 & 328 & 323 & 321 \\
\hline 0.60 & 0.00180 & 39.42 & 515 & 476 & 409 & 368 & 347 & 346 & 343 \\
\hline 0.60 & 0.00144 & 44.21 & 515 & 483 & 426 & 384 & 359 & 355 & 352 \\
\hline 0.60 & 0.00115 & 46.81 & 520 & 488 & 443 & 384 & 353 & 350 & 348 \\
\hline 0.60 & 0.00092 & 51.78 & 518 & 479 & 426 & 369 & 331 & 326 & 323 \\
\hline 0.60 & 0.00074 & 63.91 & 517 & 480 & 438 & 376 & 314 & 309 & 305 \\
\hline 0.60 & 0.00059 & 73.02 & 509 & 486 & 449 & 406 & 327 & 315 & 312 \\
\hline 0.60 & 0.00000 & 9.98 & 540 & 540 & 540 & 540 & 540 & 540 & 540 \\
\hline 0.65 & 0.10000 & 44.17 & 547 & 262 & 104 & 15 & 0 & 0 & 0 \\
\hline 0.65 & 0.08000 & 32.75 & 416 & 173 & 49 & 5 & 0 & 0 & 0 \\
\hline 0.65 & 0.06400 & 22.02 & 249 & 68 & 5 & 1 & 0 & 0 & 0 \\
\hline 0.65 & 0.05120 & 17.53 & 161 & 34 & 2 & 0 & 0 & 0 & 0 \\
\hline 0.65 & 0.04096 & 17.75 & 125 & 51 & 14 & 1 & 0 & 0 & 0 \\
\hline 0.65 & 0.03277 & 29.85 & 114 & 89 & 66 & 33 & 8 & 3 & 1 \\
\hline 0.65 & 0.02621 & 36.90 & 86 & 86 & 79 & 65 & 30 & 17 & 12 \\
\hline 0.65 & 0.02097 & 38.09 & 105 & 99 & 93 & 84 & 65 & 53 & 39 \\
\hline 0.65 & 0.01678 & 22.98 & 103 & 99 & 96 & 92 & 84 & 81 & 73 \\
\hline 0.65 & 0.01342 & 21.35 & 95 & 95 & 95 & 94 & 91 & 86 & 78 \\
\hline 0.65 & 0.01074 & 10.97 & 101 & 97 & 96 & 96 & 95 & 95 & 94 \\
\hline 0.65 & 0.00859 & 9.76 & 114 & 109 & 109 & 107 & 107 & 107 & 107 \\
\hline 0.65 & 0.00687 & 10.01 & 122 & 120 & 119 & 119 & 118 & 118 & 118 \\
\hline 0.65 & 0.00550 & 9.55 & 99 & 92 & 92 & 92 & 92 & 92 & 92 \\
\hline 0.65 & 0.00440 & 10.26 & 105 & 97 & 96 & 96 & 94 & 94 & 94 \\
\hline 0.65 & 0.00352 & 9.49 & 117 & 109 & 107 & 107 & 107 & 107 & 107 \\
\hline 0.65 & 0.00281 & 9.80 & 128 & 115 & 112 & 112 & 112 & 112 & 112 \\
\hline 0.65 & 0.00225 & 9.90 & 118 & 108 & 104 & 104 & 103 & 103 & 103 \\
\hline 0.65 & 0.00180 & 10.67 & 125 & 116 & 113 & 111 & 110 & 109 & 109 \\
\hline 0.65 & 0.00144 & 10.95 & 123 & 116 & 110 & 109 & 108 & 107 & 107 \\
\hline 0.65 & 0.00115 & 10.01 & 135 & 126 & 122 & 120 & 119 & 119 & 119 \\
\hline 0.65 & 0.00092 & 11.78 & 132 & 125 & 116 & 110 & 109 & 109 & 108 \\
\hline 0.65 & 0.00074 & 11.77 & 143 & 136 & 129 & 123 & 119 & 119 & 119 \\
\hline 0.65 & 0.00059 & 11.61 & 143 & 136 & 129 & 122 & 119 & 119 & 119 \\
\hline 0.65 & 0.00000 & 8.84 & 133 & 133 & 133 & 133 & 133 & 133 & 133 \\
\hline
\end{tabular}


- Para tamanho da população = 40 (cont.)

\begin{tabular}{|c|c|c|c|c|c|c|c|c|c|}
\hline $\mathrm{Pc}$ & $\mathrm{Pm}$ & Media & NaoAte25 & NaoAte50 & NaoAte100 & NaoAte200 & NaoAte500 & NaoAte700 & NaoAte 1000 \\
\hline 0.70 & 0.10000 & 45.90 & 562 & 273 & 109 & 19 & 0 & 0 & 0 \\
\hline 0.70 & 0.08000 & 30.58 & 419 & 162 & 30 & 1 & 0 & 0 & 0 \\
\hline 0.70 & 0.06400 & 21.55 & 246 & 70 & 6 & 0 & 0 & 0 & 0 \\
\hline 0.70 & 0.05120 & 17.51 & 166 & 27 & 1 & 0 & 0 & 0 & 0 \\
\hline 0.70 & 0.04096 & 17.32 & 120 & 35 & 13 & 3 & 0 & 0 & 0 \\
\hline 0.70 & 0.03277 & 23.26 & 99 & 71 & 45 & 24 & 3 & 1 & 1 \\
\hline 0.70 & 0.02621 & 29.66 & 77 & 70 & 61 & 45 & 23 & 14 & 10 \\
\hline 0.70 & 0.02097 & 37.50 & 94 & 93 & 91 & 78 & 62 & 50 & 36 \\
\hline 0.70 & 0.01678 & 21.13 & 91 & 90 & 88 & 83 & 77 & 73 & 66 \\
\hline 0.70 & 0.01342 & 15.42 & 101 & 99 & 98 & 97 & 95 & 95 & 90 \\
\hline 0.70 & 0.01074 & 12.00 & 89 & 86 & 86 & 86 & 84 & 84 & 82 \\
\hline 0.70 & 0.00859 & 9.33 & 95 & 92 & 92 & 92 & 92 & 92 & 92 \\
\hline 0.70 & 0.00687 & 10.56 & 115 & 115 & 115 & 113 & 112 & 111 & 111 \\
\hline 0.70 & 0.00550 & 9.43 & 105 & 99 & 99 & 99 & 99 & 99 & 99 \\
\hline 0.70 & 0.00440 & 9.97 & 102 & 99 & 98 & 98 & 98 & 98 & 97 \\
\hline 0.70 & 0.00352 & 9.26 & 98 & 91 & 91 & 91 & 91 & 91 & 91 \\
\hline 0.70 & 0.00281 & 9.06 & 114 & 110 & 110 & 110 & 110 & 110 & 110 \\
\hline 0.70 & 0.00225 & 9.09 & 112 & 106 & 106 & 106 & 106 & 106 & 106 \\
\hline 0.70 & 0.00180 & 9.52 & 97 & 95 & 91 & 91 & 90 & 90 & 90 \\
\hline 0.70 & 0.00144 & 9.42 & 112 & 106 & 101 & 100 & 100 & 100 & 100 \\
\hline 0.70 & 0.00115 & 9.56 & 99 & 96 & 93 & 91 & 90 & 90 & 90 \\
\hline 0.70 & 0.00092 & 9.86 & 103 & 100 & 95 & 90 & 90 & 90 & 90 \\
\hline 0.70 & 0.00074 & 10.79 & 100 & 97 & 94 & 89 & 87 & 87 & 87 \\
\hline 0.70 & 0.00059 & 10.14 & 93 & 91 & 84 & 83 & 81 & 81 & 81 \\
\hline 0.70 & 0.00000 & 8.70 & 119 & 119 & 119 & 119 & 119 & 119 & 119 \\
\hline 0.75 & 0.10000 & 45.60 & 559 & 301 & 116 & 12 & 0 & 0 & 0 \\
\hline 0.75 & 0.08000 & 30.99 & 402 & 150 & 43 & 3 & 0 & 0 & 0 \\
\hline 0.75 & 0.06400 & 22.34 & 255 & 75 & 10 & 0 & 0 & 0 & 0 \\
\hline 0.75 & 0.05120 & 16.88 & 134 & 30 & 1 & 0 & 0 & 0 & 0 \\
\hline 0.75 & 0.04096 & 15.61 & 105 & 29 & 5 & 0 & 0 & 0 & 0 \\
\hline 0.75 & 0.03277 & 20.42 & 95 & 57 & 31 & 11 & 2 & 0 & 0 \\
\hline 0.75 & 0.02621 & 30.56 & 72 & 57 & 52 & 41 & 13 & 10 & 2 \\
\hline 0.75 & 0.02097 & 36.71 & 80 & 78 & 75 & 71 & 48 & 37 & 24 \\
\hline 0.75 & 0.01678 & 28.08 & 84 & 78 & 78 & 73 & 69 & 58 & 48 \\
\hline 0.75 & 0.01342 & 17.25 & 96 & 95 & 95 & 93 & 92 & 88 & 83 \\
\hline 0.75 & 0.01074 & 13.82 & 97 & 95 & 95 & 94 & 91 & 90 & 87 \\
\hline 0.75 & 0.00859 & 10.14 & 70 & 70 & 70 & 70 & 69 & 68 & 68 \\
\hline 0.75 & 0.00687 & 9.07 & 77 & 76 & 75 & 75 & 75 & 75 & 75 \\
\hline 0.75 & 0.00550 & 9.42 & 78 & 76 & 76 & 76 & 75 & 75 & 75 \\
\hline 0.75 & 0.00440 & 8.89 & 90 & 87 & 86 & 86 & 86 & 86 & 86 \\
\hline 0.75 & 0.00352 & 9.96 & 79 & 76 & 73 & 73 & 73 & 73 & 72 \\
\hline 0.75 & 0.00281 & 8.80 & 80 & 77 & 77 & 77 & 77 & 77 & 77 \\
\hline 0.75 & 0.00225 & 9.06 & 89 & 86 & 83 & 83 & 83 & 83 & 83 \\
\hline 0.75 & 0.00180 & 8.99 & 90 & 85 & 83 & 83 & 83 & 83 & 83 \\
\hline 0.75 & 0.00144 & 9.39 & 85 & 80 & 78 & 76 & 76 & 76 & 76 \\
\hline 0.75 & 0.00115 & 9.62 & 83 & 78 & 76 & 72 & 72 & 72 & 72 \\
\hline 0.75 & 0.00092 & 9.53 & 100 & 98 & 96 & 94 & 93 & 93 & 93 \\
\hline 0.75 & 0.00074 & 9.02 & 95 & 92 & 90 & 90 & 90 & 90 & 90 \\
\hline 0.75 & 0.00059 & 9.96 & 89 & 88 & 88 & 84 & 83 & 82 & 82 \\
\hline 0.75 & 0.00000 & 8.58 & 72 & 72 & 72 & 72 & 72 & 72 & 72 \\
\hline
\end{tabular}


- Para tamanho da população $=40$ (cont.)

\begin{tabular}{|c|c|c|c|c|c|c|c|c|c|}
\hline Pc & Pm & Media & NaoAte25 & NaoAte50 & NaoAte100 & NaoAte200 & NaoAte500 & NaoAte700 & NaoAte1000 \\
\hline 0.80 & 0.0000 & 46.39 & &
\end{tabular}

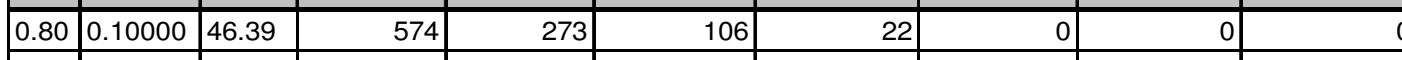

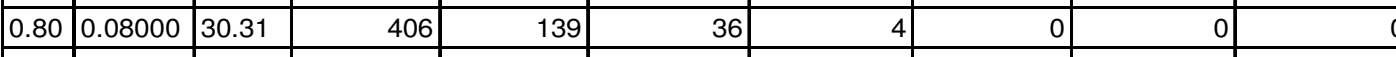

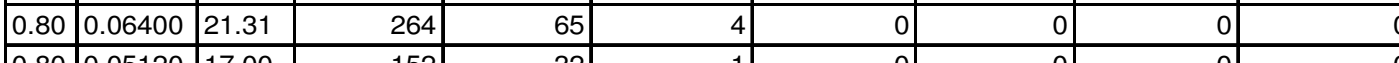

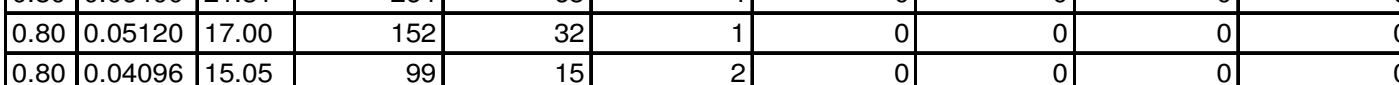

\begin{tabular}{|l|l|l|}
0.80 & 0.04096 \\
\hline 0.80 & 0.03277 \\
\hline
\end{tabular}

\begin{tabular}{|l|l|l|}
\hline 0.80 & 0.02621 & 23.66 \\
\hline 0.80 & 0.02097 & 26.51
\end{tabular}

\begin{tabular}{|l|l|l|}
\hline 0.80 & 0.02097 & 26.51 \\
\hline
\end{tabular}

\begin{tabular}{|l|l|l|}
\hline 0.80 & 0.01678 & 24.45 \\
\hline
\end{tabular}

\begin{tabular}{|l|l|l|}
\hline 0.80 & 0.01342 & 14.76 \\
\hline
\end{tabular}

\begin{tabular}{|l|l|l|}
\hline 0.80 & 0.01074 & 11.17 \\
\hline
\end{tabular}

\begin{tabular}{l|l|l|}
\hline 0.80 & 0.00859 & 10.13 \\
\hline
\end{tabular}

\begin{tabular}{|l|l|l|}
\hline 0.80 & 0.00687 & 9.76 \\
\hline
\end{tabular}

\begin{tabular}{l|l|l|}
\hline 0.80 & 0.00550 & 10.88
\end{tabular}

\begin{tabular}{|l|l|l|}
\hline 0.80 & 0.00440 & 8.97 \\
\hline
\end{tabular}

\begin{tabular}{l|l|l|l|}
0.80 & 0.00352 & 8.84 \\
\hline
\end{tabular}

\begin{tabular}{|l|l|l|}
\hline 0.80 & 0.00281 & 8.65 \\
\hline
\end{tabular}

\begin{tabular}{|l|l|l|}
\hline 0.80 & 0.00225 & 8.94 \\
\hline 0.80 & 0.00180 & 8.89 \\
\hline
\end{tabular}

\begin{tabular}{|l|l|l|}
\hline 0.80 & 0.00180 & 8.89 \\
\hline 0.80 & 0.00144 & 8.97
\end{tabular}

\begin{tabular}{|l|l|l|}
\hline 0.80 & 0.00144 & 8.97 \\
\hline
\end{tabular}

\begin{tabular}{|l|l|l|}
\hline 0.80 & 0.00115 & 8.96 \\
\hline
\end{tabular}

\begin{tabular}{|l|l|l|}
\hline 0.80 & 0.00092 & 9.10 \\
\hline 0.80 & 0.00074 & 8.94
\end{tabular}

\begin{tabular}{|l|l|l|}
\hline 0.80 & 0.00074 & 8.94 \\
\hline
\end{tabular}

\begin{tabular}{|l|l|l|}
\hline 0.80 & 0.00059 & 9.27 \\
\hline
\end{tabular}

\begin{tabular}{|l|l|l|}
\hline 0.80 & 0.00000 & 8.48 \\
\hline
\end{tabular}

\begin{tabular}{|l|l|l|}
\hline 0.85 & 0.10000 & 70.06 \\
\hline 0.85 & 0.08000 & 48.34
\end{tabular}

\begin{tabular}{|l|l|l|}
\hline 0.85 & 0.08000 & 48.34 \\
\hline 0.85 & 0.06400 & 34.34 \\
\hline
\end{tabular}

\begin{tabular}{|l|l|l|}
0.85 & 0.06400 & 34.34 \\
\hline
\end{tabular}

\begin{tabular}{|l|l|l|}
\hline 0.85 & 0.05120 & 30.43 \\
\hline
\end{tabular}

\begin{tabular}{|l|l|l|}
\hline 0.85 & 0.04096 & 35.12 \\
\hline
\end{tabular}

\begin{tabular}{|l|l|l|}
\hline 0.85 & 0.03277 & 64.79 \\
\hline 0.85 & 0.02621 & 91.86 \\
\hline
\end{tabular}

\begin{tabular}{l|l|l|}
\hline 0.85 & 0.02621 & 91.86 \\
\hline
\end{tabular}

\begin{tabular}{l|l|l|}
0.85 & 0.02097 & 70.07 \\
\hline
\end{tabular}

\begin{tabular}{|l|l|l|}
\hline 0.85 & 0.01678 & 46.62 \\
\hline
\end{tabular}

\begin{tabular}{|l|l|l|}
\hline 0.85 & 0.01342 & 30.18 \\
\hline 0.85 & 0.01074 & 25.59
\end{tabular}

\begin{tabular}{l|l|l|}
\hline 0.85 & 0.01074 & 25.59 \\
\hline
\end{tabular}

\begin{tabular}{|l|l|l|}
\hline 0.85 & 0.00859 & 19.69 \\
\hline
\end{tabular}

\begin{tabular}{|l|l|l|}
\hline 0.85 & 0.00687 & 19.48 \\
\hline
\end{tabular}

\begin{tabular}{|l|l|l|}
0.85 & 0.00550 & 17.01 \\
\hline
\end{tabular}

\begin{tabular}{l|l|l|}
0.85 & 0.00440 & 15.94 \\
\hline
\end{tabular}

\begin{tabular}{l|l|l|}
\hline 0.85 & 0.00352 & 17.33 \\
\hline
\end{tabular}

\begin{tabular}{l|l|l|}
\hline 0.85 & 0.00281 & 20.89 \\
\hline
\end{tabular}

\begin{tabular}{|l|l|l|}
\hline 0.85 & 0.00225 & 21.40 \\
\hline 0.85 & 0.00180 & 22.07
\end{tabular}

\begin{tabular}{|l|l|l|}
\hline 0.85 & 0.00180 & 22.07 \\
\hline
\end{tabular}

\begin{tabular}{l|l|l|}
\hline 0.85 & 0.00144 & 22.26 \\
\hline
\end{tabular}

\begin{tabular}{|l|l|l|}
\hline 0.85 & 0.00115 & 24.93 \\
\hline
\end{tabular}

\begin{tabular}{|l|l|l|}
\hline 0.85 & 0.00092 & 26.30 \\
\hline 0.85 & 0.00074 & 32.18
\end{tabular}

\begin{tabular}{|l|l|l|}
\hline 0.85 & 0.00074 & 32.18 \\
\hline
\end{tabular}

\begin{tabular}{l|l|l|}
\hline 0.85 & 0.00059 & 43.49
\end{tabular}

\begin{tabular}{|l|l|l|}
\hline 0.85 & 0.00000 & 9.64 \\
\hline
\end{tabular}

\begin{tabular}{l|l|l|}
99 & 15 & \\
82 & 37 & 20 \\
\hline 57 & 47 &
\end{tabular}

57

$73 \quad 70$

\begin{tabular}{l|l}
66 & 66 \\
\hline 61 & 61 \\
\hline 67 & 67 \\
\hline
\end{tabular}

\begin{tabular}{l|l}
47 & 40 \\
\hline
\end{tabular}

$66 \quad 60$

$61 \quad 60$

\begin{tabular}{l|l}
67 & 67 \\
\hline 75 & 75 \\
\hline
\end{tabular}

69

\begin{tabular}{l|l}
73 & 71 \\
\hline 72 & 70 \\
\hline
\end{tabular}

69

\begin{tabular}{l|r}
69 & 67 \\
\hline 78 & 77 \\
\hline 84 & 79 \\
\hline
\end{tabular}

67
68

73

\begin{tabular}{r|r}
73 & 71 \\
\hline 80 & 78 \\
\hline
\end{tabular}

85

\begin{tabular}{r|r}
82 & 81 \\
85 & 85 \\
\hline 668 & 393 \\
\hline 565 & 294
\end{tabular}

565

414

\begin{tabular}{l|l}
414 & 193 \\
\hline 339 & 147 \\
\hline
\end{tabular}

\begin{tabular}{l|l}
286 & 165 \\
\hline 257 & 199 \\
\hline
\end{tabular}

\begin{tabular}{l|l}
271 & 234 \\
\hline 271 & 236 \\
\hline
\end{tabular}

\begin{tabular}{l|l|l|l|}
286 & 259 & 251 & 24 \\
273 & 235 & 231 & 223 \\
\hline
\end{tabular}

\begin{tabular}{l|l|l|l|}
280 & 251 & 242 & 239 \\
\hline 292 & 259 & 244 & 243 \\
\hline
\end{tabular}

303

318

318

319

\begin{tabular}{l|l}
354 & 321 \\
361 & 324 \\
\hline 342 & 324 \\
\hline
\end{tabular}

\begin{tabular}{l|l}
354 & 321 \\
\hline 361 & 324 \\
\hline 342 & 324 \\
\hline
\end{tabular}

\begin{tabular}{l|l}
342 & 324 \\
\hline 334 & 317 \\
\hline 344 & 321 \\
\hline
\end{tabular}

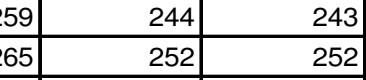

\begin{tabular}{l|l|l|}
265 & 260 & 259 \\
\hline 304 & 271 & 265 \\
\hline
\end{tabular}

344

358

\begin{tabular}{l|l}
364 & 321 \\
\hline 358 & 343 \\
\hline
\end{tabular}

\begin{tabular}{|c|c|c|}
\hline 8 & 249 & 240 \\
\hline & 286 & 271 \\
\hline
\end{tabular}

\begin{tabular}{r|r|r|}
\hline 7 & 0 & \\
\hline 28 & 14 & \\
\hline & 45 &
\end{tabular}

\begin{tabular}{r|r}
0 & \\
8 & \\
\hline 38 &
\end{tabular}

\begin{tabular}{r|r}
0 & \\
\hline 8 & \\
\hline 38 &
\end{tabular}

\begin{tabular}{|c|c|c|}
\hline 28 & 14 & 8 \\
\hline 60 & 45 & 38 \\
\hline 63 & 54 & 49 \\
\hline
\end{tabular}

58

\begin{tabular}{l|r|r}
58 & 55 & 52 \\
\hline 66 & 65 & 65
\end{tabular}

\begin{tabular}{r|r|r|r|}
66 & 65 & 65 & 63 \\
\hline 74 & 73 & 72 & 72 \\
\hline 66 & 65 & 64 & 64 \\
\hline
\end{tabular}

\begin{tabular}{l|l}
71 & 71 \\
69 & 69 \\
\hline
\end{tabular}

\begin{tabular}{l|l}
69 & 69 \\
\hline 67 & 67 \\
\hline
\end{tabular}

\begin{tabular}{l|l}
75 & 75 \\
77 & 77 \\
\hline 63 & 63 \\
\hline
\end{tabular}

\begin{tabular}{|l|l|l|}
\hline 1 & 71 & 69 \\
\hline 9 & 69 & 69 \\
\hline 7 & 67 & 67 \\
\hline 5 & 75 & 75 \\
\hline
\end{tabular}


- Para tamanho da população $=40$ (cont.)

\begin{tabular}{|c|c|c|c|c|c|c|c|c|c|}
\hline $\mathrm{Pc}$ & $\mathrm{Pm}$ & Media & NaoAte25 & NaoAte50 & \begin{tabular}{|l|} 
NaoAte100 \\
\end{tabular} & NaoAte200 & \begin{tabular}{|l|} 
NaoAte500 \\
\end{tabular} & NaoAte700 & NaoAte1000 \\
\hline 0.90 & 0.10000 & 67.41 & 683 & 411 & 207 & 69 & 2 & 1 & 0 \\
\hline 0.90 & 0.08000 & 49.74 & 564 & 298 & 128 & 26 & 1 & 0 & 0 \\
\hline 0.90 & 0.06400 & 33.32 & 402 & 176 & 57 & 3 & 0 & 0 & 0 \\
\hline 0.90 & 0.05120 & 28.85 & 350 & 143 & 40 & 2 & 0 & 0 & 0 \\
\hline 0.90 & 0.04096 & 30.17 & 257 & 130 & 59 & 15 & 0 & 0 & 0 \\
\hline 0.90 & 0.03277 & 48.77 & 243 & 163 & 122 & 68 & 12 & 5 & 0 \\
\hline 0.90 & 0.02621 & \begin{tabular}{|l|}
80.27 \\
\end{tabular} & 239 & 199 & 179 & 151 & 81 & 51 & 28 \\
\hline 0.90 & 0.02097 & 69.82 & 253 & 221 & 209 & 191 & 157 & 135 & 108 \\
\hline 0.90 & 0.01678 & 44.81 & 248 & 231 & 224 & 216 & 195 & 184 & 170 \\
\hline 0.90 & 0.01342 & 31.85 & 260 & 238 & 233 & 227 & 214 & 211 & 200 \\
\hline 0.90 & 0.01074 & 22.84 & 279 & 247 & 244 & 238 & 230 & 228 & 224 \\
\hline 0.90 & 0.00859 & 16.25 & 249 & 212 & 204 & 198 & 196 & 196 & 194 \\
\hline 0.90 & 0.00687 & 15.40 & 247 & 219 & 211 & 211 & 210 & 210 & 207 \\
\hline 0.90 & 0.00550 & 16.02 & 287 & 257 & 241 & 238 & 237 & 237 & 234 \\
\hline 0.90 & 0.00440 & 18.50 & 283 & 257 & 237 & 231 & 228 & 225 & 224 \\
\hline 0.90 & 0.00352 & 16.26 & 294 & 270 & 244 & 241 & 238 & 236 & 236 \\
\hline 0.90 & 0.00281 & 18.64 & 319 & 282 & 257 & 249 & 242 & 242 & 241 \\
\hline 0.90 & 0.00225 & 17.92 & 315 & 286 & 260 & 252 & 248 & 248 & 246 \\
\hline 0.90 & 0.00180 & 21.69 & 301 & 280 & 264 & 249 & 234 & 232 & 231 \\
\hline 0.90 & 0.00144 & 23.11 & 322 & 308 & 290 & 265 & 254 & 253 & 251 \\
\hline 0.90 & 0.00115 & 24.58 & 300 & 288 & 275 & 259 & 240 & 237 & 236 \\
\hline 0.90 & 0.00092 & 27.60 & 327 & 309 & 291 & 263 & 246 & 241 & 241 \\
\hline 0.90 & 0.00074 & 33.39 & 316 & 304 & 284 & 258 & 235 & 226 & 225 \\
\hline 0.90 & 0.00059 & 32.46 & 314 & 304 & 287 & 264 & 234 & 230 & 227 \\
\hline 0.90 & 0.00000 & 9.58 & 331 & 331 & 331 & 331 & 331 & 331 & 331 \\
\hline 0.95 & 0.10000 & 65.98 & 659 & 399 & 178 & 64 & 3 & 1 & 0 \\
\hline 0.95 & 0.08000 & 43.28 & 523 & 238 & 96 & 15 & 0 & 0 & 0 \\
\hline 0.95 & 0.06400 & 33.48 & 411 & 175 & 50 & 6 & 0 & 0 & 0 \\
\hline 0.95 & 0.05120 & 28.30 & 334 & 146 & 33 & 1 & 0 & 0 & 0 \\
\hline 0.95 & 0.04096 & 29.40 & 270 & 127 & 58 & 11 & 0 & 0 & 0 \\
\hline 0.95 & 0.03277 & 48.56 & 228 & 168 & 138 & 73 & 16 & 6 & 2 \\
\hline 0.95 & 0.02621 & 76.58 & 240 & 200 & 180 & 148 & 75 & 55 & 32 \\
\hline 0.95 & 0.02097 & 67.26 & 251 & 225 & 209 & 189 & 151 & 127 & 103 \\
\hline 0.95 & 0.01678 & 40.77 & 229 & 214 & 209 & 201 & 183 & 175 & 161 \\
\hline 0.95 & 0.01342 & 29.57 & 240 & 225 & 222 & 219 & 207 & 201 & 194 \\
\hline 0.95 & 0.01074 & 21.67 & 264 & 238 & 231 & 225 & 223 & 220 & 215 \\
\hline 0.95 & 0.00859 & 16.23 & 254 & 231 & 224 & 224 & 223 & 221 & 219 \\
\hline 0.95 & 0.00687 & 14.97 & 262 & 235 & 227 & 224 & 221 & 221 & 220 \\
\hline 0.95 & 0.00550 & 18.52 & 297 & 257 & 231 & 228 & 223 & 222 & 220 \\
\hline 0.95 & 0.00440 & 16.98 & 296 & 257 & 236 & 232 & 230 & 229 & 227 \\
\hline 0.95 & 0.00352 & 16.32 & 283 & 255 & 232 & 226 & 223 & 222 & 221 \\
\hline 0.95 & 0.00281 & 15.97 & 287 & 265 & 242 & 235 & 232 & 232 & 231 \\
\hline 0.95 & 0.00225 & 18.22 & 285 & 271 & 248 & 227 & 224 & 222 & 222 \\
\hline 0.95 & 0.00180 & 23.12 & 286 & 265 & 244 & 227 & 225 & 222 & 217 \\
\hline 0.95 & 0.00144 & 20.50 & 291 & 270 & 249 & 228 & 218 & 216 & 216 \\
\hline 0.95 & 0.00115 & 21.94 & 285 & 273 & 249 & 229 & 215 & 213 & 213 \\
\hline 0.95 & 0.00092 & 23.24 & 296 & 285 & 271 & 253 & 230 & 228 & 228 \\
\hline 0.95 & 0.00074 & 25.66 & 312 & 301 & 282 & 267 & 244 & 243 & 242 \\
\hline 0.95 & 0.00059 & 28.53 & 307 & 301 & 291 & 275 & 254 & 249 & 247 \\
\hline 0.95 & 0.00000 & 9.66 & 313 & 313 & 313 & 313 & 313 & 313 & 313 \\
\hline 1.00 & 0.10000 & 65.17 & 661 & 371 & 180 & 65 & 2 & 0 & 0 \\
\hline 1.00 & 0.08000 & 44.54 & 529 & 268 & 109 & 20 & 0 & 0 & 0 \\
\hline 1.00 & 0.06400 & 34.73 & 447 & 187 & 53 & 6 & 0 & 0 & 0 \\
\hline 1.00 & 0.05120 & 26.78 & 293 & 109 & 35 & 3 & 0 & 0 & 0 \\
\hline 1.00 & 0.04096 & 28.23 & 259 & 132 & 46 & 12 & 0 & 0 & 0 \\
\hline 1.00 & 0.03277 & 38.63 & 229 & 150 & 97 & 40 & 7 & 2 & 0 \\
\hline 1.00 & 0.02621 & 70.05 & 223 & 173 & 156 & 122 & 58 & 31 & 13 \\
\hline 1.00 & 0.02097 & 60.45 & 211 & 187 & 174 & 156 & 124 & 108 & 83 \\
\hline 1.00 & 0.01678 & 45.82 & 231 & 213 & 207 & 199 & 184 & 165 & 151 \\
\hline 1.00 & 0.01342 & 25.54 & 225 & 208 & 204 & 202 & 191 & 187 & 181 \\
\hline 1.00 & 0.01074 & 27.47 & 243 & 224 & 217 & 212 & 203 & 197 & 191 \\
\hline 1.00 & 0.00859 & 16.07 & 209 & 186 & 179 & 178 & 178 & 175 & 173 \\
\hline 1.00 & 0.00687 & 14.63 & 251 & 220 & 205 & 202 & 199 & 198 & 198 \\
\hline 1.00 & 0.00550 & 13.39 & 235 & 206 & 197 & 195 & 194 & 193 & 193 \\
\hline 1.00 & 0.00440 & 12.70 & 258 & 234 & 215 & 213 & 213 & 213 & 213 \\
\hline 1.00 & 0.00352 & 15.02 & 252 & 234 & 219 & 216 & 213 & 211 & 211 \\
\hline 1.00 & 0.00281 & 14.32 & 269 & 250 & 241 & 234 & 231 & 231 & 230 \\
\hline 1.00 & 0.00225 & 15.21 & 295 & 273 & 254 & 244 & 240 & 240 & 240 \\
\hline 1.00 & 0.00180 & 18.40 & 260 & 248 & 233 & 216 & 212 & 210 & 209 \\
\hline 1.00 & 0.00144 & 15.44 & 248 & 235 & 217 & 201 & 197 & 197 & 197 \\
\hline 1.00 & 0.00115 & 25.21 & 281 & 269 & 246 & 226 & 211 & 207 & 206 \\
\hline 1.00 & 0.00092 & 28.03 & 296 & 284 & 261 & 240 & 211 & 211 & 208 \\
\hline 1.00 & 0.00074 & 28.96 & 284 & 278 & 264 & 238 & 210 & 205 & 205 \\
\hline 1.00 & 0.00059 & 27.02 & 274 & 262 & 246 & 231 & 209 & 205 & 202 \\
\hline 1.00 & 0.00000 & 9.42 & 289 & 289 & 289 & 289 & 289 & 289 & 289 \\
\hline
\end{tabular}


- Para tamanho da população $=20$

\begin{tabular}{|c|c|c|c|c|c|c|c|c|c|}
\hline Pc & Pm & Media & NaoAte25 & NaoAte50 & NaoAte100 & NaoAte200 & NaoAte500 & NaoAte700 & NaoAte1000 \\
\hline
\end{tabular}

\begin{tabular}{|c|c|c|c|c|c|c|c|c|c|}
\hline 0.50 & 0.10000 & 153.79 & 807 & 578 & 378 & 260 & 97 & 58 & 20 \\
\hline 0.50 & 0.08000 & 130.47 & 767 & 489 & 322 & 207 & 72 & 36 & 10 \\
\hline 0.50 & 0.06400 & 118.91 & 669 & 418 & 296 & 207 & 74 & 34 & 17 \\
\hline 0.50 & 0.05120 & 134.54 & 669 & 413 & 316 & 247 & 119 & 82 & 42 \\
\hline 0.50 & 0.04096 & 153.02 & 666 & 463 & 384 & 333 & 223 & 175 & 125 \\
\hline 0.50 & 0.03277 & 136.47 & 675 & 471 & 399 & 362 & 282 & 247 & 203 \\
\hline 0.50 & 0.02621 & 93.49 & 676 & 495 & 418 & 386 & 346 & 327 & 303 \\
\hline 0.50 & 0.02097 & \begin{tabular}{|l|l|}
77.73 \\
\end{tabular} & 677 & 522 & 454 & 416 & 380 & 371 & 357 \\
\hline 0.50 & 0.01678 & 70.06 & 730 & 573 & 472 & 419 & 400 & 391 & 382 \\
\hline 0.50 & 0.01342 & 66.79 & 751 & 587 & 489 & 439 & 406 & 401 & 397 \\
\hline 0.50 & 0.01074 & 79.47 & 779 & 623 & 505 & 458 & 419 & 412 & 403 \\
\hline 0.50 & 0.00859 & 89.97 & 820 & 671 & 531 & 464 & 412 & 403 & 395 \\
\hline 0.50 & 0.00687 & 114.08 & 848 & 710 & 589 & 522 & 475 & 453 & 439 \\
\hline 0.50 & 0.00550 & 114.05 & 835 & 730 & 600 & 511 & 459 & 447 & 432 \\
\hline 0.50 & 0.00440 & 134.77 & 841 & 745 & 624 & 533 & 462 & 449 & 425 \\
\hline 0.50 & 0.00352 & 135.24 & 869 & 798 & 689 & 559 & 480 & 464 & 453 \\
\hline 0.50 & 0.00281 & 159.21 & 888 & 825 & 712 & 591 & 491 & 473 & 454 \\
\hline 0.50 & 0.00225 & 184.36 & 887 & 843 & 767 & 658 & 539 & 515 & 495 \\
\hline 0.50 & 0.00180 & 190.16 & 898 & 858 & 787 & 661 & 562 & 537 & 513 \\
\hline 0.50 & 0.00144 & 210.92 & 900 & 866 & 808 & 711 & 582 & 543 & 527 \\
\hline 0.50 & 0.00115 & 232.39 & 898 & 879 & 831 & 752 & 599 & 568 & 543 \\
\hline 0.50 & 0.00092 & 271.59 & 907 & 896 & 853 & 785 & 637 & 601 & 561 \\
\hline 0.50 & 0.00074 & 302.30 & 914 & 900 & 872 & 822 & 684 & 628 & 582 \\
\hline 0.50 & 0.00059 & 337.19 & 918 & 905 & 883 & 839 & 725 & 666 & 609 \\
\hline 0.50 & 0.00000 & 11.24 & 938 & 938 & 938 & 938 & 938 & 938 & 938 \\
\hline 0.55 & 0.10000 & 139.23 & 793 & 525 & 343 & 225 & 86 & 40 & 15 \\
\hline 0.55 & 0.08000 & 130.19 & 750 & 468 & 322 & 217 & 71 & 37 & 11 \\
\hline 0.55 & 0.06400 & 131.42 & 695 & 451 & 330 & 228 & 78 & 41 & 16 \\
\hline 0.55 & 0.05120 & 149.07 & 663 & 439 & 347 & 263 & 116 & 63 & 24 \\
\hline 0.55 & 0.04096 & 159.57 & 664 & 463 & 382 & 320 & 208 & 152 & 97 \\
\hline 0.55 & 0.03277 & 135.85 & 646 & 461 & 382 & 332 & 249 & 215 & 170 \\
\hline 0.55 & 0.02621 & 107.11 & 679 & 494 & 412 & 376 & 328 & 307 & 276 \\
\hline 0.55 & 0.02097 & 79.54 & 685 & 497 & 432 & 407 & 374 & 364 & 344 \\
\hline 0.55 & 0.01678 & 66.87 & 697 & 522 & 436 & 407 & 387 & 378 & 366 \\
\hline 0.55 & 0.01342 & 68.56 & 761 & 596 & 479 & 430 & 403 & 401 & 392 \\
\hline 0.55 & 0.01074 & 83.17 & 774 & 622 & 525 & 463 & 430 & 414 & 408 \\
\hline 0.55 & 0.00859 & 87.60 & 793 & 672 & 529 & 476 & 439 & 429 & 419 \\
\hline 0.55 & 0.00687 & 95.74 & 794 & 672 & 536 & 460 & 417 & 397 & 391 \\
\hline 0.55 & 0.00550 & 114.14 & 813 & 703 & 603 & 517 & 466 & 449 & 434 \\
\hline 0.55 & 0.00440 & 126.39 & 841 & 763 & 643 & 559 & 498 & 483 & 465 \\
\hline 0.55 & 0.00352 & 147.56 & 852 & 796 & 689 & 585 & 514 & 496 & 473 \\
\hline 0.55 & 0.00281 & 146.62 & 856 & 793 & 697 & 584 & 501 & 478 & 462 \\
\hline 0.55 & 0.00225 & 166.67 & 872 & 835 & 742 & 641 & 534 & 511 & 496 \\
\hline 0.55 & 0.00180 & 185.19 & 891 & 856 & 765 & 653 & 546 & 524 & 500 \\
\hline 0.55 & 0.00144 & 194.79 & 885 & 857 & 801 & 702 & 586 & 555 & 539 \\
\hline 0.55 & 0.00115 & 228.59 & 881 & 855 & 822 & 739 & 605 & 556 & 538 \\
\hline 0.55 & 0.00092 & 249.41 & 886 & 868 & 835 & 765 & 646 & 605 & 570 \\
\hline 0.55 & 0.00074 & 271.59 & 895 & 882 & 853 & 783 & 657 & 605 & 567 \\
\hline 0.55 & 0.00059 & 299.81 & 904 & 894 & 862 & 821 & 706 & 661 & 612 \\
\hline 0.55 & 0.00000 & 10.99 & 925 & 925 & 925 & 925 & 925 & 925 & 925 \\
\hline
\end{tabular}


Para tamanho da população $=20$ (cont.)

\begin{tabular}{|c|c|c|c|c|c|c|c|c|c|}
\hline $\mathrm{PC}$ & $\mathrm{Pm}$ & Media & NaoAte25 & NaoAte50 & NaoAte100 & NaoAte200 & NaoAte500 & \begin{tabular}{|l|l|} 
NaoAte700 \\
\end{tabular} & NaoAte1000 \\
\hline 0.60 & 0.10000 & 151.18 & 808 & 561 & 377 & 252 & 100 & 46 & 15 \\
\hline 0.60 & 0.08000 & 113.51 & 711 & 441 & 288 & 188 & 51 & 26 & 12 \\
\hline 0.60 & 0.06400 & 115.52 & 646 & 402 & 288 & 193 & 56 & 18 & 2 \\
\hline 0.60 & 0.05120 & 138.44 & 650 & 437 & 342 & 258 & 88 & 57 & 23 \\
\hline 0.60 & 0.04096 & 154.63 & 628 & 438 & 363 & 306 & 183 & 125 & 74 \\
\hline 0.60 & 0.03277 & 133.01 & 612 & 441 & 367 & 331 & 252 & 213 & 168 \\
\hline 0.60 & 0.02621 & 105.55 & 621 & 458 & 407 & 382 & 333 & 309 & 276 \\
\hline 0.60 & 0.02097 & 81.30 & 663 & 491 & 422 & 397 & 366 & 351 & 333 \\
\hline 0.60 & 0.01678 & 64.50 & 675 & 509 & 426 & 394 & 377 & 369 & 357 \\
\hline 0.60 & 0.01342 & 68.70 & 733 & 565 & 474 & 425 & 396 & 388 & 381 \\
\hline 0.60 & 0.01074 & 72.42 & 749 & 590 & 506 & 455 & 419 & 408 & 405 \\
\hline 0.60 & 0.00859 & 87.53 & 766 & 633 & 520 & 462 & 416 & 404 & 396 \\
\hline 0.60 & 0.00687 & 93.78 & 787 & $\begin{array}{ll}663 \\
\end{array}$ & 544 & 458 & 407 & 396 & 388 \\
\hline 0.60 & 0.00550 & 109.71 & 798 & 713 & 597 & 512 & 456 & 436 & 428 \\
\hline 0.60 & 0.00440 & 120.52 & 813 & 739 & 637 & 525 & 463 & 447 & 434 \\
\hline 0.60 & 0.00352 & 134.23 & 838 & 767 & 658 & 549 & 482 & 470 & 450 \\
\hline 0.60 & 0.00281 & 140.92 & 842 & 789 & 693 & 597 & 533 & 512 & 494 \\
\hline 0.60 & 0.00225 & 148.10 & 832 & 794 & 713 & 621 & 531 & 518 & 498 \\
\hline 0.60 & 0.00180 & 161.00 & 851 & 821 & 749 & 650 & 554 & 526 & 517 \\
\hline 0.60 & 0.00144 & 193.93 & 861 & 827 & 770 & 684 & 550 & 524 & 501 \\
\hline 0.60 & 0.00115 & 208.10 & 872 & \begin{tabular}{l|l}
838 \\
\end{tabular} & 792 & 704 & 577 & 548 & 525 \\
\hline 0.60 & 0.00092 & 236.39 & 870 & 851 & 809 & 741 & 618 & 572 & 541 \\
\hline 0.60 & 0.00074 & 269.89 & 886 & 867 & 843 & 771 & 647 & 602 & 563 \\
\hline 0.60 & 0.00059 & 301.86 & 895 & 877 & 855 & 804 & 685 & 633 & 579 \\
\hline 0.60 & 0.00000 & 10.34 & 907 & 907 & 907 & 907 & 907 & 907 & 907 \\
\hline 0.65 & 0.10000 & 133.51 & 796 & 547 & 328 & 224 & 77 & 35 & 13 \\
\hline 0.65 & 0.08000 & 116.33 & 704 & 468 & 303 & 194 & 50 & 19 & 6 \\
\hline 0.65 & 0.06400 & 102.44 & 644 & 394 & 275 & 170 & 39 & 11 & 4 \\
\hline 0.65 & 0.05120 & 111.17 & 593 & 373 & 286 & 197 & 62 & 31 & 12 \\
\hline 0.65 & 0.04096 & 139.26 & 587 & 384 & 315 & 249 & 141 & 78 & 40 \\
\hline 0.65 & 0.03277 & 142.63 & 605 & 424 & 368 & 321 & 239 & 199 & 142 \\
\hline 0.65 & 0.02621 & 121.49 & 608 & \begin{tabular}{l|l|}
449 \\
\end{tabular} & 381 & 350 & 307 & 268 & 228 \\
\hline 0.65 & 0.02097 & 82.15 & 630 & 481 & 408 & 379 & 340 & 321 & 307 \\
\hline 0.65 & 0.01678 & 58.45 & 647 & 500 & 414 & 388 & 367 & 360 & 352 \\
\hline 0.65 & 0.01342 & 66.71 & 703 & 553 & 472 & 436 & 408 & 397 & 392 \\
\hline 0.65 & 0.01074 & 66.38 & 710 & 578 & 488 & 438 & 410 & 401 & 396 \\
\hline 0.65 & 0.00859 & 74.25 & 750 & \begin{tabular}{l|l}
606 \\
\end{tabular} & 498 & 442 & 402 & 394 & 389 \\
\hline 0.65 & 0.00687 & 86.17 & 762 & \begin{tabular}{ll|}
662 \\
\end{tabular} & 540 & 483 & 429 & 416 & 412 \\
\hline 0.65 & 0.00550 & 101.02 & 769 & \begin{tabular}{l|}
661 \\
\end{tabular} & 528 & 458 & 420 & 397 & 386 \\
\hline \begin{tabular}{|l|}
0.65 \\
\end{tabular} & 0.00440 & 115.19 & 791 & 714 & 608 & 513 & 426 & 418 & 403 \\
\hline 0.65 & 0.00352 & 112.20 & 813 & 751 & 639 & 542 & 488 & 476 & 464 \\
\hline 0.65 & 0.00281 & 133.31 & 806 & 754 & 662 & 556 & 465 & 450 & 434 \\
\hline 0.65 & 0.00225 & 151.73 & 828 & 791 & 722 & 611 & 505 & 486 & 474 \\
\hline 0.65 & 0.00180 & 150.05 & 837 & 802 & 725 & 620 & 507 & 493 & 482 \\
\hline \begin{tabular}{|l|}
0.65 \\
\end{tabular} & 0.00144 & 176.98 & 849 & 817 & 764 & 665 & 548 & 515 & 501 \\
\hline 0.65 & 0.00115 & 222.70 & 850 & 817 & 775 & 696 & 574 & 535 & 499 \\
\hline 0.65 & 0.00092 & 226.14 & 850 & 822 & 781 & 713 & 580 & 536 & 505 \\
\hline 0.65 & 0.00074 & 238.48 & 854 & 832 & 795 & 740 & 626 & 583 & 546 \\
\hline 0.65 & 0.00059 & 264.86 & 847 & 832 & 806 & 763 & 650 & 600 & 554 \\
\hline 0.65 & 0.00000 & 10.00 & 865 & 865 & 865 & 865 & 865 & 865 & 865 \\
\hline
\end{tabular}


- Para tamanho da população = 20 (cont.)

\begin{tabular}{|c|c|c|c|c|c|c|c|c|c|}
\hline Pc & $\mathrm{Pm}$ & Media & NaoAte25 & NaoAte50 & NaoAte100 & NaoAte200 & NaoAte500 & NaoAte700 & NaoAte 1000 \\
\hline 0.70 & 0.10000 & 124.44 & 792 & 524 & 317 & 193 & 56 & 25 & 8 \\
\hline 0.70 & 0.08000 & 109.30 & 719 & 468 & 301 & 187 & 32 & 9 & 4 \\
\hline 0.70 & 0.06400 & 102.76 & 660 & 424 & 291 & 158 & 37 & 22 & 6 \\
\hline 0.70 & 0.05120 & 107.18 & 611 & 384 & 271 & 188 & 50 & 22 & 9 \\
\hline 0.70 & 0.04096 & 147.13 & 603 & 398 & 331 & 259 & 128 & 84 & 32 \\
\hline 0.70 & 0.03277 & 141.99 & 560 & 420 & 354 & 311 & 231 & 189 & 131 \\
\hline 0.70 & 0.02621 & 110.69 & 607 & 449 & 391 & 361 & 310 & 281 & 246 \\
\hline 0.70 & 0.02097 & 70.74 & 619 & 430 & 369 & 345 & 317 & 307 & 289 \\
\hline 0.70 & 0.01678 & 69.88 & 645 & 505 & 428 & 395 & 364 & 358 & 343 \\
\hline 0.70 & 0.01342 & 59.65 & 669 & 532 & 445 & 412 & 393 & 384 & 377 \\
\hline 0.70 & 0.01074 & 65.42 & 706 & 561 & 452 & 406 & 374 & 367 & 362 \\
\hline 0.70 & 0.00859 & 71.33 & 728 & 603 & 491 & 436 & 406 & 397 & 391 \\
\hline 0.70 & 0.00687 & 87.90 & 750 & 648 & 526 & 475 & 435 & 427 & 412 \\
\hline 0.70 & 0.00550 & 92.39 & 736 & 646 & 533 & 469 & 420 & 407 & 397 \\
\hline 0.70 & 0.00440 & 103.58 & 773 & 686 & 591 & 509 & 463 & 449 & 436 \\
\hline 0.70 & 0.00352 & 110.95 & 766 & 705 & 618 & 515 & 452 & 432 & 424 \\
\hline 0.70 & 0.00281 & 130.34 & 798 & 734 & 630 & 548 & 470 & 450 & 433 \\
\hline 0.70 & 0.00225 & 133.20 & 814 & 761 & 678 & 561 & 467 & 446 & 436 \\
\hline 0.70 & 0.00180 & 158.21 & 819 & 775 & 697 & 590 & 473 & 449 & 431 \\
\hline 0.70 & 0.00144 & 172.68 & 836 & 795 & 726 & 636 & 514 & 483 & 468 \\
\hline 0.70 & 0.00115 & 200.38 & 835 & 807 & 762 & 683 & 553 & 512 & 490 \\
\hline 0.70 & 0.00092 & 215.61 & 832 & 807 & 758 & 687 & 554 & 513 & 481 \\
\hline 0.70 & 0.00074 & 239.27 & 842 & 820 & 787 & 726 & 613 & 563 & 522 \\
\hline 0.70 & 0.00059 & 252.87 & 838 & 815 & 785 & 733 & 625 & 574 & 523 \\
\hline 0.70 & 0.00000 & 10.06 & 846 & 846 & 846 & 846 & 846 & 846 & 846 \\
\hline 0.75 & 0.10000 & 126.11 & 798 & 540 & 346 & 191 & 54 & 18 & 3 \\
\hline 0.75 & 0.08000 & 104.37 & 707 & 453 & 288 & 161 & 36 & 14 & 4 \\
\hline 0.75 & 0.06400 & 92.52 & 646 & 393 & 256 & 149 & 26 & 7 & 2 \\
\hline 0.75 & 0.05120 & 103.10 & 600 & 360 & 271 & 174 & 44 & 15 & 5 \\
\hline 0.75 & 0.04096 & 123.25 & 564 & 374 & 297 & 232 & 103 & 64 & 34 \\
\hline 0.75 & 0.03277 & 137.45 & 550 & 398 & 335 & 301 & 200 & 148 & 105 \\
\hline 0.75 & 0.02621 & 117.94 & 564 & 409 & 352 & 322 & 262 & 233 & 189 \\
\hline 0.75 & 0.02097 & 81.59 & 588 & 436 & 362 & 346 & 309 & 288 & 272 \\
\hline 0.75 & 0.01678 & 57.71 & 603 & 463 & 398 & 373 & 358 & 342 & 336 \\
\hline 0.75 & 0.01342 & 68.10 & 651 & 495 & 416 & 380 & 354 & 344 & 331 \\
\hline 0.75 & 0.01074 & 59.35 & 674 & 527 & 446 & 402 & 375 & 369 & 363 \\
\hline 0.75 & 0.00859 & 62.18 & 703 & 544 & 452 & 408 & 369 & 362 & 360 \\
\hline 0.75 & 0.00687 & 71.48 & 718 & 581 & 471 & 418 & 382 & 377 & 369 \\
\hline 0.75 & 0.00550 & 84.82 & 732 & 635 & 522 & 455 & 403 & 392 & 385 \\
\hline 0.75 & 0.00440 & 103.73 & 751 & 673 & 564 & 485 & 443 & 427 & 411 \\
\hline 0.75 & 0.00352 & 108.14 & 755 & 693 & 608 & 513 & 463 & 446 & 432 \\
\hline 0.75 & 0.00281 & 105.54 & 786 & 731 & 623 & 533 & 463 & 454 & 444 \\
\hline 0.75 & 0.00225 & 116.19 & 771 & 714 & 644 & 532 & 448 & 431 & 424 \\
\hline 0.75 & 0.00180 & 136.21 & 793 & 746 & 680 & 585 & 482 & 467 & 453 \\
\hline 0.75 & 0.00144 & 159.56 & 796 & 757 & 695 & 606 & 476 & 459 & 437 \\
\hline 0.75 & 0.00115 & 172.08 & 809 & 776 & 719 & 632 & 526 & 488 & 471 \\
\hline 0.75 & 0.00092 & 192.19 & 804 & 776 & 740 & 673 & 554 & 517 & 491 \\
\hline 0.75 & 0.00074 & 209.67 & 815 & 795 & 764 & 697 & 566 & 534 & 501 \\
\hline 0.75 & 0.00059 & 233.68 & 807 & 789 & 764 & 718 & 623 & 562 & 521 \\
\hline 0.75 & 0.00000 & 9.75 & 824 & 824 & 824 & 824 & 824 & 824 & 824 \\
\hline
\end{tabular}


- Para tamanho da população = 20 (cont.)

\begin{tabular}{|c|c|c|c|c|c|c|c|c|c|}
\hline $\mathrm{Pc}$ & $\mathrm{Pm}$ & Media & NaoAte25 & NaoAte50 & NaoAte100 & NaoAte200 & NaoAte500 & NaoAte700 & NaoAte1000 \\
\hline 0.80 & 0.10000 & 109.54 & 767 & 528 & 296 & 163 & 36 & 12 & 2 \\
\hline 0.80 & 0.08000 & 95.08 & 692 & 434 & 264 & 153 & 20 & 7 & 0 \\
\hline 0.80 & 0.06400 & 89.86 & 635 & 397 & 257 & 139 & 22 & 5 & 1 \\
\hline 0.80 & 0.05120 & 98.37 & 585 & 356 & 255 & 152 & 45 & 15 & 2 \\
\hline 0.80 & 0.04096 & 124.19 & 568 & 381 & 290 & 223 & 95 & 55 & 23 \\
\hline 0.80 & 0.03277 & 130.87 & 544 & 385 & 343 & 276 & 167 & 128 & 88 \\
\hline 0.80 & 0.02621 & 111.04 & 559 & 405 & 345 & 310 & 260 & 220 & 188 \\
\hline 0.80 & 0.02097 & 82.13 & 553 & 404 & 356 & 332 & 296 & 278 & 256 \\
\hline 0.80 & 0.01678 & 66.59 & 599 & 449 & 377 & 350 & 328 & 318 & 302 \\
\hline 0.80 & 0.01342 & 52.95 & 626 & 482 & 408 & 382 & 359 & 354 & 348 \\
\hline 0.80 & 0.01074 & 53.63 & 648 & 508 & 413 & 376 & 363 & 352 & 348 \\
\hline 0.80 & 0.00859 & 61.65 & 672 & 543 & 453 & 407 & 375 & 371 & 363 \\
\hline 0.80 & 0.00687 & 59.97 & 689 & 581 & 483 & 431 & 402 & 398 & 395 \\
\hline 0.80 & 0.00550 & 72.47 & 709 & 615 & 518 & 452 & 414 & 404 & 400 \\
\hline 0.80 & 0.00440 & 100.36 & 728 & 662 & 563 & 479 & 443 & 429 & 412 \\
\hline 0.80 & 0.00352 & 96.20 & 767 & 703 & 615 & 526 & 462 & 453 & 447 \\
\hline 0.80 & 0.00281 & 121.53 & 769 & 719 & 627 & 545 & 465 & 454 & 436 \\
\hline 0.80 & 0.00225 & 103.87 & 739 & 692 & 617 & 547 & 470 & 459 & 450 \\
\hline 0.80 & 0.00180 & 127.26 & 766 & 737 & 663 & 583 & 494 & 479 & 467 \\
\hline 0.80 & 0.00144 & 147.01 & 779 & 742 & 679 & 606 & 511 & 486 & 467 \\
\hline 0.80 & 0.00115 & 173.42 & 787 & 761 & 729 & 641 & 531 & 499 & 477 \\
\hline 0.80 & 0.00092 & 180.51 & 786 & 769 & 733 & 665 & 563 & 525 & 505 \\
\hline 0.80 & 0.00074 & 213.48 & 796 & 786 & 755 & 697 & 590 & 547 & 508 \\
\hline 0.80 & 0.00059 & 217.13 & 783 & 777 & 759 & 706 & 595 & 545 & 512 \\
\hline 0.80 & 0.00000 & 10.10 & 786 & 785 & 785 & 785 & 785 & 785 & 785 \\
\hline 0.85 & 0.10000 & 114.45 & 786 & 524 & 315 & 177 & 38 & 19 & 4 \\
\hline 0.85 & 0.08000 & 92.91 & 692 & 441 & 264 & 138 & 21 & 7 & 1 \\
\hline 0.85 & 0.06400 & 81.13 & 633 & 360 & 229 & 113 & 16 & 4 & 0 \\
\hline 0.85 & 0.05120 & 90.38 & 589 & 358 & 254 & 138 & 28 & 14 & 4 \\
\hline 0.85 & 0.04096 & 103.95 & 563 & 336 & 266 & 171 & 56 & 25 & 9 \\
\hline 0.85 & 0.03277 & 133.31 & 536 & 373 & 313 & 260 & 159 & 114 & 70 \\
\hline 0.85 & 0.02621 & 141.50 & 573 & 429 & 381 & 345 & 278 & 231 & 175 \\
\hline 0.85 & 0.02097 & 84.22 & 551 & 417 & 347 & 327 & 291 & 267 & 246 \\
\hline 0.85 & 0.01678 & 66.03 & 556 & 456 & 400 & 380 & 358 & 348 & 332 \\
\hline 0.85 & 0.01342 & 54.70 & 587 & 460 & 388 & 362 & 341 & 335 & 325 \\
\hline 0.85 & 0.01074 & 52.75 & 622 & 497 & 400 & 368 & 342 & 335 & 332 \\
\hline 0.85 & 0.00859 & 57.78 & 642 & 530 & 435 & 392 & 368 & 364 & 357 \\
\hline 0.85 & 0.00687 & 63.00 & 661 & 560 & 449 & 398 & 370 & 365 & 357 \\
\hline 0.85 & 0.00550 & 79.35 & 681 & 577 & 479 & 423 & 382 & 373 & 361 \\
\hline 0.85 & 0.00440 & 78.22 & 686 & 597 & 507 & 450 & 410 & 399 & 391 \\
\hline 0.85 & 0.00352 & 94.30 & 693 & 639 & 527 & 455 & 407 & 393 & 379 \\
\hline 0.85 & 0.00281 & 111.40 & 717 & 664 & 587 & 499 & 433 & 421 & 403 \\
\hline 0.85 & 0.00225 & 107.81 & 721 & 677 & 592 & 502 & 428 & 414 & 403 \\
\hline 0.85 & 0.00180 & 123.44 & 742 & 711 & 636 & 545 & 446 & 428 & 420 \\
\hline 0.85 & 0.00144 & 139.20 & 749 & 722 & 675 & 587 & 477 & 453 & 442 \\
\hline 0.85 & 0.00115 & 158.10 & 767 & 742 & 697 & 632 & 511 & 484 & 467 \\
\hline 0.85 & 0.00092 & 181.89 & 763 & 742 & 709 & 650 & 523 & 483 & 465 \\
\hline 0.85 & 0.00074 & 178.32 & 752 & 732 & 695 & 650 & 536 & 505 & 473 \\
\hline 0.85 & 0.00059 & 195.15 & 755 & 744 & 710 & 669 & 579 & 539 & 500 \\
\hline 0.85 & 0.00000 & 10.12 & 755 & 755 & 755 & 755 & 755 & 755 & 755 \\
\hline
\end{tabular}


- Para tamanho da população $=20$ (cont.)

\begin{tabular}{|c|c|c|c|c|c|c|c|c|c|}
\hline $\mathrm{Pc}$ & $\mathrm{Pm}$ & Media & NaoAte25 & NaoAte50 & NaoAte100 & NaoAte200 & NaoAte500 & NaoAte700 & NaoAte1000 \\
\hline 0.90 & 0.10000 & 107.11 & 771 & 500 & 287 & 170 & 37 & 11 & 4 \\
\hline \begin{tabular}{|l|}
0.90 \\
\end{tabular} & 0.08000 & 89.28 & 707 & 408 & 253 & 135 & 19 & 6 & 1 \\
\hline 0.90 & 0.06400 & 78.93 & 619 & 337 & 219 & 116 & 8 & 2 & 0 \\
\hline \begin{tabular}{|l|}
0.90 \\
\end{tabular} & 0.05120 & 80.35 & 541 & 329 & 223 & 124 & 17 & 4 & 1 \\
\hline \begin{tabular}{|l|}
0.90 \\
\end{tabular} & 0.04096 & 104.09 & 534 & 365 & 283 & 177 & 52 & 29 & 12 \\
\hline 0.90 & 0.03277 & 131.83 & 504 & 363 & 301 & 252 & 141 & 97 & 54 \\
\hline \begin{tabular}{|l|}
0.90 \\
\end{tabular} & 0.02621 & 120.83 & 507 & 367 & 315 & 284 & 212 & 181 & 133 \\
\hline 0.90 & 0.02097 & 102.06 & 575 & 454 & 419 & 388 & 329 & 300 & 276 \\
\hline \begin{tabular}{|l|}
0.90 \\
\end{tabular} & 0.01678 & 62.78 & 571 & 43 & 374 & 359 & 338 & 327 & 311 \\
\hline \begin{tabular}{|l|}
0.90 \\
\end{tabular} & 0.01342 & 499.48 & 582 & 453 & 392 & 365 & 344 & 334 & 331 \\
\hline 0.90 & 0.01074 & 55.66 & 615 & 496 & 420 & 393 & 370 & 365 & 355 \\
\hline \begin{tabular}{|l|}
0.90 \\
\end{tabular} & 0.00859 & 57.61 & 632 & 521 & 443 & 396 & 374 & 367 & 362 \\
\hline 0.90 & 0.00687 & 56.87 & 640 & 557 & 468 & 423 & 395 & 390 & 386 \\
\hline 0.90 & 0.00550 & 69.91 & 660 & 573 & 488 & 419 & 395 & 385 & 376 \\
\hline \begin{tabular}{|l|}
0.90 \\
\end{tabular} & 0.00440 & 74.05 & 669 & 593 & 485 & 434 & 396 & 386 & 378 \\
\hline 0.90 & 0.00352 & 79.18 & 665 & 604 & 521 & 442 & 403 & 392 & 385 \\
\hline \begin{tabular}{|l|}
0.90 \\
\end{tabular} & 0.00281 & 84.39 & 671 & 611 & 525 & 444 & 404 & 392 & 381 \\
\hline 0.90 & 0.00225 & 96.93 & 700 & 643 & 579 & 492 & 417 & 408 & 400 \\
\hline 0.90 & 0.00180 & 104.46 & 720 & 677 & 606 & 519 & 429 & 421 & 414 \\
\hline 0.90 & 0.00144 & 141.33 & 728 & 703 & 652 & 574 & 460 & 439 & 421 \\
\hline 0.90 & 0.00115 & 139.55 & 716 & 688 & 644 & 569 & 480 & 447 & 433 \\
\hline 0.90 & 0.00092 & 153.32 & 713 & 687 & 647 & 585 & 481 & 446 & 427 \\
\hline 0.90 & 0.00074 & 171.21 & 725 & 703 & 673 & 620 & 520 & 474 & 452 \\
\hline 0.90 & 0.00059 & 175.95 & 712 & 704 & 670 & 624 & 542 & 503 & 465 \\
\hline \begin{tabular}{|l|}
0.90 \\
\end{tabular} & 0.00000 & 9.82 & 741 & 741 & 741 & 741 & 741 & 741 & 741 \\
\hline 0.95 & 0.10000 & 113.68 & 797 & 517 & 299 & 172 & 36 & 9 & 1 \\
\hline 0.95 & 0.08000 & 83.87 & 698 & 415 & 236 & 108 & 15 & 0 & 0 \\
\hline 0.95 & 0.06400 & 72.33 & 591 & 340 & 208 & 98 & 10 & 1 & 0 \\
\hline 0.95 & 0.05120 & 73.98 & 535 & 312 & 208 & 112 & 13 & 1 & 0 \\
\hline 0.95 & 0.04096 & \begin{tabular}{|l|}
97.07 \\
\end{tabular} & 518 & 322 & 238 & 152 & 44 & 17 & 2 \\
\hline 0.95 & 0.03277 & 116.62 & 503 & 336 & 273 & 216 & 120 & 79 & 44 \\
\hline 0.95 & 0.02621 & 124.59 & 492 & 383 & 339 & 301 & 227 & 182 & 140 \\
\hline 0.95 & 0.02097 & 106.11 & 545 & 410 & 372 & 343 & 301 & 276 & 237 \\
\hline 0.95 & 0.01678 & 52.42 & 536 & 415 & 367 & 343 & 317 & 313 & 304 \\
\hline 0.95 & 0.01342 & 51.77 & 545 & 435 & 378 & 360 & 342 & 337 & 326 \\
\hline 0.95 & 0.01074 & 44.06 & 572 & 467 & 395 & 374 & 362 & 353 & 351 \\
\hline 0.95 & 0.00859 & 50.53 & 589 & 507 & 418 & 367 & 350 & 344 & 340 \\
\hline 0.95 & 0.00687 & 54.11 & 620 & 516 & 435 & 387 & 365 & 362 & 355 \\
\hline 0.95 & 0.00550 & 62.81 & 625 & 542 & 456 & 401 & 368 & 359 & 356 \\
\hline \begin{tabular}{|l|}
0.95 \\
\end{tabular} & 0.00440 & 63.19 & 649 & 587 & 492 & 430 & 391 & 383 & 382 \\
\hline 0.95 & 0.00352 & 66.58 & 656 & 608 & 509 & 428 & 390 & 386 & 383 \\
\hline 0.95 & 0.00281 & 82.08 & 671 & 613 & 525 & 450 & 398 & 390 & 383 \\
\hline 0.95 & 0.00225 & \begin{tabular}{|l|}
95.17 \\
\end{tabular} & 687 & 649 & 583 & 501 & 430 & 425 & 413 \\
\hline 0.95 & 0.00180 & 111.71 & 695 & 662 & 595 & 524 & 444 & 424 & 415 \\
\hline \begin{tabular}{|l|}
0.95 \\
\end{tabular} & 0.00144 & 119.72 & 710 & 675 & 622 & 541 & 449 & 433 & 418 \\
\hline 0.95 & 0.00115 & 126.25 & 698 & 674 & 628 & 562 & 465 & 441 & 428 \\
\hline 0.95 & 0.00092 & 149.30 & 709 & 687 & 645 & 579 & 473 & 443 & 423 \\
\hline 0.95 & 0.00074 & 164.65 & 706 & 684 & 649 & 602 & 502 & 461 & 434 \\
\hline 0.95 & 0.00059 & 172.20 & 704 & 692 & 665 & 631 & 522 & 490 & 456 \\
\hline 0.95 & 0.00000 & 9.79 & 742 & 742 & 742 & 742 & 742 & 742 & 742 \\
\hline 1.00 & 0.10000 & 101.86 & 781 & 498 & 287 & 151 & 23 & 8 & 2 \\
\hline 1.00 & 0.08000 & 80.27 & 680 & 401 & 254 & 109 & 10 & 2 & 0 \\
\hline 1.00 & 0.06400 & 67.68 & 601 & 328 & 198 & 75 & 6 & 2 & 0 \\
\hline 1.00 & 0.05120 & 67.82 & 523 & 308 & 199 & 94 & 7 & 1 & 0 \\
\hline 1.00 & 0.04096 & 91.17 & 507 & 314 & 234 & 139 & 34 & 18 & 4 \\
\hline 1.00 & 0.03277 & 130.06 & 503 & 373 & 312 & 237 & 118 & 76 & 35 \\
\hline 1.00 & 0.02621 & 118.25 & 482 & 365 & 314 & 286 & 208 & 167 & 125 \\
\hline 1.00 & 0.02097 & 97.00 & 506 & 393 & 344 & 323 & 281 & 254 & 221 \\
\hline 1.00 & 0.01678 & 76.67 & 484 & 401 & 348 & 331 & 303 & 281 & 260 \\
\hline 1.00 & 0.01342 & 47.39 & 542 & 425 & 371 & 355 & 335 & 331 & 323 \\
\hline \begin{tabular}{|l|}
1.00 \\
\end{tabular} & 0.01074 & 42.63 & 563 & 445 & 382 & 354 & 333 & 333 & 328 \\
\hline 1.00 & 0.00859 & 47.23 & 583 & 488 & 412 & 376 & 358 & 356 & 350 \\
\hline 1.00 & 0.00687 & 57.25 & 615 & 540 & 458 & 408 & 387 & 383 & 375 \\
\hline 1.00 & 0.00550 & 50.95 & 636 & 551 & 456 & 420 & 405 & 395 & 394 \\
\hline 1.00 & 0.00440 & 62.46 & 638 & 564 & 480 & 421 & 387 & 380 & 375 \\
\hline 1.00 & 0.00352 & 65.68 & 635 & 565 & 498 & 430 & 395 & 388 & 381 \\
\hline 1.00 & 0.00281 & 77.59 & 649 & 613 & 534 & 458 & 412 & 402 & 396 \\
\hline 1.00 & 0.00225 & 85.27 & 661 & 606 & 545 & 475 & 410 & 404 & 394 \\
\hline 1.00 & 0.00180 & 106.78 & 670 & 637 & 590 & 503 & 425 & 413 & 399 \\
\hline 1.00 & 0.00144 & 111.42 & 659 & 638 & 595 & 529 & 433 & 416 & 405 \\
\hline 1.00 & 0.00115 & 123.50 & 677 & 658 & 614 & 542 & 461 & 434 & 420 \\
\hline 1.00 & 0.00092 & 140.82 & 677 & 663 & 625 & 565 & 467 & 444 & 421 \\
\hline 1.00 & 0.00074 & 163.54 & 683 & 671 & \begin{tabular}{l|}
648 \\
\end{tabular} & 599 & 505 & 476 & 440 \\
\hline 1.00 & 0.00059 & 182.95 & 680 & 671 & 652 & 613 & 538 & 506 & 453 \\
\hline 1.00 & 0.00000 & 10.15 & 705 & 704 & 704 & 704 & 704 & 704 & 704 \\
\hline
\end{tabular}


Experimentos com o AG desenvolvido para solucionar o problema de "Minimização de Funções":

- Para tamanho da população $=200$

\begin{tabular}{|c|c|c|c|c|c|c|c|c|c|}
\hline $\mathrm{PC}$ & $\mathrm{Pm}$ & Media & NaoAte25 & NaoAte50 & NaoAte100 & NaoAte200 & NaoAte500 & NaoAte700 & NaoAte1000 \\
\hline 0,50 & 0,10000 & 24,33 & 317 & 91 & 12 & 1 & 0 & 0 & 0 \\
\hline 0,50 & 0,08000 & 17,68 & 180 & 20 & 1 & 0 & 0 & 0 & 0 \\
\hline 0,50 & 0,06400 & 15,39 & 114 & 4 & 0 & 0 & 0 & 0 & 0 \\
\hline 0,50 & 0,05120 & 13,65 & 63 & 1 & 0 & 0 & 0 & 0 & 0 \\
\hline 0,50 & 0,04096 & 15,56 & 58 & 23 & 10 & 8 & 0 & 0 & 0 \\
\hline 0,50 & 0,03277 & 24,56 & 65 & 53 & 43 & 30 & 15 & 10 & 7 \\
\hline 0,50 & 0,02621 & 32,78 & 115 & 108 & 101 & 95 & 74 & 67 & 58 \\
\hline 0,50 & 0,02097 & 24,1 & 166 & 162 & 162 & 158 & 149 & 147 & 139 \\
\hline 0,50 & 0,01678 & 14,49 & 214 & 214 & 211 & 210 & 207 & 207 & 205 \\
\hline 0,50 & 0,01342 & 11,74 & 249 & 246 & 246 & 245 & 245 & 244 & 244 \\
\hline 0,50 & 0,01074 & 11,05 & 283 & 283 & 283 & 283 & 282 & 282 & 282 \\
\hline 0,50 & 0,00859 & 10,3 & 327 & 324 & 324 & 324 & 324 & 324 & 324 \\
\hline 0,50 & 0,00687 & 10,81 & 317 & 316 & 316 & 316 & 316 & 316 & 316 \\
\hline 0,50 & 0,00550 & 10,54 & 364 & 362 & 362 & 362 & 362 & 362 & 362 \\
\hline 0,50 & 0,00440 & 10,16 & 398 & 397 & 397 & 397 & 397 & 397 & 397 \\
\hline 0,50 & 0,00352 & 10,64 & 406 & 405 & 405 & 405 & 405 & 405 & 405 \\
\hline 0,50 & 0,00281 & 10,6 & 417 & 415 & 415 & 415 & 415 & 415 & 415 \\
\hline 0,50 & 0,00225 & 10,04 & 451 & 450 & 450 & 450 & 450 & 450 & 450 \\
\hline 0,50 & 0,00180 & 10,43 & 441 & 439 & 439 & 439 & 439 & 439 & 439 \\
\hline 0,50 & 0,00144 & 10,13 & 464 & 461 & 461 & 461 & 461 & 461 & 461 \\
\hline 0,50 & 0,00115 & 10,28 & 461 & 457 & 457 & 457 & 457 & 457 & 457 \\
\hline 0,50 & 0,00092 & 10,33 & 481 & 476 & 475 & 475 & 475 & 475 & 475 \\
\hline 0,50 & 0,00074 & 10,29 & 475 & 467 & 466 & 466 & 466 & 466 & 466 \\
\hline 0,50 & 0,00059 & 10,27 & 478 & 474 & 472 & 472 & 472 & 472 & 472 \\
\hline 0,50 & 0,00000 & 26,4 & 498 & 495 & 495 & 491 & 480 & 478 & 474 \\
\hline 0,55 & 0,10000 & 24,78 & 321 & 108 & 15 & 0 & 0 & 0 & 0 \\
\hline 0,55 & 0,08000 & 18,37 & 188 & 24 & 1 & 0 & 0 & 0 & 0 \\
\hline 0,55 & 0,06400 & 15,26 & 102 & 4 & 0 & 0 & 0 & 0 & 0 \\
\hline 0,55 & 0,05120 & 13,78 & 66 & 4 & 0 & 0 & 0 & 0 & 0 \\
\hline 0,55 & 0,04096 & 13,86 & 56 & 10 & 5 & 0 & 0 & 0 & 0 \\
\hline 0,55 & 0,03277 & 24,78 & 79 & 53 & 43 & 32 & 20 & 16 & 10 \\
\hline 0,55 & 0,02621 & 31,27 & 101 & 91 & 89 & 85 & 68 & 59 & 50 \\
\hline 0,55 & 0,02097 & 19,61 & 135 & 134 & 133 & 132 & 127 & 123 & 119 \\
\hline 0,55 & 0,01678 & 14,16 & 177 & 174 & 174 & 174 & 172 & 170 & 169 \\
\hline 0,55 & 0,01342 & 11,64 & 227 & 227 & 227 & 226 & 225 & 224 & 224 \\
\hline 0,55 & 0,01074 & 11,62 & 239 & 238 & 238 & 238 & 236 & 236 & 236 \\
\hline 0,55 & 0,00859 & 10,96 & 272 & 270 & 270 & 270 & 269 & 269 & 269 \\
\hline 0,55 & 0,00687 & 10,07 & 290 & 290 & 290 & 290 & 290 & 290 & 290 \\
\hline 0,55 & 0,00550 & 12,34 & 332 & 332 & 331 & 331 & 330 & 330 & 329 \\
\hline 0,55 & 0,00440 & 10,15 & 336 & 336 & 336 & 336 & 336 & 336 & 336 \\
\hline 0,55 & 0,00352 & 10,38 & 369 & 368 & 368 & 368 & 368 & 368 & 368 \\
\hline 0,55 & 0,00281 & 10,2 & 368 & 368 & 368 & 368 & 368 & 368 & 368 \\
\hline 0,55 & 0,00225 & 10,15 & 404 & 401 & 401 & 401 & 401 & 401 & 401 \\
\hline 0,55 & 0,00180 & 10 & 410 & 407 & 407 & 407 & 407 & 407 & 407 \\
\hline 0,55 & 0,00144 & 10,09 & 416 & 413 & 413 & 413 & 413 & 413 & 413 \\
\hline 0,55 & 0,00115 & 10 & 432 & 427 & 427 & 427 & 427 & 427 & 427 \\
\hline 0,55 & 0,00092 & 10,13 & 429 & 424 & 424 & 424 & 424 & 424 & 424 \\
\hline 0,55 & 0,00074 & 10,5 & 437 & 433 & 429 & 429 & 429 & 429 & 429 \\
\hline 0,55 & 0,00059 & 10,36 & 442 & 437 & 435 & 435 & 435 & 435 & 435 \\
\hline 0,55 & 0,00000 & 15,21 & 477 & 474 & 474 & 472 & 470 & 467 & 467 \\
\hline
\end{tabular}


- Para tamanho da população $=200$ (cont.)

\begin{tabular}{|c|c|c|c|c|c|c|c|c|c|}
\hline $\mathrm{Pc}$ & $\mathrm{Pm}$ & Media & NaoAte25 & NaoAte50 & NaoAte100 & NaoAte200 & NaoAte500 & NaoAte700 & NaoAte1000 \\
\hline 0,60 & 0,10000 & 22,78 & 290 & 74 & 12 & 0 & 0 & 0 & 0 \\
\hline 0,60 & 0,08000 & 17,92 & 190 & 21 & 0 & 0 & 0 & 0 & 0 \\
\hline 0,60 & 0,06400 & 14,72 & 91 & 4 & 0 & 0 & 0 & 0 & 0 \\
\hline 0,60 & 0,05120 & 13,64 & 69 & 2 & 0 & 0 & 0 & 0 & 0 \\
\hline 0,60 & 0,04096 & 15,47 & 45 & 14 & 9 & 6 & 2 & 0 & 0 \\
\hline 0,60 & 0,03277 & 22,32 & 66 & 46 & 37 & 32 & 17 & 15 & 11 \\
\hline 0,60 & 0,02621 & 31 & 93 & 82 & 79 & 75 & 65 & 59 & 46 \\
\hline 0,60 & 0,02097 & 16,82 & 128 & 124 & 124 & 124 & 121 & 120 & 116 \\
\hline 0,60 & 0,01678 & 11,9 & 157 & 156 & 155 & 155 & 154 & 153 & 153 \\
\hline 0,60 & 0,01342 & 11,26 & 197 & 196 & 196 & 196 & 196 & 195 & 195 \\
\hline 0,60 & 0,01074 & 11,1 & 237 & 235 & 235 & 235 & 233 & 233 & 233 \\
\hline 0,60 & 0,00859 & 10,37 & 252 & 251 & 251 & 251 & 251 & 251 & 251 \\
\hline 0,60 & 0,00687 & 10,87 & 291 & 291 & 291 & 291 & 290 & 290 & 290 \\
\hline 0,60 & 0,00550 & 10,3 & 295 & 295 & 295 & 295 & 295 & 295 & 295 \\
\hline 0,60 & 0,00440 & 10,21 & 323 & 323 & 323 & 323 & 323 & 323 & 323 \\
\hline 0,60 & 0,00352 & 9,97 & 321 & 321 & 321 & 321 & 321 & 321 & 321 \\
\hline 0,60 & 0,00281 & 10,13 & 341 & 341 & 341 & 341 & 341 & 341 & 341 \\
\hline 0,60 & 0,00225 & 10,14 & 359 & 358 & 358 & 358 & 358 & 358 & 358 \\
\hline 0,60 & 0,00180 & 9,96 & 382 & 376 & 376 & 376 & 376 & 376 & 376 \\
\hline 0,60 & 0,00144 & 9,88 & 400 & 393 & 393 & 393 & 393 & 393 & 393 \\
\hline 0,60 & 0,00115 & 9,72 & 378 & 375 & 375 & 375 & 375 & 375 & 375 \\
\hline 0,60 & 0,00092 & 9,95 & 400 & 396 & 396 & 396 & 396 & 396 & 396 \\
\hline 0,60 & 0,00074 & 10,06 & 389 & 385 & 385 & 385 & 385 & 385 & 385 \\
\hline 0,60 & 0,00059 & 9,98 & 418 & 414 & 413 & 413 & 413 & 413 & 413 \\
\hline 0,60 & 0,00000 & 16,5 & 427 & 427 & 426 & 426 & 424 & 423 & 420 \\
\hline 0,65 & 0,10000 & 22,68 & 288 & 78 & 9 & 0 & 0 & 0 & 0 \\
\hline 0,65 & 0,08000 & 18,24 & 182 & 27 & 1 & 0 & 0 & 0 & 0 \\
\hline 0,65 & 0,06400 & 14,9 & 95 & 1 & 0 & 0 & 0 & 0 & 0 \\
\hline 0,65 & 0,05120 & 13,43 & 60 & 0 & 0 & 0 & 0 & 0 & 0 \\
\hline 0,65 & 0,04096 & 15,02 & 56 & 19 & 8 & 5 & 1 & 0 & 0 \\
\hline 0,65 & 0,03277 & 20,05 & 68 & 43 & 35 & 25 & 14 & 12 & 10 \\
\hline 0,65 & 0,02621 & 23,8 & 77 & 68 & 64 & 61 & 51 & 48 & 40 \\
\hline 0,65 & 0,02097 & 18,03 & 129 & 127 & 126 & 125 & 122 & 119 & 115 \\
\hline 0,65 & 0,01678 & 12,13 & 158 & 156 & 156 & 155 & 154 & 154 & 153 \\
\hline 0,65 & 0,01342 & 12,15 & 190 & 189 & 188 & 188 & 188 & 186 & 186 \\
\hline 0,65 & 0,01074 & 10,77 & 223 & 223 & 223 & 223 & 222 & 222 & 222 \\
\hline 0,65 & 0,00859 & 10,86 & 244 & 242 & 242 & 242 & 241 & 241 & 241 \\
\hline 0,65 & 0,00687 & 10,29 & 250 & 249 & 249 & 249 & 249 & 249 & 249 \\
\hline 0,65 & 0,00550 & 10 & 286 & 283 & 283 & 283 & 283 & 283 & 283 \\
\hline 0,65 & 0,00440 & 9,92 & 288 & 287 & 287 & 287 & 287 & 287 & 287 \\
\hline 0,65 & 0,00352 & 10,38 & 306 & 305 & 305 & 304 & 304 & 304 & 304 \\
\hline 0,65 & 0,00281 & 9,91 & 326 & 325 & 325 & 325 & 325 & 325 & 325 \\
\hline 0,65 & 0,00225 & 9,87 & 324 & 323 & 323 & 323 & 323 & 323 & 323 \\
\hline 0,65 & 0,00180 & 9,89 & 346 & 345 & 345 & 345 & 345 & 345 & 345 \\
\hline 0,65 & 0,00144 & 9,97 & 348 & 346 & 346 & 346 & 346 & 346 & 346 \\
\hline 0,65 & 0,00115 & 9,71 & 384 & 380 & 380 & 380 & 380 & 380 & 380 \\
\hline 0,65 & 0,00092 & 9,58 & 401 & 400 & 400 & 400 & 400 & 400 & 400 \\
\hline 0,65 & 0,00074 & 9,85 & 399 & 394 & 393 & 393 & 393 & 393 & 393 \\
\hline 0,65 & 0,00059 & 9,78 & 395 & 393 & 393 & 393 & 393 & 393 & 393 \\
\hline 0,65 & 0,00000 & 16,62 & 410 & 410 & 406 & 404 & 400 & 398 & 396 \\
\hline
\end{tabular}


- Para tamanho da população $=200$ (cont.)

\begin{tabular}{|c|c|c|c|c|c|c|c|c|c|}
\hline $\mathrm{PC}$ & $\mathrm{Pm}$ & Media & NaoAte25 & NaoAte50 & NaoAte100 & NaoAte200 & NaoAte500 & NaoAte700 & NaoAte1000 \\
\hline 0,70 & 0,10000 & 24,29 & 304 & 91 & 15 & 0 & 0 & 0 & 0 \\
\hline 0,70 & 0,08000 & $\begin{array}{ll}17,72 \\
\end{array}$ & 188 & 20 & 0 & 0 & 0 & 0 & 0 \\
\hline 0,70 & 0,06400 & 15,09 & 100 & 1 & 0 & 0 & 0 & 0 & 0 \\
\hline 0,70 & 0,05120 & 13,11 & 50 & 0 & 0 & 0 & 0 & 0 & 0 \\
\hline 0,70 & 0,04096 & 14,81 & 45 & 13 & 9 & 4 & 1 & 0 & 0 \\
\hline 0,70 & 0,03277 & 20,67 & 67 & 43 & 31 & 20 & 9 & 8 & 5 \\
\hline 0,70 & 0,02621 & 25,53 & 77 & 71 & 70 & 64 & 53 & 49 & 40 \\
\hline 0,70 & 0,02097 & 13,73 & 117 & 114 & 112 & 110 & 109 & 106 & 106 \\
\hline 0,70 & 0,01678 & 11,71 & 157 & 153 & 153 & 153 & 152 & 151 & 151 \\
\hline 0,70 & 0,01342 & 10,38 & 184 & 183 & 183 & 183 & 182 & 182 & 182 \\
\hline 0,70 & 0,01074 & 11,63 & 220 & 220 & 220 & 220 & 220 & 219 & 218 \\
\hline 0,70 & 0,00859 & 9,66 & 228 & 228 & 228 & 228 & 228 & 228 & 228 \\
\hline 0,70 & 0,00687 & 9,96 & 241 & 241 & 241 & 241 & 241 & 241 & 241 \\
\hline 0,70 & 0,00550 & 9,72 & 273 & 272 & 272 & 272 & 272 & 272 & 272 \\
\hline 0,70 & 0,00440 & 9,72 & 281 & 281 & 281 & 281 & 281 & 281 & 281 \\
\hline 0,70 & 0,00352 & 9,54 & 302 & 302 & 302 & 302 & 302 & 302 & 302 \\
\hline 0,70 & 0,00281 & 9,45 & 322 & 321 & 321 & 321 & 321 & 321 & 321 \\
\hline 0,70 & 0,00225 & 9,47 & 305 & 304 & 304 & 304 & 304 & 304 & 304 \\
\hline 0,70 & 0,00180 & 9,69 & 334 & 333 & 333 & 333 & 333 & 333 & 333 \\
\hline 0,70 & 0,00144 & 9,37 & 347 & 346 & 346 & 346 & 346 & 346 & 346 \\
\hline 0,70 & 0,00115 & 9,44 & 357 & 355 & 355 & 355 & 355 & 355 & 355 \\
\hline 0,70 & 0,00092 & 9,37 & 362 & 361 & 361 & 361 & 361 & 361 & 361 \\
\hline 0,70 & 0,00074 & 9,35 & 345 & 343 & 343 & 343 & 343 & 343 & 343 \\
\hline 0,70 & 0,00059 & 9,7 & 344 & 340 & 339 & 339 & 339 & 339 & 339 \\
\hline 0,70 & 0,00000 & 11,41 & 380 & 380 & 380 & 380 & 380 & 379 & 378 \\
\hline 0,75 & 0,10000 & 22,62 & 303 & 77 & 7 & 0 & 0 & 0 & 0 \\
\hline 0,75 & 0,08000 & 17,37 & 165 & 17 & 0 & 0 & 0 & 0 & 0 \\
\hline 0,75 & 0,06400 & 15,3 & 107 & 3 & 0 & 0 & 0 & 0 & 0 \\
\hline 0,75 & 0,05120 & 13,15 & 39 & 2 & 0 & 0 & 0 & 0 & 0 \\
\hline 0,75 & 0,04096 & 13,38 & 37 & 8 & 6 & 1 & 0 & 0 & 0 \\
\hline 0,75 & 0,03277 & 18,01 & 53 & 30 & 24 & 17 & 6 & 6 & 4 \\
\hline 0,75 & 0,02621 & 21,73 & 67 & 59 & 57 & 54 & 45 & 39 & 35 \\
\hline 0,75 & 0,02097 & 21,13 & 97 & 93 & 91 & 90 & 87 & 79 & 74 \\
\hline 0,75 & 0,01678 & 12,15 & 120 & 119 & 118 & 118 & 118 & 117 & 116 \\
\hline 0,75 & 0,01342 & 12,62 & 167 & 167 & 167 & 167 & 165 & 163 & 163 \\
\hline 0,75 & 0,01074 & 10,66 & 185 & 184 & 184 & 184 & 183 & 183 & 183 \\
\hline 0,75 & 0,00859 & 10,04 & 202 & 201 & 201 & 201 & 201 & 201 & 201 \\
\hline 0,75 & 0,00687 & 9,71 & 242 & 240 & 240 & 240 & 240 & 240 & 240 \\
\hline 0,75 & 0,00550 & 9,59 & 248 & 246 & 246 & 246 & 246 & 246 & 246 \\
\hline 0,75 & 0,00440 & 9,53 & 276 & 275 & 275 & 275 & 275 & 275 & 275 \\
\hline 0,75 & 0,00352 & 9,55 & 269 & 265 & 265 & 265 & 265 & 265 & 265 \\
\hline 0,75 & 0,00281 & 9,76 & 265 & 263 & 263 & 263 & 263 & 263 & 263 \\
\hline 0,75 & 0,00225 & 9,58 & 289 & 288 & 288 & 288 & 288 & 288 & 288 \\
\hline 0,75 & 0,00180 & 9,33 & 299 & 298 & 298 & 298 & 298 & 298 & 298 \\
\hline 0,75 & 0,00144 & 9,33 & 290 & 290 & 290 & 290 & 290 & 290 & 290 \\
\hline 0,75 & 0,00115 & 9,71 & 323 & 322 & 321 & 321 & 321 & 321 & 321 \\
\hline 0,75 & 0,00092 & 9,47 & 348 & 344 & 344 & 344 & 344 & 344 & 344 \\
\hline 0,75 & 0,00074 & 9,63 & 318 & 314 & 314 & 314 & 314 & 314 & 314 \\
\hline 0,75 & 0,00059 & 9,75 & 365 & 361 & 359 & 359 & 359 & 359 & 359 \\
\hline 0,75 & 0,00000 & 13,01 & 329 & 329 & 328 & 328 & 326 & 326 & 324 \\
\hline
\end{tabular}


- Para tamanho da população $=200$ (cont.)

\begin{tabular}{|c|c|c|c|c|c|c|c|c|c|}
\hline $\mathrm{PC}$ & $\mathrm{Pm}$ & Media & NaoAte25 & NaoAte50 & NaoAte100 & NaoAte200 & NaoAte500 & NaoAte700 & NaoAte1000 \\
\hline 0,80 & 0,10000 & 22,83 & 299 & 75 & 5 & 0 & 0 & 0 & 0 \\
\hline 0,80 & 0,08000 & 17,41 & 157 & 23 & 2 & 0 & 0 & 0 & 0 \\
\hline 0,80 & 0,06400 & 14,72 & 100 & 3 & 0 & 0 & 0 & 0 & 0 \\
\hline 0,80 & 0,05120 & 13,13 & 49 & 2 & 0 & 0 & 0 & 0 & 0 \\
\hline 0,80 & 0,04096 & 13,38 & 46 & 8 & 3 & 1 & 1 & 0 & 0 \\
\hline 0,80 & 0,03277 & 16,92 & 53 & 36 & 27 & 15 & 8 & 6 & 6 \\
\hline 0,80 & 0,02621 & 22,95 & 71 & 63 & 61 & 57 & 48 & 44 & 38 \\
\hline 0,80 & 0,02097 & 13,34 & 89 & 84 & 84 & 82 & 82 & 81 & 79 \\
\hline 0,80 & 0,01678 & 10,77 & 118 & 115 & 115 & 115 & 115 & 114 & 114 \\
\hline 0,80 & 0,01342 & 9,94 & 140 & 140 & 140 & 140 & 140 & 140 & 140 \\
\hline 0,80 & 0,01074 & 10,1 & 169 & 168 & 168 & 168 & 167 & 167 & 167 \\
\hline 0,80 & 0,00859 & 11,2 & 189 & 188 & 188 & 188 & 188 & 186 & 186 \\
\hline 0,80 & 0,00687 & 9,68 & 192 & 192 & 192 & 192 & 192 & 192 & 192 \\
\hline 0,80 & 0,00550 & 9,44 & 233 & 233 & 233 & 233 & 233 & 233 & 233 \\
\hline 0,80 & 0,00440 & 9,58 & 229 & 227 & 227 & 227 & 227 & 227 & 227 \\
\hline 0,80 & 0,00352 & 9,18 & 232 & 232 & 232 & 232 & 232 & 232 & 232 \\
\hline 0,80 & 0,00281 & 9,22 & 254 & 253 & 253 & 253 & 253 & 253 & 253 \\
\hline 0,80 & 0,00225 & 9,1 & 264 & 264 & 264 & 264 & 264 & 264 & 264 \\
\hline 0,80 & 0,00180 & 9,34 & 277 & 274 & 274 & 274 & 274 & 274 & 274 \\
\hline 0,80 & 0,00144 & 9,31 & 253 & 253 & 253 & 253 & 253 & 253 & 253 \\
\hline 0,80 & 0,00115 & 9,37 & 272 & 271 & 271 & 271 & 271 & 271 & 271 \\
\hline 0,80 & 0,00092 & 9,31 & 307 & 306 & 306 & 306 & 306 & 306 & 306 \\
\hline 0,80 & 0,00074 & 9,27 & 288 & 287 & 287 & 287 & 287 & 287 & 287 \\
\hline 0,80 & 0,00059 & 9,35 & 288 & 287 & 287 & 287 & 287 & 287 & 287 \\
\hline 0,80 & 0,00000 & 11,79 & 328 & 328 & 327 & 327 & 324 & 324 & 323 \\
\hline 0,85 & 0,10000 & 22,94 & 306 & 81 & 3 & 0 & 0 & 0 & 0 \\
\hline 0,85 & 0,08000 & 17,18 & 167 & 18 & 0 & 0 & 0 & 0 & 0 \\
\hline 0,85 & 0,06400 & 14,67 & 91 & 2 & 0 & 0 & 0 & 0 & 0 \\
\hline 0,85 & 0,05120 & 13,03 & 41 & 1 & 0 & 0 & 0 & 0 & 0 \\
\hline 0,85 & 0,04096 & 12,62 & 30 & 8 & 2 & 0 & 0 & 0 & 0 \\
\hline 0,85 & 0,03277 & 16,43 & 36 & 23 & 22 & 18 & 11 & 8 & 7 \\
\hline 0,85 & 0,02621 & 15,5 & 46 & 39 & 37 & 34 & 28 & 28 & 26 \\
\hline 0,85 & 0,02097 & 13,87 & 63 & 60 & 60 & 59 & 58 & 56 & 54 \\
\hline 0,85 & 0,01678 & 11,46 & 98 & 96 & 96 & 96 & 95 & 94 & 94 \\
\hline 0,85 & 0,01342 & 10,28 & 132 & 130 & 130 & 129 & 129 & 129 & 129 \\
\hline 0,85 & 0,01074 & 9,96 & 155 & 154 & 154 & 154 & 154 & 154 & 154 \\
\hline 0,85 & 0,00859 & 9,82 & 173 & 173 & 173 & 173 & 173 & 173 & 173 \\
\hline 0,85 & 0,00687 & 10,18 & 199 & 196 & 196 & 196 & 195 & 195 & 195 \\
\hline 0,85 & 0,00550 & 9,42 & 239 & 239 & 239 & 239 & 239 & 239 & 239 \\
\hline 0,85 & 0,00440 & 9,45 & 232 & 232 & 232 & 232 & 232 & 232 & 232 \\
\hline 0,85 & 0,00352 & 9,34 & 235 & 235 & 235 & 235 & 235 & 235 & 235 \\
\hline 0,85 & 0,00281 & 9,36 & 253 & 252 & 252 & 252 & 252 & 252 & 252 \\
\hline 0,85 & 0,00225 & 9,36 & 266 & 264 & 264 & 264 & 264 & 264 & 264 \\
\hline 0,85 & 0,00180 & 9,28 & 250 & 250 & 250 & 250 & 250 & 250 & 250 \\
\hline 0,85 & 0,00144 & 9,18 & 269 & 269 & 269 & 269 & 269 & 269 & 269 \\
\hline 0,85 & 0,00115 & 9,39 & 232 & 232 & 232 & 232 & 232 & 232 & 232 \\
\hline 0,85 & 0,00092 & 9,23 & 272 & 272 & 272 & 272 & 272 & 272 & 272 \\
\hline 0,85 & 0,00074 & 9,2 & 280 & 280 & 280 & 280 & 280 & 280 & 280 \\
\hline 0,85 & 0,00059 & 9,28 & 311 & 309 & 308 & 308 & 308 & 308 & 308 \\
\hline 0,85 & 0,00000 & 11,25 & 303 & 303 & 302 & 302 & 302 & 301 & 300 \\
\hline
\end{tabular}


- Para tamanho da população $=200$ (cont.)

\begin{tabular}{|c|c|c|c|c|c|c|c|c|c|}
\hline $\mathrm{Pc}$ & $\mathrm{Pm}$ & Media & NaoAte25 & NaoAte50 & NaoAte100 & NaoAte200 & NaoAte500 & NaoAte700 & NaoAte1000 \\
\hline 0,90 & 0,10000 & 23,49 & 297 & 79 & 9 & 0 & 0 & 0 & 0 \\
\hline 0,90 & 0,08000 & 16,98 & 163 & 20 & 0 & 0 & 0 & 0 & 0 \\
\hline 0,90 & 0,06400 & 14,45 & 83 & 1 & 0 & 0 & 0 & 0 & 0 \\
\hline 0,90 & 0,05120 & 13,37 & 46 & 2 & 1 & 0 & 0 & 0 & 0 \\
\hline 0,90 & 0,04096 & 12,56 & 44 & 4 & 1 & 0 & 0 & 0 & 0 \\
\hline 0,90 & 0,03277 & 15,88 & 36 & 21 & 18 & 16 & 10 & 8 & 6 \\
\hline 0,90 & 0,02621 & 19,11 & 54 & 48 & 48 & 47 & 37 & 33 & 30 \\
\hline 0,90 & 0,02097 & 13,14 & 76 & 70 & 69 & 68 & 66 & 66 & 64 \\
\hline 0,90 & 0,01678 & 12,07 & 100 & 97 & 97 & 96 & 96 & 96 & 94 \\
\hline 0,90 & 0,01342 & 10,77 & 129 & 127 & 127 & 127 & 125 & 125 & 125 \\
\hline 0,90 & 0,01074 & 9,95 & 129 & 126 & 126 & 126 & 126 & 126 & 126 \\
\hline 0,90 & 0,00859 & 9,8 & 142 & 142 & 142 & 142 & 142 & 142 & 142 \\
\hline 0,90 & 0,00687 & 9,42 & 189 & 189 & 189 & 189 & 189 & 189 & 189 \\
\hline 0,90 & 0,00550 & 9,41 & 185 & 183 & 183 & 183 & 183 & 183 & 183 \\
\hline 0,90 & 0,00440 & 9,28 & 200 & 199 & 199 & 199 & 199 & 199 & 199 \\
\hline 0,90 & 0,00352 & 9,55 & 215 & 214 & 214 & 214 & 214 & 214 & 214 \\
\hline 0,90 & 0,00281 & 9,48 & 225 & 223 & 223 & 223 & 223 & 223 & 223 \\
\hline 0,90 & 0,00225 & 9,39 & 218 & 218 & 218 & 218 & 218 & 218 & 218 \\
\hline 0,90 & 0,00180 & 9,32 & 218 & 218 & 218 & 218 & 218 & 218 & 218 \\
\hline 0,90 & 0,00144 & 9,22 & 264 & 263 & 263 & 263 & 263 & 263 & 263 \\
\hline 0,90 & 0,00115 & 9,2 & 229 & 229 & 229 & 229 & 229 & 229 & 229 \\
\hline 0,90 & 0,00092 & 9,25 & 263 & 262 & 262 & 262 & 262 & 262 & 262 \\
\hline 0,90 & 0,00074 & 9,21 & 272 & 272 & 271 & 271 & 271 & 271 & 271 \\
\hline 0,90 & 0,00059 & 9,22 & 281 & 280 & 280 & 280 & 280 & 280 & 280 \\
\hline 0,90 & 0,00000 & 8,98 & 258 & 258 & 257 & 257 & 257 & 257 & 257 \\
\hline 0,95 & 0,10000 & 23,02 & 295 & 75 & 6 & 0 & 0 & 0 & 0 \\
\hline 0,95 & 0,08000 & 17,53 & 189 & 15 & 0 & 0 & 0 & 0 & 0 \\
\hline 0,95 & 0,06400 & 14,4 & 86 & 1 & 0 & 0 & 0 & 0 & 0 \\
\hline 0,95 & 0,05120 & 12,82 & 40 & 1 & 0 & 0 & 0 & 0 & 0 \\
\hline 0,95 & 0,04096 & 13,38 & 37 & 7 & 4 & 3 & 1 & 0 & 0 \\
\hline 0,95 & 0,03277 & 15,31 & 35 & 24 & 17 & 12 & 8 & 7 & 5 \\
\hline 0,95 & 0,02621 & 18,94 & 51 & 42 & 42 & 37 & 32 & 27 & 24 \\
\hline 0,95 & 0,02097 & 13,57 & 73 & 72 & 71 & 70 & 66 & 65 & 64 \\
\hline 0,95 & 0,01678 & 10,13 & 87 & 86 & 86 & 86 & 86 & 86 & 86 \\
\hline 0,95 & 0,01342 & 9,75 & 120 & 118 & 118 & 118 & 118 & 118 & 118 \\
\hline 0,95 & 0,01074 & 10,01 & 144 & 144 & 144 & 143 & 143 & 143 & 143 \\
\hline 0,95 & 0,00859 & 10,49 & 169 & 168 & 168 & 168 & 168 & 168 & 167 \\
\hline 0,95 & 0,00687 & 9,49 & 170 & 170 & 170 & 170 & 170 & 170 & 170 \\
\hline 0,95 & 0,00550 & 9,44 & 177 & 177 & 177 & 177 & 177 & 177 & 177 \\
\hline 0,95 & 0,00440 & 9,23 & 209 & 209 & 209 & 209 & 209 & 209 & 209 \\
\hline 0,95 & 0,00352 & 9,47 & 197 & 196 & 196 & 196 & 196 & 196 & 196 \\
\hline 0,95 & 0,00281 & 9,49 & 230 & 229 & 229 & 229 & 229 & 229 & 229 \\
\hline 0,95 & 0,00225 & 9,29 & 217 & 217 & 217 & 217 & 217 & 217 & 217 \\
\hline 0,95 & 0,00180 & 9,34 & 220 & 219 & 219 & 219 & 219 & 219 & 219 \\
\hline 0,95 & 0,00144 & 9,29 & 227 & 226 & 226 & 226 & 226 & 226 & 226 \\
\hline 0,95 & 0,00115 & 9,26 & 236 & 236 & 236 & 236 & 236 & 236 & 236 \\
\hline 0,95 & 0,00092 & 9,16 & 247 & 247 & 247 & 247 & 247 & 247 & 247 \\
\hline 0,95 & 0,00074 & 9,06 & 258 & 257 & 257 & 257 & 257 & 257 & 257 \\
\hline 0,95 & 0,00059 & 9,15 & 271 & 269 & 269 & 269 & 269 & 269 & 269 \\
\hline 0,95 & 0,00000 & 8,88 & 248 & 248 & 248 & 248 & 248 & 248 & 248 \\
\hline 1,00 & 0,10000 & 23,13 & 309 & 71 & 7 & 0 & 0 & 0 & 0 \\
\hline 1,00 & 0,08000 & 16,73 & 163 & 14 & 0 & 0 & 0 & 0 & 0 \\
\hline 1,00 & 0,06400 & 14,19 & 75 & 1 & 0 & 0 & 0 & 0 & 0 \\
\hline 1,00 & 0,05120 & 12,97 & 51 & 3 & 0 & 0 & 0 & 0 & 0 \\
\hline 1,00 & 0,04096 & 12,67 & 32 & 5 & 4 & 1 & 0 & 0 & 0 \\
\hline 1,00 & 0,03277 & 18,36 & 41 & 30 & 25 & 17 & 10 & 7 & 5 \\
\hline 1,00 & 0,02621 & 22,17 & 50 & 42 & 42 & 39 & 35 & 33 & 23 \\
\hline 1,00 & 0,02097 & 13,32 & 56 & 54 & 54 & 53 & 50 & 50 & 48 \\
\hline 1,00 & 0,01678 & 10,06 & 79 & 79 & 79 & 79 & 79 & 79 & 79 \\
\hline 1,00 & 0,01342 & 10,57 & 110 & 109 & 108 & 108 & 108 & 107 & 107 \\
\hline 1,00 & 0,01074 & 9,68 & 121 & 120 & 120 & 120 & 120 & 120 & 120 \\
\hline 1,00 & 0,00859 & 9,35 & 157 & 156 & 156 & 156 & 156 & 156 & 156 \\
\hline 1,00 & 0,00687 & 9,51 & 155 & 155 & 155 & 155 & 155 & 155 & 155 \\
\hline 1,00 & 0,00550 & 9,51 & 151 & 151 & 151 & 151 & 151 & 151 & 151 \\
\hline 1,00 & 0,00440 & 9,38 & 164 & 164 & 164 & 164 & 164 & 164 & 164 \\
\hline 1,00 & 0,00352 & 9,19 & 181 & 181 & 181 & 181 & 181 & 181 & 181 \\
\hline 1,00 & 0,00281 & 9,18 & 218 & 217 & 217 & 217 & 217 & 217 & 217 \\
\hline 1,00 & 0,00225 & 9,19 & 199 & 197 & 197 & 197 & 197 & 197 & 197 \\
\hline 1,00 & 0,00180 & 9,16 & 224 & 223 & 223 & 223 & 223 & 223 & 223 \\
\hline 1,00 & 0,00144 & 9,02 & 211 & 211 & 211 & 211 & 211 & 211 & 211 \\
\hline 1,00 & 0,00115 & 8,96 & 223 & 221 & 221 & 221 & 221 & 221 & 221 \\
\hline 1,00 & 0,00092 & 9,07 & 217 & 217 & 217 & 217 & 217 & 217 & 217 \\
\hline 1,00 & 0,00074 & 9,16 & 227 & 227 & 227 & 227 & 227 & 227 & 227 \\
\hline 1,00 & 0,00059 & 9,28 & 225 & 224 & 222 & 222 & 222 & 222 & 222 \\
\hline 1,00 & 0,00000 & 8,81 & 234 & 234 & 234 & 234 & 234 & 234 & 234 \\
\hline
\end{tabular}


- Para tamanho da população = 70

\begin{tabular}{|c|c|c|c|c|c|c|c|c|c|}
\hline $\mathrm{Pc}$ & $\mathrm{Pm}$ & Media & NaoAte25 & NaoAte50 & NaoAte100 & NaoAte200 & NaoAte500 & NaoAte700 & NaoAte1000 \\
\hline 0.50 & 0.10000 & 44.51 & 534 & 266 & 102 & 18 & 0 & 0 & 0 \\
\hline 0.50 & 0.08000 & 35.93 & 473 & 215 & 58 & 2 & 0 & 0 & 0 \\
\hline 0.50 & 0.06400 & 31.90 & 401 & 181 & 37 & 1 & 0 & 0 & 0 \\
\hline 0.50 & 0.05120 & 41.22 & 378 & 228 & 100 & 28 & 1 & 0 & 0 \\
\hline 0.50 & 0.04096 & 105.44 & 456 & 365 & 280 & 184 & 84 & 55 & 28 \\
\hline 0.50 & 0.03277 & 141.67 & 483 & 443 & 409 & 357 & 261 & 218 & 169 \\
\hline 0.50 & 0.02621 & 91.50 & 540 & 526 & 513 & 490 & 462 & 440 & 416 \\
\hline 0.50 & 0.02097 & 80.35 & 624 & 611 & 602 & 590 & 565 & 556 & 538 \\
\hline 0.50 & 0.01678 & 73.02 & 636 & 626 & 622 & 613 & 594 & 579 & 569 \\
\hline 0.50 & 0.01342 & 61.07 & 697 & 691 & 687 & 682 & 668 & 660 & 653 \\
\hline 0.50 & 0.01074 & 49.72 & 711 & 699 & 697 & 696 & 691 & 687 & 678 \\
\hline 0.50 & 0.00859 & 22.22 & 715 & 703 & 703 & 701 & 696 & 694 & 694 \\
\hline 0.50 & 0.00687 & 22.39 & 752 & 745 & 745 & 743 & 741 & 740 & 739 \\
\hline 0.50 & 0.00550 & 20.06 & 777 & 758 & 758 & 755 & 754 & 754 & 753 \\
\hline 0.50 & 0.00440 & 18.60 & 783 & 772 & 772 & 770 & 770 & 770 & 769 \\
\hline 0.50 & 0.00352 & 18.69 & 813 & 786 & 786 & 785 & 783 & 783 & 783 \\
\hline 0.50 & 0.00281 & 17.84 & 833 & 799 & 796 & 795 & 795 & 795 & 795 \\
\hline 0.50 & 0.00225 & 22.00 & 834 & 793 & 787 & 786 & 786 & 786 & 785 \\
\hline 0.50 & 0.00180 & 18.85 & 838 & 797 & 790 & 789 & 789 & 789 & 789 \\
\hline 0.50 & 0.00144 & 21.31 & 853 & 808 & 792 & 791 & 791 & 791 & 791 \\
\hline 0.50 & 0.00115 & 24.12 & 864 & 819 & 794 & 794 & 794 & 794 & 794 \\
\hline 0.50 & 0.00092 & 24.05 & 859 & 815 & 794 & 792 & 792 & 792 & 792 \\
\hline 0.50 & 0.00074 & 30.22 & 860 & 820 & 783 & 775 & 775 & 775 & 775 \\
\hline 0.50 & 0.00059 & 31.80 & 865 & 826 & 791 & 781 & 780 & 780 & 780 \\
\hline 0.50 & 0.00000 & \begin{tabular}{|l|}
159.70 \\
\end{tabular} & 898 & 895 & 890 & 885 & 866 & 858 & 846 \\
\hline 0.55 & 0.10000 & 45.73 & 538 & 271 & 107 & 23 & 0 & 0 & 0 \\
\hline 0.55 & 0.08000 & 35.63 & 454 & 213 & 58 & 3 & 0 & 0 & 0 \\
\hline 0.55 & 0.06400 & 31.08 & 386 & 179 & 40 & 1 & 0 & 0 & 0 \\
\hline 0.55 & 0.05120 & 42.49 & 369 & 227 & 106 & 28 & 1 & 0 & 0 \\
\hline 0.55 & 0.04096 & 108.72 & 451 & 359 & 282 & 183 & 82 & 55 & 26 \\
\hline 0.55 & 0.03277 & 128.86 & 483 & 436 & 403 & 351 & 278 & 245 & 199 \\
\hline 0.55 & 0.02621 & 100.22 & 533 & 519 & 507 & 486 & 436 & 417 & 393 \\
\hline 0.55 & 0.02097 & 64.37 & 574 & 561 & 557 & 551 & 511 & 500 & 494 \\
\hline 0.55 & 0.01678 & 58.19 & 616 & 608 & 606 & 597 & 575 & 565 & 558 \\
\hline 0.55 & 0.01342 & 48.54 & 654 & 646 & 645 & 642 & 635 & 626 & 619 \\
\hline 0.55 & 0.01074 & 39.69 & 695 & 688 & 688 & 687 & 680 & 675 & 671 \\
\hline 0.55 & 0.00859 & 27.80 & 693 & 686 & 686 & 686 & 684 & 681 & 678 \\
\hline 0.55 & 0.00687 & 24.32 & 711 & 702 & 702 & 702 & 698 & 696 & 695 \\
\hline 0.55 & 0.00550 & 18.60 & 736 & 721 & 721 & 721 & 719 & 719 & 718 \\
\hline 0.55 & 0.00440 & 17.47 & 774 & 754 & 754 & 754 & 754 & 754 & 753 \\
\hline 0.55 & 0.00352 & 15.71 & 781 & 755 & 753 & 753 & 752 & 752 & 752 \\
\hline 0.55 & 0.00281 & 17.61 & 783 & 747 & 745 & 745 & 743 & 743 & 743 \\
\hline 0.55 & 0.00225 & 17.71 & 794 & 745 & 740 & 740 & 740 & 740 & 740 \\
\hline 0.55 & 0.00180 & 17.48 & 819 & 772 & 767 & 767 & 767 & 767 & 767 \\
\hline 0.55 & 0.00144 & 17.32 & 816 & 780 & 770 & 770 & 770 & 770 & 770 \\
\hline 0.55 & 0.00115 & 21.25 & 831 & 793 & 775 & 771 & 771 & 771 & 771 \\
\hline 0.55 & 0.00092 & 24.78 & 837 & 808 & 767 & 765 & 765 & 765 & 765 \\
\hline 0.55 & 0.00074 & 28.38 & 850 & 814 & 766 & 763 & 763 & 763 & 763 \\
\hline 0.55 & 0.00059 & 29.85 & 855 & 812 & 773 & 765 & 765 & 765 & 765 \\
\hline 0.55 & 0.00000 & 149.83 & 889 & 888 & 885 & 879 & 864 & 855 & 843 \\
\hline
\end{tabular}


- Para tamanho da população = 70 (cont.)

\begin{tabular}{|c|c|c|c|c|c|c|c|c|c|}
\hline $\mathrm{Pc}$ & $\mathrm{Pm}$ & Media & NaoAte25 & NaoAte50 & NaoAte100 & NaoAte200 & NaoAte500 & NaoAte700 & NaoAte1000 \\
\hline 0.60 & 0.10000 & 42.17 & 501 & 252 & $\overline{97}$ & 12 & $\overline{0}$ & 0 & 0 \\
\hline 0.60 & 0.08000 & 35.22 & 452 & 187 & 56 & 6 & 0 & 0 & 0 \\
\hline 0.60 & 0.06400 & 30.92 & 389 & 165 & 39 & 1 & 0 & 0 & 0 \\
\hline 0.60 & 0.05120 & 40.97 & 415 & 218 & 99 & 26 & 1 & 0 & 0 \\
\hline 0.60 & 0.04096 & 95.09 & 441 & 338 & 253 & 150 & 74 & 46 & 23 \\
\hline 0.60 & 0.03277 & 133.57 & 510 & 460 & 426 & 373 & 277 & 231 & 194 \\
\hline 0.60 & 0.02621 & 91.15 & 514 & 500 & 486 & 455 & $\overline{413}$ & 397 & 372 \\
\hline 0.60 & 0.02097 & 81.32 & 593 & 585 & 579 & 568 & 541 & 530 & 510 \\
\hline 0.60 & 0.01678 & 62.35 & 589 & 584 & 580 & 573 & 554 & 542 & 532 \\
\hline 0.60 & 0.01342 & 56.00 & 668 & 661 & 660 & 657 & 647 & 637 & 629 \\
\hline 0.60 & 0.01074 & 28.49 & 668 & 663 & 663 & 660 & 655 & 651 & 649 \\
\hline 0.60 & 0.00859 & 18.18 & 699 & 687 & 686 & 686 & 682 & 681 & 681 \\
\hline 0.60 & 0.00687 & 15.35 & 712 & 704 & 704 & 704 & 703 & 702 & 702 \\
\hline 0.60 & 0.00550 & 18.52 & 727 & 711 & 711 & 711 & 711 & 710 & 709 \\
\hline 0.60 & 0.00440 & 20.30 & 734 & 712 & 712 & 712 & 712 & 712 & 710 \\
\hline 0.60 & 0.00352 & 16.61 & 749 & 718 & 717 & 717 & 717 & 716 & 716 \\
\hline 0.60 & 0.00281 & 20.62 & 777 & 752 & 749 & 749 & 749 & 749 & 747 \\
\hline 0.60 & 0.00225 & 16.10 & 779 & 743 & 738 & 737 & 737 & 737 & 737 \\
\hline 0.60 & 0.00180 & 16.35 & 781 & 746 & 740 & 739 & 739 & 739 & 739 \\
\hline 0.60 & 0.00144 & 20.21 & 802 & 768 & 757 & 756 & 756 & 755 & 755 \\
\hline 0.60 & 0.00115 & 24.45 & 818 & 777 & 762 & 762 & 762 & 761 & 760 \\
\hline 0.60 & 0.00092 & 19.26 & 824 & 790 & 771 & 771 & 771 & 771 & 771 \\
\hline 0.60 & 0.00074 & 23.57 & 810 & 777 & 755 & 745 & 745 & 745 & 745 \\
\hline 0.60 & 0.00059 & 27.07 & 813 & 786 & 756 & 743 & 743 & 743 & 743 \\
\hline 0.60 & 0.00000 & 108.51 & 858 & 855 & 853 & 847 & 836 & 830 & 818 \\
\hline 0.65 & 0.10000 & 44.48 & 528 & 248 & 108 & 19 & 0 & 0 & 0 \\
\hline 0.65 & 0.08000 & 31.94 & 415 & 171 & 36 & 0 & 0 & 0 & 0 \\
\hline 0.65 & 0.06400 & 30.27 & 393 & 163 & $\overline{31}$ & 2 & $\overline{0}$ & 0 & 0 \\
\hline 0.65 & 0.05120 & 39.49 & 388 & 226 & 97 & 22 & 0 & 0 & 0 \\
\hline 0.65 & 0.04096 & 93.94 & 409 & 331 & 238 & 140 & 70 & 48 & 17 \\
\hline 0.65 & 0.03277 & 129.67 & 464 & 426 & 400 & 348 & 265 & 225 & 179 \\
\hline 0.65 & 0.02621 & 85.57 & 527 & 511 & 500 & 469 & 433 & 420 & 398 \\
\hline 0.65 & 0.02097 & 67.71 & 539 & 533 & 524 & 515 & 486 & 473 & 460 \\
\hline 0.65 & 0.01678 & 55.82 & 612 & 608 & 604 & 600 & 582 & 574 & 565 \\
\hline 0.65 & 0.01342 & 35.43 & 646 & 638 & 634 & 631 & 619 & 616 & 613 \\
\hline 0.65 & 0.01074 & 25.03 & 666 & 659 & 659 & 658 & 648 & 647 & 646 \\
\hline 0.65 & 0.00859 & 21.00 & 683 & 673 & 673 & 673 & 668 & 668 & 666 \\
\hline 0.65 & 0.00687 & 16.07 & 709 & 697 & 696 & 695 & 695 & 694 & 694 \\
\hline 0.65 & 0.00550 & 13.18 & 723 & 712 & 712 & 712 & 712 & 712 & 712 \\
\hline 0.65 & 0.00440 & 12.73 & 737 & 725 & 725 & 725 & 725 & 725 & 725 \\
\hline 0.65 & 0.00352 & 16.72 & 742 & 721 & 721 & 721 & 721 & 721 & 720 \\
\hline 0.65 & 0.00281 & 18.01 & 756 & 719 & 716 & 716 & $\overline{716}$ & 716 & 715 \\
\hline 0.65 & 0.00225 & 18.50 & 782 & 751 & 748 & 748 & 748 & 748 & 747 \\
\hline 0.65 & 0.00180 & 15.99 & 783 & 755 & 749 & 749 & 749 & 749 & 749 \\
\hline 0.65 & 0.00144 & 24.07 & 784 & 748 & 737 & 737 & 737 & 737 & 735 \\
\hline 0.65 & 0.00115 & 24.24 & 800 & 767 & 748 & 746 & 746 & 746 & 745 \\
\hline 0.65 & 0.00092 & 24.38 & 813 & 768 & 753 & 750 & 750 & 750 & 749 \\
\hline 0.65 & 0.00074 & 23.79 & 828 & 796 & 772 & 765 & 765 & 765 & 765 \\
\hline 0.65 & 0.00059 & 30.92 & 838 & 804 & 777 & 765 & 765 & 765 & 764 \\
\hline 0.65 & 0.00000 & 109.72 & 851 & 850 & 847 & 843 & 830 & 825 & 812 \\
\hline
\end{tabular}


- Para tamanho da população = 70 (cont.)

\begin{tabular}{|c|c|c|c|c|c|c|c|c|c|}
\hline $\mathrm{PC}$ & $\mathrm{Pm}$ & Media & NaoAte25 & NaoAte50 & NaoAte100 & NaoAte200 & NaoAte500 & NaoAte700 & NaoAte1000 \\
\hline 0.70 & 0.10000 & 41.58 & 509 & 247 & $\overline{94}$ & 10 & 0 & 0 & 0 \\
\hline 0.70 & 0.08000 & 36.17 & 470 & 217 & 62 & 5 & 0 & 0 & 0 \\
\hline 0.70 & 0.06400 & 29.33 & 379 & 146 & 29 & 0 & 0 & 0 & 0 \\
\hline 0.70 & 0.05120 & 38.06 & 360 & 207 & 90 & 23 & 0 & 0 & 0 \\
\hline 0.70 & 0.04096 & 92.67 & 429 & 344 & 264 & 163 & 65 & 41 & 24 \\
\hline 0.70 & 0.03277 & 107.78 & 446 & 391 & 359 & 322 & 229 & 201 & 170 \\
\hline 0.70 & 0.02621 & 82.59 & 521 & 492 & 481 & 457 & 425 & 404 & 386 \\
\hline 0.70 & 0.02097 & 63.93 & 567 & 553 & 547 & 531 & 507 & 492 & 482 \\
\hline 0.70 & 0.01678 & 52.23 & 585 & 577 & 573 & 569 & 545 & 540 & 531 \\
\hline 0.70 & 0.01342 & 37.77 & 597 & 589 & 586 & 584 & 578 & 570 & 566 \\
\hline 0.70 & 0.01074 & 25.37 & 652 & 646 & 646 & 645 & 642 & 640 & 637 \\
\hline 0.70 & 0.00859 & 28.01 & 658 & 648 & 648 & 647 & 645 & 644 & 639 \\
\hline 0.70 & 0.00687 & 14.44 & 667 & 654 & 654 & 652 & 651 & 651 & 651 \\
\hline 0.70 & 0.00550 & 14.48 & 707 & 695 & 695 & 694 & 693 & 693 & 693 \\
\hline 0.70 & 0.00440 & 15.26 & 707 & 693 & 693 & 693 & 691 & 691 & 691 \\
\hline 0.70 & 0.00352 & 13.14 & 735 & 718 & 718 & 718 & 718 & 718 & 718 \\
\hline 0.70 & 0.00281 & 14.68 & 760 & 738 & 737 & 737 & 736 & 736 & 736 \\
\hline 0.70 & 0.00225 & 18.56 & 761 & 736 & 735 & 735 & 733 & 733 & 732 \\
\hline 0.70 & 0.00180 & 19.28 & 782 & 749 & 742 & 742 & 741 & 741 & 740 \\
\hline 0.70 & 0.00144 & 18.20 & 791 & 755 & 745 & 744 & 743 & 743 & 743 \\
\hline 0.70 & 0.00115 & 20.47 & 818 & 781 & 763 & 763 & 762 & 762 & 762 \\
\hline 0.70 & 0.00092 & 19.02 & 818 & 791 & 773 & 772 & 772 & 772 & 772 \\
\hline 0.70 & 0.00074 & 22.84 & 821 & 788 & 762 & 758 & 758 & 758 & 758 \\
\hline 0.70 & 0.00059 & 23.60 & 823 & 802 & 775 & 771 & 770 & 770 & 770 \\
\hline 0.70 & 0.00000 & 101.33 & 825 & 823 & 817 & 813 & 800 & 793 & 781 \\
\hline 0.75 & 0.10000 & 42.86 & 504 & 251 & 91 & 19 & 0 & 0 & 0 \\
\hline 0.75 & 0.08000 & 33.24 & 412 & 173 & 53 & 4 & 0 & 0 & 0 \\
\hline 0.75 & 0.06400 & 29.37 & 380 & 141 & 28 & 3 & 0 & 0 & 0 \\
\hline 0.75 & 0.05120 & 39.15 & 352 & 206 & 86 & 26 & 2 & 0 & 0 \\
\hline 0.75 & 0.04096 & 91.98 & 406 & 322 & 246 & 150 & 82 & 52 & 27 \\
\hline 0.75 & 0.03277 & 120.57 & 437 & 386 & 362 & 313 & 228 & 188 & 151 \\
\hline 0.75 & 0.02621 & 75.29 & 488 & 472 & 449 & 428 & 397 & 383 & 363 \\
\hline 0.75 & 0.02097 & 58.86 & 545 & 531 & 524 & 517 & 500 & 489 & 475 \\
\hline 0.75 & 0.01678 & 49.41 & 577 & 571 & 566 & 565 & 553 & 547 & 536 \\
\hline 0.75 & 0.01342 & 45.60 & 606 & 597 & 595 & 592 & 583 & 580 & 568 \\
\hline 0.75 & 0.01074 & 23.04 & 612 & 606 & 605 & 600 & 598 & 597 & 594 \\
\hline 0.75 & 0.00859 & 22.69 & 660 & 654 & 654 & 653 & 650 & 650 & 647 \\
\hline 0.75 & 0.00687 & 15.83 & 693 & 686 & 686 & 686 & 685 & 685 & 684 \\
\hline 0.75 & 0.00550 & 12.79 & 668 & 661 & 661 & 661 & 660 & 660 & 660 \\
\hline 0.75 & 0.00440 & 13.75 & 702 & 687 & 687 & 687 & 686 & 686 & 686 \\
\hline 0.75 & 0.00352 & 13.94 & 721 & 703 & 703 & 703 & 702 & 702 & 702 \\
\hline 0.75 & 0.00282 & 12.89 & 736 & 719 & 719 & 719 & 719 & 719 & 719 \\
\hline 0.75 & 0.00225 & 16.76 & 747 & 717 & 717 & 717 & 717 & 717 & 716 \\
\hline 0.75 & 0.00180 & 15.42 & 757 & 719 & $\overline{712}$ & 712 & 712 & 712 & 712 \\
\hline 0.75 & 0.00144 & 18.12 & 759 & 718 & 700 & 699 & 699 & 699 & 699 \\
\hline 0.75 & 0.00115 & 19.65 & 773 & 740 & 713 & 712 & 712 & 712 & 712 \\
\hline 0.75 & 0.00092 & 20.23 & 783 & 745 & 728 & 726 & 725 & 725 & 725 \\
\hline 0.75 & 0.00074 & 22.56 & 798 & 764 & 738 & 732 & 732 & 732 & 732 \\
\hline 0.75 & 0.00059 & 23.30 & 801 & 764 & 734 & 729 & 729 & 729 & 729 \\
\hline 0.75 & 0.00000 & 69.35 & 815 & 811 & 810 & 809 & 797 & 789 & 784 \\
\hline
\end{tabular}


- Para tamanho da população = 70 (cont.)

\begin{tabular}{|c|c|c|c|c|c|c|c|c|c|}
\hline $\mathrm{Pc}$ & $\mathrm{Pm}$ & Media & NaoAte25 & NaoAte50 & NaoAte100 & NaoAte200 & NaoAte500 & \begin{tabular}{|l|} 
NaoAte700 \\
\end{tabular} & NaoAte1000 \\
\hline 0.80 & 0.10000 & 41.24 & 494 & 240 & 84 & 16 & 0 & 0 & 0 \\
\hline 0.80 & 0.08000 & 31.58 & 413 & 171 & 41 & 2 & 0 & 0 & 0 \\
\hline 0.80 & 0.06400 & 29.01 & 367 & 146 & 27 & 0 & 0 & 0 & 0 \\
\hline 0.80 & 0.05120 & 38.21 & 380 & 189 & 76 & 22 & 2 & 0 & 0 \\
\hline 0.80 & 0.04096 & 86.29 & 386 & 295 & 213 & 133 & 65 & 44 & 19 \\
\hline 0.80 & 0.03277 & 135.25 & 447 & 413 & 382 & 334 & 255 & 214 & 160 \\
\hline 0.80 & 0.02621 & 82.01 & 450 & 438 & 423 & 406 & 378 & 361 & 333 \\
\hline 0.80 & 0.02097 & 66.20 & 542 & 530 & 524 & 515 & 495 & 484 & 467 \\
\hline 0.80 & 0.01678 & 47.39 & 565 & 562 & 560 & 558 & 545 & 536 & 528 \\
\hline 0.80 & 0.01342 & 35.77 & 595 & 590 & 588 & 584 & 574 & 570 & 566 \\
\hline 0.80 & 0.01074 & 26.94 & 632 & 624 & 623 & 621 & 615 & 612 & 610 \\
\hline 0.80 & 0.00859 & 19.17 & 657 & 653 & 652 & 652 & 651 & 648 & 647 \\
\hline 0.80 & 0.00687 & 16.72 & 682 & 676 & 676 & 676 & 675 & 675 & 673 \\
\hline 0.80 & 0.00550 & 14.64 & 705 & 691 & 691 & 691 & 691 & 691 & 690 \\
\hline 0.80 & 0.00440 & 14.59 & 712 & 698 & 698 & 698 & 698 & 697 & 697 \\
\hline 0.80 & 0.00352 & 12.62 & 707 & 694 & 693 & 693 & 693 & 693 & 693 \\
\hline 0.80 & 0.00281 & 13.05 & 713 & 694 & 692 & 692 & 692 & 692 & 692 \\
\hline 0.80 & 0.00225 & 13.90 & 728 & 708 & 704 & 704 & 704 & 704 & 704 \\
\hline 0.80 & 0.00180 & 13.80 & 742 & 721 & 715 & 715 & 715 & 715 & 715 \\
\hline 0.80 & 0.00144 & 15.72 & 759 & 735 & 729 & 729 & 728 & 728 & 728 \\
\hline 0.80 & 0.00115 & 15.72 & 754 & 736 & 721 & 721 & 721 & 721 & 721 \\
\hline 0.80 & 0.00092 & 17.86 & 766 & 739 & 719 & 718 & 718 & 718 & 718 \\
\hline 0.80 & 0.00074 & 18.50 & 768 & 736 & 717 & 714 & 714 & 714 & 714 \\
\hline 0.80 & 0.00059 & 20.49 & 759 & 735 & 708 & 702 & 702 & 702 & 702 \\
\hline 0.80 & 0.00000 & 93.60 & 818 & 818 & 815 & 810 & 800 & 792 & 780 \\
\hline 0.85 & 0.10000 & 39.64 & 463 & 218 & 76 & 15 & 0 & 0 & 0 \\
\hline 0.85 & 0.08000 & 31.31 & 390 & 163 & 39 & 2 & 0 & 0 & 0 \\
\hline 0.85 & 0.06400 & 29.15 & 367 & 138 & 30 & 2 & 0 & 0 & 0 \\
\hline 0.85 & 0.05120 & 36.83 & 329 & 182 & 74 & 25 & 1 & 0 & 0 \\
\hline 0.85 & 0.04096 & 86.49 & 384 & 296 & 221 & 141 & 65 & 40 & 20 \\
\hline 0.85 & 0.03277 & 115.41 & 429 & 391 & 351 & 309 & 207 & 175 & 142 \\
\hline 0.85 & 0.02621 & 82.12 & 471 & 455 & 440 & 427 & 390 & 372 & 349 \\
\hline 0.85 & 0.02097 & 46.51 & 481 & 472 & 463 & 454 & 439 & 430 & 422 \\
\hline 0.85 & 0.01678 & 27.65 & 524 & 517 & 512 & 505 & 499 & 495 & 492 \\
\hline 0.85 & 0.01342 & 27.66 & 575 & 570 & 569 & 565 & 558 & 558 & 553 \\
\hline 0.85 & 0.01074 & 28.82 & 594 & 590 & 590 & 588 & 583 & 582 & 576 \\
\hline 0.85 & 0.00859 & 12.52 & 622 & 616 & 616 & 616 & 615 & 615 & 615 \\
\hline 0.85 & 0.00687 & 14.43 & 639 & 632 & 632 & 632 & 631 & 631 & 630 \\
\hline 0.85 & 0.00550 & 11.42 & 657 & 653 & 652 & 652 & 652 & 652 & 652 \\
\hline 0.85 & 0.00440 & 13.57 & 688 & 678 & 677 & 677 & 675 & 675 & 675 \\
\hline 0.85 & 0.00352 & 12.81 & 704 & 696 & 696 & 696 & 695 & 695 & 695 \\
\hline 0.85 & 0.00281 & 15.63 & 710 & 691 & 690 & 690 & 689 & 689 & 688 \\
\hline 0.85 & 0.00225 & 12.51 & 710 & 689 & 688 & 688 & 688 & 688 & 688 \\
\hline 0.85 & 0.00180 & 13.52 & 713 & 690 & 683 & 683 & 683 & 683 & 683 \\
\hline 0.85 & 0.00144 & 14.40 & 732 & 699 & 695 & 695 & 695 & 695 & 695 \\
\hline 0.85 & 0.00115 & 15.27 & 747 & 718 & 709 & 709 & 709 & 709 & 709 \\
\hline 0.85 & 0.00092 & 16.78 & 737 & 713 & 696 & 693 & 693 & 693 & 693 \\
\hline 0.85 & 0.00074 & 18.29 & 747 & 716 & 694 & 692 & 692 & 692 & 692 \\
\hline 0.85 & 0.00059 & 19.26 & 768 & 740 & 720 & 715 & 715 & 715 & 715 \\
\hline 0.85 & 0.00000 & 60.70 & 781 & 781 & 779 & 777 & 765 & 758 & 753 \\
\hline
\end{tabular}


- Para tamanho da população = 70 (cont.)

\begin{tabular}{|c|c|c|c|c|c|c|c|c|c|}
\hline $\mathrm{Pc}$ & $\mathrm{Pm}$ & Media & NaoAte25 & NaoAte50 & NaoAte100 & NaoAte200 & NaoAte500 & \begin{tabular}{|l|l|} 
NaoAte700 \\
\end{tabular} & \begin{tabular}{|l|} 
NaoAte1000 \\
\end{tabular} \\
\hline 0.90 & 0.10000 & 37.91 & 494 & 211 & 66 & 12 & 0 & 0 & 0 \\
\hline 0.90 & 0.08000 & 31.05 & 420 & 157 & 31 & 2 & 0 & 0 & 0 \\
\hline 0.90 & 0.06400 & 27.02 & 353 & 117 & 26 & 1 & 0 & 0 & 0 \\
\hline 0.90 & 0.05120 & 36.63 & 332 & 180 & 77 & 23 & 2 & 0 & 0 \\
\hline 0.90 & 0.04096 & 79.89 & 363 & 281 & 204 & 130 & 67 & 40 & 22 \\
\hline 0.90 & 0.03277 & 97.12 & 374 & 341 & 309 & 272 & 199 & 170 & 142 \\
\hline 0.90 & 0.02621 & 82.91 & 460 & 449 & 439 & 418 & 372 & 349 & 332 \\
\hline 0.90 & 0.02097 & 52.74 & 513 & 507 & 499 & 492 & 480 & 465 & 455 \\
\hline 0.90 & 0.01678 & 37.48 & 529 & 523 & 520 & 517 & 501 & 499 & 492 \\
\hline 0.90 & 0.01342 & 31.36 & 581 & 578 & 578 & 575 & 565 & 564 & 558 \\
\hline 0.90 & 0.01074 & 26.76 & 598 & 589 & 589 & 586 & 581 & 579 & 575 \\
\hline 0.90 & 0.00859 & 18.58 & 629 & 620 & 620 & 620 & 619 & 618 & 616 \\
\hline 0.90 & 0.00687 & 17.12 & 619 & 609 & 609 & 609 & 607 & 606 & 605 \\
\hline 0.90 & 0.00550 & 11.66 & 655 & 648 & 648 & 648 & 648 & 648 & 648 \\
\hline 0.90 & 0.00440 & 11.48 & 653 & 646 & 646 & 646 & 646 & 646 & 646 \\
\hline 0.90 & 0.00352 & 12.26 & 664 & 648 & 648 & 648 & 648 & 648 & 648 \\
\hline 0.90 & 0.00281 & 12.51 & 681 & 663 & 663 & 663 & 663 & 663 & 663 \\
\hline 0.90 & 0.00225 & 12.72 & 713 & 697 & 694 & 694 & 694 & 694 & 694 \\
\hline 0.90 & 0.00180 & 16.29 & 704 & 679 & 675 & 675 & 675 & 675 & 674 \\
\hline 0.90 & 0.00144 & 14.23 & 714 & 685 & 680 & 680 & 680 & 680 & 680 \\
\hline 0.90 & 0.00115 & 14.57 & 725 & 698 & 688 & 688 & 688 & 688 & 688 \\
\hline 0.90 & 0.00092 & 16.04 & 736 & 710 & 695 & 694 & 694 & 694 & 694 \\
\hline 0.90 & 0.00074 & 18.73 & 737 & 712 & 696 & 687 & 687 & 687 & 687 \\
\hline 0.90 & 0.00059 & 18.87 & 748 & 721 & 707 & 699 & 699 & 699 & 699 \\
\hline 0.90 & 0.00000 & 54.78 & 791 & 790 & 786 & 783 & 776 & 772 & 766 \\
\hline 0.95 & 0.10000 & 41.12 & 507 & 243 & 77 & 18 & 0 & 0 & 0 \\
\hline 0.95 & 0.08000 & 30.93 & 400 & 160 & 41 & 1 & 0 & 0 & 0 \\
\hline 0.95 & 0.06400 & 27.53 & 342 & 134 & 20 & 0 & 0 & 0 & 0 \\
\hline 0.95 & 0.05120 & 35.76 & 315 & 173 & 83 & 24 & 0 & 0 & 0 \\
\hline 0.95 & 0.04096 & 79.53 & 371 & 274 & 200 & 130 & 52 & 35 & 15 \\
\hline 0.95 & 0.03277 & 96.35 & 396 & 363 & 328 & 289 & 215 & 191 & 163 \\
\hline 0.95 & 0.02621 & 68.79 & 460 & 440 & 422 & 412 & 379 & 362 & 347 \\
\hline 0.95 & 0.02097 & 34.05 & 486 & 475 & 470 & 465 & 452 & 443 & 441 \\
\hline 0.95 & 0.01678 & 37.75 & 520 & 514 & 511 & 507 & 501 & 493 & 486 \\
\hline 0.95 & 0.01342 & 32.72 & 562 & 556 & 555 & 548 & 540 & 536 & 532 \\
\hline 0.95 & 0.01074 & 24.03 & 574 & 566 & 566 & 565 & 562 & 562 & 557 \\
\hline 0.95 & 0.00859 & 13.46 & 618 & 615 & 615 & 612 & 611 & 611 & 611 \\
\hline 0.95 & 0.00687 & 14.11 & 643 & 638 & 638 & 636 & 636 & 635 & 635 \\
\hline 0.95 & 0.00550 & 14.79 & 636 & 626 & 625 & 625 & 624 & 624 & 623 \\
\hline 0.95 & 0.00440 & 12.44 & 641 & 631 & 631 & 631 & 630 & 630 & 630 \\
\hline 0.95 & 0.00352 & 11.61 & 681 & 669 & 669 & 669 & 669 & 669 & 669 \\
\hline 0.95 & 0.00281 & 11.71 & 689 & 676 & 675 & 675 & 675 & 675 & 675 \\
\hline 0.95 & 0.00225 & 13.17 & 687 & 663 & 660 & 660 & 660 & 660 & 660 \\
\hline 0.95 & 0.00180 & 13.50 & 682 & 663 & 655 & 655 & 655 & 655 & 655 \\
\hline 0.95 & 0.00144 & 13.13 & 711 & 689 & 681 & 681 & 681 & 681 & 681 \\
\hline 0.95 & 0.00115 & 14.08 & 695 & 669 & 661 & 660 & 660 & 660 & 660 \\
\hline 0.95 & 0.00092 & 15.27 & 710 & 683 & 674 & 670 & 670 & 670 & 670 \\
\hline 0.95 & 0.00074 & 16.74 & 720 & 697 & 679 & 675 & 675 & 675 & 675 \\
\hline 0.95 & 0.00059 & 19.05 & 724 & 704 & 689 & 678 & 677 & 677 & 677 \\
\hline 0.95 & 0.00000 & 51.01 & 736 & 736 & 736 & 733 & 724 & 716 & 712 \\
\hline 1.00 & 0.10000 & 41.80 & 513 & 248 & 85 & 14 & 0 & 0 & 0 \\
\hline 1.00 & 0.08000 & 29.67 & 378 & 146 & 30 & 3 & 0 & 0 & 0 \\
\hline 1.00 & 0.06400 & 27.90 & 366 & 131 & 24 & 0 & 0 & 0 & 0 \\
\hline 1.00 & 0.05120 & 36.09 & 343 & 180 & 78 & 18 & 0 & 0 & 0 \\
\hline 1.00 & 0.04096 & 74.99 & 367 & 253 & 192 & 121 & 53 & 37 & 17 \\
\hline 1.00 & 0.03277 & 93.29 & 382 & 340 & 315 & 272 & 200 & 170 & 145 \\
\hline 1.00 & 0.02621 & 65.53 & 432 & 413 & 406 & 390 & 361 & 347 & 329 \\
\hline 1.00 & 0.02097 & 35.39 & 431 & 424 & 423 & 414 & 397 & 391 & 386 \\
\hline 1.00 & 0.01678 & 35.47 & 486 & 483 & 480 & 477 & 460 & 455 & 450 \\
\hline 1.00 & 0.01342 & 29.70 & 534 & 527 & 526 & 525 & 516 & 513 & 508 \\
\hline 1.00 & 0.01074 & 24.46 & 570 & 566 & 566 & 564 & 559 & 558 & 554 \\
\hline 1.00 & 0.00859 & 16.36 & 600 & 598 & 598 & 597 & 594 & 594 & 593 \\
\hline 1.00 & 0.00687 & 15.15 & 599 & 594 & 594 & 593 & 592 & 592 & 591 \\
\hline 1.00 & 0.00550 & 12.96 & 622 & 615 & 615 & 615 & 613 & 613 & 613 \\
\hline 1.00 & 0.00440 & 14.80 & 637 & 623 & 622 & 622 & 621 & 621 & 620 \\
\hline 1.00 & 0.00352 & 12.91 & 660 & 650 & 650 & 650 & 649 & 649 & 649 \\
\hline 1.00 & 0.00281 & 11.72 & 677 & 664 & 664 & 664 & 664 & 664 & 664 \\
\hline 1.00 & 0.00225 & 12.85 & 654 & 637 & 636 & 636 & 635 & 635 & 635 \\
\hline 1.00 & 0.00180 & 12.20 & 677 & 659 & 657 & 657 & 657 & 657 & 657 \\
\hline 1.00 & 0.00144 & 12.72 & 688 & 664 & 660 & 660 & 660 & 660 & 660 \\
\hline 1.00 & 0.00115 & 14.73 & 713 & 691 & 680 & 680 & 680 & 680 & 680 \\
\hline 1.00 & 0.00092 & 13.93 & 716 & 694 & 687 & 686 & 686 & 686 & 686 \\
\hline 1.00 & 0.00074 & 14.95 & 707 & 683 & 669 & 668 & 668 & 668 & 668 \\
\hline 1.00 & 0.00059 & 17.41 & 722 & 703 & 684 & 679 & 679 & 679 & 679 \\
\hline 1.00 & 0.00000 & 50.20 & 737 & 735 & 733 & 731 & 724 & 722 & 713 \\
\hline
\end{tabular}


- Para tamanho da população $=50$

\begin{tabular}{|c|c|c|c|c|c|c|c|c|c|}
\hline $\mathrm{Pc}$ & $\mathrm{Pm}$ & Media & NaoAte25 & NaoAte50 & NaoAte100 & NaoAte200 & NaoAte500 & NaoAte700 & NaoAte1000 \\
\hline 0.50 & 0.10000 & 60.76 & 637 & 364 & 177 & 61 & 2 & 0 & $\overline{0}$ \\
\hline 0.50 & 0.08000 & 51.46 & 562 & 318 & 139 & 28 & 1 & 0 & 0 \\
\hline 0.50 & 0.06400 & 51.03 & 545 & 324 & 137 & 30 & 1 & 0 & 0 \\
\hline 0.50 & 0.05120 & 87.24 & 560 & 418 & 268 & 130 & 15 & 3 & $\overline{0}$ \\
\hline 0.50 & 0.04096 & 155.73 & 610 & 529 & 437 & 344 & 184 & 134 & 97 \\
\hline 0.50 & 0.03277 & 172.75 & 659 & 622 & 582 & 534 & 421 & 379 & 337 \\
\hline 0.50 & 0.02621 & 135.45 & 709 & 686 & 676 & 646 & 583 & 562 & 538 \\
\hline 0.50 & 0.02097 & 88.08 & 715 & 702 & 692 & 670 & 640 & 627 & 619 \\
\hline 0.50 & 0.01678 & 97.88 & 754 & 744 & 737 & 728 & 705 & 698 & 682 \\
\hline 0.50 & 0.01342 & 79.20 & 802 & 791 & 789 & 787 & 778 & 773 & 762 \\
\hline 0.50 & 0.01074 & 55.00 & 782 & 764 & 762 & 757 & 750 & 745 & 740 \\
\hline 0.50 & 0.00859 & 38.77 & 809 & 792 & 791 & 790 & 785 & 782 & 780 \\
\hline 0.50 & 0.00687 & 29.30 & 809 & 784 & 782 & 782 & 780 & 779 & 777 \\
\hline 0.50 & 0.00550 & 30.02 & 844 & 812 & 811 & 810 & 810 & 809 & 807 \\
\hline 0.50 & 0.00440 & 20.84 & 857 & 816 & 812 & 811 & 810 & 810 & 810 \\
\hline 0.50 & 0.00352 & 22.10 & 866 & 815 & 808 & 807 & 807 & 807 & 807 \\
\hline 0.50 & 0.00281 & 22.51 & 870 & 821 & 814 & 813 & 813 & 813 & 813 \\
\hline 0.50 & 0.00225 & 30.47 & 896 & 833 & 811 & 811 & 811 & 810 & 810 \\
\hline 0.50 & 0.00180 & 28.66 & 902 & 846 & 821 & 820 & 820 & 820 & 820 \\
\hline 0.50 & 0.00144 & 33.11 & 917 & 865 & 839 & 834 & 834 & 834 & 834 \\
\hline 0.50 & 0.00115 & 38.66 & 922 & 868 & 839 & 829 & 828 & 828 & 828 \\
\hline 0.50 & 0.00092 & 45.70 & 933 & 888 & 848 & 828 & 828 & 828 & 828 \\
\hline 0.50 & 0.00074 & 51.91 & 932 & 895 & 854 & 827 & 825 & 825 & 825 \\
\hline 0.50 & 0.00059 & 68.17 & 934 & 906 & 874 & 834 & 825 & 825 & 825 \\
\hline 0.50 & 0.00000 & 244.33 & 961 & 960 & 959 & 954 & 948 & 940 & 930 \\
\hline 0.55 & 0.10000 & 64.49 & 606 & 344 & 192 & 69 & 4 & 0 & 0 \\
\hline 0.55 & 0.08000 & 49.00 & 564 & 295 & 133 & 22 & 0 & 0 & $\overline{0}$ \\
\hline 0.55 & 0.06400 & 51.13 & 532 & 326 & 139 & 30 & 0 & 0 & 0 \\
\hline 0.55 & 0.05120 & 77.70 & 532 & 393 & 266 & 112 & 12 & 6 & 3 \\
\hline 0.55 & 0.04096 & 156.18 & 553 & 486 & 400 & 308 & 178 & 123 & 73 \\
\hline 0.55 & 0.03277 & 158.37 & 611 & 570 & 533 & 474 & 372 & 343 & 295 \\
\hline 0.55 & 0.02621 & 127.74 & 665 & 640 & 626 & 598 & 549 & 522 & 497 \\
\hline 0.55 & 0.02097 & 92.82 & 699 & 683 & 681 & 667 & 633 & 618 & 607 \\
\hline 0.55 & 0.01678 & 115.22 & 728 & 720 & 710 & 699 & 675 & 663 & 639 \\
\hline 0.55 & 0.01342 & 97.40 & 747 & 735 & 730 & 724 & 711 & 700 & 683 \\
\hline 0.55 & 0.01074 & 52.73 & 773 & 756 & 755 & 752 & 746 & 741 & 735 \\
\hline 0.55 & 0.00859 & 37.05 & 809 & 782 & 782 & 782 & 777 & 773 & 772 \\
\hline 0.55 & 0.00687 & 38.87 & 796 & 782 & 781 & 781 & 777 & 774 & 771 \\
\hline 0.55 & 0.00550 & 34.22 & 824 & 794 & 794 & 793 & 790 & 788 & 786 \\
\hline 0.55 & 0.00440 & 25.31 & 844 & 808 & 806 & 806 & 804 & 804 & 803 \\
\hline 0.55 & 0.00352 & 22.06 & 847 & 807 & 805 & 805 & 803 & 803 & 803 \\
\hline 0.55 & 0.00281 & 19.89 & 863 & 820 & 816 & 816 & 816 & 816 & 816 \\
\hline 0.55 & 0.00225 & 22.87 & 883 & 843 & 830 & 830 & 830 & 830 & 830 \\
\hline 0.55 & 0.00180 & 24.99 & 887 & 845 & 821 & 821 & 821 & 821 & 821 \\
\hline 0.55 & 0.00144 & 29.36 & 906 & 857 & 831 & 829 & 829 & 829 & 829 \\
\hline 0.55 & 0.00115 & 36.34 & 917 & 869 & 831 & 824 & 824 & 824 & 824 \\
\hline 0.55 & 0.00092 & 38.86 & 918 & 880 & 842 & 830 & 830 & 830 & 830 \\
\hline 0.55 & 0.00074 & 47.67 & 924 & 902 & 854 & 834 & 833 & 833 & 833 \\
\hline 0.55 & 0.00059 & 62.63 & 935 & 909 & 874 & 831 & 826 & 826 & 826 \\
\hline 0.55 & 0.00000 & 151.94 & 943 & 941 & 939 & 937 & 934 & 930 & 921 \\
\hline
\end{tabular}


- Para tamanho da população $=50$ (cont.)

\begin{tabular}{|c|c|c|c|c|c|c|c|c|c|}
\hline $\mathrm{Pc}$ & $\mathrm{Pm}$ & Media & \begin{tabular}{|l|l|} 
NaoAte25 & N \\
\end{tabular} & \begin{tabular}{|l|l} 
NaoAte50 \\
\end{tabular} & NaoAte100 & NaoAte200 & NaoAte500 & NaoAte700 & NaoAte1000 \\
\hline 0.60 & 0.10000 & 63.39 & 634 & 383 & 189 & 61 & 2 & 1 & $\overline{0}$ \\
\hline 0.60 & 0.08000 & 46.89 & 532 & 294 & 108 & 21 & 1 & 0 & 0 \\
\hline 0.60 & 0.06400 & 50.73 & 535 & 323 & 144 & 29 & 0 & 0 & 0 \\
\hline 0.60 & 0.05120 & 88.06 & 543 & 405 & 252 & 136 & 23 & 6 & 0 \\
\hline 0.60 & 0.04096 & 145.95 & 553 & 468 & 382 & 282 & 164 & 120 & 72 \\
\hline \begin{tabular}{|l|}
0.60 \\
\end{tabular} & 0.03277 & 167.70 & 627 & 589 & 546 & 491 & 397 & 356 & 306 \\
\hline 0.60 & 0.02621 & 122.86 & 656 & 637 & 614 & 588 & 542 & 525 & 495 \\
\hline 0.60 & 0.02097 & 92.12 & 686 & 677 & 671 & 657 & 622 & 608 & 597 \\
\hline 0.60 & 0.01678 & 81.25 & 700 & 689 & 682 & 674 & 655 & 644 & 631 \\
\hline 0.60 & 0.01342 & 69.44 & 734 & 724 & 720 & 717 & 706 & 701 & 689 \\
\hline 0.60 & 0.01074 & 55.88 & 777 & 771 & 770 & 767 & 763 & 758 & 751 \\
\hline 0.60 & 0.00859 & 27.04 & 803 & 776 & 775 & 772 & 770 & 769 & 768 \\
\hline 0.60 & 0.00687 & 27.45 & 817 & 802 & 800 & 798 & 798 & 796 & 795 \\
\hline 0.60 & 0.00550 & 15.24 & 832 & 806 & 806 & 806 & 806 & 806 & 806 \\
\hline 0.60 & 0.00440 & 23.48 & 849 & 815 & 814 & 813 & 812 & 812 & 811 \\
\hline 0.60 & 0.00352 & 27.61 & 854 & 816 & 814 & 813 & 812 & 811 & 810 \\
\hline 0.60 & 0.00281 & 31.79 & 870 & 835 & 824 & 823 & 822 & 822 & 820 \\
\hline 0.60 & 0.00225 & 28.88 & 878 & 836 & 818 & 818 & 817 & 817 & 816 \\
\hline 0.60 & 0.00180 & 33.79 & 891 & 843 & 821 & 818 & 816 & 816 & 815 \\
\hline 0.60 & 0.00144 & 31.39 & 896 & 847 & 816 & 811 & 811 & 811 & 811 \\
\hline 0.60 & 0.00115 & 36.64 & 898 & 854 & 814 & 806 & 805 & 805 & 805 \\
\hline 0.60 & 0.00092 & 43.36 & 918 & 882 & 836 & 821 & 820 & 820 & 820 \\
\hline 0.60 & 0.00074 & 50.86 & 918 & 893 & 852 & 828 & 825 & 825 & 825 \\
\hline 0.60 & 0.00059 & 58.97 & 917 & 892 & 848 & 819 & 813 & 813 & 813 \\
\hline 0.60 & 0.00000 & 169.07 & 949 & 949 & 948 & 944 & 935 & 931 & 924 \\
\hline 0.65 & 0.10000 & 57.78 & 622 & 345 & 170 & 47 & 0 & 0 & 0 \\
\hline 0.65 & 0.08000 & 45.28 & 544 & 285 & 104 & 24 & 0 & 0 & 0 \\
\hline 0.65 & 0.06400 & 48.44 & 521 & 312 & 118 & 29 & 0 & 0 & 0 \\
\hline 0.65 & 0.05120 & 84.45 & 548 & 396 & 257 & 125 & 19 & 2 & 0 \\
\hline 0.65 & 0.04096 & 161.73 & 570 & 500 & 426 & 318 & 174 & 119 & 69 \\
\hline 0.65 & 0.03277 & 170.08 & 612 & 583 & 546 & 504 & 414 & 366 & 316 \\
\hline 0.65 & 0.02621 & 112.55 & 665 & 654 & 630 & 605 & 555 & 533 & 516 \\
\hline 0.65 & 0.02097 & 97.60 & 689 & 677 & 663 & 646 & 615 & 606 & 588 \\
\hline 0.65 & 0.01678 & 83.74 & 728 & 720 & 710 & 703 & 688 & 675 & 665 \\
\hline 0.65 & 0.01342 & 53.94 & 738 & 729 & 724 & 721 & 713 & 707 & 700 \\
\hline 0.65 & 0.01074 & 36.59 & 767 & 747 & 745 & 739 & 736 & 736 & 731 \\
\hline 0.65 & 0.00859 & 28.76 & 783 & 771 & 769 & 768 & 765 & 764 & 762 \\
\hline 0.65 & 0.00687 & 27.07 & 798 & 776 & 776 & 776 & 776 & 775 & 772 \\
\hline 0.65 & 0.00550 & 23.12 & 800 & 772 & 771 & 771 & 768 & 768 & 767 \\
\hline 0.65 & 0.00440 & 24.27 & 834 & 804 & 802 & 802 & 800 & 800 & 799 \\
\hline 0.65 & 0.00352 & 29.47 & 831 & 803 & 801 & 801 & 795 & 795 & 794 \\
\hline 0.65 & 0.00281 & 21.97 & 844 & 806 & 801 & 801 & 798 & 798 & 798 \\
\hline 0.65 & 0.00225 & 22.90 & 866 & 822 & 806 & 806 & 805 & 805 & 805 \\
\hline 0.65 & 0.00180 & 24.62 & 871 & 827 & 802 & 802 & 802 & 802 & 802 \\
\hline 0.65 & 0.00144 & 26.68 & 876 & 830 & 801 & 799 & 799 & 799 & 799 \\
\hline 0.65 & 0.00115 & 33.79 & 898 & 853 & 813 & 805 & 805 & 805 & 805 \\
\hline 0.65 & 0.00092 & 36.13 & 905 & 870 & 832 & 821 & 821 & 821 & 821 \\
\hline 0.65 & 0.00074 & 43.02 & 915 & 886 & 844 & 831 & 828 & 828 & 828 \\
\hline 0.65 & 0.00059 & 49.47 & 920 & 898 & 856 & 832 & 829 & 829 & 829 \\
\hline
\end{tabular}


- Para tamanho da população = 50 (cont.)

\begin{tabular}{|c|c|c|c|c|c|c|c|c|c|}
\hline $\mathrm{PC}$ & $\mathrm{Pm}$ & Media & NaoAte25 & NaoAte50 & NaoAte100 & NaoAte200 & NaoAte500 & NaoAte700 & NaoAte1000 \\
\hline 0.70 & 0.10000 & 55.34 & 618 & 325 & 161 & 30 & 2 & 0 & 0 \\
\hline 0.70 & 0.08000 & 46.15 & 528 & 296 & 114 & 18 & 0 & 0 & 0 \\
\hline 0.70 & 0.06400 & 46.35 & 510 & 300 & 111 & 19 & 1 & 0 & 0 \\
\hline 0.70 & 0.05120 & 79.48 & 512 & 364 & 245 & 108 & 20 & 5 & 0 \\
\hline 0.70 & 0.04096 & 154.34 & 558 & 483 & 408 & 302 & 160 & 113 & 68 \\
\hline 0.70 & 0.03277 & 163.71 & 589 & 555 & 519 & 446 & 358 & 315 & 259 \\
\hline 0.70 & 0.02621 & 138.69 & 652 & 636 & 628 & 607 & 556 & 521 & 495 \\
\hline 0.70 & 0.02097 & 83.45 & 664 & 644 & 638 & 630 & 599 & 588 & 575 \\
\hline 0.70 & 0.01678 & 88.21 & 723 & 714 & 712 & 707 & 690 & 679 & 664 \\
\hline 0.70 & 0.01342 & 68.06 & 743 & 734 & 732 & 730 & 724 & 720 & 707 \\
\hline 0.70 & 0.01074 & 44.52 & 766 & 755 & 754 & 751 & 746 & 744 & 738 \\
\hline 0.70 & 0.00859 & 24.62 & 788 & 774 & 774 & 772 & 769 & 768 & 767 \\
\hline 0.70 & 0.00687 & 22.51 & 811 & 795 & 795 & 794 & 793 & 792 & 791 \\
\hline 0.70 & 0.00550 & 26.65 & 810 & 792 & 792 & 792 & 788 & 787 & 786 \\
\hline 0.70 & 0.00440 & 23.12 & 828 & 801 & 801 & 800 & 797 & 796 & 796 \\
\hline 0.70 & 0.00352 & 24.44 & 840 & 810 & 808 & 808 & 807 & 806 & 805 \\
\hline 0.70 & 0.00281 & 21.16 & 855 & 818 & 813 & 813 & 813 & 812 & 812 \\
\hline 0.70 & 0.00225 & 19.57 & 860 & 821 & 811 & 811 & 811 & 811 & 811 \\
\hline 0.70 & 0.00180 & 23.17 & 857 & 819 & 797 & 797 & 796 & 796 & 796 \\
\hline 0.70 & 0.00144 & 27.92 & 873 & 829 & 801 & 796 & 795 & 795 & 795 \\
\hline 0.70 & 0.00115 & 32.76 & 881 & 850 & 810 & 802 & 800 & 800 & 800 \\
\hline 0.70 & 0.00092 & 36.32 & 893 & 853 & 818 & 803 & 802 & 802 & 802 \\
\hline 0.70 & 0.00074 & 37.18 & 889 & 854 & 826 & 808 & 807 & 807 & 807 \\
\hline 0.70 & 0.00059 & 49.29 & 898 & 868 & 830 & 804 & 798 & 798 & 798 \\
\hline 0.70 & 0.00000 & 150.47 & 923 & 922 & 921 & 917 & 912 & 907 & 896 \\
\hline 0.75 & 0.10000 & 57.65 & 612 & 321 & 152 & 51 & 0 & 0 & 0 \\
\hline 0.75 & 0.08000 & 49.32 & 528 & 309 & 123 & 26 & 0 & 0 & 0 \\
\hline 0.75 & 0.06400 & 45.12 & 492 & 292 & 112 & 17 & 0 & 0 & 0 \\
\hline 0.75 & 0.05120 & 78.05 & 514 & 383 & 240 & 116 & 14 & 3 & 1 \\
\hline 0.75 & 0.04096 & 142.81 & 548 & 467 & 381 & 282 & 140 & 95 & 57 \\
\hline 0.75 & 0.03277 & 162.90 & 590 & 557 & 528 & 468 & 384 & 340 & 287 \\
\hline 0.75 & 0.02621 & 102.39 & 642 & 623 & 610 & 579 & 531 & 511 & 493 \\
\hline 0.75 & 0.02097 & 84.53 & 666 & 658 & 652 & 637 & 606 & 595 & 581 \\
\hline 0.75 & 0.01678 & 59.93 & 697 & 685 & 679 & 675 & 657 & 654 & 644 \\
\hline 0.75 & 0.01342 & 58.68 & 714 & 703 & 702 & 700 & 689 & 681 & 673 \\
\hline 0.75 & 0.01074 & 41.75 & 762 & 753 & 753 & 752 & 742 & 740 & 736 \\
\hline 0.75 & 0.00859 & 29.53 & 755 & 743 & 742 & 740 & 739 & 736 & 734 \\
\hline 0.75 & 0.00687 & 22.62 & 799 & 785 & 785 & 783 & 780 & 779 & 779 \\
\hline 0.75 & 0.00550 & 19.41 & 797 & 780 & 778 & 777 & 775 & 775 & 775 \\
\hline 0.75 & 0.00440 & 25.59 & 818 & 789 & 786 & 786 & 786 & 784 & 783 \\
\hline 0.75 & 0.00352 & 17.66 & 834 & 800 & 795 & 794 & 794 & 794 & 794 \\
\hline 0.75 & 0.00281 & 26.93 & 857 & 822 & 817 & 817 & 817 & 817 & 815 \\
\hline 0.75 & 0.00225 & 24.04 & 868 & 828 & 818 & 818 & 818 & 818 & 817 \\
\hline 0.75 & 0.00180 & 25.93 & 860 & 830 & 812 & 812 & 812 & 812 & 811 \\
\hline 0.75 & 0.00144 & 23.01 & 867 & 823 & 801 & 801 & 801 & 801 & 801 \\
\hline 0.75 & 0.00115 & 28.13 & 879 & 834 & 797 & 795 & 795 & 795 & 795 \\
\hline 0.75 & 0.00092 & 32.78 & 877 & 835 & 794 & 785 & 785 & 785 & 785 \\
\hline 0.75 & \begin{tabular}{|l|l|}
0.00074 \\
\end{tabular} & 40.12 & 883 & 854 & 806 & 790 & 789 & 789 & 789 \\
\hline 0.75 & \begin{tabular}{|l|}
0.00059 \\
\end{tabular} & 43.84 & 883 & 853 & 807 & 783 & 781 & 781 & 781 \\
\hline 0.75 & 0.00000 & 107.26 & 904 & 903 & 902 & 900 & 891 & 886 & 879 \\
\hline
\end{tabular}


- Para tamanho da população = 50 (cont.)

\begin{tabular}{|c|c|c|c|c|c|c|c|c|c|}
\hline $\mathrm{Pc}$ & $\mathrm{Pm}$ & Media & NaoAte25 & NaoAte50 & NaoAte100 & NaoAte200 & NaoAte500 & NaoAte700 & NaoAte1000 \\
\hline 0.80 & 0.10000 & 52.76 & 582 & 299 & 145 & 36 & 0 & 0 & 0 \\
\hline 0.80 & 0.08000 & 45.53 & 514 & 264 & 109 & 24 & 0 & 0 & 0 \\
\hline 0.80 & 0.06400 & 43.04 & 473 & 272 & 103 & 16 & 0 & 0 & 0 \\
\hline 0.80 & 0.05120 & 71.07 & 476 & 351 & 214 & 99 & 9 & 2 & 0 \\
\hline 0.80 & 0.04096 & 143.36 & 537 & 461 & 390 & 298 & 157 & 104 & 67 \\
\hline 0.80 & 0.03277 & 171.45 & 595 & 564 & 533 & 483 & 380 & 343 & 286 \\
\hline 0.80 & 0.02621 & 95.15 & 606 & 585 & 569 & 542 & 492 & 473 & 458 \\
\hline 0.80 & 0.02097 & 83.10 & 670 & 659 & 653 & 644 & 614 & 604 & 591 \\
\hline 0.80 & 0.01678 & 55.02 & 652 & 646 & 645 & 635 & 616 & 612 & 603 \\
\hline 0.80 & 0.01342 & 47.64 & 710 & 704 & 702 & 698 & 691 & 689 & 681 \\
\hline 0.80 & 0.01074 & 29.57 & 742 & 732 & 732 & 732 & 729 & 728 & 725 \\
\hline 0.80 & 0.00859 & 20.95 & 742 & 726 & 725 & 725 & 724 & 724 & 722 \\
\hline 0.80 & 0.00687 & 18.95 & 760 & 744 & 744 & 744 & 743 & 743 & 742 \\
\hline 0.80 & 0.00550 & 23.51 & 793 & 770 & 770 & 770 & 769 & 769 & 767 \\
\hline 0.80 & 0.00440 & 24.42 & 793 & 758 & 757 & 757 & 755 & 755 & 753 \\
\hline 0.80 & 0.00352 & 22.39 & 819 & 783 & 780 & 779 & 778 & 778 & 777 \\
\hline 0.80 & 0.00281 & 19.37 & 830 & 790 & 779 & 778 & 778 & 778 & 778 \\
\hline 0.80 & 0.00225 & 18.84 & 847 & 804 & 796 & 796 & 796 & 796 & 796 \\
\hline 0.80 & 0.00180 & 24.68 & 862 & 826 & 811 & 810 & 810 & 810 & 809 \\
\hline 0.80 & 0.00144 & 29.18 & 850 & 808 & 788 & 784 & 783 & 783 & 782 \\
\hline 0.80 & 0.00115 & 31.80 & 862 & 831 & 803 & 797 & 796 & 796 & 795 \\
\hline 0.80 & 0.00092 & 29.22 & 869 & 837 & 810 & 801 & 800 & 800 & 800 \\
\hline 0.80 & 0.00074 & 33.91 & 872 & 846 & 813 & 800 & 799 & 799 & 799 \\
\hline 0.80 & 0.00059 & 35.60 & 871 & 848 & 813 & 794 & 794 & 794 & 794 \\
\hline 0.80 & 0.00000 & 111.22 & 902 & 901 & 898 & 893 & 882 & 878 & 871 \\
\hline 0.85 & 0.10000 & 55.07 & 599 & 308 & 151 & 46 & 1 & 0 & 0 \\
\hline 0.85 & 0.08000 & 43.09 & 506 & 260 & 92 & 15 & 0 & 0 & 0 \\
\hline 0.85 & 0.06400 & 44.25 & 489 & 273 & 112 & 17 & 0 & 0 & 0 \\
\hline 0.85 & 0.05120 & 78.08 & 521 & 374 & 233 & 100 & 18 & 7 & 1 \\
\hline 0.85 & 0.04096 & 134.74 & 536 & 436 & 367 & 270 & 144 & 109 & 64 \\
\hline 0.85 & 0.03277 & 154.07 & 595 & 554 & 527 & 484 & 388 & 348 & 306 \\
\hline 0.85 & 0.02621 & 103.79 & 591 & 572 & 559 & 536 & 500 & 480 & 454 \\
\hline 0.85 & 0.02097 & 84.91 & 659 & 649 & 640 & 625 & 603 & 596 & 577 \\
\hline 0.85 & 0.01678 & 72.53 & 699 & 695 & 694 & 691 & 671 & 661 & 651 \\
\hline 0.85 & 0.01342 & 53.37 & 699 & 694 & 694 & 690 & 679 & 675 & 666 \\
\hline 0.85 & 0.01074 & 36.29 & 727 & 720 & 720 & 719 & 715 & 712 & 708 \\
\hline 0.85 & 0.00859 & 24.07 & 730 & 722 & 721 & 721 & 718 & 717 & 715 \\
\hline 0.85 & 0.00687 & 22.26 & 765 & 745 & 744 & 744 & 743 & 743 & 741 \\
\hline 0.85 & 0.00550 & 18.65 & 787 & 769 & 769 & 769 & 768 & 768 & 767 \\
\hline 0.85 & 0.00440 & 18.64 & 796 & 774 & 773 & 773 & 773 & 773 & 772 \\
\hline 0.85 & 0.00352 & 19.22 & 801 & 772 & 769 & 769 & 769 & 769 & 768 \\
\hline 0.85 & 0.00281 & 22.83 & 799 & 770 & 763 & 763 & 763 & 762 & 761 \\
\hline 0.85 & 0.00225 & 22.08 & 837 & 798 & 786 & 786 & 786 & 786 & 785 \\
\hline 0.85 & 0.00180 & 20.16 & 832 & 790 & 773 & 773 & 773 & 773 & 773 \\
\hline 0.85 & 0.00144 & 24.31 & 857 & 814 & 787 & 785 & 785 & 785 & 785 \\
\hline 0.85 & 0.00115 & 24.42 & 850 & 818 & 794 & 789 & 789 & 789 & 789 \\
\hline 0.85 & 0.00092 & 28.69 & 858 & 829 & 803 & 794 & 793 & 793 & 793 \\
\hline 0.85 & 0.00074 & 33.12 & 867 & 836 & 804 & 792 & 791 & 791 & 791 \\
\hline 0.85 & 0.00059 & 39.90 & 875 & 846 & 818 & 799 & 795 & 795 & 795 \\
\hline 0.85 & 0.00000 & 118.11 & 878 & 878 & 876 & 873 & 867 & 859 & 848 \\
\hline
\end{tabular}


- Para tamanho da população = 50 (cont.)

\begin{tabular}{|c|c|c|c|c|c|c|c|c|c|}
\hline $\mathrm{Pc}$ & $\mathrm{Pm}$ & Media & NaoAte25 & NaoAte50 & NaoAte100 & NaoAte200 & NaoAte500 & NaoAte700 & NaoAte1000 \\
\hline 0.90 & 0.10000 & 51.35 & 572 & 298 & 138 & 33 & 1 & 0 & 0 \\
\hline 0.90 & 0.08000 & 44.65 & 540 & 269 & 96 & 17 & 0 & 0 & 0 \\
\hline \begin{tabular}{|l|}
0.90 \\
\end{tabular} & 0.06400 & 42.95 & 479 & 288 & 94 & 15 & 0 & 0 & 0 \\
\hline 0.90 & 0.05120 & 67.15 & 469 & 329 & 207 & 86 & 10 & 2 & 1 \\
\hline 0.90 & 0.04096 & 132.53 & 489 & 424 & 366 & 264 & 144 & 110 & 64 \\
\hline \begin{tabular}{|l|}
0.90 \\
\end{tabular} & 0.03277 & 146.29 & 545 & 512 & 480 & 440 & 360 & 321 & 271 \\
\hline 0.90 & 0.02621 & 107.62 & 631 & 621 & 612 & 588 & 547 & 530 & 506 \\
\hline 0.90 & 0.02097 & 74.11 & 613 & 602 & 598 & 585 & 554 & 547 & 532 \\
\hline 0.90 & 0.01678 & 61.61 & 666 & 659 & 656 & 651 & 637 & 631 & 620 \\
\hline 0.90 & 0.01342 & 53.95 & 710 & 703 & 702 & 701 & 694 & 690 & 680 \\
\hline 0.90 & 0.01074 & 28.35 & 737 & 725 & 724 & 724 & 721 & 721 & 717 \\
\hline 0.90 & 0.00859 & 18.06 & 746 & 735 & 735 & 735 & 732 & 732 & 732 \\
\hline 0.90 & 0.00687 & 16.35 & 738 & 720 & 720 & 720 & 720 & 720 & 719 \\
\hline 0.90 & 0.00550 & 15.99 & 766 & 745 & 744 & 744 & 743 & 743 & 743 \\
\hline 0.90 & 0.00440 & 16.88 & 794 & 771 & 771 & 771 & 771 & 770 & 770 \\
\hline 0.90 & 0.00352 & 17.35 & 800 & 782 & 781 & 781 & 781 & 780 & 780 \\
\hline 0.90 & 0.00281 & 15.37 & 821 & 798 & 795 & 795 & 795 & 795 & 795 \\
\hline 0.90 & 0.00225 & 19.10 & 839 & 813 & 806 & 806 & 806 & 805 & 805 \\
\hline 0.90 & 0.00180 & 22.75 & 817 & 791 & 773 & 773 & 773 & 773 & 772 \\
\hline 0.90 & 0.00144 & 24.23 & 837 & 804 & 782 & 781 & 781 & 781 & 780 \\
\hline 0.90 & 0.00115 & 24.12 & 844 & 822 & 789 & 785 & 785 & 785 & 785 \\
\hline 0.90 & 0.00092 & 25.88 & 845 & 822 & 789 & 783 & 783 & 783 & 783 \\
\hline 0.90 & 0.00074 & 33.86 & 861 & 832 & 793 & 781 & 779 & 779 & 779 \\
\hline 0.90 & 0.00059 & 40.80 & 875 & 851 & 817 & 793 & 791 & 791 & 791 \\
\hline 0.90 & 0.00000 & 68.15 & 882 & 881 & 880 & 878 & 869 & 866 & 862 \\
\hline 0.95 & 0.10000 & 52.22 & 585 & 306 & 149 & 32 & 1 & 0 & 0 \\
\hline 0.95 & 0.08000 & 44.29 & 550 & 276 & 103 & 13 & 0 & 0 & 0 \\
\hline 0.95 & 0.06400 & 40.85 & 460 & 259 & 85 & 10 & 0 & 0 & 0 \\
\hline 0.95 & 0.05120 & 67.92 & 477 & 339 & 229 & 76 & 11 & 1 & 0 \\
\hline 0.95 & 0.04096 & 127.24 & 514 & 429 & 357 & 269 & 135 & 104 & 69 \\
\hline 0.95 & 0.03277 & 151.94 & 560 & 524 & 491 & 461 & 374 & 328 & 280 \\
\hline 0.95 & 0.02621 & 89.49 & 610 & 587 & 573 & 555 & 521 & 499 & 485 \\
\hline 0.95 & 0.02097 & 71.46 & 671 & 657 & 655 & 643 & 616 & 606 & 597 \\
\hline 0.95 & 0.01678 & 58.11 & 665 & 657 & 655 & 650 & 638 & 631 & 621 \\
\hline 0.95 & 0.01342 & 42.73 & 716 & 704 & 702 & 698 & 692 & 685 & 682 \\
\hline 0.95 & 0.01074 & 29.24 & 723 & 716 & 716 & 715 & 713 & 711 & 707 \\
\hline 0.95 & 0.00859 & 19.46 & 710 & 702 & 702 & 701 & 701 & 699 & 698 \\
\hline 0.95 & 0.00687 & 13.92 & 755 & 732 & 732 & 732 & 732 & 732 & 732 \\
\hline \begin{tabular}{|l|}
0.95 \\
\end{tabular} & 0.00550 & 16.84 & 761 & 739 & 739 & 739 & 739 & 739 & 738 \\
\hline \begin{tabular}{|l|}
0.95 \\
\end{tabular} & 0.00440 & 13.91 & 787 & 761 & 761 & 761 & 761 & 761 & 761 \\
\hline 0.95 & 0.00352 & 14.86 & 788 & 756 & 754 & 754 & 754 & 754 & 754 \\
\hline 0.95 & 0.00281 & 16.45 & 795 & 761 & 755 & 755 & 755 & 755 & 755 \\
\hline 0.95 & 0.00225 & 16.45 & 820 & 785 & 780 & 780 & 780 & 780 & 780 \\
\hline 0.95 & 0.00180 & 17.47 & 826 & 782 & 777 & 777 & 777 & 777 & 777 \\
\hline \begin{tabular}{|l|}
0.95 \\
\end{tabular} & 0.00144 & 18.50 & 836 & 807 & 795 & 794 & 794 & 794 & 794 \\
\hline 0.95 & 0.00115 & 21.13 & 831 & 795 & 775 & 772 & 772 & 772 & 772 \\
\hline 0.95 & 0.00092 & 23.64 & 839 & 805 & 779 & 775 & 775 & 775 & 775 \\
\hline 0.95 & 0.00074 & 29.34 & 840 & 817 & 780 & 769 & 768 & 768 & 768 \\
\hline 0.95 & 0.00059 & 34.42 & 851 & 824 & 793 & 776 & 773 & 773 & 773 \\
\hline 0.95 & 0.00000 & 94.80 & 875 & 874 & 870 & 863 & 854 & 848 & 840 \\
\hline 1.00 & 0.10000 & 47.69 & 580 & 288 & 114 & 22 & 1 & 0 & 0 \\
\hline 1.00 & 0.08000 & 41.33 & 514 & 257 & 81 & 9 & 0 & 0 & 0 \\
\hline 1.00 & 0.06400 & 42.67 & 462 & 270 & 109 & 15 & 0 & 0 & 0 \\
\hline 1.00 & 0.05120 & 70.41 & 506 & 350 & 214 & 95 & 8 & 4 & 1 \\
\hline 1.00 & 0.04096 & 136.89 & 513 & 439 & 374 & 283 & 149 & 115 & 73 \\
\hline 1.00 & 0.03277 & 165.08 & 570 & 540 & 511 & 460 & 363 & 312 & 264 \\
\hline 1.00 & 0.02621 & 98.88 & 584 & 568 & 555 & 532 & 482 & 469 & 445 \\
\hline 1.00 & 0.02097 & 69.82 & 622 & 613 & 607 & 594 & 570 & 560 & 549 \\
\hline 1.00 & 0.01678 & 61.79 & 665 & 658 & 657 & 652 & 639 & 632 & 622 \\
\hline 1.00 & 0.01342 & 51.35 & 676 & 671 & 670 & 667 & 656 & 647 & 641 \\
\hline 1.00 & 0.01074 & 26.92 & 703 & 692 & 691 & 691 & 687 & 683 & 682 \\
\hline 1.00 & 0.00859 & 26.69 & 715 & 702 & 702 & 702 & 700 & 698 & 695 \\
\hline \begin{tabular}{|l|}
1.00 \\
\end{tabular} & 0.00687 & 20.39 & 735 & 720 & 720 & 719 & 717 & 716 & 715 \\
\hline 1.00 & 0.00550 & 17.59 & 747 & 728 & 727 & 726 & 725 & 725 & 724 \\
\hline 1.00 & 0.00440 & 15.00 & 759 & 742 & 741 & 741 & 741 & 740 & 740 \\
\hline 1.00 & 0.00352 & 14.62 & 766 & 738 & 736 & 736 & 735 & 735 & 735 \\
\hline 1.00 & 0.00281 & 18.16 & 781 & 755 & 750 & 749 & 748 & 747 & 747 \\
\hline 1.00 & 0.00225 & 19.38 & 793 & 754 & 744 & 743 & 743 & 742 & 742 \\
\hline 1.00 & 0.00180 & 19.67 & 799 & 773 & 758 & 757 & 757 & 756 & 756 \\
\hline 1.00 & 0.00144 & 21.65 & 828 & 791 & 778 & 776 & 776 & 775 & 775 \\
\hline 1.00 & 0.00115 & 28.39 & 838 & 804 & 777 & 773 & 772 & 771 & 771 \\
\hline 1.00 & 0.00092 & 25.34 & 827 & 801 & 773 & 765 & 765 & 765 & 765 \\
\hline 1.00 & 0.00074 & 32.48 & 838 & 814 & 791 & 775 & 774 & 773 & 773 \\
\hline 1.00 & 0.00059 & 38.40 & 848 & 822 & 795 & 775 & 771 & 771 & 770 \\
\hline 1.00 & 0.00000 & 83.98 & 837 & 836 & 835 & 835 & 823 & 818 & 810 \\
\hline
\end{tabular}


- Para tamanho da população = 20

\begin{tabular}{|c|c|c|c|c|c|c|c|c|c|}
\hline $\mathrm{Pc}$ & $\mathrm{Pm}$ & Media & NaoAte25 & NaoAte50 & NaoAte100 & NaoAte200 & NaoAte500 & NaoAte700 & NaoAte1000 \\
\hline 0.50 & 0.10000 & 183.70 & 819 & 637 & 486 & 325 & 129 & 73 & 27 \\
\hline 0.50 & 0.08000 & 200.35 & 816 & 661 & 545 & 376 & 143 & 81 & 37 \\
\hline 0.50 & 0.06400 & 260.59 & 823 & 712 & 616 & 509 & 251 & 161 & 75 \\
\hline 0.50 & 0.05120 & 306.97 & 850 & 783 & 727 & 648 & 484 & 394 & 289 \\
\hline 0.50 & 0.04096 & 247.00 & 871 & 823 & 777 & 725 & 642 & 604 & 549 \\
\hline 0.50 & 0.03277 & 208.52 & 879 & 847 & 828 & 799 & 739 & 714 & 689 \\
\hline 0.50 & 0.02621 & 188.66 & 903 & 866 & 848 & 826 & 783 & 769 & 749 \\
\hline \begin{tabular}{|l|}
0.50 \\
\end{tabular} & 0.02097 & 164.20 & 926 & 891 & 881 & 866 & 839 & 823 & 815 \\
\hline 0.50 & 0.01678 & 167.77 & 932 & 903 & 898 & 887 & 872 & 857 & 848 \\
\hline 0.50 & 0.01342 & 127.73 & 957 & 915 & 905 & 899 & 892 & 887 & 880 \\
\hline 0.50 & 0.01074 & 99.44 & 955 & 923 & 911 & 903 & 898 & 898 & 892 \\
\hline 0.50 & 0.00859 & 81.14 & 961 & 926 & 915 & 915 & 910 & 907 & 905 \\
\hline 0.50 & 0.00687 & 105.39 & 975 & 940 & 924 & 922 & 918 & 914 & 911 \\
\hline 0.50 & 0.00550 & 107.11 & 977 & 941 & 922 & 917 & 916 & 912 & 908 \\
\hline 0.50 & 0.00440 & 103.06 & 979 & 949 & 925 & 920 & 918 & 916 & 912 \\
\hline 0.50 & 0.00352 & 78.06 & 986 & 965 & 930 & 921 & 920 & 919 & 918 \\
\hline 0.50 & 0.00281 & 85.75 & 986 & 972 & 941 & 924 & 923 & 922 & 921 \\
\hline 0.50 & 0.00225 & 90.28 & 987 & 978 & 947 & 929 & 926 & 926 & 925 \\
\hline 0.50 & 0.00180 & 103.68 & 989 & 983 & 959 & 935 & 927 & 927 & 927 \\
\hline 0.50 & 0.00144 & 110.50 & 990 & 987 & 970 & 938 & 932 & 932 & 932 \\
\hline 0.50 & 0.00115 & 142.96 & 992 & 989 & 978 & 945 & 931 & 931 & 931 \\
\hline 0.50 & 0.00092 & 164.70 & 994 & 991 & 979 & 954 & 934 & 934 & 934 \\
\hline 0.50 & 0.00074 & 230.07 & 996 & 993 & 987 & 968 & 935 & 932 & 932 \\
\hline 0.50 & 0.00059 & 243.38 & 996 & 993 & 987 & 970 & 936 & 933 & 932 \\
\hline \begin{tabular}{|l|}
0.50 \\
\end{tabular} & 0.00000 & 6.00 & 995 & 995 & 995 & 995 & 995 & 995 & 995 \\
\hline \begin{tabular}{|l|}
0.55 \\
\end{tabular} & 0.10000 & 167.10 & 818 & 614 & 465 & 311 & 104 & 56 & 26 \\
\hline \begin{tabular}{|l|}
0.55 \\
\end{tabular} & 0.08000 & 200.29 & 842 & 682 & 536 & 393 & 150 & 95 & 41 \\
\hline \begin{tabular}{|l|}
0.55 \\
\end{tabular} & 0.06400 & 250.35 & 826 & 721 & 624 & 503 & 258 & 165 & 93 \\
\hline \begin{tabular}{|l|}
0.55 \\
\end{tabular} & 0.05120 & 275.74 & 838 & 753 & 692 & 614 & 463 & 379 & 293 \\
\hline \begin{tabular}{|l|}
0.55 \\
\end{tabular} & 0.04096 & 254.01 & 854 & 801 & 758 & 706 & 623 & 576 & 517 \\
\hline \begin{tabular}{|l|}
0.55 \\
\end{tabular} & 0.03277 & 222.16 & 880 & 847 & 818 & 792 & 741 & 714 & 679 \\
\hline \begin{tabular}{|l|}
0.55 \\
\end{tabular} & 0.02621 & 181.81 & 897 & 867 & 855 & 832 & 791 & 779 & 760 \\
\hline \begin{tabular}{|l|}
0.55 \\
\end{tabular} & 0.02097 & 163.09 & 914 & 882 & 868 & 849 & 825 & 815 & 801 \\
\hline \begin{tabular}{|l|}
0.55 \\
\end{tabular} & 0.01678 & 129.25 & 933 & 900 & 894 & 884 & 867 & 859 & 854 \\
\hline \begin{tabular}{|l|}
0.55 \\
\end{tabular} & 0.01342 & 133.60 & 951 & 912 & 908 & 900 & 894 & 889 & 880 \\
\hline \begin{tabular}{|l|}
0.55 \\
\end{tabular} & 0.01074 & 118.00 & 961 & 921 & 915 & 909 & 902 & 899 & 893 \\
\hline 0.55 & 0.00859 & 101.69 & 969 & 935 & 924 & 920 & 912 & 912 & 907 \\
\hline 0.55 & 0.00687 & 68.70 & 972 & 936 & 918 & 915 & 913 & 913 & 910 \\
\hline 0.55 & 0.00550 & 80.73 & 974 & 937 & 911 & 906 & 905 & 905 & 901 \\
\hline 0.55 & 0.00440 & 93.27 & 981 & 951 & 931 & 923 & 922 & 922 & 918 \\
\hline 0.55 & 0.00352 & 76.62 & 982 & 956 & 938 & 928 & 928 & 928 & 926 \\
\hline 0.55 & 0.00281 & 81.43 & 983 & 961 & 932 & 917 & 916 & 916 & 914 \\
\hline 0.55 & 0.00225 & 84.59 & 987 & 973 & 941 & 917 & 916 & 916 & 915 \\
\hline 0.55 & 0.00180 & 99.84 & 988 & 980 & 957 & 928 & 927 & 927 & 926 \\
\hline 0.55 & 0.00144 & 125.00 & 993 & 986 & 961 & 929 & 923 & 923 & 922 \\
\hline 0.55 & 0.00115 & 151.67 & 997 & 991 & 969 & 942 & 927 & 926 & 925 \\
\hline 0.55 & 0.00092 & 188.83 & 997 & 992 & 976 & 957 & 932 & 931 & 930 \\
\hline 0.55 & 0.00074 & 228.14 & 996 & 993 & 982 & 966 & 928 & 924 & 924 \\
\hline 0.55 & 0.00059 & 259.20 & 995 & 993 & 985 & 969 & 933 & 924 & 924 \\
\hline 0.55 & 0.00000 & 128.25 & 995 & 995 & 994 & 994 & 992 & 992 & 992 \\
\hline
\end{tabular}


- Para tamanho da população = 20 (cont.)

\begin{tabular}{|c|c|c|c|c|c|c|c|c|c|}
\hline $\mathrm{Pc}$ & $\mathrm{Pm}$ & Media & NaoAte25 & NaoAte50 & NaoAte100 & NaoAte200 & NaoAte500 & NaoAte700 & NaoAte1000 \\
\hline 0.60 & 0.10000 & 182.78 & 836 & 626 & 486 & 332 & 122 & 61 & 25 \\
\hline 0.60 & 0.08000 & 189.80 & 798 & 647 & 519 & 365 & 126 & 66 & 29 \\
\hline 0.60 & 0.06400 & 254.58 & 814 & 706 & 624 & 488 & 246 & 160 & 77 \\
\hline 0.60 & 0.05120 & 292.73 & 856 & 783 & 710 & 611 & 440 & 369 & 261 \\
\hline 0.60 & 0.04096 & 255.35 & 859 & 806 & 765 & 711 & 618 & 569 & 510 \\
\hline 0.60 & 0.03277 & 203.56 & 886 & 850 & 820 & 783 & 722 & 690 & 672 \\
\hline 0.60 & 0.02621 & 220.93 & 898 & 871 & 858 & 837 & 800 & 776 & 751 \\
\hline 0.60 & 0.02097 & 188.39 & 910 & 882 & 873 & 864 & 846 & 832 & 813 \\
\hline 0.60 & 0.01678 & 140.91 & 927 & 896 & 891 & 884 & 870 & 864 & 854 \\
\hline 0.60 & 0.01342 & 123.41 & 939 & 899 & 896 & 892 & 884 & 881 & 872 \\
\hline 0.60 & 0.01074 & 93.79 & 945 & 901 & 894 & 888 & 883 & 881 & 875 \\
\hline 0.60 & 0.00859 & 71.82 & 949 & 906 & 894 & 892 & 891 & 889 & 885 \\
\hline 0.60 & 0.00687 & 83.02 & 956 & 917 & 906 & 902 & 897 & 896 & 892 \\
\hline 0.60 & 0.00550 & 79.33 & 964 & 928 & 914 & 911 & 908 & 907 & 904 \\
\hline 0.60 & 0.00440 & 80.93 & 972 & 937 & 906 & 902 & 900 & 900 & 896 \\
\hline 0.60 & 0.00352 & 64.96 & 979 & 947 & 919 & 911 & 910 & 910 & 909 \\
\hline 0.60 & 0.00281 & 56.35 & 984 & 959 & 920 & 911 & 911 & 911 & 911 \\
\hline 0.60 & 0.00225 & 63.54 & 984 & 964 & 928 & 915 & 915 & 915 & 915 \\
\hline 0.60 & 0.00180 & 81.04 & 987 & 970 & 936 & 911 & 907 & 907 & 907 \\
\hline 0.60 & 0.00144 & 103.26 & 989 & 978 & 952 & 913 & 906 & 906 & 906 \\
\hline 0.60 & 0.00115 & 124.87 & 992 & 984 & 958 & 923 & 909 & 909 & 909 \\
\hline 0.60 & 0.00092 & 153.67 & 990 & 985 & 972 & 934 & 909 & 909 & 909 \\
\hline 0.60 & 0.00074 & 201.44 & 990 & 987 & 979 & 950 & 906 & 905 & 905 \\
\hline 0.60 & 0.00059 & 246.01 & 992 & 990 & 982 & 958 & 910 & 903 & 902 \\
\hline 0.60 & 0.00000 & 246.20 & 995 & 995 & 994 & 994 & 993 & 991 & 990 \\
\hline 0.65 & 0.10000 & 158.19 & 810 & 602 & 444 & 301 & 92 & 55 & 26 \\
\hline 0.65 & 0.08000 & 187.14 & 805 & 637 & 504 & 343 & 138 & 70 & 31 \\
\hline 0.65 & 0.06400 & 264.65 & 834 & 718 & 632 & 494 & 256 & 173 & 79 \\
\hline 0.65 & 0.05120 & 283.44 & 827 & 750 & 681 & 597 & 428 & 347 & 247 \\
\hline 0.65 & 0.04096 & 251.97 & 857 & 807 & 768 & 716 & 627 & 586 & 524 \\
\hline 0.65 & 0.03277 & 212.23 & 870 & 832 & 810 & 774 & 721 & 698 & 663 \\
\hline 0.65 & 0.02621 & 190.41 & 887 & 858 & 846 & 825 & 778 & 756 & 739 \\
\hline 0.65 & 0.02097 & 166.22 & 894 & 868 & 859 & 853 & 830 & 817 & 799 \\
\hline 0.65 & 0.01678 & 128.72 & 924 & 889 & 881 & 874 & 859 & 855 & 844 \\
\hline 0.65 & 0.01342 & 101.58 & 924 & 885 & 881 & 876 & 863 & 860 & 854 \\
\hline 0.65 & 0.01074 & 53.91 & 936 & 898 & 894 & 886 & 881 & 880 & 879 \\
\hline 0.65 & 0.00859 & 53.18 & 944 & 903 & 890 & 885 & 880 & 879 & 878 \\
\hline 0.65 & 0.00687 & 78.31 & 955 & 912 & 897 & 893 & 886 & 886 & 882 \\
\hline 0.65 & 0.00550 & 49.38 & 960 & 926 & 904 & 902 & 898 & 898 & 898 \\
\hline 0.65 & 0.00440 & 64.09 & 965 & 941 & 917 & 914 & 911 & 911 & 909 \\
\hline 0.65 & 0.00352 & 78.19 & 973 & 952 & 919 & 907 & 904 & 904 & 902 \\
\hline 0.65 & 0.00281 & 76.75 & 976 & 960 & 921 & 902 & 899 & 899 & 898 \\
\hline 0.65 & 0.00225 & 78.79 & 979 & 963 & 928 & 902 & 898 & 898 & 898 \\
\hline 0.65 & 0.00180 & 82.17 & 981 & 964 & 926 & 902 & 898 & 897 & 897 \\
\hline 0.65 & 0.00144 & 107.30 & 981 & 969 & 945 & 904 & 894 & 893 & 893 \\
\hline 0.65 & 0.00115 & 125.40 & 985 & 973 & 955 & 912 & 898 & 898 & 897 \\
\hline 0.65 & 0.00092 & 152.17 & 985 & 977 & 963 & 929 & 902 & 902 & 901 \\
\hline 0.65 & 0.00074 & 175.53 & 985 & 981 & 968 & 935 & 897 & 895 & 895 \\
\hline 0.65 & 0.00059 & 232.07 & 984 & 980 & 971 & 944 & 907 & 899 & 895 \\
\hline 0.65 & 0.00000 & 102.57 & 990 & 989 & 989 & 989 & 987 & 987 & 986 \\
\hline
\end{tabular}


- Para tamanho da população = 20 (cont.)

\begin{tabular}{|c|c|c|c|c|c|c|c|c|c|}
\hline $\mathrm{Pc}$ & $\mathrm{Pm}$ & Media & NaoAte25 & NaoAte50 & NaoAte100 & NaoAte200 & NaoAte500 & NaoAte700 & NaoAte1000 \\
\hline 0.70 & 0.10000 & 167.70 & 807 & 613 & 482 & 312 & 95 & 52 & 22 \\
\hline 0.70 & 0.08000 & 188.03 & 812 & 652 & 520 & 351 & 110 & 60 & 22 \\
\hline 0.70 & 0.06400 & 265.07 & 830 & 725 & 625 & 503 & 270 & 160 & 77 \\
\hline 0.70 & 0.05120 & 302.31 & 833 & 768 & 704 & 626 & 472 & 368 & 263 \\
\hline 0.70 & 0.04096 & 244.14 & 855 & 801 & 761 & 709 & 608 & 568 & 513 \\
\hline 0.70 & 0.03277 & 210.19 & 862 & 823 & 801 & 772 & 722 & 700 & 661 \\
\hline 0.70 & 0.02621 & 212.32 & 899 & 867 & 859 & 841 & 806 & 783 & 759 \\
\hline 0.70 & 0.02097 & 193.43 & 917 & 891 & 887 & 870 & 848 & 827 & 815 \\
\hline 0.70 & 0.01678 & 167.46 & 928 & 900 & 895 & 891 & 879 & 865 & 854 \\
\hline 0.70 & 0.01342 & 127.67 & 928 & 898 & 894 & 890 & 883 & 877 & 868 \\
\hline 0.70 & 0.01074 & 71.99 & 928 & 894 & 889 & 884 & 880 & 876 & 874 \\
\hline 0.70 & 0.00859 & 68.36 & 950 & 908 & 902 & 901 & 897 & 893 & 892 \\
\hline 0.70 & 0.00687 & 69.42 & 952 & 915 & 907 & 906 & 902 & 901 & 898 \\
\hline 0.70 & 0.00550 & 73.25 & 967 & 932 & 916 & 913 & 911 & 910 & 907 \\
\hline 0.70 & 0.00440 & 54.89 & 967 & 936 & 910 & 904 & 904 & 903 & 902 \\
\hline 0.70 & 0.00352 & 68.86 & 973 & 949 & 908 & 904 & 901 & 900 & 899 \\
\hline 0.70 & 0.00281 & 84.98 & 980 & 960 & 924 & 914 & 910 & 910 & 908 \\
\hline 0.70 & 0.00225 & 85.46 & 979 & 962 & 931 & 908 & 904 & 904 & 903 \\
\hline 0.70 & 0.00180 & 98.70 & 980 & 971 & 942 & 909 & 902 & 902 & 901 \\
\hline 0.70 & 0.00144 & 132.37 & 984 & 976 & 955 & 917 & 899 & 899 & 898 \\
\hline 0.70 & 0.00115 & 165.06 & 987 & 980 & 965 & 927 & 901 & 899 & 898 \\
\hline 0.70 & 0.00092 & 181.80 & 987 & 978 & 966 & 933 & 901 & 897 & 895 \\
\hline 0.70 & 0.00074 & 210.84 & 990 & 980 & 971 & 953 & 915 & 910 & 908 \\
\hline 0.70 & 0.00059 & 242.59 & 990 & 983 & 975 & 965 & 912 & 909 & 908 \\
\hline 0.70 & 0.00000 & 186.83 & 992 & 992 & 992 & 991 & 990 & 990 & 988 \\
\hline 0.75 & 0.10000 & 179.17 & 819 & 635 & 460 & 311 & 111 & 57 & 15 \\
\hline 0.75 & 0.08000 & 194.53 & 816 & 668 & 516 & 362 & 135 & 75 & 31 \\
\hline 0.75 & 0.06400 & 254.16 & 820 & 723 & 627 & 498 & 237 & 150 & 66 \\
\hline 0.75 & 0.05120 & 272.59 & 831 & 760 & 696 & 618 & 437 & 358 & 276 \\
\hline 0.75 & 0.04096 & 254.82 & 851 & 807 & 762 & 709 & 619 & 567 & 510 \\
\hline 0.75 & 0.03277 & 202.46 & 855 & 821 & 805 & 767 & 704 & 676 & 648 \\
\hline 0.75 & 0.02621 & 194.74 & 884 & 858 & 853 & 840 & 800 & 782 & 761 \\
\hline 0.75 & 0.02097 & 149.91 & 905 & 871 & 864 & 854 & 837 & 824 & 812 \\
\hline 0.75 & 0.01678 & 157.87 & 916 & 886 & 880 & 872 & 856 & 844 & 832 \\
\hline 0.75 & 0.01342 & 120.99 & 925 & 894 & 889 & 886 & 878 & 869 & 862 \\
\hline 0.75 & 0.01074 & 94.50 & 929 & 898 & 892 & 886 & 879 & 875 & 870 \\
\hline 0.75 & 0.00859 & 61.93 & 946 & 898 & 890 & 885 & 877 & 876 & 875 \\
\hline 0.75 & 0.00687 & 48.54 & 952 & 902 & 891 & 888 & 885 & 884 & 883 \\
\hline 0.75 & 0.00550 & 47.36 & 964 & 917 & 904 & 900 & 900 & 899 & 898 \\
\hline 0.75 & 0.00440 & 45.94 & 970 & 929 & 909 & 908 & 907 & 907 & 906 \\
\hline 0.75 & 0.00352 & 92.14 & 970 & 940 & 912 & 905 & 903 & 903 & 898 \\
\hline 0.75 & 0.00281 & 70.46 & 972 & 950 & 920 & 908 & 906 & 906 & 904 \\
\hline 0.75 & 0.00225 & 65.48 & 975 & 955 & 932 & 911 & 909 & 909 & 909 \\
\hline 0.75 & 0.00180 & 90.41 & 981 & 960 & 940 & 913 & 909 & 909 & 908 \\
\hline 0.75 & 0.00144 & 93.96 & 985 & 968 & 942 & 915 & 907 & 907 & 907 \\
\hline 0.75 & 0.00115 & 101.51 & 988 & 973 & 950 & 925 & 916 & 916 & 916 \\
\hline 0.75 & 0.00092 & 124.53 & 988 & 974 & 954 & 930 & 912 & 911 & 911 \\
\hline 0.75 & 0.00074 & 160.10 & 988 & 976 & 959 & 937 & 912 & 910 & 910 \\
\hline 0.75 & 0.00059 & 196.24 & 986 & 978 & 963 & 947 & 909 & 904 & 903 \\
\hline 0.75 & 0.00000 & 310.00 & 995 & 995 & 995 & 993 & 992 & 990 & 988 \\
\hline
\end{tabular}


- Para tamanho da população = 20 (cont.)

\begin{tabular}{|c|c|c|c|c|c|c|c|c|c|}
\hline $\mathrm{Pc}$ & $\mathrm{Pm}$ & Media & NaoAte25 & NaoAte50 & NaoAte100 & NaoAte200 & NaoAte500 & NaoAte700 & NaoAte1000 \\
\hline 0.80 & 0.10000 & 181.14 & 834 & 644 & 495 & 337 & 102 & 44 & 13 \\
\hline 0.80 & 0.08000 & 195.99 & 825 & 657 & 521 & 371 & 131 & 62 & 17 \\
\hline 0.80 & 0.06400 & 239.30 & 820 & 706 & 606 & 465 & 220 & 130 & 69 \\
\hline 0.80 & 0.05120 & 281.32 & 812 & 746 & 680 & 600 & 427 & 331 & 239 \\
\hline 0.80 & 0.04096 & 248.05 & 860 & 806 & 768 & 714 & 626 & 581 & 526 \\
\hline 0.80 & 0.03277 & 189.20 & 868 & 830 & 807 & 769 & 715 & 692 & 667 \\
\hline 0.80 & 0.02621 & 167.67 & 867 & 832 & 825 & 804 & 768 & 752 & 732 \\
\hline 0.80 & 0.02097 & 136.54 & 887 & 848 & 846 & 833 & 804 & 789 & 782 \\
\hline 0.80 & 0.01678 & 125.70 & 910 & 864 & 862 & 856 & 840 & 830 & 821 \\
\hline 0.80 & 0.01342 & 80.73 & 907 & 884 & 881 & 879 & 866 & 863 & 860 \\
\hline 0.80 & 0.01074 & 64.98 & 931 & 896 & 889 & 887 & 877 & 876 & 875 \\
\hline 0.80 & 0.00859 & 67.28 & 940 & 898 & 890 & 888 & 881 & 879 & 877 \\
\hline \begin{tabular}{|l|}
0.80 \\
\end{tabular} & 0.00687 & 62.89 & 945 & 902 & 890 & 890 & 886 & 885 & 882 \\
\hline 0.80 & 0.00550 & 78.20 & 960 & 918 & 900 & 898 & 897 & 896 & 891 \\
\hline 0.80 & 0.00440 & 83.80 & 963 & 927 & 905 & 899 & 899 & 899 & 893 \\
\hline 0.80 & 0.00352 & 92.11 & 963 & 940 & 912 & 907 & 906 & 905 & 899 \\
\hline \begin{tabular}{|l|}
0.80 \\
\end{tabular} & 0.00281 & 75.26 & 965 & 948 & 921 & 908 & 908 & 908 & 905 \\
\hline 0.80 & 0.00225 & 74.01 & 973 & 955 & 926 & 909 & 907 & 907 & 906 \\
\hline 0.80 & 0.00180 & 82.21 & 974 & 965 & 934 & 907 & 901 & 901 & 901 \\
\hline 0.80 & 0.00144 & 98.71 & 978 & 970 & 946 & 917 & 906 & 906 & 906 \\
\hline \begin{tabular}{|l|}
0.80 \\
\end{tabular} & 0.00115 & 118.83 & 980 & 972 & 954 & 925 & 906 & 905 & 905 \\
\hline 0.80 & 0.00092 & 132.97 & 982 & 974 & 963 & 933 & 909 & 908 & 908 \\
\hline 0.80 & 0.00074 & 161.64 & 982 & 976 & 964 & 936 & 905 & 903 & 902 \\
\hline 0.80 & 0.00059 & 193.21 & 981 & 976 & 968 & 945 & 916 & 913 & 911 \\
\hline 0.80 & 0.00000 & 170.36 & 993 & 993 & 992 & 992 & 991 & 991 & 989 \\
\hline 0.85 & 0.10000 & 163.90 & 828 & 647 & 473 & 294 & 82 & 49 & 18 \\
\hline 0.85 & 0.08000 & 181.70 & 814 & 667 & 515 & 335 & 108 & 51 & 18 \\
\hline 0.85 & 0.06400 & 252.20 & 798 & 681 & 580 & 463 & 235 & 144 & 51 \\
\hline 0.85 & 0.05120 & 290.93 & 847 & 766 & 697 & 620 & 438 & 341 & 253 \\
\hline 0.85 & 0.04096 & 233.23 & 834 & 787 & 746 & 692 & 598 & 557 & 502 \\
\hline 0.85 & 0.03277 & 189.58 & 861 & 824 & 803 & 761 & 707 & 687 & 660 \\
\hline 0.85 & 0.02621 & 171.61 & 879 & 850 & 842 & 825 & 782 & 761 & 748 \\
\hline 0.85 & 0.02097 & 169.13 & 893 & 862 & 854 & 840 & 822 & 809 & 790 \\
\hline 0.85 & 0.01678 & 133.60 & 913 & 880 & 876 & 874 & 860 & 852 & 842 \\
\hline 0.85 & 0.01342 & 89.51 & 907 & 877 & 872 & 867 & 858 & 858 & 850 \\
\hline 0.85 & 0.01074 & 47.15 & 920 & 896 & 889 & 887 & 883 & 883 & 881 \\
\hline 0.85 & 0.00859 & 58.16 & 936 & 900 & 895 & 893 & 889 & 886 & 885 \\
\hline 0.85 & 0.00687 & 72.22 & 950 & 909 & 896 & 894 & 890 & 885 & 884 \\
\hline 0.85 & 0.00550 & 97.24 & 964 & 930 & 903 & 898 & 893 & 890 & 885 \\
\hline 0.85 & 0.00440 & 88.34 & 964 & 930 & 901 & 897 & 894 & 891 & 887 \\
\hline 0.85 & 0.00352 & 70.81 & 970 & 944 & 920 & 909 & 907 & 906 & 905 \\
\hline 0.85 & 0.00281 & 71.13 & 973 & 953 & 930 & 916 & 915 & 914 & 913 \\
\hline 0.85 & 0.00225 & 74.11 & 978 & 958 & 933 & 915 & 912 & 911 & 911 \\
\hline 0.85 & 0.00180 & 77.44 & 979 & 966 & 943 & 911 & 910 & 910 & 910 \\
\hline 0.85 & 0.00144 & 101.51 & 980 & 972 & 948 & 908 & 897 & 897 & 897 \\
\hline 0.85 & 0.00115 & 113.01 & 983 & 977 & 959 & 916 & 906 & 906 & 906 \\
\hline 0.85 & 0.00092 & 139.18 & 980 & 976 & 965 & 929 & 908 & 908 & 908 \\
\hline 0.85 & 0.00074 & 173.73 & 983 & 981 & 974 & 947 & 921 & 919 & 919 \\
\hline 0.85 & 0.00059 & 226.41 & 983 & 980 & 976 & 961 & 921 & 916 & 915 \\
\hline 0.85 & 0.00000 & 104.00 & 987 & 987 & 986 & 986 & 984 & 982 & 982 \\
\hline
\end{tabular}


- Para tamanho da população = 20 (cont.)

\begin{tabular}{|c|c|c|c|c|c|c|c|c|c|}
\hline $\mathrm{Pc}$ & $\mathrm{Pm}$ & Media & NaoAte25 & NaoAte50 & NaoAte100 & NaoAte200 & NaoAte500 & NaoAte700 & NaoAte1000 \\
\hline \begin{tabular}{|l|}
0.90 \\
\end{tabular} & 0.10000 & 160.64 & 821 & 619 & 458 & 278 & 81 & 36 & 11 \\
\hline 0.90 & 0.08000 & 187.14 & 817 & 677 & 546 & 371 & 94 & 36 & 8 \\
\hline 0.90 & 0.06400 & 241.87 & 803 & 714 & 614 & 460 & 214 & 133 & 60 \\
\hline 0.90 & 0.05120 & 287.66 & 814 & 733 & 657 & 576 & 417 & 339 & 223 \\
\hline \begin{tabular}{|l|}
0.90 \\
\end{tabular} & 0.04096 & 274.10 & 847 & 800 & 762 & 716 & 619 & 558 & 494 \\
\hline 0.90 & 0.03277 & 204.38 & 858 & 804 & 788 & 760 & 711 & 689 & 649 \\
\hline \begin{tabular}{|l|}
0.90 \\
\end{tabular} & 0.02621 & 189.96 & 867 & 840 & 832 & 815 & 770 & 752 & 730 \\
\hline 0.90 & 0.02097 & 178.83 & 887 & 858 & 849 & 839 & 814 & 801 & 780 \\
\hline 0.90 & 0.01678 & 122.21 & 900 & 879 & 876 & 870 & 856 & 848 & 840 \\
\hline \begin{tabular}{|l|}
0.90 \\
\end{tabular} & 0.01342 & 61.50 & 913 & 880 & 877 & 873 & 868 & 863 & 862 \\
\hline 0.90 & 0.01074 & 60.39 & 933 & 894 & 890 & 888 & 882 & 878 & 878 \\
\hline 0.90 & 0.00859 & 53.89 & 939 & 905 & 899 & 893 & 890 & 889 & 888 \\
\hline 0.90 & 0.00687 & 68.71 & 942 & 902 & 889 & 887 & 884 & 882 & 879 \\
\hline \begin{tabular}{|l|}
0.90 \\
\end{tabular} & 0.00550 & 80.53 & 944 & 915 & 897 & 892 & 890 & 886 & 883 \\
\hline 0.90 & 0.00440 & 73.77 & 960 & 931 & 909 & 903 & 901 & 899 & 897 \\
\hline 0.90 & 0.00352 & 63.60 & 964 & 934 & 913 & 909 & 907 & 906 & 905 \\
\hline 0.90 & 0.00281 & 76.32 & 968 & 947 & 916 & 907 & 903 & 902 & 901 \\
\hline 0.90 & 0.00225 & 75.55 & 975 & 955 & 927 & 908 & 906 & 905 & 905 \\
\hline 0.90 & 0.00180 & 90.84 & 979 & 963 & 931 & 905 & 899 & 899 & 898 \\
\hline 0.90 & 0.00144 & 97.61 & 979 & 968 & 938 & 908 & 895 & 895 & 895 \\
\hline 0.90 & 0.00115 & 112.31 & 984 & 976 & 956 & 926 & 912 & 912 & 912 \\
\hline 0.90 & 0.00092 & 132.06 & 983 & 976 & 959 & 936 & $\overline{913}$ & 913 & 913 \\
\hline 0.90 & 0.00074 & 168.12 & 983 & 977 & 962 & 946 & 911 & 910 & 910 \\
\hline 0.90 & 0.00059 & 221.85 & 984 & 980 & 967 & 953 & 913 & 907 & 906 \\
\hline 0.90 & 0.00000 & 224.87 & 992 & 992 & 992 & 990 & 988 & 986 & 985 \\
\hline 0.95 & 0.10000 & 162.81 & 836 & 652 & 477 & 276 & 84 & 34 & 10 \\
\hline 0.95 & 0.08000 & 178.70 & 795 & 672 & 529 & 340 & 105 & 59 & 27 \\
\hline \begin{tabular}{|l|}
0.95 \\
\end{tabular} & 0.06400 & 248.30 & 808 & 695 & 611 & 481 & 237 & 139 & 68 \\
\hline 0.95 & 0.05120 & 298.21 & 816 & 743 & 682 & 605 & 438 & 347 & 234 \\
\hline 0.95 & 0.04096 & 239.22 & 836 & 782 & 736 & 691 & 607 & 559 & 501 \\
\hline 0.95 & 0.03277 & 198.39 & 865 & 829 & 812 & 779 & 724 & 698 & 669 \\
\hline 0.95 & 0.02621 & 158.67 & 882 & 843 & 835 & 822 & 787 & 778 & 761 \\
\hline 0.95 & 0.02097 & 185.44 & 896 & 869 & 865 & 860 & 836 & 822 & 803 \\
\hline 0.95 & 0.01678 & 144.06 & 919 & 882 & 876 & 870 & 859 & 852 & 838 \\
\hline 0.95 & 0.01342 & 124.65 & 912 & 881 & 878 & 875 & 868 & 863 & 851 \\
\hline 0.95 & 0.01074 & 67.56 & 921 & 889 & 887 & 882 & 876 & 874 & 871 \\
\hline 0.95 & 0.00859 & 86.47 & 933 & 896 & 889 & 887 & 883 & 882 & 875 \\
\hline \begin{tabular}{|l|}
0.95 \\
\end{tabular} & 0.00687 & 74.82 & 942 & 905 & 892 & 890 & 886 & 886 & 881 \\
\hline 0.95 & 0.00550 & 49.81 & 946 & 910 & 899 & 899 & 896 & 895 & 894 \\
\hline 0.95 & 0.00440 & 51.20 & 958 & 925 & 911 & 910 & 909 & 908 & 907 \\
\hline 0.95 & 0.00352 & 49.07 & 963 & 932 & 906 & 903 & 901 & 900 & 900 \\
\hline \begin{tabular}{|l|}
0.95 \\
\end{tabular} & 0.00281 & 67.17 & 971 & 946 & 916 & 905 & 903 & 902 & 901 \\
\hline 0.95 & 0.00225 & 69.03 & 976 & 958 & 929 & 910 & 910 & 909 & 909 \\
\hline 0.95 & 0.00180 & 86.98 & 977 & 965 & 931 & 902 & 897 & 896 & 896 \\
\hline 0.95 & 0.00144 & 90.17 & 974 & 966 & 941 & 910 & 904 & 904 & 904 \\
\hline \begin{tabular}{|l|}
0.95 \\
\end{tabular} & 0.00115 & 106.01 & 975 & 971 & 954 & 919 & 908 & 908 & 908 \\
\hline 0.95 & 0.00092 & 137.71 & 978 & 975 & 960 & 928 & 903 & 902 & 902 \\
\hline 0.95 & 0.00074 & 180.48 & 979 & 977 & 966 & 938 & 902 & 899 & 899 \\
\hline 0.95 & 0.00059 & 199.05 & 979 & 977 & 969 & 940 & 901 & 898 & 897 \\
\hline 0.95 & 0.00000 & 208.86 & 986 & 986 & 986 & 985 & 985 & 981 & 979 \\
\hline 1.00 & 0.10000 & 152.03 & 821 & 609 & 429 & 271 & 69 & 24 & 9 \\
\hline 1.00 & 0.08000 & 169.28 & 810 & 635 & 489 & 329 & 83 & 34 & 13 \\
\hline 1.00 & 0.06400 & 234.76 & 803 & 684 & 581 & 456 & 207 & 137 & 64 \\
\hline 1.00 & 0.05120 & 271.91 & 815 & 732 & 676 & 589 & 426 & 355 & 259 \\
\hline 1.00 & 0.04096 & 247.54 & 847 & 803 & 767 & 715 & 610 & 557 & 508 \\
\hline 1.00 & 0.03277 & 214.15 & 854 & 818 & 802 & 776 & 714 & 681 & 652 \\
\hline 1.00 & 0.02621 & 204.93 & 865 & 839 & 828 & 808 & 774 & 751 & 721 \\
\hline 1.00 & 0.02097 & 175.52 & 879 & 865 & 855 & 848 & 836 & 824 & 803 \\
\hline \begin{tabular}{|l|}
1.00 \\
\end{tabular} & 0.01678 & 120.47 & 901 & 874 & 869 & 863 & 854 & 844 & 836 \\
\hline 1.00 & 0.01342 & 91.78 & 912 & 889 & 886 & 875 & 869 & 867 & 861 \\
\hline 1.00 & 0.01074 & 74.83 & 918 & 887 & 885 & 883 & 874 & 871 & 867 \\
\hline 1.00 & 0.00859 & 50.29 & 931 & 900 & 894 & 894 & 889 & 888 & 887 \\
\hline 1.00 & 0.00687 & 62.93 & 940 & 904 & 891 & 891 & 883 & 882 & 881 \\
\hline 1.00 & 0.00550 & 43.97 & 957 & 920 & 904 & 900 & 897 & 897 & 897 \\
\hline 1.00 & 0.00440 & 57.80 & 964 & 924 & 906 & 898 & 897 & 896 & 895 \\
\hline 1.00 & 0.00352 & 74.54 & 965 & 924 & 901 & 891 & 887 & 885 & 883 \\
\hline 1.00 & 0.00281 & 83.73 & 966 & 938 & 907 & 891 & 890 & 890 & 886 \\
\hline 1.00 & 0.00225 & 75.96 & 967 & 947 & 917 & 899 & 897 & 897 & 895 \\
\hline 1.00 & 0.00180 & 73.80 & 974 & 951 & 925 & 895 & 891 & 891 & 891 \\
\hline 1.00 & 0.00144 & 82.68 & 973 & 958 & 940 & 909 & 903 & 903 & 903 \\
\hline 1.00 & 0.00115 & 101.27 & 974 & 962 & 947 & 917 & 904 & 904 & 904 \\
\hline 1.00 & 0.00092 & 133.21 & 979 & 968 & 951 & 921 & 899 & 898 & 898 \\
\hline 1.00 & 0.00074 & 155.80 & 982 & 973 & 960 & 932 & 908 & 906 & 906 \\
\hline 1.00 & 0.00059 & $\mid 187.07$ & 982 & 974 & 964 & 943 & 915 & 911 & 909 \\
\hline 1.00 & 0.00000 & 74.93 & 977 & 977 & 976 & 976 & 973 & 973 & 972 \\
\hline
\end{tabular}




\section{Apêndice B - Análise da Suficiência da Utilização de 1000 Seqüências Diferentes de Números Aleatórios}

Segundo o tipo de implementação de AG's seguida no presente trabalho, bem como em diversos outros trabalhos,como [Rezende - 2003] e [Obitko, Slavík - 1999], os AG's necessitam da geração de números aleatórios para seu funcionamento. Esta geração é fundamental, principalmente para a implementação dos operadores de seleção, para a decisão quanto à execução (ou não execução) de operadores de cruzamento e/ou operadores de mutação (em função de suas probabilidades), e até mesmo para o próprio funcionamento de determinados operadores de mutação e de cruzamento.

A partir dos experimentos realizados no capítulo $<i>5$ do presente trabalho, ficou muito claro que os resultados obtidos a partir e um determinado AG podem não apenas depender de parâmetros específicos do próprio AG (como o tamanho da população, a taxa de mutação e a taxa de cruzamento), mas também podem depender muito da seqüência de números aleatórios à qual o AG é submetido, durante seu funcionamento.

Assim sendo, ficou claro que, para se avaliar a influência de diferentes configurações de parâmetros para um determinado $A G$, é necessário que se tenha conhecimento da existência da influência de seqüências específicas de valores aleatórios envolvidas em sua execução, para se evitar conclusões errôneas. Em outras palavras: experimentos realizados com quantidades não suficientes de execuções (com diferentes seqüências de números aleatórios) do mesmo AG, podem atribuir somente à configuração do mesmo a causa de resultados obtidos, enquanto que os resultados podem ser, na verdade, conseqüências também destas seqüências.

Para se evitar estas possíveis conclusões equivocadas, uma alternativa seria testar todas as seqüências possíveis de números aleatórios às quais um determinado AG poderia ser submetido, durante sua execução. Esta solução é, a princípio, impossível, uma vez que os AG's implementados trabalham também com a geração de números aleatórios reais, no intervalo $[0,1]$, a qual compreende infinitas possibilidades. É conhecido porém, que na implementação utilizada nos algoritmos do presente trabalho, a geração destes números reais aleatórios foi realizada a partir da geração de números inteiros aleatórios, utilizando-se a função "rand()" da linguagem de programação "C", a qual gera números inteiros entre " 0 " e 
um valor máximo (denominado nesta linguagem como "RAND_MAX") de "32767", e o valor real aleatório pertencente ao intervalo $[0,1]$ era gerado pela geração de um número inteiro aleatório e sua divisão pelo valor "RAND_MAX". Mesmo assim, embora não se esteja trabalhando com infinitas possibilidades de seqüências aleatórias, o número de possíveis seqüências ainda é demasiadamente grande - devido ao enorme número de possibilidades e também ao enorme número de gerações de números aleatórios para do AG - o que torna esta abordagem impraticável.

Assim sendo, entende-se que será necessário trabalhar com amostras de seqüências de números aleatórios. Para isso, parte-se do pressuposto que, para um número mínimo de amostras suficientemente grande, o fenômeno observado será muito próximo ao que seria observado caso todas as seqüências possíveis fossem testadas.

Para se determinar o número mínimo de execuções necessárias para os AG's implementados no presente trabalho, resolveu-se aumentar gradativamente o número de execuções (cada uma com uma diferente seqüência de números aleatórios, por utilizar uma diferente "semente" para esta geração na linguagem "C") até se encontrar o ponto em que os resultados não apresentem diferenças significativas com o aumento do tamanho da amostra.

Este teste foi realizado com o AG-MF com população de 70 indivíduos, para cinco configurações diferentes, todas com $\mathrm{Pc}=0,95$, e cada uma com um diferente valor de $\mathrm{Pm}$, pertencente ao conjunto de valores: $(1 ; 0,08 ; 0,064 ; 0,0512 ; 0,04096)$. Para cada configuração, o AG foi executado por um número "Ns" de vezes, até a milésima iteração. Os resultados são demonstrados na tabela da próxima página.

Observando-se estes resultados, percebe-se que se utilizando uma amostra de execuções de $\mathrm{Ns}=1000$, pode-se basicamente observar o mesmo fenômeno observado com números maiores (até mesmo para Ns $=20000$ ). Embora, para valores de Ns maiores que 1000, existam pequenas diferenças nos valores obtidos, estas não são significativas, e não prejudicam a observação do comportamento do AG. 


\begin{tabular}{|c|c|c|c|c|c|c|c|}
\hline & & & & & Para Ns & $s=20$ & \\
\hline Pc & Pm & Media & NaoAte25 & NaoAte50 & NaoAte 100 & NaoAte200 & NaoAte500 \\
\hline 0,95 & 0,10000 & 32,25 & $45,0 \%$ & $20,0 \%$ & $5,0 \%$ & $0,0 \%$ & $0,0 \%$ \\
\hline 0,95 & 0,08000 & 29,95 & $40,0 \%$ & $15,0 \%$ & $5,0 \%$ & $0,0 \%$ & $0,0 \%$ \\
\hline 0,95 & 0,06400 & 20,25 & $15,0 \%$ & $5,0 \%$ & $0,0 \%$ & $0,0 \%$ & $0,0 \%$ \\
\hline 0,95 & 0,05120 & 47,3 & $40,0 \%$ & $25,0 \%$ & $15,0 \%$ & $5,0 \%$ & $0,0 \%$ \\
\hline 0,95 & 0,04096 & 58,25 & $25,0 \%$ & $20,0 \%$ & $20,0 \%$ & $15,0 \%$ & $0,0 \%$ \\
\hline & & & & & Para Ns & $s=40$ & \\
\hline Pc & $\mathrm{Pm}$ & Media & NaoAte25 & NaoAte50 & NaoAte100 & NaoAte200 & NaoAte500 \\
\hline 0,95 & 0,10000 & 39,15 & $45,0 \%$ & $22,5 \%$ & $7,5 \%$ & $2,5 \%$ & $0,0 \%$ \\
\hline 0,95 & 0,08000 & 27,45 & $37,5 \%$ & $12,5 \%$ & $2,5 \%$ & $0,0 \%$ & $0,0 \%$ \\
\hline 0,95 & 0,06400 & 24,65 & $25,0 \%$ & $10,0 \%$ & $2,5 \%$ & $0,0 \%$ & $0,0 \%$ \\
\hline 0,95 & 0,05120 & 40 & $32,5 \%$ & $17,5 \%$ & $12,5 \%$ & $5,0 \%$ & $0,0 \%$ \\
\hline 0,95 & 0,04096 & 66,32 & $27,5 \%$ & $22,5 \%$ & $20,0 \%$ & $17,5 \%$ & $7,5 \%$ \\
\hline & & & & & Para Ns & $s=60$ & \\
\hline $\mathbf{P c}$ & $\mathrm{Pm}$ & Media & NaoAte25 & NaoAte50 & NaoAte100 & NaoAte200 & NaoAte500 \\
\hline \begin{tabular}{|l|}
0,95 \\
\end{tabular} & 0,10000 & 38,48 & $46,7 \%$ & $20,0 \%$ & $6,7 \%$ & $1,7 \%$ & $0,0 \%$ \\
\hline 0,95 & 0,08000 & 32 & $43,3 \%$ & $15,0 \%$ & $5,0 \%$ & $0,0 \%$ & $0,0 \%$ \\
\hline 0,95 & 0,06400 & 26,38 & $30,0 \%$ & $15,0 \%$ & $1,7 \%$ & $0,0 \%$ & $0,0 \%$ \\
\hline 0,95 & 0,05120 & 45,33 & $38,3 \%$ & $23,3 \%$ & $15,0 \%$ & $5,0 \%$ & $0,0 \%$ \\
\hline 0,95 & 0,04096 & 86,41 & $38,3 \%$ & $28,3 \%$ & $23,3 \%$ & $20,0 \%$ & $6,7 \%$ \\
\hline & & & & & Para Ns & $=80$ & \\
\hline Pc & $\mathrm{Pm}$ & Media & NaoAte25 & NaoAte50 & NaoAte100 & NaoAte200 & NaoAte500 \\
\hline 0,95 & 0,10000 & 38,61 & $45,0 \%$ & $21,3 \%$ & $7,5 \%$ & $1,3 \%$ & $0,0 \%$ \\
\hline 0,95 & 0,08000 & 32,22 & $41,3 \%$ & $16,3 \%$ & $6,3 \%$ & $0,0 \%$ & $0,0 \%$ \\
\hline 0,95 & 0,06400 & 27,02 & $31,3 \%$ & $16,3 \%$ & $1,3 \%$ & $0,0 \%$ & $0,0 \%$ \\
\hline 0,95 & 0,05120 & 38,85 & $32,5 \%$ & $18,8 \%$ & $11,3 \%$ & $3,8 \%$ & $0,0 \%$ \\
\hline 0,95 & 0,04096 & 92,14 & $37,5 \%$ & $28,8 \%$ & $21,3 \%$ & $18,8 \%$ & $7,5 \%$ \\
\hline & & & & & Para Ns & $=100$ & \\
\hline $\mathbf{P c}$ & $\mathrm{Pm}$ & Media & NaoAte25 & NaoAte50 & NaoAte100 & NaoAte200 & NaoAte500 \\
\hline 0,95 & 0,10000 & 38,51 & $44,0 \%$ & $20,0 \%$ & $7,0 \%$ & $2,0 \%$ & $0,0 \%$ \\
\hline 0,95 & 0,08000 & 30,95 & $39,0 \%$ & $15,0 \%$ & $5,0 \%$ & $0,0 \%$ & $0,0 \%$ \\
\hline 0,95 & 0,06400 & 29,45 & $34,0 \%$ & $19,0 \%$ & $2,0 \%$ & $0,0 \%$ & $0,0 \%$ \\
\hline 0,95 & 0,05120 & 36,28 & $30,0 \%$ & $17,0 \%$ & $10,0 \%$ & $3,0 \%$ & $0,0 \%$ \\
\hline 0,95 & 0,04096 & 79,45 & $37,0 \%$ & $25,0 \%$ & $19,0 \%$ & $15,0 \%$ & $6,0 \%$ \\
\hline & & & & & Para Ns & $=200$ & \\
\hline Pc & $\mathrm{Pm}$ & Media & \begin{tabular}{|l|} 
NaoAte25 \\
\end{tabular} & NaoAte50 & NaoAte100 & NaoAte200 & NaoAte500 \\
\hline 0,95 & 0,10000 & 40,58 & $48,5 \%$ & $22,0 \%$ & $9,0 \%$ & $1,5 \%$ & $0,0 \%$ \\
\hline 0,95 & 0,08000 & 32,67 & $42,5 \%$ & $17,5 \%$ & $5,0 \%$ & $0,0 \%$ & $0,0 \%$ \\
\hline 0,95 & 0,06400 & 27,35 & $31,5 \%$ & $14,5 \%$ & $1,5 \%$ & $0,0 \%$ & $0,0 \%$ \\
\hline 0,95 & 0,05120 & 38,73 & $29,5 \%$ & $18,5 \%$ & $9,5 \%$ & $3,5 \%$ & $0,0 \%$ \\
\hline 0,95 & $\begin{array}{l}0,04096 \\
\end{array}$ & 68,57 & $35,5 \%$ & $25,5 \%$ & $18,5 \%$ & $12,0 \%$ & $4,5 \%$ \\
\hline & & & & & Para Ns & $=500$ & \\
\hline $\mathrm{Pc}$ & $\mathrm{Pm}$ & Media & \begin{tabular}{|l|} 
NaoAte25 \\
\end{tabular} & NaoAte50 & NaoAte100 & NaoAte200 & NaoAte500 \\
\hline 0,95 & 0,10000 & 41,61 & $51,0 \%$ & $22,6 \%$ & $8,0 \%$ & $2,0 \%$ & $0,0 \%$ \\
\hline 0,95 & 0,08000 & 32,3 & $42,8 \%$ & $17,4 \%$ & $4,8 \%$ & $0,0 \%$ & $0,0 \%$ \\
\hline 0,95 & 0,06400 & 27,51 & $33,2 \%$ & $12,6 \%$ & $2,0 \%$ & $0,0 \%$ & $0,0 \%$ \\
\hline 0,95 & 0,05120 & 36,14 & $32,4 \%$ & $17,4 \%$ & $8,2 \%$ & $2,2 \%$ & $0,0 \%$ \\
\hline 0,95 & 0,04096 & 74,63 & $36,0 \%$ & $26,6 \%$ & $19,2 \%$ & $12,6 \%$ & $4,6 \%$ \\
\hline & & & & & Para Ns & $=1000$ & \\
\hline Pc & $\mathrm{Pm}$ & Media & \begin{tabular}{|l|} 
NaoAte25 \\
\end{tabular} & NaoAte50 & NaoAte100 & NaoAte200 & NaoAte500 \\
\hline 0,95 & 0,10000 & 41,12 & $50,7 \%$ & $24,3 \%$ & $7,7 \%$ & $1,8 \%$ & $0,0 \%$ \\
\hline 0,95 & 0,08000 & 30,93 & $40,0 \%$ & $16,0 \%$ & $4,1 \%$ & $0,1 \%$ & $0,0 \%$ \\
\hline 0,95 & 0,06400 & 27,53 & $34,2 \%$ & $13,4 \%$ & $2,0 \%$ & $0,0 \%$ & $0,0 \%$ \\
\hline 0,95 & 0,05120 & 35,76 & $31,5 \%$ & $17,3 \%$ & $8,3 \%$ & $2,4 \%$ & $0,0 \%$ \\
\hline 0,95 & 0,04096 & 79,53 & $37,1 \%$ & $27,4 \%$ & $20,0 \%$ & $13,0 \%$ & $5,2 \%$ \\
\hline & & & & & Para Ns & $=1500$ & \\
\hline Pc & Pm & Media & NaoAte25 & NaoAte50 & NaoAte100 & NaoAte200 & NaoAte 500 \\
\hline 0,95 & 0,10000 & 40,98 & $51,7 \%$ & $24,0 \%$ & $7,6 \%$ & $1,6 \%$ & $0,0 \%$ \\
\hline 0,95 & 0,08000 & 31,12 & $39,9 \%$ & $16,4 \%$ & $3,9 \%$ & $0,1 \%$ & $0,0 \%$ \\
\hline 0,95 & 0,06400 & 28,35 & $34,5 \%$ & $14,3 \%$ & $2,7 \%$ & $0,1 \%$ & $0,0 \%$ \\
\hline 0,95 & 0,05120 & 35,72 & $33,1 \%$ & $17,4 \%$ & $8,2 \%$ & $2,1 \%$ & $0,0 \%$ \\
\hline 0,95 & 0,04096 & 79,68 & $36,3 \%$ & $26,9 \%$ & $19,9 \%$ & $13,2 \%$ & $5,4 \%$ \\
\hline & & & & & Para Ns = & $=2000$ & \\
\hline Pc & Pm & Media & NaoAte25 & NaoAte50 & NaoAte100 & NaoAte200 & NaoAte500 \\
\hline 0,95 & 0,10000 & 40,47 & $51,5 \%$ & $24,0 \%$ & $7,7 \%$ & $1,4 \%$ & $0,0 \%$ \\
\hline 0,95 & 0,08000 & 31,38 & $40,5 \%$ & $16,3 \%$ & $3,8 \%$ & $0,2 \%$ & $0,0 \%$ \\
\hline 0,95 & 0,06400 & 27,92 & $33,9 \%$ & $13,8 \%$ & $2,5 \%$ & $0,1 \%$ & $0,0 \%$ \\
\hline 0,95 & 0,05120 & 35,74 & $33,0 \%$ & $17,3 \%$ & $7,9 \%$ & $2,3 \%$ & $0,0 \%$ \\
\hline 0,95 & 0,04096 & 77,48 & $35,8 \%$ & $26,2 \%$ & $19,1 \%$ & $12,6 \%$ & $5,3 \%$ \\
\hline & & & & & Para Ns = & $=5000$ & \\
\hline $\mathrm{Pc}$ & $\mathrm{Pm}$ & Media & NaoAte25 & NaoAte50 & NaoAte100 & NaoAte200 & NaoAte500 \\
\hline 0,95 & 0,10000 & 39,98 & $50,3 \%$ & $23,0 \%$ & $8,2 \%$ & $1,1 \%$ & $0,0 \%$ \\
\hline 0,95 & 0,08000 & 30,44 & $40,1 \%$ & $15,1 \%$ & $3,4 \%$ & $0,1 \%$ & $0,0 \%$ \\
\hline 0,95 & 0,06400 & 27,28 & $33,9 \%$ & $13,1 \%$ & $2,1 \%$ & $0,0 \%$ & $0,0 \%$ \\
\hline 0,95 & 0,05120 & 35,02 & $33,0 \%$ & $17,2 \%$ & $7,5 \%$ & $1,9 \%$ & $0,0 \%$ \\
\hline 0,95 & 0,04096 & 75,34 & $35,6 \%$ & $26,4 \%$ & $18,9 \%$ & $12,4 \%$ & $5,4 \%$ \\
\hline & & & & & Para Ns = & $=10000$ & \\
\hline $\mathrm{Pc}$ & $\mathrm{Pm}$ & Media & NaoAte25 & NaoAte50 & NaoAte100 & NaoAte200 & NaoAte500 \\
\hline 0,95 & 0,10000 & 40,14 & $50,3 \%$ & $23,3 \%$ & $8,1 \%$ & $1,2 \%$ & $0,0 \%$ \\
\hline 0,95 & 0,08000 & 30,44 & $40,0 \%$ & $15,4 \%$ & $3,4 \%$ & $0,1 \%$ & $0,0 \%$ \\
\hline 0,95 & 0,06400 & 27,04 & $34,2 \%$ & $12,6 \%$ & $2,0 \%$ & $0,0 \%$ & $0,0 \%$ \\
\hline 0,95 & 0,05120 & 34,61 & $32,4 \%$ & $17,0 \%$ & $7,2 \%$ & $1,8 \%$ & $0,1 \%$ \\
\hline 0,95 & 0,04096 & 78,85 & $36,2 \%$ & $27,1 \%$ & $19,6 \%$ & $12,8 \%$ & $5,8 \%$ \\
\hline & & & & & Para Ns = & $=20000$ & \\
\hline Pc & Pm & Media & NaoAte25 & NaoAte50 & NaoAte100 & NaoAte200 & NaoAte500 \\
\hline 0,95 & 0,10000 & 39,98 & $50,2 \%$ & $23,1 \%$ & $8,0 \%$ & $1,1 \%$ & $0,0 \%$ \\
\hline 0,95 & 0,08000 & 30,58 & $40,0 \%$ & $15,5 \%$ & $3,4 \%$ & $0,2 \%$ & $0,0 \%$ \\
\hline 0,95 & 0,06400 & 27,03 & $34,0 \%$ & $12,6 \%$ & $2,0 \%$ & $0,0 \%$ & $0,0 \%$ \\
\hline 0,95 & 0,05120 & 34,24 & $32,5 \%$ & $17,0 \%$ & $7,0 \%$ & $1,8 \%$ & $0,0 \%$ \\
\hline 0,95 & 0,04096 & 77,04 & $35,6 \%$ & $26,6 \%$ & $19,4 \%$ & $12,6 \%$ & $5,7 \%$ \\
\hline
\end{tabular}




\section{Apêndice $C$ - Tabelas dos Experimentos do AGD-CV e do AGD-MF com diferentes Iterações de Troca}

Experimentos com o AGD-CV:

- Para tamanho da população $=100$

\begin{tabular}{|c|c|c|c|c|c|c|c|c|c|}
\hline Pop & $\begin{array}{c}\text { Iteração } \\
\text { de Troca }\end{array}$ & Media & NaoAte25 & NaoAte50 & NaoAte100 & NaoAte200 & NaoAte500 & NaoAte700 & NaoAte1000 \\
\hline 100 & 2 & 13,4 & 62 & 7 & 0 & 0 & 0 & 0 & 0 \\
\hline 100 & 3 & 13,09 & 69 & 1 & 0 & 0 & 0 & 0 & 0 \\
\hline 100 & 4 & 12,6 & 59 & 4 & 0 & 0 & 0 & 0 & 0 \\
\hline 100 & 5 & 12,15 & 55 & 5 & 0 & 0 & 0 & 0 & 0 \\
\hline 100 & 6 & 11,47 & 47 & 3 & 0 & 0 & 0 & 0 & 0 \\
\hline 100 & 7 & 10,93 & 49 & 6 & 0 & 0 & 0 & 0 & 0 \\
\hline 100 & 8 & 10,54 & 46 & 5 & 2 & 0 & 0 & 0 & 0 \\
\hline 100 & 9 & 9,43 & 24 & 3 & 0 & 0 & 0 & 0 & 0 \\
\hline 100 & 10 & 9,09 & 23 & 1 & 0 & 0 & 0 & 0 & 0 \\
\hline 100 & 11 & 9,15 & 27 & 6 & 0 & 0 & 0 & 0 & 0 \\
\hline 100 & 12 & 9,02 & 27 & 4 & 0 & 0 & 0 & 0 & 0 \\
\hline 100 & 13 & 9,01 & 26 & 4 & 1 & 0 & 0 & 0 & 0 \\
\hline 100 & 14 & 8,73 & 19 & 3 & 0 & 0 & 0 & 0 & 0 \\
\hline 100 & 15 & 9,02 & 22 & 10 & 1 & 0 & 0 & 0 & 0 \\
\hline 100 & 16 & 9,08 & 24 & 12 & 0 & 0 & 0 & 0 & 0 \\
\hline 100 & 17 & 9,03 & 28 & 9 & 1 & 0 & 0 & 0 & 0 \\
\hline 100 & 18 & 9,01 & 25 & 10 & 0 & 0 & 0 & 0 & 0 \\
\hline 100 & 19 & 9,13 & 29 & 12 & 0 & 0 & 0 & 0 & 0 \\
\hline 100 & 20 & 9,12 & 29 & 10 & 0 & 0 & 0 & 0 & 0 \\
\hline 100 & 21 & 9,24 & 30 & 13 & 2 & 0 & 0 & 0 & 0 \\
\hline 100 & 22 & 9,12 & 29 & 12 & 0 & 0 & 0 & 0 & 0 \\
\hline 100 & 23 & 9,29 & 30 & 11 & 2 & 0 & 0 & 0 & 0 \\
\hline 100 & 24 & 9,21 & 30 & 13 & 0 & 0 & 0 & 0 & 0 \\
\hline 100 & 25 & 9,14 & 30 & 10 & 0 & 0 & 0 & 0 & 0 \\
\hline 100 & 26 & 9,33 & 30 & 16 & 0 & 0 & 0 & 0 & 0 \\
\hline 100 & 27 & 9,55 & 30 & 17 & 2 & 0 & 0 & 0 & 0 \\
\hline 100 & 28 & 9,39 & 30 & 16 & 1 & 0 & 0 & 0 & 0 \\
\hline 100 & 29 & 9,48 & 30 & 18 & 0 & 0 & 0 & 0 & 0 \\
\hline 100 & 30 & 9,41 & 30 & 16 & 1 & 0 & 0 & 0 & 0 \\
\hline
\end{tabular}


- Para tamanho da população $=80$

\begin{tabular}{|c|c|c|c|c|c|c|c|c|c|}
\hline Pop & $\begin{array}{c}\text { Iteração } \\
\text { de Troca }\end{array}$ & Media & NaoAte25 & NaoAte50 & NaoAte100 & NaoAte200 & NaoAte500 & NaoAte700 & NaoAte1000 \\
\hline 80 & 6 & 12,86 & 81 & 5 & 0 & 0 & 0 & 0 & 0 \\
\hline 80 & 7 & 12,24 & 78 & 8 & 0 & 0 & 0 & 0 & 0 \\
\hline 80 & 8 & 11,65 & 73 & 12 & 0 & 0 & 0 & 0 & 0 \\
\hline 80 & 9 & 10,87 & 50 & 7 & 1 & 0 & 0 & 0 & 0 \\
\hline 80 & 10 & 10,47 & 48 & 5 & 0 & 0 & 0 & 0 & 0 \\
\hline 80 & 11 & 10,17 & 45 & 7 & 0 & 0 & 0 & 0 & 0 \\
\hline 80 & 12 & 9,94 & 41 & 3 & 0 & 0 & 0 & 0 & 0 \\
\hline 80 & 13 & 9,92 & 33 & 10 & 0 & 0 & 0 & 0 & 0 \\
\hline 80 & 14 & 10,2 & 47 & 7 & 0 & 0 & 0 & 0 & 0 \\
\hline 80 & 15 & 10,12 & 43 & 8 & 0 & 0 & 0 & 0 & 0 \\
\hline 80 & 16 & 10,08 & 45 & 11 & 0 & 0 & 0 & 0 & 0 \\
\hline 80 & 17 & 10,48 & 48 & 18 & 2 & 0 & 0 & 0 & 0 \\
\hline 80 & 18 & 10,45 & 49 & 20 & 1 & 0 & 0 & 0 & 0 \\
\hline 80 & 19 & 10,63 & 53 & 16 & 1 & 0 & 0 & 0 & 0 \\
\hline 80 & 20 & 10,73 & 52 & 22 & 1 & 0 & 0 & 0 & 0 \\
\hline
\end{tabular}

- Para tamanho da população $=60$

\begin{tabular}{|c|c|c|c|c|c|c|c|c|c|}
\hline Pop & $\begin{array}{c}\text { Iteração } \\
\text { de Troca }\end{array}$ & Media & NaoAte25 & NaoAte50 & NaoAte100 & NaoAte200 & NaoAte500 & NaoAte700 & NaoAte1000 \\
\hline 60 & 2 & 20,12 & 226 & 49 & 5 & 0 & 0 & 0 & 0 \\
\hline 60 & 3 & 19,66 & 215 & 42 & 4 & 0 & 0 & 0 & 0 \\
\hline 60 & 4 & 19,6 & 216 & 49 & 5 & 0 & 0 & 0 & 0 \\
\hline 60 & 5 & 18,9 & 221 & 57 & 3 & 0 & 0 & 0 & 0 \\
\hline 60 & 6 & 17,34 & 178 & 39 & 4 & 0 & 0 & 0 & 0 \\
\hline 60 & 7 & 17,03 & 176 & 47 & 3 & 0 & 0 & 0 & 0 \\
\hline 60 & 8 & 15,59 & 157 & 36 & 1 & 0 & 0 & 0 & 0 \\
\hline 60 & 9 & 14,84 & 130 & 39 & 3 & 0 & 0 & 0 & 0 \\
\hline 60 & 10 & 14,19 & 138 & 27 & 2 & 0 & 0 & 0 & 0 \\
\hline 60 & 11 & 13,41 & 108 & 28 & 1 & 0 & 0 & 0 & 0 \\
\hline 60 & 12 & 12,87 & 95 & 23 & 1 & 0 & 0 & 0 & 0 \\
\hline 60 & 13 & 12,56 & 94 & 23 & 2 & 0 & 0 & 0 & 0 \\
\hline 60 & 14 & 12,62 & 91 & 26 & 2 & 0 & 0 & 0 & 0 \\
\hline 60 & 15 & 12,64 & 90 & 24 & 3 & 0 & 0 & 0 & 0 \\
\hline 60 & 16 & 12,69 & 93 & 27 & 1 & 0 & 0 & 0 & 0 \\
\hline 60 & 17 & 12,74 & 94 & 23 & 4 & 0 & 0 & 0 & 0 \\
\hline 60 & 18 & 12,94 & 100 & 32 & 3 & 0 & 0 & 0 & 0 \\
\hline 60 & 19 & 12,98 & 103 & 31 & 2 & 0 & 0 & 0 & 0 \\
\hline 60 & 20 & 13,21 & 108 & 35 & 2 & 0 & 0 & 0 & 0 \\
\hline 60 & 21 & 12,97 & 103 & 29 & 0 & 0 & 0 & 0 & 0 \\
\hline 60 & 22 & 14 & 109 & 49 & 5 & 0 & 0 & 0 & 0 \\
\hline
\end{tabular}


- Para tamanho da população $=40$

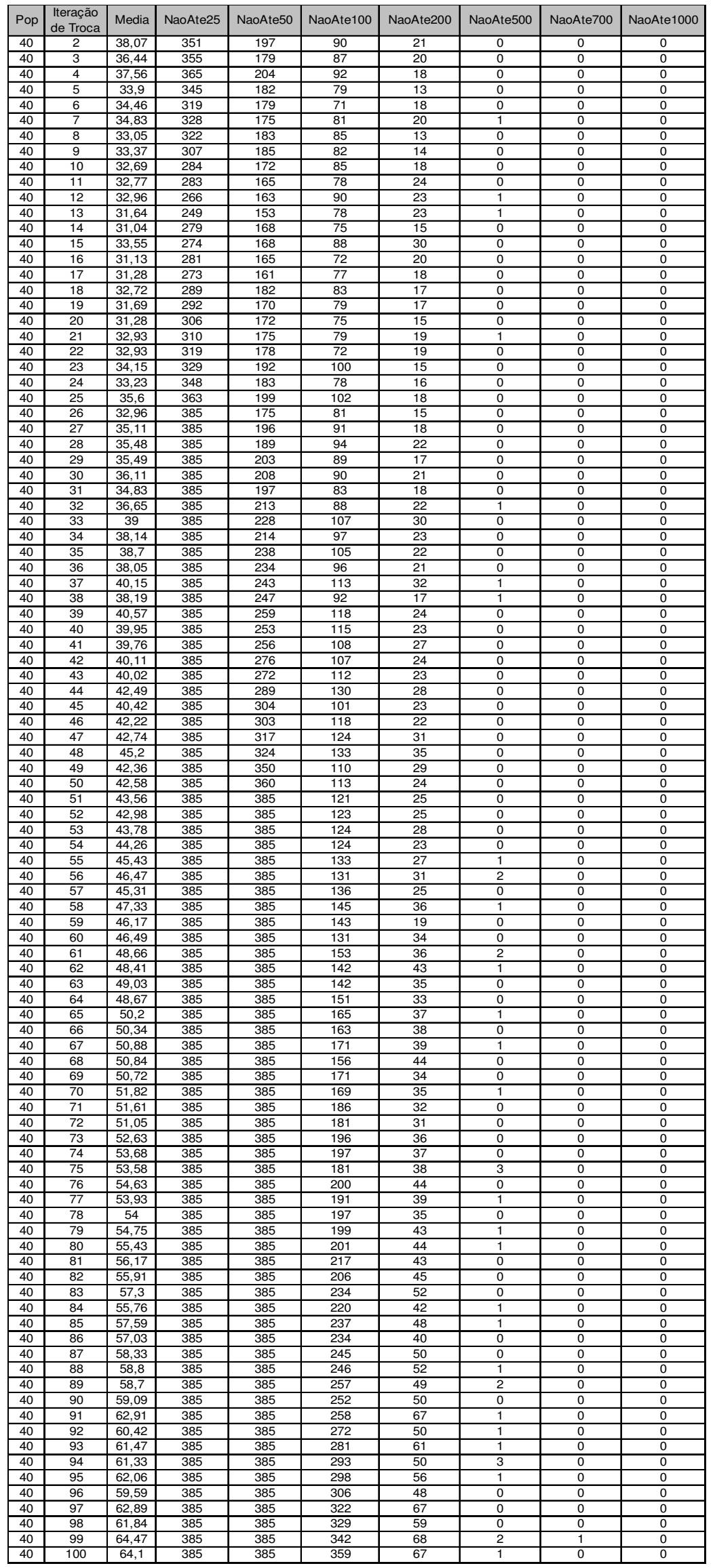


- Para tamanho da população $=20$

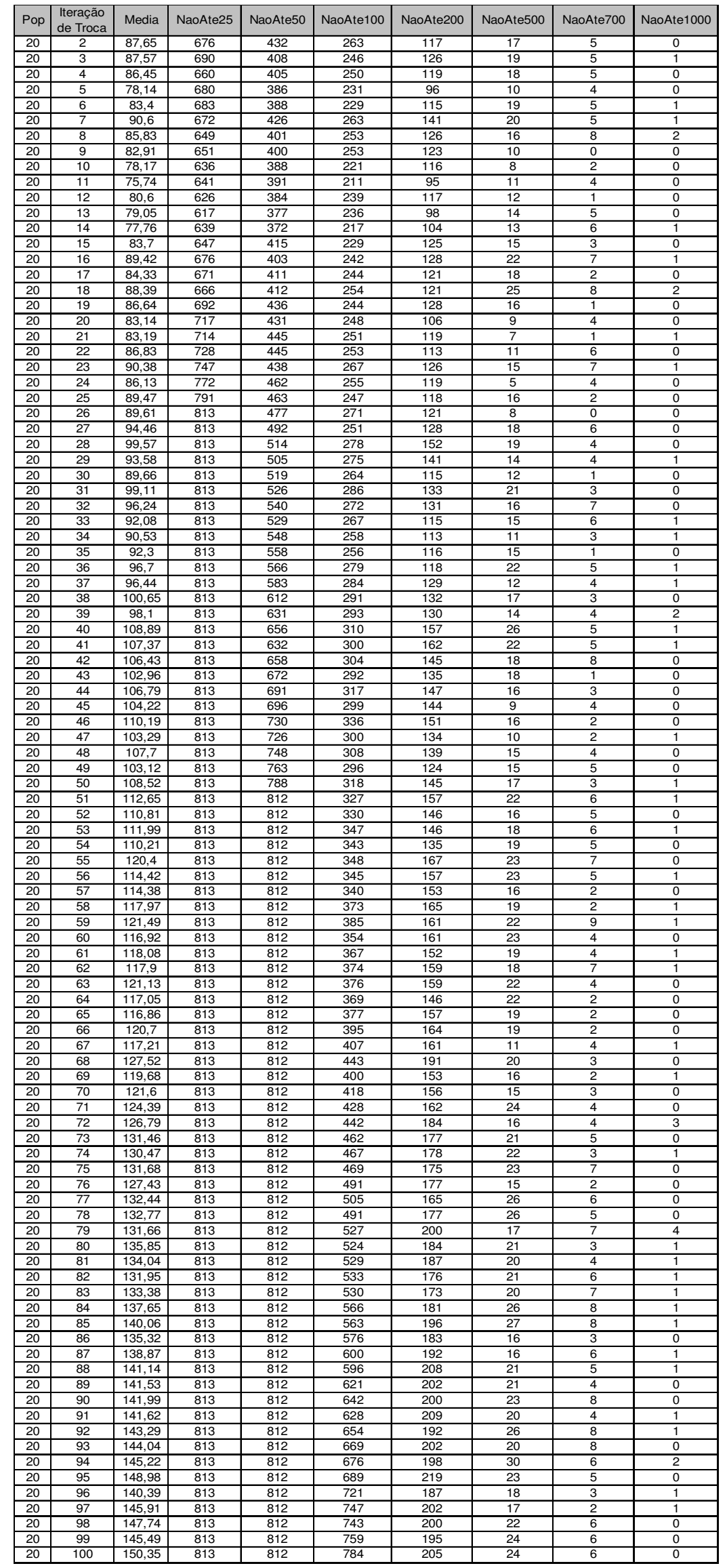




\section{Experimentos com o AGD-MF:}

- Para tamanho da população $=200$

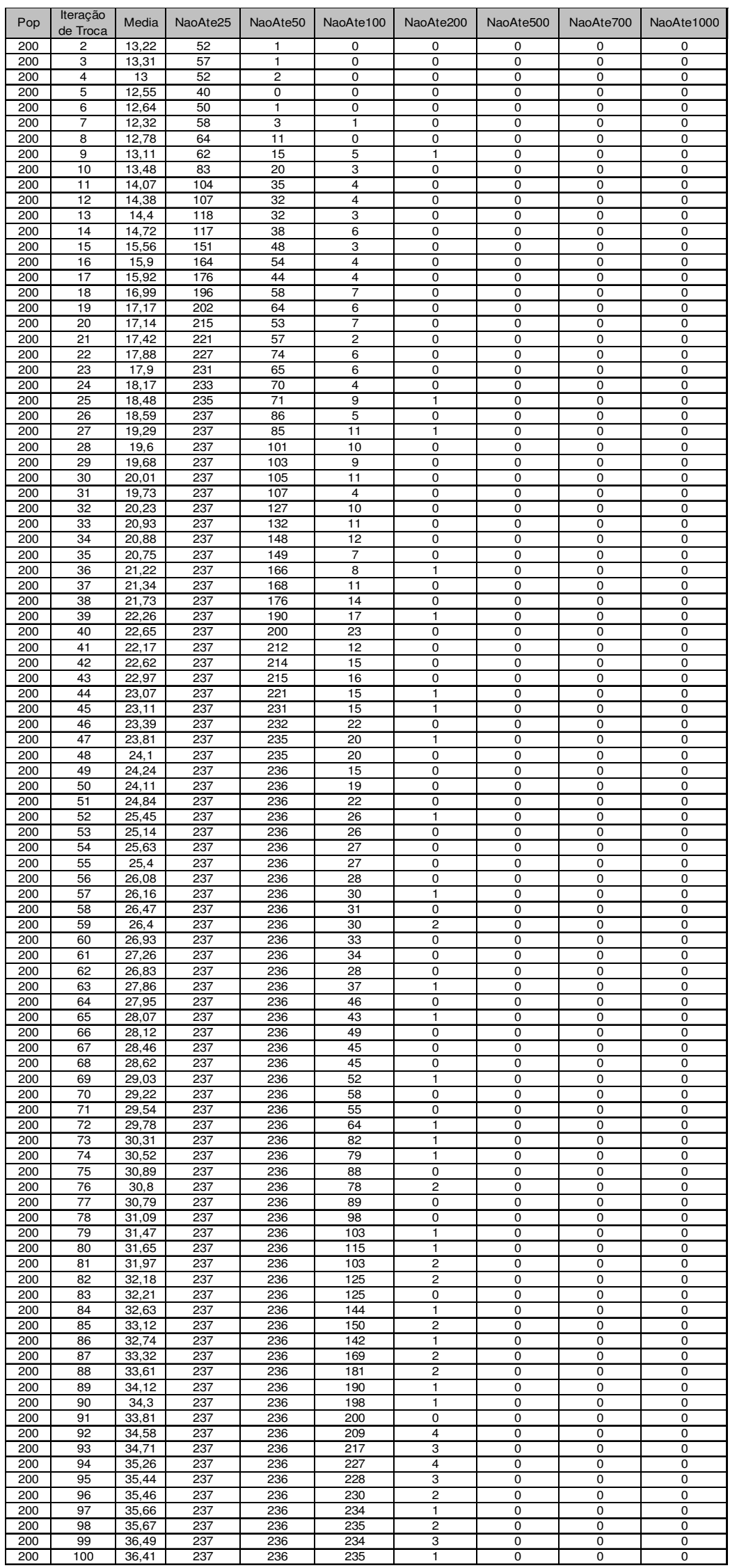


- Para tamanho da população $=70$

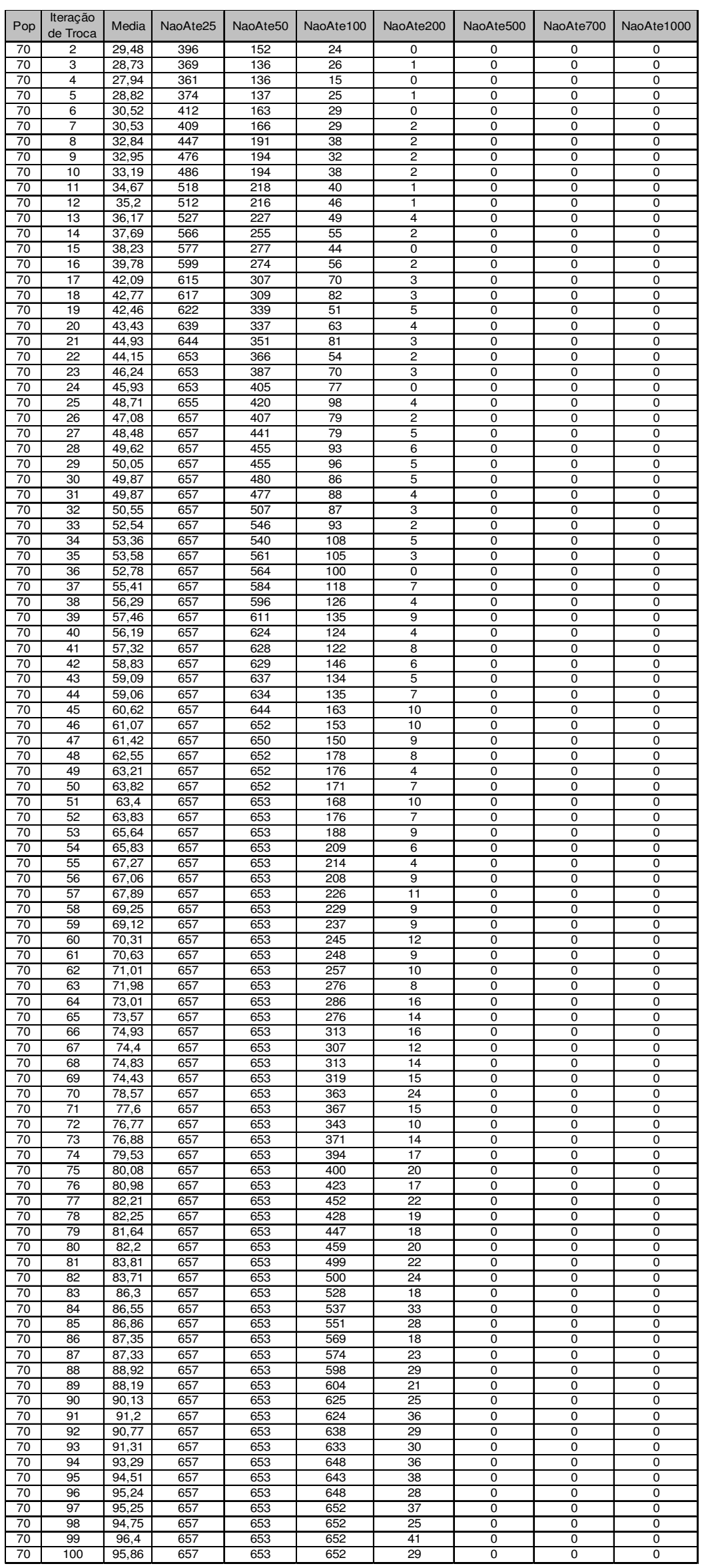


- Para tamanho da população $=50$

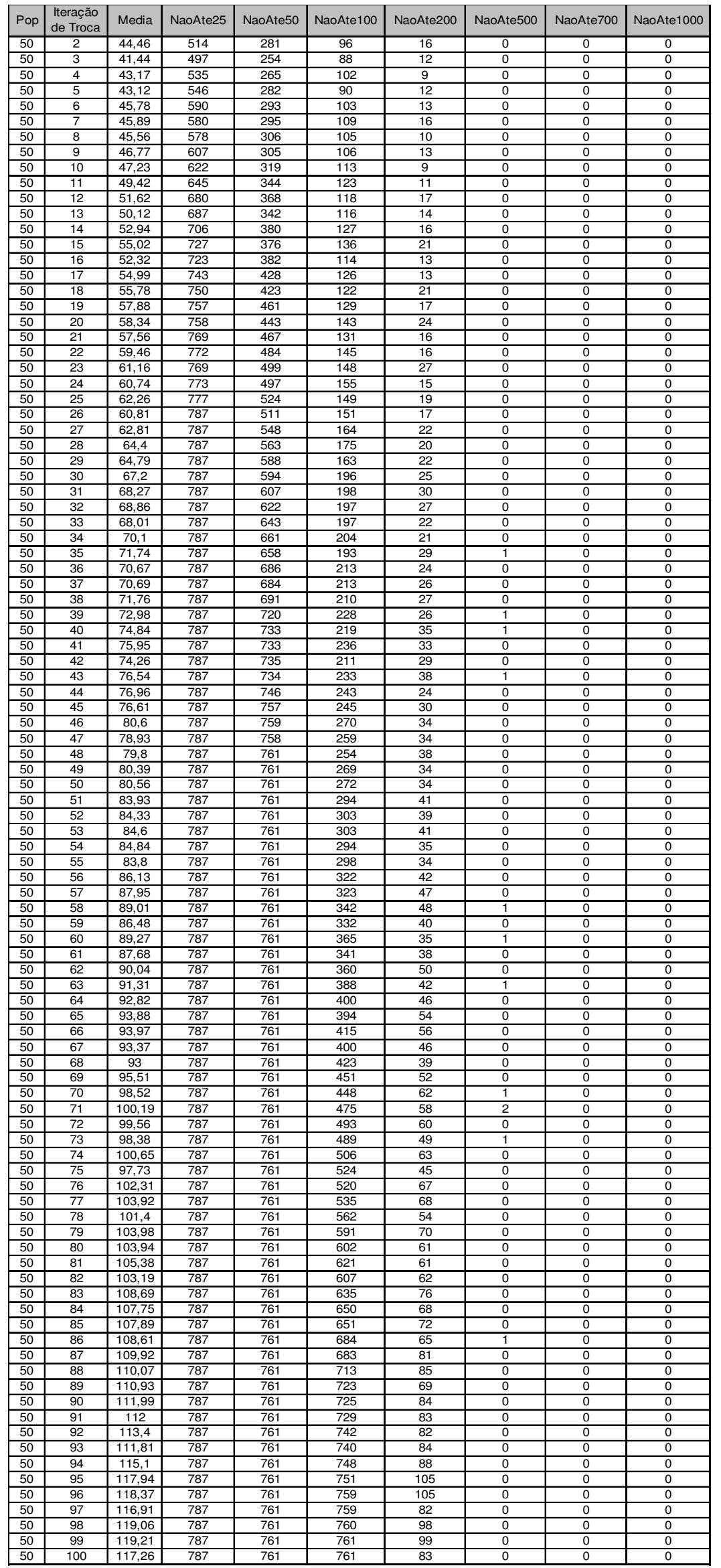


- Para tamanho da população $=20$

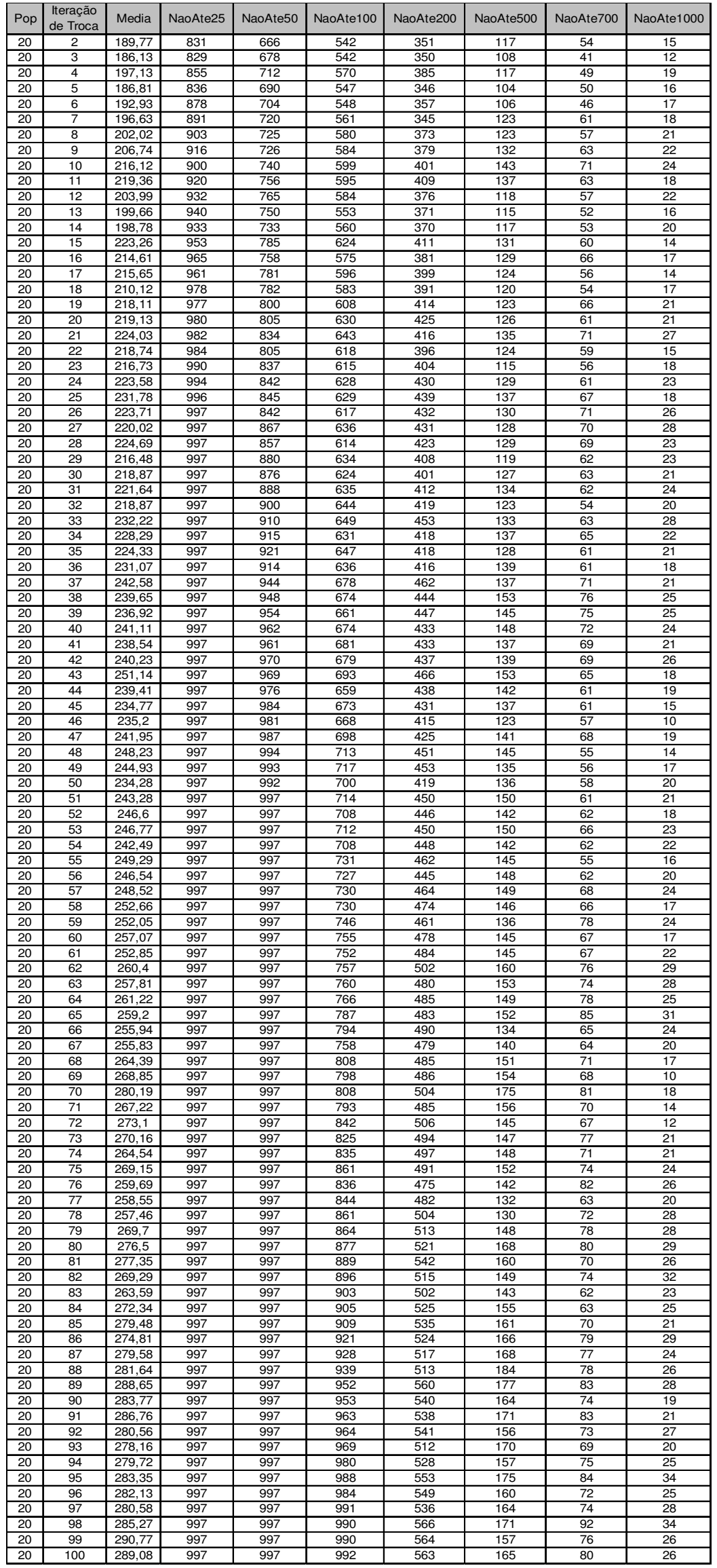

